CENTRO DE ESTUDIOS SUPERIORES EN EDUCACIÓN

\title{
PERCEPCIÓN SOBRE EL USO DE HERRAMIENTAS TECNOLÓGICAS DIGITALES EN LA DOCENCIA E INVESTIGACIÓN CASO: PROFESORES-INVESTIGADORES UAM-A, MÉXICO, ADSCRITOS A QUÍMICA
}

TESIS QUE PARA OBTENER EL GRADO DE DOCTORA EN EDUCACIÓN

\section{PRESENTA LILIA FERNÁNDEZ SÁNCHEZ}

ASESORA

Dra. Elsa González Paredes 
PERCEPCIÓN SOBRE EL USO DE HERRAMIENTAS TECNOLÓGICAS DIGITALES

COMO APOYO EN LA DOCENCIA E INVESTIGACIÓN

CASO: DOCENTES-INVESTIGADORES UAM-A, MÉXICO, ADSCRITOS A QUÍMICA

El gusto por la investigación:

La concepción de problema no es para crear un estado de angustia sino más bien de motivación y gusto por conocer situaciones nuevas y placenteras al intelecto.

Sorprenderse, captar y construir el problema de investigación es quehacer del investigador. La capacidad de asombro del investigador, su poder creativo e imaginación creadora, hacen posible la problematización que conlleva a la captura y construcción del problema.

Ricardo Sánchez Puentes (Investigador)

Solo la evidencia y mucho trabajo podrán conducirnos a la conformación de una nueva verdad en torno a un tema apasionante, que de resultar cierto, mostrarían lo maravilloso que es formular y comprobar la valides de las hipótesis científicas (Prats, 2012).

La profesión docente requiere un permanente ensamblaje y profunda articulación entre acción y conocimiento, entre práctica y teoría. Este es el punto crítico en que reside la verdadera profesionalidad del docente ${ }^{1}$.

Hay que seguir estudiando y preparándose, para eso es la vida.

Ela Velden (Actriz)

La vida es dura y difícil, el cual implica seguir preparándose.

Mtra. Maribel Castillo Díaz

A la UAM-A, institución inteligente A mis alumnos, agentes del cambio

\footnotetext{
${ }^{11}$ Ángels Domingo Roget. Práctica reflexiva para docentes. De la reflexión ocasional a la reflexión metodológica. Saarbrücken, Alemania: PUBLICIA.
} 


\section{PERCEPCIÓN SOBRE EL USO DE HERRAMIENTAS TECNOLÓGICAS DIGITALES COMO APOYO EN LA DOCENCIA E INVESTIGACIÓN CASO: DOCENTES-INVESTIGADORES UAM-A, MÉXICO, ADSCRITOS A QUÍMICA}

\begin{tabular}{|c|c|}
\hline \multicolumn{2}{|l|}{ Dedicatoria - ÍNDICE } \\
\hline \multirow{2}{*}{\multicolumn{2}{|c|}{ Resumen - }} \\
\hline & \\
\hline \multirow{2}{*}{$\begin{array}{l}\text { CAPÍTULO 1: EL PROBLEMA - } \\
\text { Introducción }\end{array}$} & \\
\hline & \\
\hline 1.1 Planteamiento del problema & \\
\hline 1.2 Formulación del problema & \\
\hline 1.3 Enunciado del $p$ & 10 \\
\hline 1.4 Preguntas de investigación & 0 \\
\hline 1.5 Objetivos - & 0 \\
\hline 1.6 Justi & 1 \\
\hline 1.7 Limit & 2 \\
\hline 1.8 Ante & \\
\hline CAPITULO 2: ESTADO DEL ARTE & 36 \\
\hline 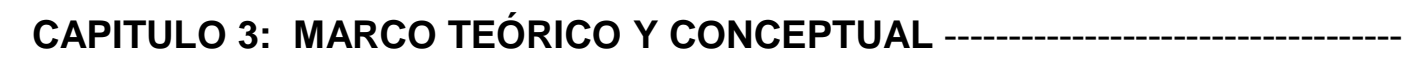 & 55 \\
\hline Introducción --1--- & 5 \\
\hline 3.1 Bases teóricas --------------- & 56 \\
\hline 3.2 Definición de Términos Básicos & 66 \\
\hline 3.3 Sistema de variables & 58 \\
\hline 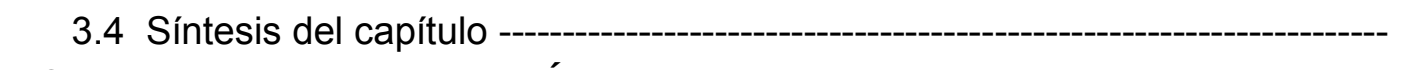 & 70 \\
\hline 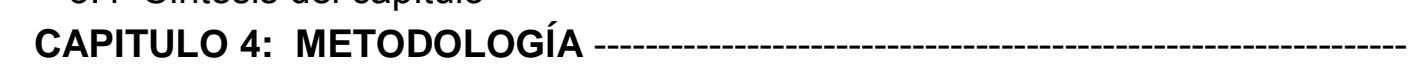 & 72 \\
\hline 4.1 Enfoque de la inve & 72 \\
\hline 4.2 Tipo de investi & 72 \\
\hline 4.3 Diseño de investigació & 13 \\
\hline 4.4 Población y Mu & 4 \\
\hline 4.5 Técnicas e Instrumentos de Recolección de Datos & 4 \\
\hline 4.6 Modelo teórico ------------------ & \\
\hline CAPITULO 5: RESULTADOS & 77 \\
\hline \multirow{2}{*}{ Introducción --- 5.1 Resultados y análisis estadístico de los cuestionarios USOHTD } & 77 \\
\hline & 7 \\
\hline CONCLUSIONES Y OBSERVACIONES - & 37 \\
\hline & 96 \\
\hline ANEXOS - & 110 \\
\hline 1 Cuestionario USOHTD para medir la percepción en la Investigación en Química & 111 \\
\hline 2 Cuestionario USOHTD para medir la percepción en la Docencia de Química ---- & 116 \\
\hline 3..Cuestionario USOHTD para medir la percepción en el Laboratorio de Química - & 121 \\
\hline 4 Frecuencia de respuestas iguales en los tres Ámbitos de Química & 126 \\
\hline 5 Medias aritméticas de los cuatro Ejes de Análisis por Ámbito de Química -------- & 127 \\
\hline Media aritmética Global del Uso de HTD por Ámbito de Química & 12 \\
\hline
\end{tabular}




\section{PERCEPCIÓN SOBRE EL USO DE HERRAMIENTAS TECNOLÓGICAS DIGITALES COMO APOYO EN LA DOCENCIA E INVESTIGACIÓN CASO: DOCENTES-INVESTIGADORES UAM-A, MÉXICO, ADSCRITOS A QUÍMICA}

\section{Resumen.}

EL ARTE MAESTRO DEL OFICIO DE INVESTIGADOR

El quehacer científico es un actividad académica que tiene por objetivo el enseñar a investigar en el arte maestro de los saberes prácticos que conforman la generación de conocimientos (habitus ${ }^{2}$ )

Ricardo Sánchez Puentes (Docente UNAM).

. El presente trabajo de tesis indaga en la percepción del profesor-investigador de la Universidad Autónoma Metropolitana Unidad Azcapotzalco UAM-A sobre la utilización, creencias y concepción en el uso o no uso de las Herramientas Tecnológicas Digitales (HTD) en el proceso de Enseñanza e Investigación en el área de la química como un estudio descriptivo-cuantitativo de caso. Posteriormente se identifican las diferencias a través de un comparativo de su utilización por profesoresinvestigadores en tres ámbitos de la química: la docencia teórica, la docencia experimental y la investigación, correlacionando algunas teorías que soporten los hallazgos.

Los datos se registran a través de un cuestionario-encuesta, el análisis se realiza mediante valores de la estadística descriptiva ${ }^{3}$

El trabajo está dividido en cinco capítulos: el primero trata sobre el problema o curiosidad que inicia la investigación, la pregunta de investigación, objetivos, justificación y limitaciones de la investigación. Se describen los antecedentes sobre la tecnología digital en la educación y en específico en la educación superior y en particular en la UAM-A (conocimiento de las HTD usadas en la educación, beneficios, infraestructura y políticas). El segundo presenta una descripción del Estado del Arte acerca de las HTD y su uso en la docencia e investigación en diferentes perspectivas. El tercero trata sobre el Marco Teórico y Conceptual sobre la percepción, la tecnología digital teorías y conceptos y el sistema de variables. El cuarto trata sobre la metodología y proceso de investigación, como el diseño del instrumento USOHTD y el método para el análisis de la información obtenida; y el quinto tiene que ver con el análisis de la percepción de los profesores sobre la frecuencia de uso, beneficios, infraestructura y políticas con relación a las HTD en su práctica docente e investigación en química. Finalmente se redactan las conclusiones y observaciones del estudio de tesis doctoral.

\footnotetext{
${ }^{2}$ Habitus. Pensar, sentir y actuar asociado a una comunidad con percepciones similares del mundo y actuación en él. Herramienta teórico-metodológica en diferentes campos sociales. En el ámbito científico son dinámicas generadas por la acción social en donde "los agentes actúan de acuerdo con unas intenciones conscientes y calculadas, de acuerdo con unos métodos y unos programas conscientemente elaborados, ..." (Bourdieu, 2001:72).

${ }^{3}$ Estadística descriptiva. Sustituye o reduce el conjunto de datos obtenidos por un pequeño número de valores descriptivos, como pueden ser: el promedio, la mediana, la media geométrica, la varianza, la desviación típica, etc. Técnica matemática que obtiene, organiza, presenta y describe un conjunto de datos con el apoyo de tablas, medidas numéricas o gráficas.
} 


\title{
PERCEPCIÓN SOBRE EL USO DE HERRAMIENTAS TECNOLÓGICAS DIGITALES COMO APOYO EN LA DOCENCIA E INVESTIGACIÓN CASO: DOCENTES-INVESTIGADORES UAM-A, MÉXICO, ADSCRITOS A QUÍMICA
}

\begin{abstract}
CAPITULO 1. EL PROBLEMA
Problematizar es un don del investigador, cultivado en el esfuerzo y la constancia, y la obra de una vida de dedicación a la enseñanza conceptual, lingüística y sobre todo del ejercicio práctico del conocer científico.

Ricardo Sánchez Puentes
\end{abstract}

“La verdad puede ser desconcertante. Entenderla nos puede llevar algún tiempo"

Carl Sagan

\section{Introducción:}

La información y el conocimiento han jugado un papel importante a lo largo de la historia de la humanidad, en el tercer milenio, la era digital y sociedad del conocimiento $^{4}$ y la información han incrementado las relaciones entre los distintos agentes sociales por el desarrollo de la tecnología digital TD, ésta ha propiciado interdependencias cada vez más complejas entre distintos países e instituciones. La revolución de las redes telemáticas ${ }^{5}$ impactan a nivel global y local, a la educación en general y a la universidad en particular, prioritariamente en los campos de la docencia, la investigación y la difusión de la información. Es así que la globalización del mundo en diferentes aspectos del desarrollo humano lleva necesariamente al uso de diversas tecnologías digitales (TIC, redes teleinformáticas, plataformas y equipos digitales de punta) que propician la innovación, la creatividad y la competitividad en los sectores económicos, políticos, administrativos y de servicios, así como en los campos de la docencia e investigación. Estas TD brindan oportunidades y diversidad de servicios a las nuevas generaciones, a los académicos, a los estudiantes y a los ciudadanos en general (Torres, Barona y García, 2010)

No obstante para Fernández (2007), la tecnología digital transforma la realidad en una realidad virtual, donde las transnacionales comunicativas hacen del lenguaje digital una tecnología de poder, y de la voluntad de los usuarios una nada que rebaja al hombre a la condición de siervo de su propia creación. El reencantamiento digital recupera el sojuzgamiento ${ }^{6}$ del hombre (los new mass media) a cargo del absolutismo de las representaciones simbólicas digitales dirigidas por la Industria Cultural. En materia de educación la TD mal aplicada contribuye al abandono escolar (desvanecimiento del sentido del aprendizaje escolar en César Coll, 2008, 2009). En este sentido se puede precisar que la buena administración de las tecnologías digitales en el proceso educativo es fundamental por parte del docente, esta práctica

\footnotetext{
${ }^{4}$ Para la Comisión Europea la sociedad del conocimiento deriva de: a) La investigación y la producción de conocimientos, b) La transmisión principalmente por la educación, c) Su difusión a través de las TIC, d) Y su aplicación, sobre todo en la innovación pedagógica (Sangra y González, 2004:22)

${ }^{5}$ Redes telemáticas: Redes de ordenadores (tecnología) para generar, procesar y transmitir información

${ }^{6}$ Sojuzgamiento: Esclavizar, dominar, someter
} 


\section{PERCEPCIÓN SOBRE EL USO DE HERRAMIENTAS TECNOLÓGICAS DIGITALES COMO APOYO EN LA DOCENCIA E INVESTIGACIÓN CASO: DOCENTES-INVESTIGADORES UAM-A, MÉXICO, ADSCRITOS A QUÍMICA}

de buena administración implica su correcta utilización (Quintero, Ávila y Riascos, 2010; Logan, 1995)

En materia de educación superior, la sociedad del conocimiento (Didriksson, 2007; Guzmán; Larios y Chaparro, 2010; Liaw, 2002; Martínez, 2007; Oppenheimer, 2011; Ruiz y Martínez 2007; Ruiz, Martínez, Noguera y Valladares, 2009; UNESCO, 2005) que se ha ido conformando con el uso de herramientas tecnológicas digitales HTD cada vez más elaboradas que facilitan los procesos de enseñanza, aprendizaje e investigación (Quintero et al. 2010), demanda elevar la calidad de la enseñanza en los sistemas de educación superior (Cid, Andrés-Pérez y Zabalza, 2009; Hativa y Goodyear, 2002). En la educación basada en competencias EBC el uso de HTD es un medio para obtenerlas (Obaya., Vargas y Delgadillo, 2012).

Es así que los países deben prepararse para tener los conocimientos y habilidades con el objetivo de competir en un mercado global, reducir la pobreza, la desigualdad y elevar la calidad de vida de sus ciudadanos. La clave de todo está en la educación (Oppenheimer, 2011), la calidad de la educación (Guzmán, 2011) y en donde el docente forma parte de este desarrollo social, económico y ambiental.

Una de las principales necesidades del Sistema Educativo Nacional Mexicano es la de contar con recursos humanos altamente capacitados (Rodríguez, 2017; PND, 2013). Docentes con un elevado compromiso ético y con un vasto herramental para detectar necesidades, problemas y diseñar alternativas viables de solución. Se requiere que el docente acepte capacitarse con habilidades, características y actitudes específicas para mejorar el aprendizaje; una mayor formación pedagógica; una interacción colaborativa con los alumnos y pares además de un manejo adecuado de las HTD.

Para la UNESCO (UNESCO y la Educación, 2011) la excelencia de los docentes y su capacitación profesional permanente son fundamentales para una educación de calidad y las HTD se hacen necesarias en la educación superior. En la investigación el profesor-investigador es formador de jóvenes investigadores y las HTD son imprescindibles, por tanto el docente se ve en la necesidad de formarse en el uso, conceptos y alcances de las HTD.

Las Tecnologías de la Información y Comunicación TIC han sido estudiadas como herramientas de enseñanza-aprendizaje y de investigación en distintas universidades nacionales: Guadalajara en: Castillo et al, 2010; Norte y Sur de México en: LagunesDomínguez et al., 2015; Morelos en: Torres, et al., 2010. Así como en universidades extranjeras: España; Argentina; Venezuela en: Jimenez, Eliecer y Vivas, 2011; Colombia, en: Quintero, 2010; Estados unidos en: Bruenjes, 2001; Jacobsen, 1998; Mosley, 2014; Tanzania, África en: Mwalongo, 2011; K-12 Education Team, 2015; Wright, 2013.

Investigaciones han distinguido a los años ochenta como los del surgimiento de las TIC. A lo largo de las últimas tres décadas las universidades han experimentado su uso en la parte administrativa, académica, de gestión y de investigación, sin objetivos claros de cómo utilizarlas. Además los profesores no utilizan los recursos 


\section{PERCEPCIÓN SOBRE EL USO DE HERRAMIENTAS TECNOLÓGICAS DIGITALES COMO APOYO EN LA DOCENCIA E INVESTIGACIÓN CASO: DOCENTES-INVESTIGADORES UAM-A, MÉXICO, ADSCRITOS A QUÍMICA}

tecnológicos en su práctica docente (prefieren el confort de la clase tradicional) 0 bien las herramientas sólo las usan para actividades básicas como el procesamiento de texto, aunque se cuente con infraestructura, recursos tecnológicos y políticas de uso, necesarios para soportar las TIC (Bruenjes, 2001; Castillo et al, 2010; Jimenez, 2011; Lagunes, 2015; Mosley, 2014; Mwalongo, 2011; Torres, 2010; Valdez et al., 2011), y que éstas otorguen mayor eficiencia y beneficios a los procesos educativos y académicos (López de la Madrid, 2011). En un estudio realizado en la Universidad Autónoma del Estado de Morelos AEM (Guerrero, 2005), se pone de manifiesto la resistencia de los profesores, para utilizar las HTD. Las razones dadas se referían a la necesidad de capacitación en el uso de dichos medios, por un lado y por el otro, a que los profesores mayores de edad mencionaban que seguirían con sus formas de enseñanza sin incorporar las TIC. La experiencia y la teoría muestran que toda apuesta por el cambio implica también la exposición a la resistencia. En el ámbito educativo, la resistencia al cambio se percibe y se nombra a través de sus actores. Profesores, estudiantes, directivos; y los docentes son identificados como "resistentes al cambio" La resistencia como una forma de conflicto, aparece, emerge, habla y explica. Resistencia al cambio o a lo que presenta autoritarismo (por ejemplo La Reforma Educativa Mexicana). Las resistencias de los grupos deben ser trabajadas porque los logros en educación tienden a mejorar el nivel social de los estudiantes.

En otro estudio (Bruenjens, 2001) se da a conocer la misión educativa de ofrecer instrucción diversificada para satisfacer las necesidades educativas de los nativos digitales, pero son pocos los docentes entusiastas (los más jóvenes) hacia el uso de HTD (Rogers, 1995).

Una educación de calidad que emplea HTD son las finalidades de la educación superior como de sus docentes. La Universidad Autónoma Metropolitana Unidad Azcapotzalco UAM-A en el documento "Las Políticas Operativas de Docencia Unidad Azcapotzalco" (UAM-A, 2003) plantea una educación de calidad de tal manera que se hace necesaria una indagación en la UAM-A, en sus Áreas de Química para conocer si se está apoyando a esta educación en el marco de la globalización con el uso de HTD. La investigación también dará luz acerca de los motivos de su uso o no y podría continuarse, en un futuro, la investigación para fortalecer las estrategias a seguir para aumentar el uso de HTD en el contexto descrito.

Importancia de la investigación. La investigación se hace pertinente porque: La educación esta globalizada, surgiendo la sociedad del conocimiento en donde el uso de las HTD se hace necesario (Didriksson, 2007; Brunner, 1990). Las instituciones de educación superior IES se ven presionadas por esta globalización a dar una educación de calidad con el empleo de HTD y realizar investigación para innovar los conocimientos (Brunner, 1990; Brunner, 2003) y tecnologías (Oppenheimer, 2011) para competir en un mundo globalizado, apoyada con la tecnología digital de punta. En la UAM-A, institución de educación superior e investigación, en sus áreas de química es necesario indagar a través de un estudio descriptivo de corte cuantitativo el número de profesores en docencia y de investigación que usan o no herramientas tecnológicas en el proceso de enseñanza e investigación. Y conocer la(s) razón(es) o 


\section{PERCEPCIÓN SOBRE EL USO DE HERRAMIENTAS TECNOLÓGICAS DIGITALES COMO APOYO EN LA DOCENCIA E INVESTIGACIÓN CASO: DOCENTES-INVESTIGADORES UAM-A, MÉXICO, ADSCRITOS A QUÍMICA}

causa(as) por las que un porcentaje de profesores no utilizan HTD en el proceso de enseñanza e investigación. Para que conociendo los resultados de las investigaciones anteriores, se puedan tener conclusiones de la frecuencia del uso de HTD en la docencia e investigación y proponer una teoría que sustente los resultados del uso o no de HTD, y llevar a cabo en un futuro investigaciones sobre estrategias para aumentar su uso en el contexto descrito.

Propósito de la Investigación. El propósito se plantea a través de la pregunta ¿Cuál es la percepción de los profesores-investigadores de la UAM-A adscritos a química, acerca del uso de las HTD como apoyo en la docencia y en la investigación en química? Esta finalidad es la de comprender la frecuencia del uso de HTD por parte de los docentes de la UAM-A tanto en la docencia como en la investigación, y las causas de este uso o no para (no es la intención en este proyecto de tesis) en un futuro establecer una serie de procesos para gestionar políticas educativas de enseñanza y capacitación, identificando en la percepción de su impacto y la continuidad de este proceso que permitan mejorar o apoyar y beneficiar la educación superior, en particular en la UAM-A con la utilización de HTD. Contexto en el que finalmente soy parte del fenómeno. La comparación del uso de HTD en los ámbitos de la química teorica, práctica e investigación implica saber hacia dónde se inclina el mayor uso y aplicar o construir una teoría que explique los hallazgos (Grounded theory $^{7}$ en: Corbitt, Yoong, 2007; Guerrero, 2005; Guillemette. 2006; Hunt y Ropo, 1995; Mahtani, 2009; Páramo, 2015; Pauleen, 2007; Glaser y Strauss, 1967).

1.1 Planteamiento del problema. A nivel mundial los sistemas de educación superior están siendo sometidos a fuertes presiones para elevar la calidad de su enseñanza (Cid et al., 2009; Hativa \& Goodyear, 2002) e investigación, y competir en un mundo globalizado hasta el punto que ésta se ha convertido en su prioridad estratégica. Hativa (2000) indica que, independientemente del tipo de disciplina o especialidad, las universidades deben formar en sus estudiantes un pensamiento de alto nivel y convertirlos en aprendices autónomos. En el terreno de la investigación las universidades deben ser semilleros de investigadores jóvenes. Las HTD son de gran apoyo en el desarrollo de este proceso de calidad y son los profesores los encargados de elevar la calidad utilizando estrategias como el uso ya sea de equipos de punta, programas computacionales para resolver problemas teóricamente y en general el uso de las tecnologías de la información y la comunicación TIC. En resumen en las universidades en general y en la UAM-A en particular existen las necesidades de investigación y producción de impacto de la actividad docente y de investigación que demanda el manejo de laboratorios y de HTD para realizar investigación innovadora ofreciendo respuestas que beneficien a la sociedad y por su parte la docencia exige el manejo de las nuevas Tecnologías de la Información para comunicarse con los estudiantes y ofrecer panoramas alentadores al dotar al alumno

\footnotetext{
${ }^{7}$ Grounded theory o teoría fundamentada, es la que surge del análisis de los resultados o hallazgos de una investigación. Es un método de investigación que permite desarrollar una teoría la cual ofrece una explicación sobre un problema, asunto o preocupación de una determinada población de personas de un área específica, además permite emitir como puede resolverse o procesarse esta preocupación. Permite el estudio de la percepción en la investigación cualitativa (Mahtani-Chugani, 2009; Guerrero, 2005)
} 


\section{PERCEPCIÓN SOBRE EL USO DE HERRAMIENTAS TECNOLÓGICAS DIGITALES COMO APOYO EN LA DOCENCIA E INVESTIGACIÓN CASO: DOCENTES-INVESTIGADORES UAM-A, MÉXICO, ADSCRITOS A QUÍMICA}

con competencias útiles para la vida laboral, personal y social en la sociedad (digital) actual. Pero de acuerdo a la percepción (el pensar, sentir y actuar) ${ }^{8}$ de los docentes en muchos trabajos ya mencionados; revela que su concepción, creencias y uso de la tecnología digital es la que condiciona el uso de la misma ya que conociendo de políticas, teniendo infraestructura y sabiendo de los beneficios de ésta en la docencia e investigación pero por varias causas y ese es el problema, la mayor parte no parece tomar en cuenta en el proceso de enseñanza-aprendizaje el uso de HTD y se mantiene en el confort de una educación tradicional. El profesor que se detiene en esta rutina de aprendizaje condicionado por su percepción al no uso de HTD, puede impactar negativamente en el estudiante; y también se limita a realizar investigación científica y/o educativa. De ahí la preocupación de las universidades por mejorar sus formas de enseñanza, utilizando HTD, reconociendo la escasez de trabajos acerca de cómo hacerlo y agravado por el hecho de que en las universidades se valora más la investigación que la enseñanza (Cid et al., 2009, UAM-A, 2003), Los investigadores utilizan ampliamente la TD pero en su práctica docente la ignoran.

1.2 Formulación del problema. El enfoque de la investigación es de corte cuantitativo $^{9}$ y de tipo descriptivo ${ }^{10}$ sobre la utilización, concepción y creencias acerca del uso de HTD por parte del profesor-investigador en el proceso de enseñanza en la docencia teórica, experimental y la investigación en química.

Método. Estudio descriptivo de caso $^{11}$ (Hernández, Fernández y Baptista, 2006 en Solórzano, 2013), con 10 profesores de tiempo completo (muestra por conveniencia $^{12}$ ) que imparten teoría, 10 que asisten al laboratorio de química y 10 que realizan investigación en química.

La técnica empleada para la recolección de datos es a través de un cuestionario encuesta digital USOHTD ${ }^{13}$ (Liaw, 2002; Torres, Barona y García, 2010), con cuatro dimensiones o categorías acerca de la utilización, beneficios, infraestructura y políticas; de las HTD (anexo 1).

\footnotetext{
${ }^{8}$ Percepción. Es un proceso mental (cognitivo) que ocurre a través de los sentidos (estímulos). Se observa, analiza, sintetiza, ordena y almacena la información obtenida de la realidad de un fenómeno, proceso, objeto o conducta (libre pensamiento, sujeto pasivo es el pensar) y posterior aplicación de lo conceptualizado (libre pensamiento de acción, sujeto activo, es el actuar). Se piensa (desarrollo cognitivo), se siente (desarrollo emocional) y se actúa positiva o negativamente (desarrollo conductual) ante un fenómeno, un hecho, un objeto. Es "El arte de donar respuestas, de condicionar conductas". Concepción (pensar), creencia (sentir) y actuar (aplicar, usar).

${ }^{9}$ Enfoque cuantitativo: Utiliza la recolección de datos para probar hipótesis, con base en la medición numérica y el análisis estadístico, para establecer patrones de comportamiento.

${ }^{10}$ Tipo de investigación descriptivo: Pretenden medir o recoger información de manera independiente sin indicar cómo se relacionan las variables medidas

${ }^{11}$ (Fdz. Lilia) (Tema 4. Justificación y cronograma). Del seminario Desarrollo de la Investigación III. Dr. Rafael Demetrio Herrera Herrera. 2 de abril del 2017, CESE, México.

${ }^{12}$ Muestra por conveniencia: El muestreo de o por conveniencia es una técnica de muestreo no probabilístico donde los sujetos son seleccionados dada la conveniente accesibilidad y proximidad de los sujetos para el investigador. Permite seleccionar una muestra con muchísima facilidad.

${ }^{13}$ Cuestionario-encuesta USOHTD: instrumento para evaluar la percepción de los profesores con relación a la utilización, concepción y creencias de las HTD en la docencia teórica, experimental e investigación en química.
} 


\section{PERCEPCIÓN SOBRE EL USO DE HERRAMIENTAS TECNOLÓGICAS DIGITALES COMO APOYO EN LA DOCENCIA E INVESTIGACIÓN CASO: DOCENTES-INVESTIGADORES UAM-A, MÉXICO, ADSCRITOS A QUÍMICA}

El instrumento consiste en preguntas cerradas cuantificadas (medición numérica) con la escala de Likert, validado, estadísticamente tratado, aplicado el instrumento a una muestra piloto y finalmente a la muestra de trabajo Cuestionario usado ya validado).

1.3 Enunciado del problema. Los profesores-investigadores de la UAM-A adscritos a química, limitan el uso de las HTD en su práctica docente y de investigación ${ }^{14}$, por tal razón se hace un estudio para conocer la percepción que tienen al respecto de su uso o no uso.

\subsection{Preguntas de investigación}

Pregunta de investigación general

¿Cuál es la percepción de los profesores-investigadores de la UAM-A adscritos a química, acerca del uso de las HTD como apoyo en la docencia y en la investigación científica?

\section{Preguntas de investigación particulares}

Se indagará en la percepción del uso de las HTD las cuales abarcan aspectos tales como: la frecuencia, beneficio, infraestructura tecnológica, y políticas; de uso:

- ¿Cuál es la percepción de los profesores-investigadores de la UAM-A adscrito a química, acerca del uso de las HTD como apoyo en la docencia teórica en química?

- ¿Cuál es la percepción de los profesores-investigadores de la UAM-A adscritos a química, acerca del uso de las HTD como apoyo en la docencia experimental en química?

- ¿Cuál es la percepción de los profesores-investigadores de la UAM-A adscritos a química, acerca del uso de las HTD como apoyo en la Investigación científica en las áreas de química?

- ¿Cuál es la diferencia (comparativo) entre las percepciones, de los profesoresinvestigadores de la UAM-A adscritos a química, acerca del uso de las HTD como apoyo entre la docencia teórica y entre la docencia experimental en química?

- ¿Cuál es la diferencia (comparativo) entre las percepciones, de los profesoresinvestigadores de la UAM-A adscritos a química, acerca del uso de las HTD como apoyo entre la docencia teórica y la investigación científica en las áreas de química?

\subsection{Objetivos}

\section{Objetivo general:}

\footnotetext{
${ }^{14}$ Un problema de investigación es una frase, oración o proposición expresada en términos positivos, nunca en forma de pregunta o interrogación (Lezaca, 2010). Para Cauas, (2006), sin embargo, existen dos formas de enunciar el problema de investigación y estas proposiciones son: el interrogativo y el declarativo
} 


\section{PERCEPCIÓN SOBRE EL USO DE HERRAMIENTAS TECNOLÓGICAS DIGITALES COMO APOYO EN LA DOCENCIA E INVESTIGACIÓN CASO: DOCENTES-INVESTIGADORES UAM-A, MÉXICO, ADSCRITOS A QUÍMICA}

Analizar ${ }^{15}$ en la percepción de los profesores-investigadores adscritos a química de la UAM-A, acerca de la frecuencia, beneficio, infraestructura, y políticas; de uso de las HTD.como apoyo en la docencia teórica, experimental y en la investigación científica, por tal razón es necesario hacer un estudio para conocer la percepción que tienen al respecto del uso de las HTD

\section{Objetivos específicos:}

Se analizará en la percepción del uso de las HTD, la cual abarca aspectos tales como: beneficio, frecuencia, infraestructura, y políticas; de uso de las HTD.

- Analizar cuál es la percepción de los profesores-investigadores de la UAM-A adscrito a química, acerca del uso de las HTD como apoyo en la docencia teórica en química

- Analizar cuál es la percepción de los profesores-investigadores de la UAM-A adscrito a química acerca del uso de las HTD como apoyo en la docencia experimental en química

- Analizar cuál es la percepción de los profesores-investigadores de la UAM-A adscrito a química acerca del uso de las HTD como apoyo en la investigación científica en las áreas de química

- Comparar la percepción de los profesores investigadores de la UAM-A adscrito a química, acerca del uso de las HTD como apoyo en la docencia teórica y en la docencia experimental en química

- Comparar la percepción de los profesores investigadores de la UAM-A adscrito a química, acerca del uso de las HTD como apoyo en la docencia teórica, la docencia experimental y en la investigación en química

1.6 Justificación de la investigación. La investigación se justifica porque el uso limitado de HTD en la educación superior, implica un rezago en el desarrollo de la misma con respecto a su desarrollo a nivel mundial. Por lo que la investigación de las causas de su uso o no, por parte del profesor-investigador adscrito a química de la UAM-A, en la docencia e investigación proporciona información para buscar las razones del origen del problema que conduce en un futuro, a formular propuestas de estrategias para fomentar su uso, beneficiándose así la academia (el proceso de enseñanza-aprendizaje e investigación), elevando su calidad en favor de: la institución, los profesores-investigadores y para que los estudiantes compitan en el mundo actual con éxito como lo demanda la sociedad del conocimiento (tercer milenio) y sus organizaciones educativas globales y nacionales.

Justificación teórica. La reflexión de los resultados y hallazgos de la investigación (datos, indicadores) guían a confrontarlos con alguna(s) teoría(s) relacionada(s) con el uso de HTD en la docencia y en la investigación, por ejemplo la Teoría de la

\footnotetext{
${ }^{15}$ Analizar. Nivel cognoscitivo de análisis. Dividir el conocimiento en partes y mostrar relaciones entre ellas
} 


\section{PERCEPCIÓN SOBRE EL USO DE HERRAMIENTAS TECNOLÓGICAS DIGITALES \\ COMO APOYO EN LA DOCENCIA E INVESTIGACIÓN \\ CASO: DOCENTES-INVESTIGADORES UAM-A, MÉXICO, ADSCRITOS A QUÍMICA}

capacidad cognitiva que describen la cantidad de esfuerzo mental que se relaciona con el desempeño de una tarea y influye en el docente de mayor edad que se resiste a innovarse tecnológicamente; la Teoría del aprendizaje de adultos o Teoría de andragogía y la Teoría de la difusión de innovaciones. La comparación de la percepción de uso de HTD entre la docencia teórica y experimental e investigación en química lleva necesariamente a fundamentar los hallazgos en la Teoría fundamentada (Grounded theory).

Justificación práctica. En el desarrollo de la investigación se analiza la información generada de la problemática (del uso limitado de HTD en el profesor-investigador en la educación superior) para proponer en un futuro un nuevo método, técnica o una nueva estrategia para resolver el problema de mejorar el uso de HTD y por consiguiente la mejora en la educación que se imparte. En el presente trabajo de tesis no se propone algún modelo de enseñanza para la gestión de nuevos ambientes mediatizados de aprendizaje y desarrollo de competencias en el aula, método o estrategia para generar conocimiento (Obaya, 2012), por ejemplo un diseño de un software, un programa, una plataforma o un ambiente informático. Se mencionen las competencias específicas que los docentes deberían adquirir para una utilización efectiva de las mismas y que algunos docentes pertenecientes a la muestra deberían adquirir para utilizar efectivamente las HTD.

1.7 Limitaciones. Debido a un tamaño de muestra limitado de este estudio de caso, los resultados no son representativos de todas las universidades. Dado que la muestra se limita a la Unidad de Azcapotzalco de la UAM, en las áreas de química los resultados se aplican solo a esta población y no es adecuado generalizar los hallazgos a poblaciones fuera de las áreas de química u otras instituciones donde se toma la muestra. Las restricciones de tiempo de los participantes es un factor limitante para este estudio. Algunos profesores-investigadores de la muestra no quieren participar en este estudio, lo que obliga a buscar participantes adicionales y además de otras áreas de química. La disponibilidad de los administrativos de las infraestructuras tecnológicas es otra limitante. Así como la disponibilidad de los estudiantes participantes. Los costos de la investigación y la disponibilidad de documentos para la investigación documental

\subsection{Antecedentes}

Para la Organización de las Naciones Unidas para la Educación, la Ciencia y la Cultura ${ }^{16}$ UNESCO $\left(2017^{a}\right)$, como ya se ha señalado anteriormente el empleo de HTD en la educación mejora la calidad en el proceso de enseñanza-aprendizaje, hay la posibilidad de aumentar la cobertura para proporcionar instrucción a todos con igualdad de género y equidad. Contribuyen al desarrollo profesional de los docentes. Los encargados de formular políticas sobre las HTD en apoyo a la docencia perciben que éstas pueden mejorar el rendimiento académico de los alumnos, ampliar el acceso a la escolaridad, aumentar la eficiencia y reducir los costos, preparar a los estudiantes para el aprendizaje a lo largo de toda la vida y capacitarlos para incorporarse a una fuerza de trabajo que compite a escala mundial. UNESCO (2017 $\left.{ }^{\text {b }}\right)$

\footnotetext{
${ }^{16}$ UNESCO: United Nations Educational, Scientific and Cultural Organization.
} 


\section{PERCEPCIÓN SOBRE EL USO DE HERRAMIENTAS TECNOLÓGICAS DIGITALES COMO APOYO EN LA DOCENCIA E INVESTIGACIÓN CASO: DOCENTES-INVESTIGADORES UAM-A, MÉXICO, ADSCRITOS A QUÍMICA}

apoya la aplicación de las TIC a la educación, mediante una política educativa dinámica y transformadora y una infraestructura de apoyo. UNESCO se ha comprometido a proporcionar a los Estados Miembros la asistencia técnica necesaria para la formulación de políticas y planes maestros nacionales sobre la aplicación de las TIC en la educación.

En la Cumbre Mundial de la Sociedad de la Información CMSI ${ }^{17}$ ) los gobiernos de los países del mundo declaran su deseo y compromiso de construir una sociedad de la información, comunicación y del conocimiento para que todos se enteren de sus propósitos entre ellos que la infraestructura es esencial para el uso de la TIC y la capacitación en su uso para todos (UIT $\left.{ }^{18}, 2005\right)$. Pero la infraestructura es costosa y se reafirma la brecha digital entre naciones poderosas y naciones débiles, crece la desigualdad, se crean contaminaciones y basureros "digitales" afectando principalmente a los países del tercer mundo. La capacitación en la tecnología digital para los docentes (y sus alumnos), es también cara y complicada y además es un reto en la educación por la resistencia al cambio de los profesores (CMSI, 2003).

Banco mundial BM $\mathbf{B M}^{\mathbf{1 9}}$. El informe del Banco Mundial (Banco Mundial, 2016) advierte que las tecnologías digitales se han extendido rápidamente en todo el mundo, lo están transformado facilitando el flujo de la información, los países deben mejorar el clima de negocios, invertir en la educación y la salud de las personas, y promover el buen gobierno, pero los dividendos digitales (crecimiento, empleo, servicios y la educación) no han avanzado en la misma medida, han quedado a la zaga. Las tecnologías digitales pueden promover la inclusión, la eficiencia y la innovación en todos los ámbitos y en especial en la docencia e investigación en la educación superior. Pero el BM advierte que es improbable que la expansión de las tecnologías digitales por si sola signifique el fin a la brecha de conocimientos que existe en el mundo, el BM recomienda acortar la brecha digital haciendo que Internet sea universal, accesible, abierto y seguro; y reforzar las regulaciones que garantizan la competencia entre empresas, adaptar las habilidades de los trabajadores a las exigencias de la nueva economía, y promover instituciones responsables que rindan cuentas a las personas, como las instituciones de educación superior IES con las mismas estrategias de desarrollo digital para obtener el máximo provecho, se deben crear las condiciones adecuadas para la tecnología, regulaciones que faciliten la competencia y el ingreso en el mercado laboral, habilidades que permitan a los trabajadores, maestros y futuros profesionistas aprovechar las oportunidades que ofrece la tecnología digital, que puede a su vez, acelerar el ritmo de desarrollo de un país. Invertir en infraestructura básica, y facilitar la competencia en las plataformas digitales son algunas de las medidas recomendadas en el Informe sobre el Desarrollo Mundial (Mishra y Deichmann, 2016) que pueden contribuir a que las

\footnotetext{
${ }^{17}$ The World Summit on the Information Society (WSIS).

${ }^{18}$ Unión Internacional de Telecomunicaciones, UTI por sus siglas en inglés ITU.

${ }^{19}$ El Grupo Banco Mundial, es una asociación mundial conformada por 189 países, que trabaja para reducir la pobreza y generar prosperidad compartida en los países en desarrollo. Trabaja el desarrollo sostenible con el medio ambiente, la economía y el aspecto social brindando apoyo financiero, asistencia técnica y ayuda a los países a enfrentar los desafíos mediante el intercambio de conocimiento de vanguardia y la aplicación de soluciones innovadoras.
} 


\section{PERCEPCIÓN SOBRE EL USO DE HERRAMIENTAS TECNOLÓGICAS DIGITALES \\ COMO APOYO EN LA DOCENCIA E INVESTIGACIÓN \\ CASO: DOCENTES-INVESTIGADORES UAM-A, MÉXICO, ADSCRITOS A QUÍMICA}

escuelas sean más productivas e innovadoras. Además, si bien un nivel básico de alfabetización sigue siendo esencial para los niños, la enseñanza de habilidades cognitivas y de pensamiento crítico avanzadas y la formación fundacional en sistemas técnicos avanzados de TIC serán fundamentales a medida que Internet se siga extendiendo. La enseñanza precoz de habilidades técnicas y la exposición de los niños a la tecnología promueven los conocimientos relacionados con las TIC e influyen a la hora de elegir una carrera.

La Unión Europea UE $\left(E C^{20}\right.$ ) recomienda invertir en la Educación Superior (Comisión Europea, 2018 ${ }^{a}$ ) ya que la forma en que se financia tiene un impacto importante en su eficacia general. La Estrategia Europa 2020 (COM, 2010) de la UE subraya que los sistemas educativos más avanzados requieren una financiación adecuada. Esto es necesario porque las instituciones autónomas pueden especializarse más fácilmente, promoviendo un mejor rendimiento educativo y de investigación a la vez que fomentan la excelencia dentro de los sistemas de educación superior. La educación superior relevante y de alta calidad es capaz de equipar a los estudiantes con los conocimientos, habilidades y competencias básicas transferibles que necesitan para tener éxito en la vida laboral en nuestra actual sociedad del conocimiento y era digital, dentro de un ambiente de aprendizaje de alta calidad que reconoce y apoya la buena enseñanza (Comisión Europea, 2018 ${ }^{\mathrm{b}}$ ). Una forma clave de lograr esto, de acuerdo con el documento de política de la UE sobre Repensando la educación, es aprovechar las ventajas en la transformación de las TIC y otras nuevas tecnologías para enriquecer la enseñanza, mejorar las experiencias de aprendizaje y apoyar el aprendizaje personalizado. Todo depende de que las IES brinden el apoyo de infraestructura tecnológica y programas de capacitación docente y de esta manera contar con profesores-investigadores capacitados y motivados. Sin embargo, los niveles del personal académico y de investigación a menudo no han seguido el ritmo de la expansión del número de estudiantes, lo que ejerce una mayor presión sobre capacidades ya tensas. La CE propone Mejores condiciones para un mejor desarrollo profesional inicial y continuo, y un mejor reconocimiento y recompensa de la enseñanza, la investigación y la innovación del trabajo cotidiano (Triangulo del conocimiento en Comisión Europea, $2018^{c}$ ), son esenciales para asegurar, atraer y retener al personal académico de excelencia que necesita la educación superior para tener calidad. En el Plan de Acción de Educación Digital de la UE (Comisión Europea, 2018 ${ }^{\mathrm{d}}$ ) se proponen tres prioridades y sus acciones para ayudar a afrontar los desafíos y las oportunidades de la educación en la era digital:

Prioridad 1: Hacer un mejor uso de la tecnología digital para la enseñanza y el aprendizaje: Estableciendo el internet en todas las escuelas y respaldando la preparación digital de los centros de educación general y de formación profesional reforzando su capacidad digital para que llegue a un millón de profesores, formadores y alumnos a finales de 2019.

\footnotetext{
${ }^{20}$ European Commission.
} 


\section{PERCEPCIÓN SOBRE EL USO DE HERRAMIENTAS TECNOLÓGICAS DIGITALES COMO APOYO EN LA DOCENCIA E INVESTIGACIÓN CASO: DOCENTES-INVESTIGADORES UAM-A, MÉXICO, ADSCRITOS A QUÍMICA}

Prioridad 2: Desarrollar competencias y capacidades digitales: Desarrollar una plataforma para la enseñanza superior digital que ofrecerá aprendizaje en línea, movilidad combinada, campus virtuales e intercambio de buenas prácticas entre centros de educación superior. Impartir cursos de formación especializada sobre ciencia abierta en centros de educación superior para estudiantes, investigadores y docentes. Poner en marcha una campaña de sensibilización a escala de la UE para fomentar la seguridad en línea, la higiene cibernética y la alfabetización mediática, así como un programa de formación sobre ciberseguridad.

Prioridad 3: Mejorar la educación gracias a un mejor análisis de los datos y de las previsiones: Poner en marcha un estudio de referencia sobre la integración del uso de las TIC en la educación (Comisión Europea, $2018^{\mathrm{e}}$ ): disponibilidad y utilización de infraestructuras y herramientas y niveles de capacidades digitales. Crear proyectos piloto de inteligencia artificial y análisis del aprendizaje en el ámbito de la educación. Poner en marcha una prospectiva estratégica sobre las tendencias clave derivadas de la transformación digital para el futuro de los sistemas educativos.

Son necesarias las anteriores prioridades porque existe una necesidad urgente de impulsar las competencias digitales en todos los ámbitos y mejorar la utilización de las tecnologías en la educación, ya que se tiene escasas competencias digitales, o ninguna. Pocos estudiantes están escolarizados en centros bien equipados desde el punto de vista digital. Solo entre un $20-25 \%$ reciben clases impartidas por profesores que se sienten seguros utilizando la tecnología en clase. Muchos centros escolares no están conectados a la banda ancha de internet (DESI, 2018).

Las encuestas. Sobre la actividad de la prioridad 3 acerca de estudios de referencia sobre el uso de las TIC y demás HTD la disponibilidad y utilización de infraestructuras y herramientas, y niveles de capacidades digitales, la Comisión Europea generó un cuestionario-encuesta (Comisión Europea, $2018^{\mathrm{e}}$ ) denominado "2nd Survey of Schools: ICT in Education" (" $2^{a}$ Encuesta de escuelas: TIC en la Educación"), el documento del estudio pdf 2016-2020 puede consultarse en la Comisión Europea (2018f). El objetivo del estudio (SMART 2015/0071) (acceso, uso y actitudes hacia la tecnología en las escuelas de Europa) es medir el progreso en el uso y evaluar el impacto del uso de las TIC en las escuelas con el propósito de enseñar / aprender. El estudio se basa en los resultados de la Encuesta de Escuelas: TIC en Educación de febrero del 2013. Con este resultado, se diseñarán y llevarán a cabo encuestas en los 28 Estados miembros de la UE más Islandia, Noruega y Turquía, y los resultados se evaluarán y debatirán en un informe de estudio, que también contendrá un amplio conjunto de gráficos y tablas de datos. Incluirá información sobre la situación en cada país, en forma de un conjunto de perfiles de países individuales. Además, se deben realizar estimaciones para determinar cuánto costaría equipar y conectar todas las aulas de primaria y secundaria de la UE en la UE, en línea con la visión de tener todas las aulas de la UE conectadas para 2020 


\section{PERCEPCIÓN SOBRE EL USO DE HERRAMIENTAS TECNOLÓGICAS DIGITALES COMO APOYO EN LA DOCENCIA E INVESTIGACIÓN CASO: DOCENTES-INVESTIGADORES UAM-A, MÉXICO, ADSCRITOS A QUÍMICA}

Marcos para capacidades y competencias digitales para promover el proceso de enseñanza-aprendizaje efectivo, la currícula y el desarrollo profesional docente inicial y continuo, de la era digital. La Comisión Europea ha elaborado éstos marcos para ayudar a evaluar las capacidades digitales y el nivel de preparación. El marco de capacidades y competencias digitales para los docentes DigCompOrg (European Framework for Digitally Competent Educational Organizations) se publicó en diciembre de 2017 (Comisión Europea, 2018 ). Hace un inventario de las competencias digitales para los docentes de todos los niveles de enseñanza, desde la primera infancia hasta la enseñanza superior y la educación de adultos, incluidos la formación general y la formación profesional, la educación para necesidades especiales y el aprendizaje no formal. Las tecnologías digitales son habilitadoras de un cambio en las prácticas de aprendizaje y enseñanza; sin embargo, no lo garantizan. Para consolidar el progreso y garantizar la cobertura de la educación y la sostenibilidad, las instituciones educativas deben revisar sus estrategias organizativas a fin de mejorar su capacidad de innovación y explotar todo el potencial de las tecnologías digitales y el contenido. El marco DigCompOrg puede ser utilizado por organizaciones educativas, escuelas primarias, secundarias, vocacional, así como por instituciones de educación superior para guiar un proceso de autorreflexión sobre su progreso digital, o utilizarse como herramienta de planificación estratégica para promover políticas integrales para la adopción efectiva de las tecnologías de aprendizaje digital.

Las instituciones de educación también cuentan con un marco de referencia de capacidades y competencias digitales propuesto por la UE, publicado en diciembre de 2015 (Comisión Europea, 2015) cuyo objetivo es que las instituciones evalúen sus progreso en la integración del aprendizaje y las pedagogías digitales y apoyar a los responsables políticos a diseñar, aplicar y evaluar las intervenciones políticas destinadas a integrar y utilizar de manera eficaz las tecnologías digitales de aprendizaje. El marco sirvió de referencia conceptual para crear una herramienta de autoevaluación SELFIE (Self-reflection on Effective Learning by Fostering Innovation through Educational Technologies ${ }^{21}$ ) sobre las capacidades y competencias digitales en los centros escolares (Comisión Europea, 2018 ) (una descripción detallada de lo que se necesita para que las organizaciones educativas sean digitalmente capaces). La auto reflexión se basa en el aprendizaje más que en la tecnología, considera las estrategias de la escuela, la enseñanza, el aprendizaje y su evaluación, infraestructura, currícula, y la experiencia de los estudiantes. Involucra a todos los actores en el proceso de aprendizaje: autoridades escolares, profesores y alumnos. SELFIE apoya su desarrollo. La información es anónima y se recaba en cuestionarios adecuados al tipo de escuela y la cual puede seleccionar e incluso agregar sus propias preguntas a la herramienta para adaptarlas a sus propios objetivos. El cuestionario permite conocer la percepción de la comunidad escolar. Se sintetiza la información proporcionada y se genera el informe escolar de SELFIE, donde se presentan las fortalezas, debilidades y áreas de mejora de una manera gráfica. El informe se puede utilizar para un diálogo dentro de la

\footnotetext{
${ }^{21}$ Autorreflexión sobre el aprendizaje efectivo fomentando la innovación a través de las tecnologías educativas
} 


\section{PERCEPCIÓN SOBRE EL USO DE HERRAMIENTAS TECNOLÓGICAS DIGITALES COMO APOYO EN LA DOCENCIA E INVESTIGACIÓN CASO: DOCENTES-INVESTIGADORES UAM-A, MÉXICO, ADSCRITOS A QUÍMICA}

comunidad escolar, para crear un plan de acción para mejorar el uso de las tecnologías digitales para un mejor aprendizaje y una comparación año tras año. En enero de 2017 se diseñó SELFIE con la opinión de más de 5000 autoridades, profesores y estudiantes y se probó (prueba piloto) en su versión beta en más de 67000 líderes escolares, docentes y estudiantes de 650 escuelas en 14 países de la Unión Europea (México no participó y la prueba piloto no fue aplicada en el nivel superior) en octubre del 2017 (Comisión Europea, 2018'). La comisión Financia la investigación sobre las capacidades y competencias digitales y sobre la utilización en los centros de enseñanza de la innovación y las nuevas oportunidades. El Centro Común de Investigación de la Comisión (Comisión Europea, 2018j) publica periódicamente informes y estudios de investigación al respecto. A continuación se dan ejemplos de algunos de los estudios recientes:

1. Políticas de educación digital en Europa y el resto del mundo: principios clave para la creación de políticas más eficaces (Conrads et al., 2017)

2. Apertura de la educación: marco de apoyo para las instituciones de enseñanza superior. (Inamorato dos Santos, Punie y Castaño, 2016).

3. Casos abiertos: estudio de casos sobre la transparencia en educación (SoutoOtero et al., 2016).

4. Survey of schools: ICT in Education - data in SPSS format. Databases in SPSS. (Comisión Europea, 2013).

5. Survey of schools: ICT in Education. Technical report (pdf). (Comisión Europea, 2010).

Oportunidades de Financiamiento de proyectos. El programa Erasmus+ financia intercambios para apoyar la educación del profesorado en capacidades digitales, así como proyectos destinados a explorar y desarrollar el potencial del uso de la tecnología en la educación. También promueve la creación y la difusión de nuevas pedagogías digitales y recursos educativos (Comisión Europea, 2018k).

Infraestructura. Los Fondos Estructurales y de Inversión Europeos ayudan a equipar y conectar los centros de enseñanza y apoyan la formación en capacidades digitales para jóvenes y adultos Comisión Europea. 2018')

Organización para la Cooperación y el Desarrollo Económicos OCDE (OECD ${ }^{22}$ ). Para la OCDE invertir en TIC para el sector educativo no ha visto ninguna mejora evidente en el rendimiento de los estudiantes en los resultados de la prueba PISA (OECD, 2015). No obstante para la Mtra. Gabriela Ramos (OCDE, 2015) es necesario que los sistemas escolares encuentren formas más eficaces de integrar la tecnología en la enseñanza y el aprendizaje para proporcionar a los docentes entornos de instrucción que apoyen las pedagogías del siglo $\mathrm{XXI}$, y preparen a los

${ }^{22}$ OECD: Organization for Economic Cooperation and Development 


\section{PERCEPCIÓN SOBRE EL USO DE HERRAMIENTAS TECNOLÓGICAS DIGITALES \\ COMO APOYO EN LA DOCENCIA E INVESTIGACIÓN \\ CASO: DOCENTES-INVESTIGADORES UAM-A, MÉXICO, ADSCRITOS A QUÍMICA}

niños con las habilidades necesarias para triunfar en el futuro. "La tecnología es la mejor manera de ampliar el acceso al conocimiento de manera significativa. Para materializar el potencial que ofrece esa tecnología, los países deben invertir con mayor eficacia y asegurar que los maestros vayan a la vanguardia en cuanto al diseño y aplicación de este cambio." "La tecnología no es un fin en sí mismo, sino un medio para fortalecer el aprendizaje." Con respecto a la tecnología digital en la educación superior en América Latina (OECD, 2017) la OECD refiere que se enfrenta a retos cruciales como: acceso a educación de calidad, recursos financieros limitados y lograr la pertinencia de la educación a las necesidades del mercado laboral, enfocándose así principalmente a lo denominado comúnmente "educación a distancia" o "e-learning", las TIC

EI Banco Interamericano de Desarrollo BID. Las nuevas tecnologías abren oportunidades para incrementar los aprendizajes de los estudiantes y reducir brechas entre grupos socioeconómicos. Los gobiernos han invertido fuertemente en aumentar el acceso de los estudiantes a computadoras e internet. Sin embargo la evidencia sugiere que la infraestructura y la tecnología son necesarias, pero no suficientes, y deben orientarse de manera específica (a través del diseño e implementación de programas efectivos de tecnología) a mejorar los aprendizajes (Arias y Cristia, 2014).

El Programa de las Naciones Unidas para el Desarrollo (PNUD, 2000. Citado en Rocha y Pérez, s.f.), menciona que las TIC son un instrumento indispensable para la lucha contra la pobreza en todo el mundo, además de ser un factor relevante para el desarrollo económico y social, al facilitar la provisión de servicios básicos de salud y educación.

La Asociación Nacional de Universidades e Instituciones de Educación Superior ANUIES, congrega a las principales universidades de México, con el fin de proponer y formular programas, planes y políticas nacionales, para el desarrollo de la educación superior. "El siglo XXI se caracterizará por ser la era de la sociedad del conocimiento..." (ANUIES, 2000:7, citada en López de la Madrid y Flores, 2011). La ANUIES en 2007, creó el Observatorio Mexicano de Innovación en Educación Superior OMIES, para conocer, promover, difundir e intercambiar información sobre propuestas de innovación en los ámbitos académico, administrativo y tecnológico. En torno al uso de las TIC se establecen redes de colaboración en los ámbitos de investigación, docencia y extensión, con el fin de diversificar su aplicación en busca de una mejora continua de la calidad educativa. ANUIES, cuenta con 187 IES de las cuales 149 participaron en el 2017 (ANUIES, 2017: 255-259) en una encuesta y 140 en el año 2016 sobre el indicador "Presupuesto Anual en Tecnologías de información TI".(ANUIES, 2017: 44-45; ANUIES, 2016). Los resultados de la encuesta se observan en el Gráfico 1.1 


\section{PERCEPCIÓN SOBRE EL USO DE HERRAMIENTAS TECNOLÓGICAS DIGITALES COMO APOYO EN LA DOCENCIA E INVESTIGACIÓN CASO: DOCENTES-INVESTIGADORES UAM-A, MÉXICO, ADSCRITOS A QUÍMICA}

Gráfico 1.1. Presupuesto anual en Tecnologías de información, en las IES mexicanas

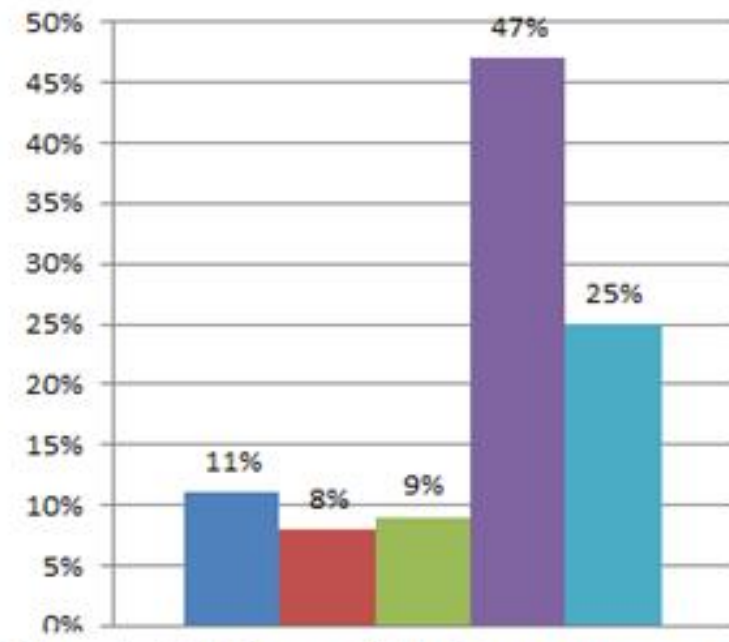

W Más de 100 millones de pesos

Entre 50 y 100

$=$ Entre 20 y 50 millones

= Menos de 20 millones

$=$ No contestó

Nota: Casi 6 de cada 10 IES encuestadas tienen un presupuesto anual en TI menor a 20 millones de pesos

Análisis de la encuesta basada en el Gráfico 1.1 Sin tomar en cuenta las IES que no contestaron la encuesta (el $25 \%$ ), el $16 \%$ reporta que su presupuesto en $\mathrm{TI}$ es mayor a 100 millones de pesos, el $7 \%$ informa que su presupuesto está en el rango entre 50 y 100 millones de pesos, el 8\% está en el rango entre 20 y 50 millones de pesos y finalmente el $44 \%$ informa que su presupuesto Total es menor a 20 millones. Las IES que respondieron a la pregunta acumulan un Presupuesto Anual invertido en $\mathrm{TI}$ aproximado de 5,617,715,728 pesos. El presupuesto promedio anual en Ti de las instituciones de Educación Superior que respondieron a la pregunta es de $50,158,176$ pesos

La Secretaría de Educación Pública en México SEP (máxima instancia a nivel nacional que dirige a todo el sistema educativo), tiene como propósito esencial crear condiciones que permitan asegurar el acceso de todas las mexicanas y mexicanos a una educación de calidad, en el nivel y modalidad que la requieran y en el lugar donde la demanden. Por lo que es importante promover el uso y aprovechamiento de las tecnologías para este fin. La SEP cuenta con una Dirección General de Tecnología de la Información, cuya misión es la mejora en el sistema educativo, a través del uso óptimo de la tecnología de la información y de telecomunicaciones, que coadyuve en el beneficio educativo, operativo, administrativo y económico. Algunos de los servicios que ofrece la Dirección al interior de la SEP, son:

- Asesoría y soporte técnico para equipos de cómputo personal y periféricos

- Instalación y configuración de software institucional para equipos de cómputo personal y periféricos

- Administración y soporte técnico a equipos servidores, procesamiento de la información, seguridad informática, Internet y correo electrónico

- Administración de Servicios y de Soporte Técnico de Telecomunicaciones; 


\section{PERCEPCIÓN SOBRE EL USO DE HERRAMIENTAS TECNOLÓGICAS DIGITALES COMO APOYO EN LA DOCENCIA E INVESTIGACIÓN CASO: DOCENTES-INVESTIGADORES UAM-A, MÉXICO, ADSCRITOS A QUÍMICA}

\section{- Administración General del Portal SEP}

La SEP propone políticas y programas de desarrollo, otorga beca y genera dinámicas innovadoras. Como lo señala la OCDE "el número de elementos motores de la educación superior dependen de las prioridades definidas por el estado. En varios países, el Ministerio de Educación (Secretario de Educación) sigue siendo el guardián de la lógica tradicional de la educación superior, mientras que el Ministerio de Ciencia y Tecnología adopta la lógica que consiste en poner el conocimiento al servicio de la economía". La SEP diseña políticas tendientes a habilitar a las escuelas de una base tecnológica para que los estudiantes aprendan a manejarlas y aplicarlas en su proceso de enseñanza. Proyectos, como el de Bachillerato Virtual, buscan ampliar el acceso al nivel medio superior a través del uso de las TIC. En el Programa Sectorial de Educación 2007 - 2012, uno de sus objetivos generales fue "impulsar el desarrollo y utilización de TIC en el sistema educativo para apoyar el aprendizaje de los estudiantes, ampliar sus competencias para la vida y favorecer su inserción en la sociedad del conocimiento" (SEP, 2007: 11). Un indicador del objetivo anterior (3), es el porcentaje de instituciones públicas de educación superior con conectividad a Internet en bibliotecas. Las acciones correspondientes son:

- Fomentar el desarrollo y uso de las TIC para mejorar los ambientes y procesos de aprendizaje, la operación de redes de conocimiento y el desarrollo de proyectos intra e interinstitucionales.

- Propiciar la utilización de espacios virtuales que acerquen a los docentes y estudiantes a esas tecnologías y les permitan desarrollar competencias avanzadas para su uso.

- Promover el desarrollo de habilidades en el manejo de las tecnologías de la información y la comunicación.

- Promover que la inversión del Estado en las TIC, en diversos formatos, posibilite el acceso a un público más amplio.

- Coadyuvar a la formación integral, a orientar la recepción crítica de los medios de comunicación y a estimular el interés por los retos que conlleva la sociedad del conocimiento (SEP, 2007: 40 - 41).

En cuanto a la habilitación tecnológica de las escuelas, el nivel superior es el que cuenta con una mayor cantidad de equipos tecnológicos.

El Instituto Latinoamericano de la Comunicación Educativa (ILCE) ${ }^{23}$ ha enfocado sus esfuerzos al desarrollo y difusión de la investigación y aplicación de las TIC para la educación y formación a distancia, producción de materiales educativos y la capacitación de recursos humanos. El Instituto ha desarrollado modelos educativos de vanguardia que fomenten el uso de plataformas y espacios virtuales de

\footnotetext{
${ }^{23}$ La información presentada en éste apartado puede ser consultada en el portal del ILCE, http://www.ilce.edu.mx/index.htm .
} 


\section{PERCEPCIÓN SOBRE EL USO DE HERRAMIENTAS TECNOLÓGICAS DIGITALES COMO APOYO EN LA DOCENCIA E INVESTIGACIÓN CASO: DOCENTES-INVESTIGADORES UAM-A, MÉXICO, ADSCRITOS A QUÍMICA}

aprendizaje -vía satelital, videoconferencia, e-Learning y multimedia-. Sus principales acciones van encaminadas a:

- Potenciar las TIC

- Promover la investigación

- Desarrollar contenidos en diferentes medios

- Producir materiales para la educación y formación

- Innovar modelos educativos

- Fomentar el uso de plataformas y espacios virtuales de aprendizaje

EI ILCE ha trabajado en el Centro de Documentación para América Latina, la Red Escolar, y la Red Satelital de Televisión Educativa, que tienen como base el uso de las TIC como apoyo educativo, tanto para el acceso a las fuentes de información como para el desarrollo de materiales multimedia específicos para todos los grupos de edad, maestros, directivos y padres de familia.

Consejo Nacional de Ciencia y Tecnología (CONACyT). INFOTEC Centro de Investigación e Innovación en Tecnologías de la Información y Comunicación pertenece a la red de Centros Públicos de Investigación del Consejo Nacional de Ciencia y Tecnología (CONACyT). Su misión es hacer posible que las organizaciones y las personas se desarrollen mediante la apropiación de las TIC. Es un centro público, enfocado a la investigación e innovación en TIC y su circulación. En la sociedad de la información y el conocimiento es a través de proyectos que se pretende acelerar el progreso de México. Los posgrados (maestrías y doctorado), están dirigidos a desarrollar las habilidades y competencias que la industria de las TIC demanda. La investigación desarrollada en INFOTEC tiene por finalidad la generación de conocimiento y su aplicación en el campo de las TIC para el desarrollo de productos y servicios tecnológicos, y de modelos y metodologías destinados al crecimiento nacional. INFOTEC cuenta con diversos ámbitos del conocimiento, los cuales representan tendencias en TIC, a nivel global, y derivan en proyectos de investigación que inciden de manera directa en el desarrollo de sectores clave del país. Estos proyectos están encaminados a:

- Desarrollo de las TIC: generación de productos, diseños, procesos o servicios con aplicación de las TIC

- Gestión innovadora de las TIC: proyectos asociados a la implementación y evaluación de las tecnologías en contextos industriales, gubernamentales y/o sociales

- Regulación de las TIC: análisis de la relación entre el marco constitucional y legal asociado a las TIC y su impacto en los derechos humanos, la propiedad intelectual, la seguridad, entre otros

- Apropiación de las TIC: estudios e investigaciones que aportan conocimiento sobre los procesos para incorporar las tecnologías en la vida diaria 


\section{PERCEPCIÓN SOBRE EL USO DE HERRAMIENTAS TECNOLÓGICAS DIGITALES COMO APOYO EN LA DOCENCIA E INVESTIGACIÓN CASO: DOCENTES-INVESTIGADORES UAM-A, MÉXICO, ADSCRITOS A QUÍMICA}

INFOTEC participa en el programa de laboratorios nacionales de Conacyt con la creación del Laboratorio Nacional de Internet del Futuro (LaNIF), además cuenta con el Laboratorio de Analítica Computacional de Grandes Cúmulos de Información (LABD), el Laboratorio de Sistemas Embebidos (LabSE) y el Laboratorio de Apropiación de TIC (LAPTIC).

La sociedad actual cambia día a día, el auge tecnológico ha detonado la necesidad de generar expertos en los posgrados que analicen, exploren, experimenten y combinen los grandes cúmulos de información existentes y facilitando con ello el acceso para el análisis. Todo está cambiando de manera significativa gracias a la convergencia de las TIC, que concretizan las nuevas demandas de productos y servicios enfocados en sistemas embebidos y analítica computacional.

INFOTEC ha puesto énfasis en la formación de profesionales y especialistas en TIC capaces de desarrollar, satisfacer y mejorar estrategias enfocadas en esta área de aplicación y conocimiento.

INFOTEC ofrece programas en dos modalidades: presencial y en línea. Los posgrados que ofrece son:

1. Maestría en Ciencias en Ciencia de Datos

2. Maestría en Dirección Estratégica de las Tecnologías de la Información y Comunicación

3. Maestría en Ciencia de Datos e Información

4. Maestría en Derecho de las Tecnologías de la Información y Comunicación

5. Maestría en Gestión de Innovación en las Tecnologías de la información y Comunicación

6. Maestría en Sistemas Embebidos

7. Maestría en Regulación y Competencia Económica de las Telecomunicaciones

8. Doctorado en Ciencias en Ciencia de Datos

Vinculación y Servicios. INFOTEC como un centro público de innovación y desarrollo tecnológico ha contribuido en el desarrollo de la estrategia nacional de e-Gobierno, en la creación de diversos portales ciudadanos y en el impulso al desarrollo de ciudades digitales. En actividades de investigación y docencia, INFOTEC está considerado como un centro estratégico en TIC y mantiene relación con distintos organismos de gobierno en los ámbitos federal, estatal y municipal, así como con instituciones públicas y privadas y con la sociedad en general.

INFOTEC otorga servicios a los sectores público y privado soportados por la infraestructura tecnológica: redes LAN/WAN e inalámbricas; telefonía y videotelefonía IP; tecnologías para usuarios móviles; infraestructura para esquemas de operación en oficinas virtuales; centro de datos de alta disponibilidad; manejo de plataformas de procesamiento; almacenamiento externo para servidores; administración y control de aplicaciones web y bases de datos corporativas, 


\section{PERCEPCIÓN SOBRE EL USO DE HERRAMIENTAS TECNOLÓGICAS DIGITALES COMO APOYO EN LA DOCENCIA E INVESTIGACIÓN CASO: DOCENTES-INVESTIGADORES UAM-A, MÉXICO, ADSCRITOS A QUÍMICA}

seguridad de la información en redes; planes de recuperación de desastres y continuidad; niveles de servicio con enfoque en el negocio; así como software de administración de contenidos open source. Se puede concluir que la investigación y la docencia están fortalecidas por las TIC

El Sistema Nacional e- México (e = electrónico) (Fox, 2000 Citada en López de la Madrid, 2011). El $1^{\circ}$ de Diciembre del 2000, inicia el proyecto e-México, a fin de que la información y la comunicación tengan un carácter nacional, y la tecnología llegue hasta el último rincón de México, y se reduzca la brecha digital entre las instituciones, hogares e individuos y logre que un mayor número de mexicanos utilice las TIC en su beneficio adecuadamente y con pertinencia. En el espacio de e-aprendizaje, se presentan ligas a algunos de los sitios relacionados con la educación a distancia; becas para educación, tanto nacionales como internacionales; ligas a diversas bibliotecas digitales del país; algunos materiales y recursos didácticos en diferentes temáticas; y, en general, una gran cantidad de información sobre la educación básica, media y superior de México. Para el sistema e-México "Hablar de la Sociedad de la Información es mucho más que hablar de tecnología. Lo relevante son los contenidos y el acceso a los mismos"

La Organización para la Cooperación y el Desarrollo Económico OCDE hace referencia a las políticas mexicanas en educación superior, y señala que las IES y los centros de investigación del país han realizado una serie de actividades tendientes a construir una sola red académica nacional llamada Internet Mexicana. Las redes mexicanas de instituciones académicas son: Red UNAM, Red Total CONACYT ${ }^{24}$; Red América Nacional de Teleinformática y Cómputo (Rantec): creada por la SESIC $^{25}$ y CONACYT (RTN): La Red Teleinformática Nacional RTN es una iniciativa que integra a los centros de investigación coordinados por SEP - CONACYT a través de enlaces satelitales y terrestres. En 1999 se crea la Corporación Universitaria para el Desarrollo de Internet CUDI, creada por las 7 universidades más grandes de México, con el fin de dotar a la Comunidad Científica y Universitaria de México de una red de telecomunicaciones que le permita crear una nueva generación de investigadores, dotándolos de mejores herramientas que les permitan desarrollar aplicaciones científicas y educativas de alta tecnología a nivel mundial.

En el 2006, un grupo de asociaciones relacionadas con las TIC que conforman el Instituto Mexicano para la Competitividad y encabezadas por la Asociación Mexicana de la Industria de Tecnologías de Información (AMTI, 2006), publicaron el documento titulado Visión México 2020. Políticas públicas en materia de Tecnologías de información y comunicación para impulsar la competitividad de México. En él se presenta la situación actual de las TIC en ese país desde diversas áreas, así como prospectiva al año 2020, mediante la recomendación de políticas públicas encaminadas a establecer una agenda nacional para la competitividad, la innovación y la adopción de TIC, que promueva la transición de México hacia la sociedad del conocimiento.

\footnotetext{
${ }^{24}$ CONACYT: Consejo Nacional de Ciencia y Tecnología

${ }^{25}$ SESIC: Educación Superior e Investigación científica
} 


\section{PERCEPCIÓN SOBRE EL USO DE HERRAMIENTAS TECNOLÓGICAS DIGITALES COMO APOYO EN LA DOCENCIA E INVESTIGACIÓN CASO: DOCENTES-INVESTIGADORES UAM-A, MÉXICO, ADSCRITOS A QUÍMICA}

Beneficios del uso de HTD (Hernández, Mera, Chávez, Soto, Fernández y Naranjo, 2018). La tecnología digital tiene un papel importante en el proceso de enseñanzaaprendizaje e investigación. Ésta comunicación socio digital es importante para los alumnos y los profesores, pues mediante la misma, los primeros, adquieren la confianza y empatía de preguntar y resolver dudas. También los alumnos que en determinado momento no pueden asistir en forma presencial, se les permite enviar sus tareas o trabajos finales sin hacerlo presencialmente. Esta comunicación permite ahorro de material, hojas de papel, manejo de impresora, y por lo tanto ahorro económico y ecológico. Raymond Williams, (2011) Menciona el aprovechamiento de medios de comunicación como la TV, como apoyo a los docentes en el proceso de enseñanza reactiva e interactiva en el aula, ofreciendo un desarrollo interactivo pleno* Para: Manso, Pérez, Libedinsky y Garzón (2011) las redes sociales facilitan el intercambio de conocimientos y experiencias permitiendo la colaboración de individuos cercanos o alejados, ofreciendo conectividad educativa e Informativa para el Aprendizaje en Línea.

Winocur y Sánchez (2015), hace mención que Facebook es un sistema de red social de código abierto donde se vuelcan un sinnúmero de comentarios sobre un tema en particular, collage o montaje de diversos elementos como las fotografías. Es por ello que lo colaborativo en las imágenes "son una de las herramientas fundamentales para comprender los mecanismos que articulan y modulan la sociedad en la que vivimos".

Francesc Llorens y Neus Capdeferro (2011), refieren que las aplicaciones llamadas "sociales" son capaces de funcionar como "socio intelectuales" para impulsar el pensamiento crítico y facilitar el procesamiento cognitivo (Voithofere et al., 2007 en Llorens y Capdeferro, 2011). Mencionan que la combinación de texto, voz, música, gráficos, fotografías, animación y videos promueven el pensamiento y creatividad de usuarios en la realización de tareas de alto nivel. También, que la agrupación más o menos heterogénea de alumnos para realizar tareas puede favorecer la creación de "zonas de desarrollo próximo" (Vygotsky, 1978).

Ellison, Steinfield y Lampe (2007) mencionado en Llorens (2011) afirman que Facebook estimula la creatividad e incrementa la dimensión espontánea y agradable hacia el aprendizaje. También, que la interacción social proporciona un mayor beneficio para personas con baja autoestima.

De acuerdo a Del-Fresno, Marqués \& Paunero (2014) el acopio de datos sobre las relaciones en redes sociales, puede hacerse mediante diversos métodos, como entrevistas, temas de discusión, archivos o encuestas, que pueden analizarse utilizando un conjunto de enfoques que abarcan el estudio descriptivo, la inferencia y la modelización estadística.

El correo electrónico es un método para crear y recibir mensajes a través de sistemas de comunicación electrónica, y se puede utilizar en la educación para enviar y recibir artículos, tareas, investigaciones, ejercicios y contestar dudas, que no fueron planteadas en la clase, sin importar la hora de entrega. 


\section{PERCEPCIÓN SOBRE EL USO DE HERRAMIENTAS TECNOLÓGICAS DIGITALES COMO APOYO EN LA DOCENCIA E INVESTIGACIÓN CASO: DOCENTES-INVESTIGADORES UAM-A, MÉXICO, ADSCRITOS A QUÍMICA}

Situación de las TIC en la educación superior de México. El tercer ciclo de educación en México corresponde a la educación superior, que comprende a los niveles de Técnico Superior (Profesional Asociado), la Licenciatura y el Posgrado. A partir de la década de los 80 , iniciaron los esfuerzos para dotar a las universidades de las primeras computadoras que vendrían a modificar la dinámica universitaria, tanto desde la administración como desde la academia. Como se mencionó en ANUIES (2000:177), "el impresionante desarrollo de la tecnología, especialmente en los campos de la computación y las telecomunicaciones, permite pensar en una modificación de los modelos educativos.. Fue hasta la década de los 90 que estas iniciativas comienzan a expandirse poco a poco aumentando significativamente el número de equipos y los usos que de ellos se hacían. Este fenómeno de expansión tecnológica no fue exclusivo de las Universidades, ya que según estudios del Instituto Nacional de Estadística, Geografía e Informática INEGI (2007), para el 2007 el $22.1 \%$ de los hogares mexicanos disponía de una computadora, pero inferior al de otras tecnologías, como la televisión $(93 \%)$ y el servicio de telefonía $(73 \%)$. Hasta noviembre de 2007, se tenían registrados 30.5 millones de usuarios de computadora y 20.8 millones de usuarios de Internet. El siguiente Grafico 1 refleja un aumento en cuanto a la penetración tecnológica (computadora e internet), y esto se ha reflejado a su vez en las instituciones educativas, sobre todo en el nivel superior. En el Gráfico 1.2 podemos ver el aumento de usuarios de computadora e Internet para el grupo de edad de 18 a 24 años, mismo que corresponde al nivel superior.

Gráfico 1.2. Usuarios de Internet y computadora para el grupo de edad de 18 a 24 años

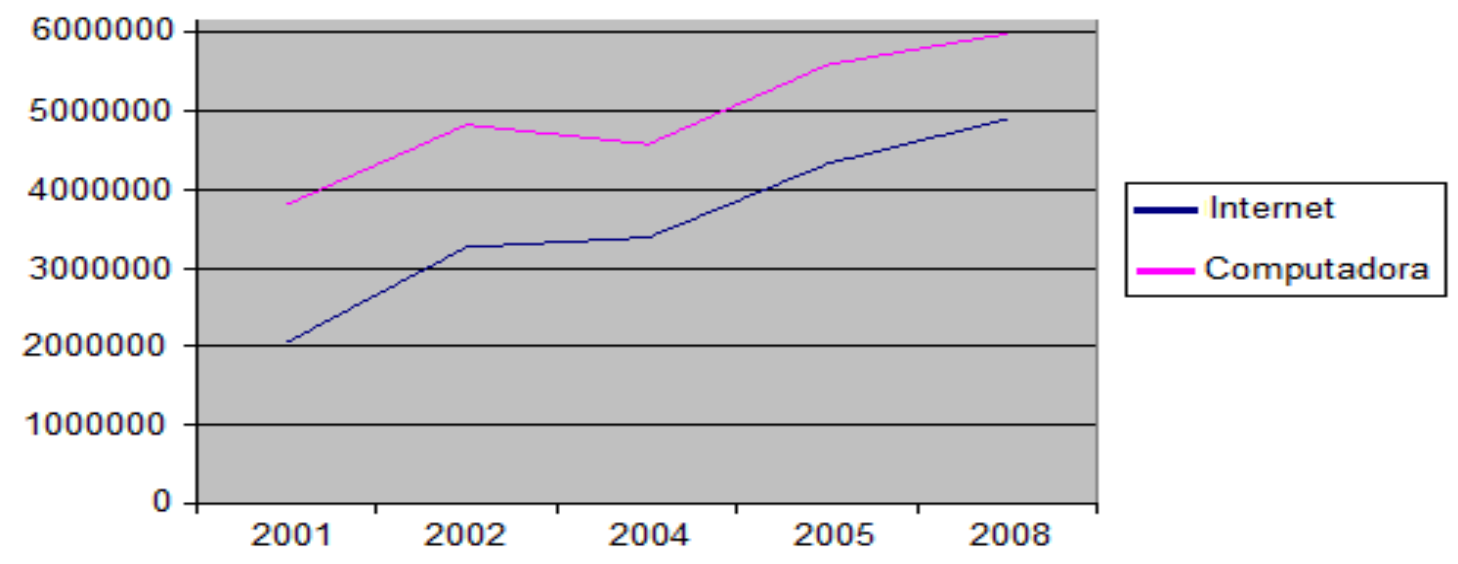

Fuente: López de la Madrid y Flores, K (2011) a partir de los datos del INEGI (2007).

Las estadísticas de 2012 del INEGI (Instituto Nacional de Estadística, Geografía e Informática, 2012), señalan que $43,4 \%$ del total de la población tiene acceso a una computadora; $55,7 \%$ desde su hogar, $32,3 \%$ desde un sitio público y desde la escuela $21,1 \%$. De éstos, $51,8 \%$ la usa como apoyo escolar y, de $56 \%$ que no tiene acceso, en más de la mitad de los casos es por falta de recursos económicos. $39,8 \%$ tiene acceso a Internet; $52 \%$ de ellos desde su hogar, $48 \%$ fuera de él; $59,7 \%$ del total lo utiliza para obtener información y comunicarse, $31,1 \%$ para apoyar su educación/capacitación. Dentro del porcentaje de la población que no tiene acceso 


\section{PERCEPCIÓN SOBRE EL USO DE HERRAMIENTAS TECNOLÓGICAS DIGITALES COMO APOYO EN LA DOCENCIA E INVESTIGACIÓN CASO: DOCENTES-INVESTIGADORES UAM-A, MÉXICO, ADSCRITOS A QUÍMICA}

se indicó que en $52,2 \%$ de los casos es por no tener recursos económicos, 17,5\% porque no lo necesita, y $4,2 \%$ por no tener el equipo suficiente.

Las acciones, propuestas, políticas y estrategias planteadas por los organismos y asociaciones nacionales e internacionales en torno al uso de las TIC en la educación, específicamente en el nivel superior, reflejan un esfuerzo conjunto para lograr integrar las herramientas en éste espacio educativo. Sin embargo, el cambio integral del pensamiento ciudadano, requiere del desarrollo de otros elementos que actúen conjuntamente con el adecuado uso de las TIC.

Situación de las TIC en las Universidades Mexicanas: UNAM. La institución, inmersa en la sociedad del conocimiento, dispone de computadoras y cuentas de correo habilitadas. Tiene salas de videoconferencia distribuidas en las diferentes dependencias universitarias. Cuenta con una Red Inalámbrica Universitaria riu en Ciudad Universitaria, extendida hacia los planteles de educación media superior, con el fin de impulsar el uso de las TIC en apoyo a las actividades académicas e institucionales, con la que alumnos, profesores e investigadores tienen conexión a Internet a través de dispositivos móviles en bibliotecas, auditorios, aulas magnas, explanadas y recintos culturales.

IPN. La institución cuenta con una red de videoconferencias y un Sistema de Aprendizaje en Ambientes Virtuales y Educación en Red (SAAVER) que atiende tanto a cursos presenciales como programas a distancia. El uso de las TIC es intenso tanto en las áreas académicas como administrativas.

Universidad Autónoma de Nuevo León UANL. La universidad cuenta con un sistema integral de apoyo a la administración con una cobertura del $100 \%$ de sus dependencias. Tiene laboratorios de cómputo equipados y una red de videoconferencias que da soporte a las gestiones académicas y administrativas.

Universidad Veracruzana UV. Como uno de los aspectos fundamentales de su Misión, la UV señala la importancia del uso eficiente de las TIC y la actualización de plataformas tecnológicas y se atienden las necesidades tanto en programas presenciales que quieren enriquecerse con las $\mathrm{TIC}$, como de los programas a distancia.

U de G. Esta institución tiene 14 centros universitarios y un sistema de Universidad Virtual. Cuenta con un sistema integral de información (SIIAU) que trabaja en red atendiendo a las necesidades administrativas de alumnos, académicos y administrativos. Tiene una red de videoconferencias que sirve de enlace para todos los centros universitarios, y una amplia infraestructura tecnológica con servicio de Internet de banda ancha.

Ámbito de estudio: Universidad Autónoma Metropolitana Unidad Azcapotzalco UAM-A.

Desde sus inicios la UAM ha buscado la vinculación con la sociedad a través de sus funciones sustantivas: docencia, investigación y preservación y difusión de la cultura. Como "Casa abierta al tiempo" la universidad responde a las necesidades actuales 


\section{PERCEPCIÓN SOBRE EL USO DE HERRAMIENTAS TECNOLÓGICAS DIGITALES COMO APOYO EN LA DOCENCIA E INVESTIGACIÓN CASO: DOCENTES-INVESTIGADORES UAM-A, MÉXICO, ADSCRITOS A QUÍMICA}

de educación en nuevos ambientes de aprendizaje en términos de calidad, cobertura y equidad.

Consiente la UAM-A en estas políticas ha tomado acción y ha impulsado la TD en sus ámbitos administrativos, de docencia e investigación.

En la unidad Azcapotzalco en materia de docencia el alumno es el centro del aprendizaje y el docente el medio para lograrlo y por lo cual debe capacitarse en su disciplina y en la tecnología digital para dar una educación de calidad.

Con base en estas políticas internacionales y nacionales es que la UAM-A ha conformado sus políticas informáticas educativas y de investigación como a continuación se hace una breve descripción de los ejercicios institucionales para profesionalizar a los docentes en el área tecnológica, para que la utilicen en el aula y en la investigación.

Las políticas al respecto de la educación con tecnología digital se buscaron en diferentes documentos y algunos resultados se encuentran en el Cuadro 1.1.

Cuadro 1.1. ESCUDRIÑO DE LOS DOCUMENTOS OFICIALES DE LA UAM

\begin{tabular}{|c|c|c|}
\hline Documento & Descripción & $\begin{array}{l}\text { Uso de la tecnología en } \\
\text { la docencia e } \\
\text { investigación }\end{array}$ \\
\hline \multicolumn{3}{|c|}{ Legislación UAM $2017^{2627}$} \\
\hline -Ley organica ${ }^{28}$ & 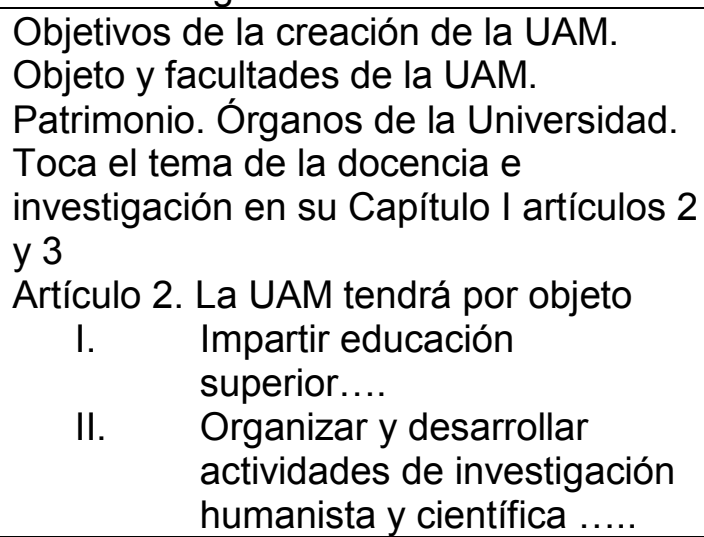 & $\begin{array}{l}\text { No alude a la tecnología } \\
\text { como apoyo a la } \\
\text { docencia e investigación }\end{array}$ \\
\hline $\begin{array}{l}\text {-Reglamento orgánico } \\
\text { de la UAM }\end{array}$ & $\begin{array}{l}\text { Función principal: precisar las } \\
\text { competencias de los órganos y de las } \\
\text { instancias de apoyo académico y } \\
\text { administrativo de la Universidad. No } \\
\text { toca los lineamientos de la docencia e } \\
\text { investigación y por supuesto su } \\
\text { innovación con la tecnología }\end{array}$ & $\begin{array}{l}\text { No alude a la tecnología } \\
\text { como apoyo a la } \\
\text { docencia e investigación }\end{array}$ \\
\hline $\begin{array}{l}\text {-Reglamento interno } \\
\text { de los órganos } \\
\text { colegiados }\end{array}$ & $\begin{array}{l}\text { Contiene disposiciones normativas } \\
\text { relacionadas con la integración y el } \\
\text { funcionamiento del Colegio Académico, } \\
\text { los Consejos Académicos y de los }\end{array}$ & $\begin{array}{l}\text { No alude a la tecnología } \\
\text { como apoyo a la } \\
\text { docencia e investigación }\end{array}$ \\
\hline
\end{tabular}

\footnotetext{
${ }^{26}$ Legislación UAM 2017. Sitio web: http://www.uam.mx/legislacion/

${ }^{27}$ Conjunto de leyes que regulan la estructura y las actividades de la Universidad

${ }^{28}$ Deriva de la Constitución.
} 


\section{PERCEPCIÓN SOBRE EL USO DE HERRAMIENTAS TECNOLÓGICAS DIGITALES COMO APOYO EN LA DOCENCIA E INVESTIGACIÓN \\ CASO: DOCENTES-INVESTIGADORES UAM-A, MÉXICO, ADSCRITOS A QUÍMICA}

\begin{tabular}{|c|c|c|}
\hline & $\begin{array}{l}\text { Consejos Divisionales. Se establece que } \\
\text { los Consejos Divisionales analizaran, } \\
\text { discutirán, y en su caso aprobará las } \\
\text { propuestas de creación, modificación o } \\
\text { suspensiones de planes y programas de } \\
\text { estudio, no toca el tema de la } \\
\text { integración de las tecnologías digitales } \\
\text { como herramienta de enseñanza- } \\
\text { aprendizaje. }\end{array}$ & \\
\hline $\begin{array}{l}\text {-Reglamento de } \\
\text { presupuesto }^{29}\end{array}$ & $\begin{array}{l}\text { Asignación de recursos a los programas } \\
\text { de la Universidad de acuerdo a la } \\
\text { Planeación. Son reglas relacionadas } \\
\text { con la elaboración, formulación, } \\
\text { autorización, ejercicio, control y } \\
\text { evaluación presupuestal. Son cuatro } \\
\text { tipos de programas en la Universidad } \\
\text { que son los de investigación, docencia, } \\
\text { preservación y difusión de la cultura; y } \\
\text { apoyo institucional, para la elaboración } \\
\text { del presupuesto. El colegio académico } \\
\text { autoriza el presupuesto, el proyecto de } \\
\text { presupuesto es formulado por el } \\
\text { Patronato, el pago lo hace la Tesorería } \\
\text { General de la Universidad } \\
\text { La UAM cuenta con patrimonio propio } \\
\text { que administra por tanto la } \\
\text { infraestructura de las HTD depende del } \\
\text { presupuesto asignado por la institución }\end{array}$ & $\begin{array}{l}\text { Es partida presupuestal } \\
\text { de prioridad } 1 \text { en la } \\
\text { UAMA }{ }^{30} \text { el mantenimiento } \\
\text { de la Infraestructura de } \\
\text { Tecnología de la } \\
\text { Información, la } \\
\text { Comunicación y } \\
\text { Seguridad de la } \\
\text { Información } \\
\text { Información institucional } \\
\text { disponible en la página } \\
\text { web institucional, en la } \\
\text { sección de Nuestra } \\
\text { Institución - } \\
\text { Transparencia- } \\
\text { Presupuesto de Ingresos } \\
\text { y Egresos y Estados } \\
\text { Financieros - } \\
\text { Presupuesto- } 2017\end{array}$ \\
\hline $\begin{array}{l}\text {-Reglamento para la } \\
\text { Adjudicación de } \\
\text { Obras, Bienes y } \\
\text { Servicios }\end{array}$ & $\begin{array}{l}\text { La Universidad, como organismo } \\
\text { descentralizado del Estado y autónoma } \\
\text { por ley, cuenta con personalidad } \\
\text { jurídica, patrimonio propio y con la } \\
\text { facultad y responsabilidad para } \\
\text { gobernarse a sí misma, administrar su } \\
\text { patrimonio y organizarse. Autoriza al } \\
\text { Colegio Académico para expedir las } \\
\text { normas y disposiciones reglamentarias } \\
\text { de aplicación general para la mejor } \\
\text { organización y funcionamiento } \\
\text { académico y administrativo. El Colegio } \\
\text { Académico autoriza el presupuesto } \\
\text { anualmente y en base a él se realiza la }\end{array}$ & $\begin{array}{l}\text { El reglamento da facultad } \\
\text { de administrar, entre } \\
\text { otras adjudicaciones, la } \\
\text { de la infraestructura } \\
\text { tecnológica, se busca } \\
\text { calidad pero también } \\
\text { seguridad, oportunidad, } \\
\text { simplicidad, eficacia y las } \\
\text { mejores condiciones } \\
\text { económicas y técnicas. } \\
\text { Es partida presupuestal } \\
\text { de prioridad } 1 \text { en la } \\
\text { UAMA }{ }^{31} \text { el mantenimiento } \\
\text { de la Infraestructura de }\end{array}$ \\
\hline
\end{tabular}

${ }^{29}$ El presupuesto se planea y evalúa en base a proyectos y anteproyectos presentados por Docentes, Jefes de Área, Jefes de División y aprobados por Rector-Consejo Académico-Patronato). Va dirigido a la Docencia, la Investigación, la Preservación y Difusión de la Cultura y apoyo institucional.

${ }^{30}$ Proceso de planeación, Presupuestación y evaluación 2014. http://www.uam.mx/transparencia/presupuesto/presup2014/CARPETA-DE-APOYO-2014.pdf

${ }^{31}$ Proceso de planeación, Presupuestación y evaluación 2014. http://www.uam.mx/transparencia/presupuesto/presup2014/CARPETA-DE-APOYO-2014.pdf 


\section{PERCEPCIÓN SOBRE EL USO DE HERRAMIENTAS TECNOLÓGICAS DIGITALES COMO APOYO EN LA DOCENCIA E INVESTIGACIÓN \\ CASO: DOCENTES-INVESTIGADORES UAM-A, MÉXICO, ADSCRITOS A QUÍMICA}

\begin{tabular}{|c|c|c|}
\hline & $\begin{array}{l}\text { gestión de obras, bienes y servicios. } \\
\text { Este reglamento considera (lo que } \\
\text { interesa en esta trabajo), propiciar la } \\
\text { mejora continua de servicios, } \\
\text { infraestructura y equipamiento de } \\
\text { bibliotecas, laboratorios, plantas piloto, } \\
\text { talleres, librerías, sistemas escolares y } \\
\text { de cómputo, áreas de estudio, culturales } \\
\text { y deportivas, entre otros. Procurar el } \\
\text { funcionamiento y mantenimiento de las } \\
\text { instalaciones e infraestructura de la } \\
\text { UAM. } \\
\text { El colegio académico, la Junta } \\
\text { Administrativa (Secretario General, } \\
\text { Secretarios de Unidad, Tesorero } \\
\text { General, Abogado General, Asesores y } \\
\text { Contralor) y comités, colaboran en las } \\
\text { decisiones que corresponde tomar a la } \\
\text { Secretaría General. } \\
\text { La Universidad, por su naturaleza de } \\
\text { institución pública, tiene el compromiso } \\
\text { y la convicción de favorecer y fortalecer } \\
\text { la rendición de cuentas en la } \\
\text { administración de sus recursos, por lo } \\
\text { que considera como principios básicos } \\
\text { para la contratación de obras, servicios, } \\
\text { arrendamientos y adquisición de bienes, } \\
\text { la transparencia, imparcialidad y la } \\
\text { comparabilidad de propuestas. Se } \\
\text { regulan las condiciones para que en las } \\
\text { contrataciones se consideren también } \\
\text { elementos de seguridad, calidad, } \\
\text { oportunidad, simplicidad, eficacia y las } \\
\text { mejores condiciones económicas y } \\
\text { técnicas. }\end{array}$ & $\begin{array}{l}\text { Tecnología de la } \\
\text { Información, la } \\
\text { Comunicación y } \\
\text { Seguridad de la } \\
\text { Información } \\
\text { Información institucional } \\
\text { disponible en la página } \\
\text { web institucional, en la } \\
\text { sección de Nuestra } \\
\text { Institución - } \\
\text { Transparencia- } \\
\text { Presupuesto de Ingresos } \\
\text { y Egresos y Estados } \\
\text { Financieros - } \\
\text { Presupuesto- } 2017\end{array}$ \\
\hline $\begin{array}{l}\text { Reglamento de } \\
\text { programas de } \\
\text { investigación }\end{array}$ & $\begin{array}{l}\text { Los programa de investigación, que } \\
\text { incluye la metodología, técnicas e } \\
\text { instrumentos de investigación } \\
\text { requeridas, son propuestos por un } \\
\text { cuerpo de profesores-investigadores al } \\
\text { Rector de Unidad, Rector general, } \\
\text { Colegio académico y Divisional quienes } \\
\text { con apoyo de asesores internos y } \\
\text { externos, comisiones, Director de } \\
\text { División y Jefes de Departamento } \\
\text { aprueban el programa y el presupuesto } \\
\text { asignado. Vigilan el cumplimiento del } \\
\text { proyecto para fortalecerlo }\end{array}$ & $\begin{array}{l}\text { El cuerpo académico de } \\
\text { investigación tiene la } \\
\text { facultad, una vez } \\
\text { aprobado el programa y } \\
\text { de acuerdo al } \\
\text { presupuesto, de solicitar } \\
\text { la compra de HTD, la } \\
\text { infraestructura y su } \\
\text { mantenimiento. En base } \\
\text { a los productos de trabajo } \\
\text { científico se puede } \\
\text { solicitar financiamiento } \\
\text { externo y la continuidad } \\
\text { del proyecto }\end{array}$ \\
\hline Políticas Generales & Contienen las orientaciones o & En las políticas de \\
\hline
\end{tabular}




\section{PERCEPCIÓN SOBRE EL USO DE HERRAMIENTAS TECNOLÓGICAS DIGITALES COMO APOYO EN LA DOCENCIA E INVESTIGACIÓN CASO: DOCENTES-INVESTIGADORES UAM-A, MÉXICO, ADSCRITOS A QUÍMICA}

\begin{tabular}{|c|c|c|}
\hline & $\begin{array}{l}\text { lineamientos generales acerca de la } \\
\text { forma en que se puede cumplir el objeto } \\
\text { de la Universidad y las actividades } \\
\text { relacionadas con el mismo }\end{array}$ & $\begin{array}{l}\text { Investigación, la UAM-A } \\
\text { tiene libertad de } \\
\text { investigación (aprobada } \\
\text { por las instancias de la } \\
\text { UAM-A a través de } \\
\text { proyectos) y cuyo fin es } \\
\text { servir a la sociedad y } \\
\text { resolver sus problemas. } \\
\text { De ahí que se tiene la } \\
\text { facultad de solicitar TD } \\
\text { en el presupuesto } \\
\text { asignado } \\
\text { En las Políticas de } \\
\text { Docencia, espacio del } \\
\text { proceso de E-A, se } \\
\text { vincula a la investigación. } \\
\text { Entre sus objetivos está } \\
\text { fortalecer la actualización } \\
\text { disciplinaria del personal } \\
\text { académico y con la } \\
\text { incorporación de los } \\
\text { avances tecnológicos que } \\
\text { hagan más eficiente y } \\
\text { participativo el proceso } \\
\text { de E-A }\end{array}$ \\
\hline $\begin{array}{l}\text { Políticas Operativas } \\
\text { de la Docencia POD }\end{array}$ & $\begin{array}{l}\text { Descripción: Las POD se enmarcan en } \\
\text { las Políticas Generales y las Políticas } \\
\text { Operacionales de Docencia. Su } \\
\text { propósito es el de orientar las acciones } \\
\text { que propicien el mejoramiento de la } \\
\text { docencia, con base en las } \\
\text { características y necesidades de la } \\
\text { Unidad Azcapotzalco. }\end{array}$ & $\begin{array}{l}\text { Uso de la tecnología en } \\
\text { la docencia: En } \\
\text { exposición de motivos } \\
\text { apartado } 3 \text { pág. } 8 \text {. } \\
\text { ORIENTACIONES } \\
\text { PARTICULARES } \\
\text { Se estima pertinente que } \\
\text { los Planes y programas } \\
\text { de estudio que ofrece la } \\
\text { Unidad, estén centrados } \\
\text { en el alumno, } \\
\text { caracterizados por un } \\
\text { diseño curricular flexible, } \\
\text { e incorporen la modalidad } \\
\text { virtual, así como la } \\
\text { aplicación de } \\
\text { herramientas } \\
\text { innovadoras para el } \\
\text { aprendizaje. } \\
\text { La modalidad virtual } \\
\text { incluye la enseñanza no } \\
\text { presencial, }\end{array}$ \\
\hline
\end{tabular}

32 Políticas Operativas de Docencia de la UAM-A. Disponible en: https://www.azc.uam.mx/coord_general/docencia/08politicas_operativas.pdf 


\section{PERCEPCIÓN SOBRE EL USO DE HERRAMIENTAS TECNOLÓGICAS DIGITALES COMO APOYO EN LA DOCENCIA E INVESTIGACIÓN}

CASO: DOCENTES-INVESTIGADORES UAM-A, MÉXICO, ADSCRITOS A QUÍMICA

\begin{tabular}{|c|c|c|}
\hline & 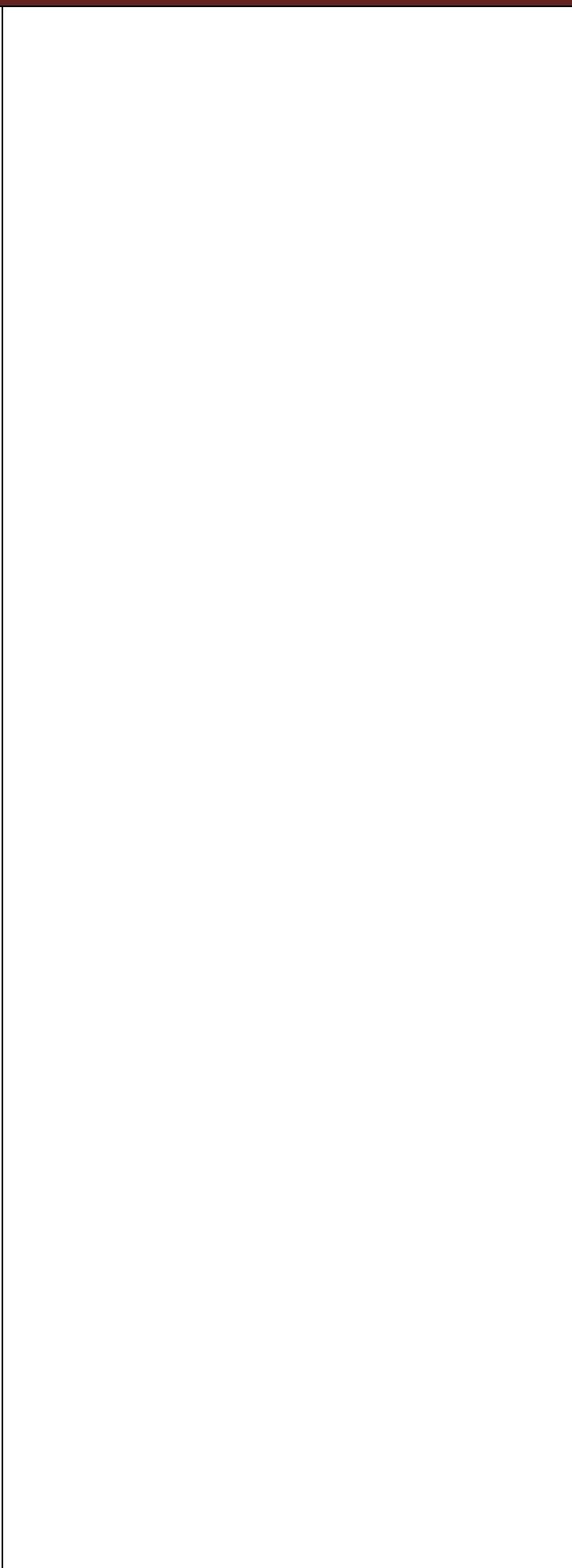 & $\begin{array}{l}\text { semipresencial y a } \\
\text { distancia, apoyada en las } \\
\text { tecnologías de la } \\
\text { información y la } \\
\text { comunicación. Su } \\
\text { implementación deberá } \\
\text { estar prevista en el } \\
\text { apartado correspondiente } \\
\text { a las modalidades de } \\
\text { operación y conducción } \\
\text { del proceso de } \\
\text { enseñanza-aprendizaje } \\
\text { dentro de los planes y } \\
\text { programas de estudio. } \\
\text { Se reforma lo anterior en } \\
\text { la hoja 10: } \\
\text { Por lo que respecta a } \\
\text { Planes y programas de } \\
\text { estudio, se subrayó la } \\
\text { importancia de incorporar } \\
\text { el término “múltiples } \\
\text { modalidades" entendidas } \\
\text { éstas como presencial, } \\
\text { no presencial, } \\
\text { semipresencial, Sistema } \\
\text { de Aprendizaje } \\
\text { Individualizado, u otras, } \\
\text { que pueden estar } \\
\text { apoyadas o no en el uso } \\
\text { de las tecnologías de la } \\
\text { información y la } \\
\text { comunicación, con el } \\
\text { propósito de ofrecer a los } \\
\text { alumnos distintas } \\
\text { opciones para la } \\
\text { acreditación de las UEA. } \\
\text { Su implementación } \\
\text { deberá estar prevista en } \\
\text { los planes y programas } \\
\text { de estudio en el apartado } \\
\text { correspondiente a } \\
\text { modalidades de } \\
\text { conducción del proceso } \\
\text { de enseñanza- } \\
\text { aprendizaje. }\end{array}$ \\
\hline
\end{tabular}




\section{PERCEPCIÓN SOBRE EL USO DE HERRAMIENTAS TECNOLÓGICAS DIGITALES COMO APOYO EN LA DOCENCIA E INVESTIGACIÓN CASO: DOCENTES-INVESTIGADORES UAM-A, MÉXICO, ADSCRITOS A QUÍMICA}

\begin{tabular}{|c|c|c|}
\hline $\begin{array}{l}\text { Políticas } \\
\text { Operacionales de la } \\
\text { Docencia POD }\end{array}$ & $\begin{array}{l}\text { Las POD tienen el propósito de } \\
\text { establecer un marco adecuado para la } \\
\text { planeación del proceso de enseñanza- } \\
\text { aprendizaje y buscar la excelencia } \\
\text { académica: éstas encuentran su } \\
\text { fundamento en las Políticas Generales } \\
\text { de Docencia, de las cuales se derivan, } \\
\text { así como en el artículo } 10 \text { del } \\
\text { Reglamento de Planeación. }\end{array}$ & $\begin{array}{l}\text { En el proceso de } \\
\text { Enseñanza-Aprendizaje } \\
\text { promueve que los } \\
\text { alumnos utilicen } \\
\text { tecnologías de la } \\
\text { información y } \\
\text { comunicación TIC para la } \\
\text { discusión, análisis, } \\
\text { adquisición y transmición } \\
\text { del conocimiento }\end{array}$ \\
\hline
\end{tabular}

La UAM-A cuenta con infraestructura y plataformas para el funcionamiento pleno de la Tecnología Digital TD.

Portal UAM-A. La Universidad tiene un Sitio Web de internet (puerta virtual de entrada a la institución) a través del cual se puede acceder a multitud de recursos y de servicios administrativos, entre los que suelen encontrarse buscadores, foros, documentos, cursos en la Agenda Azcapotzalco, información para los alumnos (fechas de admisión, suscripción) y docentes, información de los docentes y autoridades. Directorio de personal administrativo y docente. Información de la Institución (quienes somos donde estamos) y de las carreras, maestrías y doctorados que ofrece. Cursos de actualización para docentes, alumnos y administrativos. Correos electrónicos de los miembros de la UAM-A, avisos de Secretaria de la unidad. Se puede consultar el calendario de la UAM-A. Cuenta con módulo de información escolar, publicaciones periódicas, biblioteca, sistema de museos virtuales, planes institucionales, teléfonos de emergencia, buzón, y los enlaces a rectoría y demás unidades académicas. (Portal UAM-A, 2018).

CAMVIA. Es el campus virtual de la UAM Azcapotzalco y constituye una herramienta tecnológica que aumenta las capacidades de interacción entre alumnos, docentes y contenidos educativos. CAMVIA no es un instrumento estático sino que se modifica y mejora para aumentar su capacidad de apoyo a la comunidad universitaria por medios digitales. Con CAMVIA (2018) la UAM-A da un paso adelante para fortalecer la experiencia educativa de los alumnos. Es parte de la misión como universidad pública de calidad.

Oficina de Educación Virtual OEV. Su objetivo es "que el personal académico y los alumnos de la UAM-A utilicen de manera práctica y eficaz los instrumentos tecnológicos y pedagógicos basados en la corriente de innovación en educación virtual; y que los alumnos reciban una parte de su formación a través de sistemas virtuales, para que su aprendizaje sea acorde con el estilo de vida profesional que demanda la sociedad contemporánea". En este objetivo están plasmados dos principios importantes: uno es que la educación virtual es una corriente de innovación, y por ende no un instrumento fijo y estático, y otro es que la educación virtual incide en una parte de la formación del alumno brindándole un aprendizaje vinculado al

\footnotetext{
${ }^{33}$ Políticas Operacionales de la Docencia POD de a UAM-A. Disponible en: http://www.uam.mx/legislacion/pod/2/\#zoom=z
} 


\section{PERCEPCIÓN SOBRE EL USO DE HERRAMIENTAS TECNOLÓGICAS DIGITALES COMO APOYO EN LA DOCENCIA E INVESTIGACIÓN CASO: DOCENTES-INVESTIGADORES UAM-A, MÉXICO, ADSCRITOS A QUÍMICA}

estilo de su futura vida profesional. La OEV creó y administra dos sistemas de enseñanza aprendizaje en línea: http://aulavirtual.azc.uam.mx, http://aulaexperimental.azc.uam.mx, y un espacio colaborativo para docentes y administrativos: http://ecolaboracion.azc.uam.mx. La plataforma que emplea y ha adaptado a las necesidades de la UAM es Moodle. El modelo de educación virtual que desarrolla la OEV es el blended learning, es decir, una mezcla de enseñanza presencial con apoyo de enseñanza virtual. El Sistema de Educación Virtual y a Distancia de la UAM-A configura una estrategia educativa para ser implementada en planes y programas de licenciatura, posgrado y educación continua, con apoyo de las tecnologías de la información y comunicación (TIC) en forma multidisciplinaria e interdisciplinaria. Sus objetivos (de todas las unidades) son:

- Consolidar la educación virtual y a distancia como apoyo a las funciones sustantivas: docencia, investigación y preservación y difusión de la cultura para el crecimiento de la UAM en beneficio de la comunidad universitaria.

- Participar en la formación y actualización docente para integrar la modalidad mixta de manera gradual.

- Posicionar a la UAM a nivel nacional e internacional mediante redes de conocimiento de colaboración científico-cultural y de gestión en nuevos entornos de aprendizaje.

La OEV también incursiona en la vinculación de la universidad con su entorno, y genera procesos de educación a distancia con entidades del sector público, como la CONAGUA, SEDESOL, CONANP. (OEV, 2018).

Coordinación de Docencia. El Programa de Formación Docente (PFD), tiene como objetivo principal fortalecer el perfil docente establecido en nuestra casa de estudios. De esta forma, desde 2003, el programa coadyuva a elevar la calidad del ejercicio docente, a través de la sensibilización y capacitación en temas diversos relacionados con la andragogía y didáctica, tecnología educativa, desarrollo humano y fortalecimiento (Coordinación de Docencia, 2018) (presupuesto \$375, 121)

Coordinación de servicios de cómputo. La Universidad en su afán por involucrar las TIC en su quehacer cotidiano ha constituido una unidad dedicada (servicios de cómputo) únicamente para el estudio e inclusión de las nuevas tecnologías en el proceso educativo cuya Misión es: administrar, regular y orientar con responsabilidad, ética y calidad los servicios de TIC, que apoyan las actividades de las alumnas, alumnos, académicas, académicos, administrativas, administrativos e instancias que cumplan con las funciones sustantivas de la UAM. Visión: La Coordinación de Servicios de Cómputo mantiene servicios informáticos con alto grado de confiabilidad, seguridad, simplicidad y calidad certificada. Para llegar a ser una instancia clave en la consulta o implementación de tecnologías de la información u comunicación en la UAM Azcapotzalco. Objetivo: Administrar óptimamente los espacios físicos y la infraestructura de tecnologías de la información y comunicación con que contamos, para ofrecer servicios de alta calidad, seguridad y confiabilidad que apoyen las funciones sustantivas de nuestra Universidad. 


\section{PERCEPCIÓN SOBRE EL USO DE HERRAMIENTAS TECNOLÓGICAS DIGITALES COMO APOYO EN LA DOCENCIA E INVESTIGACIÓN CASO: DOCENTES-INVESTIGADORES UAM-A, MÉXICO, ADSCRITOS A QUÍMICA}

Servicios de apoyo de cómputo. Comunicación: Como mecanismo de comunicación entre la comunidad universitaria se ha implementado que todos los Docentes y estudiantes posean una cuenta de correo, acceso a la plataforma virtual (Moodle), y a través de la web a servicios académicos, facilitando de esta forma la inclusión de las TIC en los diferentes ambientes de la universidad. Infraestructura: La UAM-A ha incursionado en la inclusión de las TIC mediante la adecuación de salas de cómputo, dotadas con varias computadoras, las cuales se distribuyen salas para prácticas libres por parte de los estudiantes y docentes y para clases de asignaturas que requieran utilizar el software instalado

La Coordinación de Servicios de Información COSEl (2018). Es una Coordinación académica y cultural, consolidada, moderna y dinámica, que toma como eje el logro de las funciones sustantivas de la UAM-A, bajo una cultura de desarrollo y cooperación de servicios bibliotecarios digitales y tradicionales, que nos permiten ser la mejor opción en la obtención de información para nuestros usuarios, donde la tecnología es el medio para atenderlos de manera personal y a distancia. La misión de la Coordinación de Servicios de Información es ofrecer a la Comunidad Universitaria servicios documentales de manera oportuna, eficiente y actualizada, así como concentrar, desarrollar y resguardar el patrimonio documental; coadyuvando responsablemente a la realización de las funciones sustantivas de la UAM que son la docencia, la investigación y la preservación de la cultura. Su principal objetivo es aprovechar al máximo sus recursos, para brindar de manera oportuna cada uno de los servicios de información orientados hacia el apoyo de las funciones sustantivas de nuestra Unidad. Cuenta con: Biblioteca, Hemeroteca, Documentación, Acervo audiovisual y Base de datos en CD. Sus recursos electrónicos son: La Biblioteca digital BIDI-UAM, Revistas y libros electrónicos, un Repositorio institucional Zaloamati, Casa del libro abierto, Recursos libres, Librería virtual y un canal UAM-A iTunez. Así como la modalidad de renovación virtual.

BIDI-UAM. La Biblioteca Digital BIDI (BIDI-UAM, 2018), reúne los recursos electrónicos de información suscritos por la UAM, contenidos en 80 bases de datos, 8,000 títulos de revistas especializadas, y aproximadamente 7,000 libros electrónicos.

Repositorio Institucional. Zaloamati (Preservar con amor y cariño el saber), en este Repositorio los docentes e investigadores de la UAM Azcapotzalco, depositan sus documentos en acceso abierto (Zaloamati, 2018).

Dirección de Tecnologías de la Información UAM. La Universidad cuenta con una Coordinación de Tecnologías de la Información cuyo objetivo es comunicar a través de la tecnología digital acerca de los servicios que ofrece a la comunidad y que se encuentra en una mejora continua.

Capacitación docente: En cuanto a la formación docente, la Universidad a través de la Escuela de formación docente ha implementado: Módulos de informática. Investigación Específica: Uso de las TIC en los proceso de enseñanza y aprendizaje.

Correo electrónico. La UAM-A provee un servicio de red que permite el intercambio de mensajes e información a través medios electrónicos y redes de datos. Estos 


\section{PERCEPCIÓN SOBRE EL USO DE HERRAMIENTAS TECNOLÓGICAS DIGITALES COMO APOYO EN LA DOCENCIA E INVESTIGACIÓN CASO: DOCENTES-INVESTIGADORES UAM-A, MÉXICO, ADSCRITOS A QUÍMICA}

mensajes se elaboran por un remitente y son enviados a uno o más destinatarios. Para usar el servicio es necesario contar con acceso a la red y con una dirección de correo electrónico en un servidor que provea este servicio. El uso de la dirección de correo electrónico de la UAM permite identificarnos como miembros de la Comunidad Universitaria, además de permitir espacios de colaboración y comunicación eficaz de manera interna y externa ${ }^{34}$. Se cuenta con una red inalámbrica para los portátiles personales de docentes, investigadores, alumnos y administrativos.

Laboratorio de idiomas: Donde cada estudiante puede practicar alemán, francés e inglés, interactuando con un computador y auxiliado por un tutor de idioma y de la tecnología empleada.

Dirección de Tecnologías de la Información $\mathrm{TI}^{35}$. Estrategia de la Dirección:

- Mejorar los servicios de TI

- Integrar los diferentes servicios de TI

- Mejorar la Infraestructura Tecnológica

- Coordinar la administración de proyectos

- Implementar ambientes colaborativos

- Alinear los servicios a metodologías de mejores prácticas

- Comunicar

- Desarrollar al Personal

- Reducir costos en la entrega de servicios

Misión "Proveer servicios en Tecnologías de la Información y Comunicaciones necesarios para facilitar la docencia, investigación y gestión administrativa con criterios de innovación, anticipación, planificación, eficiencia, mejora continua y promoviendo las potencialidades del elemento humano".

Transparencia de presupuestos para la implementación, uso y mantenimiento de las TIC. En la UAM-A, el presupuesto es de ffinanciamiento público. Debido a la transparencia de información se pueden conocer las sumas dadas. Se dan 3 ejemplos

1. Coordinación general de desarrollo Académico ${ }^{36} \$ 408,863$ M.N. Prioridad 1.

2. Repositorio Digital $\$ 34,422$

3. Coordinación de servicios de cómputo (COSEI): \$11, 731, 781

\footnotetext{
${ }_{35}^{34}$ Correo electrónico de la UAM-A. Sitio Web es: http://gsuite.azc.uam.mx/

${ }^{35}$ Dirección de las Tecnologías de la Información. Sitio Web:

http://www.cudi.edu.mx/primavera_2016/presentaciones/encuesta_UAM.pdf

${ }^{36}$ Presupuesto a instancias que hacen referencia a las HTD, infraestructura y políticas http://www.azc.uam.mx/transparencia/PRESUPUESTO_2017_APROBADO_POR_COLEGIO_ACA DEMICO_PARA_TRANSPARENCIA.pdf
} 


\title{
PERCEPCIÓN SOBRE EL USO DE HERRAMIENTAS TECNOLÓGICAS DIGITALES \\ COMO APOYO EN LA DOCENCIA E INVESTIGACIÓN \\ CASO: DOCENTES-INVESTIGADORES UAM-A, MÉXICO, ADSCRITOS A QUÍMICA
}

\section{CAPÍTULO 2: ESTADO DEL ARTE}

En este capítulo se presentan investigaciones acerca del uso de la tecnología digital en el proceso de enseñanza-aprendizaje y de investigación en la educación superior desde el punto de vista de la percepción del docente como profesor e investigador.

\section{Percepción}

\section{Tecnología digital}

\section{Proceso de enseñanza-aprendizaje e investigación}

\author{
Referencias/Resumen
}

1. Andrade, R., Bozo, R., Cendrós, R. (2011). Percepción de los docentes universitarios en la implementación de las Tecnologías de Información y Comunicación (TIC). Télématique 10(2):107-120. Universidad Privada Dr. Rafael Belloso Chacín. Zulia, Venezuela https://www.redalyc.org/pdf/784/78421854007.pdf

El objetivo de esta investigación estudiar la percepción de los docentes ante la implementación de las TIC en la Universidad Dr. Rafael Belloso Chacín (URBE), cuyo propósito es brindar información sobre el uso de las tecnologías en las labores docentes. El tipo de investigación fue cuali-cuantitativa y de campo con un diseño no experimental. La muestra probabilística estratificada, está representada por 35 docentes universitarios adscritos a URBE. Para la recolección de datos se utilizó un cuestionario de 25 preguntas con cuatro alternativas de respuestas cerradas, con un escalamiento de tipo Likert, el cual fue validado por expertos con una confiabilidad de 0.891 . Los resultados obtenidos con el software SPSS 12 indican que la percepción de los docentes en cuanto a la implementación de las TIC, es positiva ya que existen facilidades tecnológicas para el desarrollo de las clases

2. Arancibia, Cosimo y Casanova (2018). Percepción de los profesores sobre integración de TIC en las prácticas de enseñanza en relación a los marcos normativos para la profesión docente en Chile. Ensaio: aval. pol. públ. Educ., Rio de Janeiro 26(98): 163184.

http://www.scielo.br/pdf/ensaio/v26n98/1809-4465-ensaio-26-98-0163.pdf

Investigación que busca relacionar las percepciones de profesores sobre el uso de tecnologías con la Política Pública "Estándares y Competencias TIC para la profesión docente". Estudio cualitativo en el que se aplican 40 entrevistas a profesores en 3 regiones de Chile. Los resultados evidencian una caracterización de los profesores según el uso que otorgaban a las tecnologías, la organización de matrices analíticas y el reconocimiento de las competencias TIC presentes en su discurso. Si bien la mayoría de profesores manifiestan tener competencias asociadas a la dimensión pedagógica, existe una amplitud de criterios y competencias reconocidas. Esta investigación es una primera aproximación al conocimiento e identificación de las competencias TIC que poseen los profesores en concordancia con la Política Pública definida a nivel País.

La investigación es cualitativa, lo cual otorga una característica de investigación holística; por 


\section{PERCEPCIÓN SOBRE EL USO DE HERRAMIENTAS TECNOLÓGICAS DIGITALES COMO APOYO EN LA DOCENCIA E INVESTIGACIÓN CASO: DOCENTES-INVESTIGADORES UAM-A, MÉXICO, ADSCRITOS A QUÍMICA}

ello es importante la observación de los datos e interpretación de la realidad de los casos de estudio, pues como manifiesta Pérez (2004) ello permite desarrollar categorías conceptuales, o ilustrar, defender o desafiar presupuestos teóricos.

3. Bruenjes, L. (2001). A multi-case study investigating the disposition of faculty use of technology as a teaching and learning tool in the higher education classroom. Tesis doctoral, Universidad de Massachusetts Lowell.

Bruenjes (2001) en su tesis doctoral (Universidad de Massachusetts Lowell) analiza un multicaso sobre la disposición de los docentes en el uso de la tecnología como herramienta de E-A en las clases de educación superior ES, en donde los docentes universitarios y las mismas universidades se enfrentan a la preparación de una población estudiantil diversa, con diversos antecedentes educativos y culturales que representan una variedad de necesidades de aprendizajes y estilos. Al mismo tiempo, las instituciones de ES han invertido en infraestructuras que tienen la promesa de satisfacer las necesidades de aprendizaje de los estudiantes que no aprenden en el método tradicional y que prevalece en muchos de los salones de clase de hoy en día. Informes han demostrado, que la mayoría de los profesores no han adoptado la tecnología como recurso. El propósito de este proyecto de investigación multi-caso fue investigar las razones de por qué algunos profesores están más o menos dispuestos a adoptar la tecnología como una herramienta de enseñanza y aprendizaje pero la mayoría se muestran renuentes. Los fundamentos en que se basa la investigación son:

1. La teoría del desarrollo profesional,

2. La teoría del aula centrada en el aprendizaje

3. La teoría del aprendizaje de adultos

4. La teoría del constructivismo

5. La teoría del estilo de aprendizaje.

El estudio se llevó a cabo en una universidad pública de dos años cuya misión incluía el objetivo de ofrecer instrucción de una manera diversificada para satisfacer las necesidades educativas de sus estudiantes. El tecnólogo de instrucción de la universidad recomendó a los participantes para el estudio, que reflejó a docentes en varias etapas de adopción de la innovación de Rogers (1995 en Jacobsen, 1998). Los casos fueron codificados como: Innovator (Innovador), Early Adopter (Adoptante Temprano), Hesitant Adopter (Adoptante Vacilante) y Resistor (Resistor o Renuente). Los datos de este estudio cualitativo se recopilaron mediante entrevistas estructuradas, observaciones, inventarios de estilos de enseñanza y aprendizaje y análisis de documentos.

Resultados:

Usos de la tecnología como herramienta de enseñanza, productora de herramientas y como herramienta de comunicación $(a \rightarrow j)$

$$
\text { Uso de HTD }
$$

a. para preparar clase

b. mantenimiento de registros

c. e-mail

d. recursos de internet

e. cursos on line

f. chat

g. pizarrón electrónico de discusión

h. computadora con proyector

i. video conferencia 


\section{PERCEPCIÓN SOBRE EL USO DE HERRAMIENTAS TECNOLÓGICAS DIGITALES COMO APOYO EN LA DOCENCIA E INVESTIGACIÓN CASO: DOCENTES-INVESTIGADORES UAM-A, MÉXICO, ADSCRITOS A QUÍMICA}

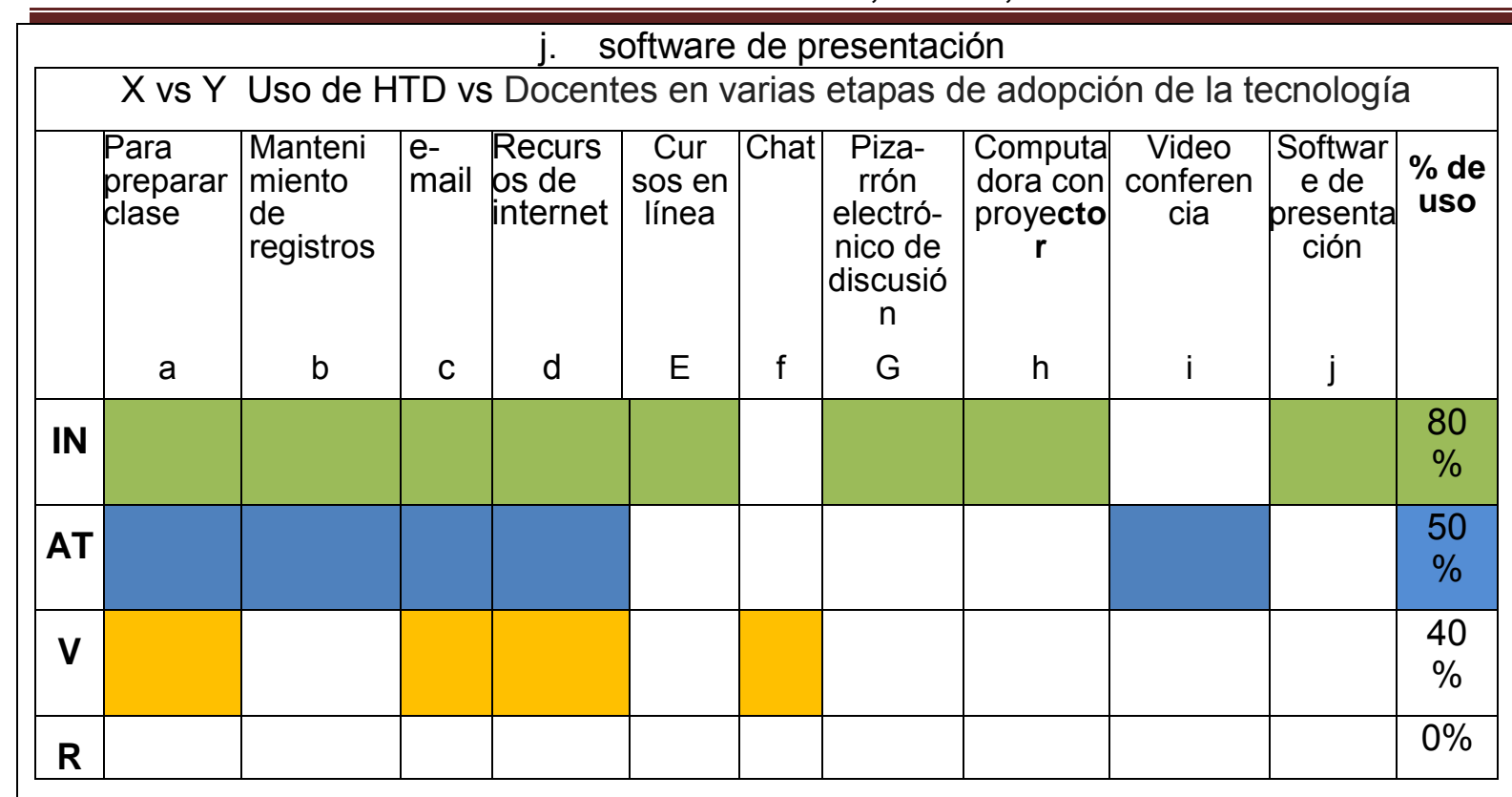

El profesor innovador IN estudiado uso las HTD desde $a \rightarrow j$ excepto en los puntos $\mathrm{f}$, i.

El profesor adoptador temprano AT (early adopter EA), las uso en las categorías: $a \rightarrow d$ e i.

Los adoptadores vacilantes $V$ (HA de la tecnología) solo en tres aplicaciones: $a, c, d, f$

El profesor renuente (resistor) R no uso las HTD como apoyo en su clase.

Los resultados de este estudio sugieren que la presencia de una infraestructura tecnológica y el reconocimiento por parte del profesorado de que los estudiantes actuales pueden beneficiarse del uso de la tecnología como herramientas de enseñanza y aprendizaje no es suficiente motivación incluso para profesores que entienden claramente las diversas necesidades de aprendizaje de estos estudiantes y que saben que enseñar con tecnología representa "una oportunidad para mejorar y reforzar diferentes estilos de aprendizaje, así como para desafiar a los estudiantes a probar diferentes enfoques de aprendizaje" (Bransford, 1979, p. 45). Sin embargo, incluso los educadores que muestran un entusiasmo por cumplir con los desafíos pedagógicos presentados por una población de aprendizaje diversa rara vez se considera el uso de recursos tecnológicos accesibles y como lo mencionan diversos autores (Velleman citado en Rickard, 1999 p.45; Smith 1997 p.48) que sin un reconocimiento adecuado del trabajo realizado por la academia de profesores para desarrollar herramientas de aprendizaje basadas en tecnología y que poseen habilidades tecnológicas sólidas, se verán disuadidos a seguir desarrollando y trabajando con TD a menos que tal desarrollo se considere uno de los criterios en el proceso de promoción y permanencia del personal académico, revisión que reconozca y premie tanto la excelencia docente como la innovación docente.

Byrom (1998) reporta que "El liderazgo es el factor más importante que afecta la integración exitosa de tecnología "(p. 1) como herramienta de enseñanza y aprendizaje. El compromiso, la articulación y la planificación de una filosofía de la educación comprometida con el crecimiento cognitivo de los estudiantes; el desarrollo de un plan estratégico para mejorar la infraestructura; la asignación de fondos para apoyar la adquisición de equipos; y el reconocimiento de la necesidad de que los profesores participen en oportunidades de desarrollo profesional continuo son parte del soporte administrativo y todos son críticos 


\section{PERCEPCIÓN SOBRE EL USO DE HERRAMIENTAS TECNOLÓGICAS DIGITALES COMO APOYO EN LA DOCENCIA E INVESTIGACIÓN CASO: DOCENTES-INVESTIGADORES UAM-A, MÉXICO, ADSCRITOS A QUÍMICA}

inclusive aplicable a los investigadores en ciencias. Baldwin (1998), insiste en que "es fundamental que los profesores tengan acceso a capacitación, tiempo para aprender y trabajar con la tecnología, y un apoyo adecuado (técnico, pedagógico, académico y de pares) (p. 16). La aplicación exitosa de la tecnología como herramienta de aprendizaje se basa en la cohesión de estos sistemas de apoyo.

Hay una serie de barreras institucionales y personales que la academia debe superar para adoptar innovaciones que requieren el uso de la tecnología. Estas barreras se describen como administrativas, técnicas y pedagógicas.

"Los profesores universitarios, constituyen una de las profesiones más integradas en el uso de la tecnología para la investigación y una de las más retrógradas en el uso de la tecnología para la enseñanza" (Saltrick, 1996).

Los resultados de este estudio sugieren que los desarrolladores profesionales quieran rediseñar los programas para cubrir las necesidades individuales del profesorado basadas en estilos de aprendizaje, conocimientos sobre tecnología, etapa de adopción de la innovación, limitaciones de tiempo y necesidades pedagógicas.

4. Castillo, M., Larios, M., García, O. (2010). Percepción de los docentes de la utilización de las tecnologías de la información y la comunicación, Revista Iberoamericana de Educación, 53(6) 1-10.

Castillo y sus colaboradores, realizaron una investigación cuantitativa/descriptiva sobre la percepción de los profesores con relación al uso, beneficios, infraestructura y política de las TIC en la Universidad de Guadalajara en México UDG.

Tomaron como caso de estudio el Centro Universitario de Ciencias Económico Administrativas CUCEA, de la Universidad de Guadalajara ya que es el centro con mayor infraestructura tecnológica de la universidad. Castillo et al., refieren que los profesores no utilizan los recursos tecnológicos digitales en su práctica docente y más bien las herramientas sólo las usan para actividades básicas como el procesamiento de texto. El estudio de caso es interesante porque el CUCEA cuenta con los espacios y los recursos tecnológicos para soportar las TIC y que éstas otorguen mayor eficiencia a los procesos educativos y académicos.

Para el análisis de la información obtenida los autores usaron el Método de Análisis de Componentes Principales (ACP) (en inglés, PCA). Es una técnica estadística de síntesis de la información, o reducción de la dimensión (número de variables).

A continuación se muestran los resultados de las encuestas a los docentes en 4 ejes de análisis que reporta el artículos (ver Gráfico) en la respuesta "aceptablemente" o de "acuerdo" de la escala de Likert:

1. El $\mathbf{5 7} \%$ de los profesores de licenciatura perciben que existen políticas.

2. El $43 \%$ acepta estar de acuerdo en que hay beneficios.

3. El $25 \%$ acuerda la existencia de las infraestructuras

4. Mientras que la frecuencia de uso solo recoge un $9.5 \%$ de las respuestas.

Con base en estos datos los autores visualizan que el hecho de que los docentes consideren que hay políticas, beneficios e infraestructura, no implica que utilicen las TIC para el proceso de enseñanza-aprendizaje. No se capacitan y en el caso de los profesores de mayor edad tienen dificultad en la asimilación de las TIC y de acuerdo a este último hallazgo de los autores es de suponerse que los profesores prefieren el confort de la clase tradicional. 


\section{PERCEPCIÓN SOBRE EL USO DE HERRAMIENTAS TECNOLÓGICAS DIGITALES COMO APOYO EN LA DOCENCIA E INVESTIGACIÓN CASO: DOCENTES-INVESTIGADORES UAM-A, MÉXICO, ADSCRITOS A QUÍMICA}

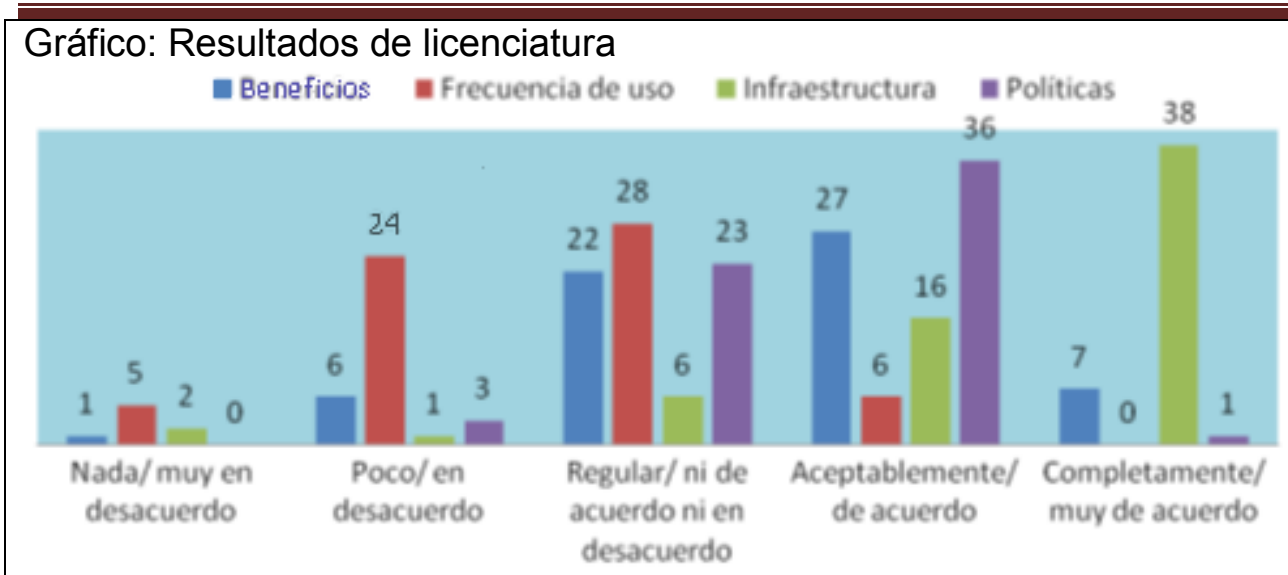

Fuente: Elaboración propia de Castillo, M., Larios, M. y García, O.

Analizando en el mismo Gráfico los ejes de mayor frecuencia se tienen los siguientes resultados de 63 profesores encuestados:

38 están completamente de acuerdo que hay infraestructura tecnológica

36 están aceptablemente de acuerdo en que hay políticas (de capacitación de TIC)

27 están aceptablemente de acuerdo en que hay beneficios al emplear TIC como herramienta de enseñanza-aprendizaje

28 están regularmente de acuerdo en utilizar las TIC en la enseñanza-aprendizaje

Pero: solo 6 están aceptablemente de acuerdo en utilizarlas en el aula (9.5\%)

Las categorías, dimensiones o escalas ${ }^{37}$ que se analizaron sobre la utilización, concepción y creencias sobre las TIC en la práctica docente son:

\section{Beneficios, 2 frecuencia de uso, 3 infraestructura y 4 políticas}

Nota: las categorías de los Ítem fueron "Nada o muy en desacuerdo", "Poco o en desacuerdo", "Regular o ni de acuerdo ni en desacuerdo " "Aceptablemente o de acuerdo" y "Completamente o muy de acuerdo"

Nada de acuerdo, poco acuerdo, regular acuerdo, aceptablemente de acuerdo y completamente de acuerdo.

5. Fernández, A. (2000). Modelo de enseñanza para la gestión de nuevos ambientes mediatizados de aprendizaje en la Universidad Central de Venezuela. Tesis.

Fernández, Alejandra (2000) tiene como objetivo, en su tesis doctoral, diseñar un modelo de enseñanza para los nuevos medios digitalizados para la educación superior, propuesta que fusione: fundamentos cognitivos, constructivistas y de creatividad e inteligencia, para facilitar la gestión e integración pedagógica de herramientas tecnológicas en los nuevos ambientes de aprendizaje en la educación superior venezolana, ya que durante las últimas décadas, los procesas de enseñanza y aprendizaje han sido impactados por los hallazgos de la investigación cognitiva y los enfoques constructivistas de aprendizaje, todo ello en el marco de las Nuevas Tecnologías de Comunicación e Información NTIC, Modelo que aproveche y explote los aportes tanto de las corrientes y enfoques teóricos como de las herramientas

${ }^{37}$ Escala: término del articular Survey of schools: ICT in Education. "Technical report (pdf)". Disponible en: https://ec.europa.eu/digital-single-market/en/news/survey-schools-ict-education-technical-reportpdf 


\section{PERCEPCIÓN SOBRE EL USO DE HERRAMIENTAS TECNOLÓGICAS DIGITALES COMO APOYO EN LA DOCENCIA E INVESTIGACIÓN CASO: DOCENTES-INVESTIGADORES UAM-A, MÉXICO, ADSCRITOS A QUÍMICA}

tecnológicas que potencian los ambientes de aprendizaje para lograr mejorar la calidad de tos sistemas de enseñanza y en consecuencia de los aprendizajes (Bagley y Hunter 1992). Los modelos para apoyar y conducir los procesos de enseñanza en el marco de las nuevas tecnologías, no resuelven los problemas ligados a la adquisición del aprendizaje pero pueden gestionarse para su aprovechamiento pedagógico y en los cuales se ve a los profesores como gestores estratégicos (Tardif, 1992) del proceso de enseñanza y a los estudiantes como responsables de su proceso de aprendizaje. Profesor-gestor se traduce en cambios en su manera de enseñan e incluye su experticia frente al conocimiento de la disciplina y al conocimiento pedagógico, subrayada por Tochon (1993) y Tardif (1992), como el uso de técnicas adecuadas de explotación de las herramientas tecnológicas. El poder de las herramientas tecnológicas, soportan y activan el aprendizaje y se promueve el trabajo individual, en pares y grupos colaborativos. Los estudiantes de hoy, requieren cada vez menos asistencia del profesor que en el caso de usar materiales convencionales, por otra parte, los miembros del grupo se estimulan y se ayudan. (Rhoads, 1986 en Fernández, 2000). Sin embargo, la promesa de eficiencia no ha sido definitoria. En Venezuela, las nuevas tecnologías se están instalando y utilizando en la educación con un alto nivel de interés y profesionalismo, pese a las fuertes limitaciones de formación en los profesores y déficits de apoyo financiero para el manejo de herramientas y la conformación de ambientes tecnológicas. Se subraya que, aunque los profesores de educación superior en Venezuela, se están sensibilizando y están interesados en formarse en el marco del aprovechamiento pedagógico de las nuevas tecnologías, todavía hay una cultura fuertemente arraigada del lenguaje escrito y de las prácticas y estrategias convencionales con medios también convencionales en aula. Alejandra Fernández en su tesis reconoce la posibilidad de que los profesores se comporten de una manera más creativa, al utilizar los recursos y tecnologías disponibles para mejorar su enseñanza y para indagar en los hallazgos de la investigación de la ciencia cognitiva, de la tecnología educativa, de la creatividad y del desarrollo de la inteligencia y los estudiantes sean más responsables de su aprendizaje, sean creativos, colaborativos, cooperativos y comunicativos.

6. Guerrero, P. (2005). Estudio de las Resistencias de los Profesores a una Estrategia Para el Desarrollo de la Creatividad en Tres Unidades Educativas. Psykhe (Santiago), 14(1), 31-45.

http://www.scielo.cl/scielo.php?script=sci arttext\&pid=S0718-22282005000100003

El siguiente artículo da cuenta de una investigación-acción que tiene por objetivo analizar las dificultades de inserción en tres liceos de una estrategia para desarrollar la creatividad. El trabajo se especializa en las resistencias de los profesores, en el marco de la Reforma Educacional chilena. Se discute bibliografía sobre la temática desde la sociología y la psicología de la educación. Luego, se analizan observaciones y entrevistas desde el enfoque de la Grounded Theory, triangulando la información desde los participantes en la estrategia. Se presentan también los resultados encontrados y algunas conclusiones para futuras intervenciones en educación.

La experiencia y la teoría nos muestran que toda apuesta por el cambio implica también la exposición a la resistencia. En el ámbito educativo, la resistencia al cambio se percibe y se nombra a través de sus actores. Profesores, estudiantes, directivos y para docentes son identificados como "resistentes al cambio", en tanto estamento o como individuos. La resistencia como una forma de conflicto, aparece, emerge, habla y explica.

Resistencia al cambio o a lo que presenta autoritarismo. Las resistencias de los grupos deben ser trabajadas porque los logros en educación tienden a mejorar el nivel social de los estudiantes. 


\section{PERCEPCIÓN SOBRE EL USO DE HERRAMIENTAS TECNOLÓGICAS DIGITALES COMO APOYO EN LA DOCENCIA E INVESTIGACIÓN CASO: DOCENTES-INVESTIGADORES UAM-A, MÉXICO, ADSCRITOS A QUÍMICA}

La resistencia al cambio se analiza a través de las siguientes teorías

$\rightarrow$ la Teoría Funcionalista,

$\rightarrow$ la Teoría de la Reproducción,

$\rightarrow$ la Teoría del Capital Humano y

$\rightarrow$ la Teoría de las Resistencias.

La Teoría Funcionalista (Parsons) supone que el cambio en la escuela debe fundamentalmente lograr la inserción de los estudiantes al trabajo y al empleo. El profesorado se guía por valores de orden superior, universales, neutrales, que se complementan con los de la familia. Éstos son principalmente valores de la sociedad industrial.

El cambio social propuesto por el funcionalismo no detenta el bien universal, sino que perpetúa los intereses de las clases dominantes.

En esta teoría, el conflicto es visto como negativo para los fines de la organización y la estrategia para abordarlo es:

1. Ignorarlo o inhibirse frente a éste.

2. Bajo situaciones de autoritarismo puede realizarse mediante la expulsión de la disidencia,

3. En situaciones democráticas se aborda a partir de la adopción de las demandas de los sectores disidentes, realizando esfuerzos por negociar parte de las soluciones a las peticiones de estos grupos.

Teoría de la Reproducción (Bourdieu y Passeron, 1977). Pone el acento en cómo el sistema educativo perpetúa la estructura de las clases sociales. Esta teoría explica la forma en que las escuelas utilizan sus recursos materiales e ideológicos para reproducir las relaciones sociales y las actitudes necesarias para sostener las divisiones sociales de trabajo que se requieren para el mantenimiento de relaciones de producción (Bonal, Giroux, Guerrero). Los conceptos centrales de esta teoría son "violencia simbólica", "capital cultural" y "habitus".

Violencia simbólica. Es la capacidad de las acciones pedagógicas de imponer significaciones culturales y hacerlas parecer como legítimas (Bourdieu y Passeron, 1977). Esta violencia se enmarca en el modelo creado por los que tienen el poder (grupos o clases dominantes) y la capacidad de imponer determinados objetivos a las clases dominadas.

Capital cultural. Cultura que se hereda y que se configura en clases sociales.

Habitus. Gusto, conocimiento y conductas inscritos en el cuerpo y esquemas de pensamiento de cada persona en desarrollo (Bourdieu; Giroux). Este habitus es el vínculo entre las estructuras de prácticas sociales y las de reproducción.

En el sistema de "violencia simbólica" no se impone al oprimido mecánicamente, sino en el habitus, el dominado construye su propia dominación. Bourdieu y Passeron señalan que bajo este sistema, la dominación es casi imperceptible y por lo tanto, la resistencia es algo que se debe intencionar para develar el conflicto.

En educación, el valor de esta teoría permite analizar las resistencias en función de los conceptos de "habitus" y "violencia simbólica". Bajo esta teoría los oprimidos, tienen a menudo incorporados como "habitus" maneras de resistir que no pongan en riesgo los logros que han adquirido, tales como un trabajo estable o una posición social. 


\section{PERCEPCIÓN SOBRE EL USO DE HERRAMIENTAS TECNOLÓGICAS DIGITALES COMO APOYO EN LA DOCENCIA E INVESTIGACIÓN CASO: DOCENTES-INVESTIGADORES UAM-A, MÉXICO, ADSCRITOS A QUÍMICA}

\section{Teoría del capital humano.}

\section{La educación}

1. es fundamental para el crecimiento económico y la competitividad internacional.

2. debe orientarse a las nuevas necesidades del mercado y la fuerza de trabajo.

3. como cualquier otra forma de capital puede dar una tasa de rentabilidad determinada.

4. cada individuo debe saber que invertir en su educación es rentable, porque puede comparar el costo de su escolaridad y los ingresos que puede esperar una vez concluida.

5. el individuo es un "capitalista" porque puede invertir en sí mismo.

6. Se legitima el principio de la meritocracia

La claridad de las metas de la teoría y su concordancia con el sistema político y económico dejan un limitado espacio a la aparición del conflicto. Por tanto, en el ámbito de las escuelas, las resistencias de los grupos deben trabajarse para lograr una educación de calidad que tienda a mejorar el nivel social de los estudiantes y por ende un mejor país.

Ante los cambios educativos (Reforma educativa) y la resistencia de los docentes a ello es que se describe la Teoría de la Resistencia inscrita en la pedagogía radical o pedagogía crítica. Esta teoría dirige su atención a la complejidad de los procesos antes mencionados y que sufren los "oprimidos", a la vez que otorga mayor importancia a la oposición (o resistencia) que genera cambios educativos. La pedagogía radical ha revelado y desafiado el papel que tienen las escuelas en la vida política. La escuela es un lugar de selección de grupos de estudiantes que son favorecidos por su raza, clase o género y es un lugar en el cual se adquiere poder social e individual. Las clases sociales dominantes tienen la hegemonía de la escuela y a través de prácticas sociales en espacios específicos tales como la iglesia, el estado, la escuela, los medios de comunicación, el sistema político y la familia. Por lo que es importante revisar la cultura y contexto como espacio donde interactúan los actores sociales y sus condiciones de vida.

El cambio en educación implica integrar la cultura popular a la escuela con el fin de democratizar la enseñanza y revertir la dominación. La resistencia es a las intervenciones y acciones de la cultura dominante (de mi pensamiento: ¿y las HTD no son herramientas de la clase dominante que distraen desdibujando el sentido del aprendizaje?).

Los profesores deben promover una idea de cambio social que intente transformar los rasgos opresores y antidemocráticos que frecuentemente estructuran el trabajo cotidiano en las aulas. Se debe intervenir en el currículo, en las rutinas de los estudiantes y profesores y en la estructura el pensamiento. El cambio incorpora al profesor crítico, quien debe promover desde su propia realidad nuevos valores democráticos en favor de la justicia y la igualdad. Desde esta perspectiva, la resistencia tiene también un contenido y una orientación.

En un cambio educativo si se deja fuera al profesor, éste se resistirá al cambio o lo hará paulatinamente. A veces se les incorpora entregándoles un protagonismo obligatorio que conlleva a una sobrecarga su trabajo y deterioro de su calidad de vida (Hargreaves; Fullan y Stiegelbauuer). Los profesores para sobrevivir a la excesiva demanda de cambios, generan simulaciones en las cuales pareciera existir colaboración y compromiso, conductas de aparente aceptación, pero son rechazos encubiertos por riesgos a represalias. El docente al intervenir en los cambios debe tener la oportunidad de poner los límites a las innovaciones.

La pregunta por las resistencias aparece dentro de una investigación-acción para el desarrollo de la creatividad, por lo que se realizó una investigación cualitativa/participante llamada "Estudio de las resistencias de los profesores a una estrategia para el desarrollo de 


\section{PERCEPCIÓN SOBRE EL USO DE HERRAMIENTAS TECNOLÓGICAS DIGITALES COMO APOYO EN LA DOCENCIA E INVESTIGACIÓN CASO: DOCENTES-INVESTIGADORES UAM-A, MÉXICO, ADSCRITOS A QUÍMICA}

la creatividad en tres unidades educativas" Para la recolección y el análisis de los datos se utilizó el enfoque de la teoría fundamentada o "Grounded Theory" (Strauss \& Corbin ), en el cual a partir de los datos se descubren teorías, conceptos. Se identificaron dos tipos de resistencias los rechazos implícitos (acciones que demuestran rechazo) y rechazos explícitos (argumentos o motivos para rechazar al proyecto).

Los autores del artículo trabajaron durante dos años en liceos pero la resistencia al cambio por parte de los profesores fue constante ya que los talleres fueron impuestos a éstos.

7. Jacobsen, D.M. (1998). Adoption Patterns of Faculty Who integrate Computer Technology for Teaching and Learning in Higher Education. Social Sciences and Humanities Research Council of Canada, Ottawa (Ontario). Disponible en: https://www.researchgate.net/publication/234774180_Adoption_Patterns_of_Faculty_ Who_Integrate_Computer_Technology_for_Teaching_and_Learning_in_Higher_Educ ation [accedido el 23 de junio de 2017]

Jacobsen estudió los patrones de adopción de los profesores que integran la tecnología computacional en el proceso de enseñanza y aprendizaje en la educación superior de dos grandes universidades de Norte América.

Utiliza como modelo teórico la Teoría de la difusión de innovaciones de Rogers. Se reporta la innovatividad de los docentes a adoptar la tecnología digital (tecnología computacional) para la enseñanza y el aprendizaje. El estudio fue comparativo entre dos categorías de adoptantes los "Adoptantes tempranos" ("early adopters") y los "de la corriente principal o mayoría" ("mainstream") El presente estudio indica que la adopción de la tecnología para el uso en el aula es cada vez mayor. El procesamiento de textos es utilizado por el $60 \%$ de los profesores, Hojas de cálculo en un $38 \%$, tablas y gráficos en un $36 \%$, bases de datos en un $34 \%$, software de presentación en un $34 \%$ y $18 \%$ en materiales basados en CD-ROM. Cursos didácticos de uso para la enseñanza: tutoriales $18 \%$, ejercicios y práctica $14 \%$, simulaciones $17 \%$, y juegos $6 \%$. El correo electrónico es utilizado por el $67 \%$ de los facilitadores en su enseñanza, bases de datos o catálogos de bibliotecas en línea en un $46 \%$, grupos (newsgroups) y foros en un $21 \%$, listservs (programa de red para administrar grupos de discusión por correo electrónico) en un $29 \%$ y servidor FTP protocolos de la red Internet, concretamente significa File Transfer Protocol (Protocolo de Transferencia de Ficheros) y es el ideal para transferir grandes bloques de datos por la red, es usado por los docentes en un $23 \%$. Nuevas Tecnologías, como la World Wide Web, han sido adoptadas para la búsqueda y navegación por $56 \%$ de los docentes adoptantes, y un $36 \%$ para la creación y edición de páginas web. El profesorado clasificó su nivel de experiencia en las TICC en la siguiente clasificación:

0 ninguna

1 un poco

2 lo justo (razonable)

3 sustancialmente (considerablemente)

4 extensamente (vasto)

Estas tecnologías son adoptadas para la enseñanza por la mayoría tardía después de haber desarrollado experiencias personales con alguna de ellas.

8. Jaimes, Jimenez, Jorge Eliecer., Vivas García, Mireya. (2011). Percepciones de los Docentes Universitarios sobre las Tecnologías de la Información y la Comunicación. Acción pedagógica, № 20 / Enero - Diciembre, 2011 - pp. 74 - 90

En este trabajo se muestran los resultados de una investigación que tuvo como objetivo 


\section{PERCEPCIÓN SOBRE EL USO DE HERRAMIENTAS TECNOLÓGICAS DIGITALES COMO APOYO EN LA DOCENCIA E INVESTIGACIÓN CASO: DOCENTES-INVESTIGADORES UAM-A, MÉXICO, ADSCRITOS A QUÍMICA}

conocer las percepciones de los profesores de la Universidad de Los Andes, núcleo Dr. Pedro Rincón Gutiérrez (San Cristóbal, Venezuela), acerca de las Tecnologías de la Información y la Comunicación (TIC). El estudio fue de tipo descriptivo. La información se recogió por medio de un cuestionario que se validó por juicio de expertos y cuya fiabilidad se situó en $94 \%$. Los resultados obtenidos revelan un cuerpo docente que emplea con frecuencia el computador e internet como herramientas de trabajo personal. Aunque no reportan una masiva utilización de estos recursos en el aula, se infiere que tienen una actitud positiva hacia su utilización. Los docentes se autoperciben con un grado de formación y un dominio práctico en el área catalogado como bueno dentro de la escala: excelente, bueno, regular y deficiente. El uso que dan los profesores a las TIC se enfoca principalmente a la exposición de contenidos a través de proyector multimedia ${ }^{38}$, presentaciones, videos, páginas web, etc., a la búsqueda de información en internet, a mantener comunicación con los alumnos vía correo electrónico y para la elaboración de materiales académicos.

9. K-12 Education Team. (2015). What Educators Want from Digital Instructional Tools 2.0 - Report, Bill y Melinda Gates foundation. https://s3.amazonaws.com/edtech-production/reports/Teachers-Know-Best-2.0.pdf

La fundación Bill y Melinda Gates, informa cómo los maestros usan actualmente las herramientas educativas digitales o de instrucción digital, las brechas en la disponibilidad, las actitudes de los maestros hacia la tecnología digital TD y la evolución de la percepción de los maestros sobre la efectividad de la TD, para continuar brindándoles apoyo a los maestros, a los que obtienen recursos para ellos y a los desarrolladores de productos, este informe de seguimiento ofrece un análisis actualizado de cómo las herramientas digitales satisfacen las necesidades de los educadores. Para la fundación "Nadie sabe cómo puede y debe usarse la tecnología en las aulas, mejor que los maestros que la utilizan todos los días" y el reporte menciona algunos de los beneficios al usar la tecnología digital:

- los maestros pueden apoyar mejor a los estudiantes al abordar sus necesidades específicas e involucrar sus pasiones e intereses

- lograr resultados de aprendizaje notablemente mejores.

10. Lagunes-Domínguez, A., Torres-Gastelú C., Flores-García, M., Rodríguez-Figueroa, A. (2015). Comparativo del uso de tecnologías de la información y comunicación (TIC) por Profesores de dos universidades públicas de México. Scielo 8(2) 11-18.

El propósito de la investigación fue identificar las diferencias de uso de Tecnologías de la Información y Comunicación (TIC) por profesores adscritos a dos universidades públicas mexicanas (una en el norte del país). Para ello, se diseñó y aplicó un instrumento cuantitativo que buscaba identificar la frecuencia de uso de diez herramientas tecnológicas definidas. El análisis de los datos se realizó mediante valores de la estadística descriptiva calculadas por medio del software estadístico SPSS. Los resultados indican que no hay diferencias significativas entre las universidades en estudio. Se propone que se deben elaborar programas de educación continua para el profesorado como un elemento clave de actualización permanente de las tecnologías disponibles.

La investigación indica que el $96.7 \%$ de los profesores que se encuestaron en la universidad del Norte recurren a los medios tecnológicos como un apoyo alternativo para la impartición de sus clases, quedando solo en $3.3 \%$ que no las utiliza. En correspondencia se muestra

\footnotetext{
${ }^{38}$ Proyector multimedia de: texto, imágenes, video y audio, Cuenta con entradas para computador, laptop. Dispositivos de almacenamiento de información: USB, reproductor de DVD, VCR, CD, BluRay, tarjeta de memoria, etc.
} 


\section{PERCEPCIÓN SOBRE EL USO DE HERRAMIENTAS TECNOLÓGICAS DIGITALES COMO APOYO EN LA DOCENCIA E INVESTIGACIÓN CASO: DOCENTES-INVESTIGADORES UAM-A, MÉXICO, ADSCRITOS A QUÍMICA}

que en la universidad del Sur el $88.9 \%$ utiliza la TIC con cierta frecuencia, aunque nadie respondió que no las utiliza.

11. Liaw. (2002). An internet survey for perceptions of computers and the World Wide Web: relationship, prediction, and difference https://www.sciencedirect.com/science/article/pii/S0747563201000322

Shu-Sheng Liaw en su artículo reafirma que con los enormes avances en comunicación y tecnología informática, el sistema educativo necesita urgentemente la aplicación de esta tecnología para mejorar la calidad de la enseñanza y el aprendizaje. Su estudio, a través de la aplicación de cuestionario encuesta usando internet, enfoca a los estudiantes en su actitud hacia el uso de la computadora ${ }^{39}$ como de la Web ${ }^{40}$, como herramienta utiliza un cuestionario-encuesta psicométrico en internet para medir" las percepciones. En diferentes estudios citados por Liaw, el éxito de la utilización de la computadora dependió en gran medida de las actitudes de los docentes y alumnos (Al-Khaldi y Al-Jabri, 1998; Anderson, 1973; Ayersman, 1996; Brock y Sulsky, 1994; Culpan, 1995; Harrison y Rainer, 1992; Havice, 1994; Mitra, 1998; Pancer, George, y Gebotys, 1992; Winter, Chudoba, y Gutek, 1998). En la utilización de la Web es también la actitud hacia esta que determina su uso o no (Daugherty, y Funke, 1998; Fenech, 1998; Johnson y Hignite, 2000; Lederer, Maupin, Sena, y Zhuang, 2000; Liu, Ayersman, y Reed, 1995; Moon y Kim, 2001; Reed y Oughton, 1997; Ruffini, 1999; Takacs, Reed, Weels y Dombrowski, 1999; Welles 1997).y de acuerdo con estos autores, es que la utilización de HTD dependerá de la percepción de los docentes y alumnos a usarlas o no.

Comprender por qué las personas aceptan o rechazan la tecnología de la información ha demostrado ser uno de los temas más importantes y desafiantes en la investigación de sistemas de información (Davis, Bagozzi y Washaw, 1989). Herbert y Benbasat (1994) encontraron que el $77 \%$ de la varianza de la intención de usar la tecnología de la información fue explicada por las actitudes hacia las computadoras. La actitud consta de tres componentes cognitivos, afectivos y conductuales (pensar ${ }^{41}$, sentir ${ }^{42}$ y actuar ${ }^{43}$ ). Un enfoque para definir el constructo psicológico "actitud hacia las computadoras" es recurrir a la teorización contemporánea en el área general de las actitudes el CAM (Medida de la actitud hacia las computadoras) desarrollado por Kay (1989) y consistente con Ajzen y la posición teórica de Fishbein $(1977,1980)$, se definió como la evaluación general de una persona o su sentimiento de favorecimiento o desfavorecimiento hacia las computadoras y actividades específicas relacionadas con la computadora. La CAM se refiere a actitudes afectivas, cognitivas y conductuales para la acción y objetivo "uso de la computadora" (Kay, 1989). Esta medida se administró a estudiantes y profesores y obtuvo un alto coeficientes de fiabilidad para cada subescala (cognitivo fue $\alpha=0,97$, afectivo fue $\alpha=0,89$, y el comportamiento fue $\alpha=0,94)$. Kay (1993) revisó la CAM para evaluar las actitudes de los docentes en formación hacia las computadoras. En el estudio revisado, el coeficiente de confiabilidad interno total fue $\alpha=0.95$.

Algunos estudios de actitudes hacia la web se basaron en el Modelo de Aceptación de la Tecnología (TAM). TAM que fue desarrollado a partir de la psicología social, la Teoría de la Acción Razonado (TRA), (Ajzen y Fishbein, 1980; Fishbein y Ajzen, 1975) que explica que la aceptación del usuario de una tecnología se basa en sus actitudes. TAM sugiere que dos

\footnotetext{
${ }^{39}$ Computadora e informática

${ }^{40}$ Web: WWW World Wide Web (el ancho mundo de la red o internet)

${ }^{41}$ Pensar: Es la declaración de creencias, por ej. Creer que algo puede ser bueno o beneficioso

${ }^{42}$ Sentir: Emoción o sentimiento (me gusta o me disgusta)

${ }^{43}$ Actuar: Es lo que un individuo realmente hace o pretende hacer (Al-Khaldi y Al-Jabri, 1998).
} 


\section{PERCEPCIÓN SOBRE EL USO DE HERRAMIENTAS TECNOLÓGICAS DIGITALES COMO APOYO EN LA DOCENCIA E INVESTIGACIÓN CASO: DOCENTES-INVESTIGADORES UAM-A, MÉXICO, ADSCRITOS A QUÍMICA}

específicas creencias de comportamiento: facilidad de uso percibida (EOU) y utilidad percibida (U), determinar la intención de comportamiento de un individuo para usar tecnologías. La facilidad de uso percibida EOU es la medida en que una persona cree que el uso de una tecnología será libre de esfuerzo. La utilidad percibida $\mathbf{U}$ es el grado en que una persona cree que el uso de una tecnología mejorará su productividad (Venkatesh, Davis yMorris, 2007). En contraste con la EOU, que es la expectativa del proceso, la utilidad percibida $U$ es la expectativa de resultado. El comportamiento de la intención de usar tecnologías lleva al uso real del sistema. Investigaciones anteriores han demostrado la validez de este modelo en una amplia variedad de sistemas web (Fenech, 1998; Lederer et al., 2000; Lin y Lu, 2000; Moon y Kim, 2001). La CWAS (Escala de Actitud hacia la Informática y la Web) se basa en el CAM y la TRA para descubrir actitudes afectivas, cognitivas y de comportamiento individuales hacia las tecnologías informáticas y la Web.

En general, no importa lo sofisticada y poderosa sea la tecnología. Su implementación efectiva depende de que los usuarios tengan una actitud positiva hacia ella

12. López de la Madrid María Cristina; Katiuzka Flores Guerrero. (2010). Las TIC en la Educación Superior de México. Políticas y acciones. Módulo: La universidad en la sociedad del conocimiento.

http://reposital.cuaed.unam.mx:8080/jspui/bitstream/123456789/1507/1/Las\%20TIC\%2 0en\%20la\%20educaci\%C3\%B3n\%20superior\%20de\%20M\%C3\%A9xico.doc.

http://webcache.googleusercontent.com/search?q=cache:I3SFgJ18EmwJ:reposital.cuaed.una m.mx:8080/jspui/bitstream/123456789/1507/1/Las\%2520TIC\%2520en\%2520la\%2520educaci $\% 25 \mathrm{C} 3 \% 25 \mathrm{~B} 3 \mathrm{n} \% 2520$ superior\%2520de $\% 2520 \mathrm{M} \% 25 \mathrm{C} 3 \% 25 \mathrm{~A} 9 \mathrm{xico} . \mathrm{doc}+\& \mathrm{~cd}=1 \& \mathrm{hl}=\mathrm{es}-$ 419\&ct=clnk\&gl=mx

En este trabajo se presentan algunos datos actuales para México en cuanto a las TIC en la educación superior. Para tal efecto, el documento se divide en dos secciones. En la primera presenta algunas de las acciones y políticas mexicanas en torno a las TIC y que tienen relación directa con la educación superior; dichas acciones y políticas han surgido tanto desde los organismos institucionales como desde otras asociaciones del país. Así mismo, se presentarán algunos datos de habilitación tecnológica en el subsistema de educación superior de México, en donde resaltará el importante desarrollo que se ha tenido en ese campo desde la experiencia de cinco universidades mexicanas. En la segunda sección se presentan los resultados de un estudio de caso en cinco de las instituciones del nivel superior del Municipio de Zapotlán el Grande, Jalisco, en donde se aplicó una encuesta de preguntas cerradas a un total de 833 alumnos y 65 docentes. La muestra fue probabilística estratificada conservando los parámetros de un nivel de confianza del $95 \%$ y un margen de error del 5\%. Algunos de los resultados refieren un uso amplio de las TIC, tanto por los docentes como por los alumnos del nivel estudiado; sin embargo, los actores dejaron sentir la falta de estrategias de implementación de las TIC en sus instituciones.

13. Mosley, S. (2014). The Overlooked Faculty: A qualitative case study of adjunct instructors' perspective on using educational technology tools in traditional classrooms (Thesis PhD in Philosophy). Capella University, Minneapolis, EE. UU.

La investigación ha demostrado que en los últimos 75 años, numerosas tecnologías han sido Introducidos en las aulas de educación superior. Las universidades están gastando millones de dólares en herramientas de tecnología educativa para mejorar la calidad de la educación, pero no se satisfacen las expectativas de la educación superior. Según los investigadores, la adopción de Tecnología por instructores era una expectativa que habría tenido un impacto positivo en el valor de la experiencia docente; Sin embargo, esas expectativas no se cumplen porque los instructores no están dispuestos o no están interesados en la adopción 


\section{PERCEPCIÓN SOBRE EL USO DE HERRAMIENTAS TECNOLÓGICAS DIGITALES COMO APOYO EN LA DOCENCIA E INVESTIGACIÓN CASO: DOCENTES-INVESTIGADORES UAM-A, MÉXICO, ADSCRITOS A QUÍMICA}

de la tecnología de instrucción. Si bien hay investigaciones que indican que el uso de herramientas de tecnología educativa es beneficioso Sólo unos pocos instructores adjuntos están incorporando herramientas de tecnología educativa en sus planes de lecciones. Este estudio de caso cualitativo utilizó 15 participantes de una universidad privada ubicada en la región sureste de Estados Unidos para determinar los factores que limitaban a los instructores adjuntos incorporar herramientas de tecnología educativa HTD en sus planes de lección (programas de estudio). Se utilizaron observaciones y entrevistas en profundidad para recolectar datos, y se utilizó NVivo10 para ayudar en la fase de análisis de datos. Hubo cuatro hallazgos como resultado de este estudio: la falta de conocimientos o habilidades adecuadas, miedo a problemas técnicos, problemas con los cursos en el aula remota; y la necesidad de la formación tradicional de aula. Las conclusiones llevaron al desarrollo de la teoría de aceptación tecnológica entre adyuvantes que asiste, colabora o ayuda (TAAA) Technology Acceptance Amongst Adjuncts (TAAA) theory Además la investigación debe centrarse en el uso de mentores en las aulas; utilizando tecnología de la información con el fin de proporcionar datos sobre la frecuencia con la que los instructores solicitan asistencia; usando una población más joven para discernir cómo la edad puede crear diferentes factores. Y finalmente, usando la teoría de TAAA para confirmar, desconfirmar y priorizar los factores que limitan al docente de incorporar la tecnología educativa en las aulas

14. Mwalongo, A. (2011). Teachers' perceptions about ICT for teaching, professional development, administration and personal use. International Journal of Education and Development using Information and Communication Technology (IJEDICT), 2011, Vol. 7, Issue 3, pp. 36-49.

Tanzania ha invertido en la integración de las tecnologías de la información y la comunicación (TIC) en la educación durante varias décadas. Sin embargo, poco se sabe acerca de las percepciones de los profesores acerca de la integración de las TIC en la educación. Este estudio examinó las percepciones de los profesores sobre el uso de herramientas de TIC para la enseñanza, la administración, el desarrollo profesional y el uso personal. Setenta y cuatro profesores participaron en el estudio. Los datos fueron recogidos a través de una encuesta en línea utilizando SurveyMonkey y las publicaciones generadas a partir del blog del investigador. Se descargaron datos cualitativos del blog y SurveyMonkey; y se analizó utilizando Weft QDA donde los temas relacionados con las preguntas de investigación fueron codificados mientras que los datos cuantitativos de SurveyMonkey se analizaron en línea como porcentajes. Los resultados indican que, aunque la frecuencia del uso de las TIC estuvo influenciada por el acceso, la competencia en el uso de las TIC estuvo influenciada por la capacitación; los maestros utilizan las TIC en una amplia gama para la enseñanza, la administración, el desarrollo profesional y el uso personal. Sin embargo, los profesores no utilizaron prácticas pedagógicas sino más bien mantuvieron sus prácticas tradicionales. La investigación futura podría centrarse en las observaciones en el aula para determinar el uso real de las TIC, ya que los datos de este estudio sólo se han basado en autoinformes. El papel del liderazgo escolar en la integración de las TIC en el proceso de enseñanza debe ser examinado.

15. Quintero, D.M., Avila, G.P., Riascos, S.C. (2010). Inclusión de las TIC en la Educación Superior.-Estudio de casos. Universidad del Valle, Colombia. En Zoloamati (UAM-A) o en

http://www.academia.edu/11527759/INCLUSI\%C3\%93N DE LAS TIC EN LA EDU CACl\%C3\%93N SUPERIOR ESTUDIO DE CASOS

La excelencia de la educación superior requiere de una constante investigación en búsqueda 


\section{PERCEPCIÓN SOBRE EL USO DE HERRAMIENTAS TECNOLÓGICAS DIGITALES COMO APOYO EN LA DOCENCIA E INVESTIGACIÓN CASO: DOCENTES-INVESTIGADORES UAM-A, MÉXICO, ADSCRITOS A QUÍMICA}

del mejor logro de su objetivo, formar personas críticas y reflexivas sobre el mundo de hoy en pro del progreso de un país, en este contexto, la inclusión de las TIC pretende optimizar los procesos de enseñanza - aprendizaje, lo cual implica una inversión de carácter económico que permita obtener la infraestructura necesaria, además requiere un conocimiento claro de cómo incluir la tecnología en el ambiente educativa y finalmente, obliga a un cambio de roles de la comunidad educativa; en este sentido, el presente artículo presenta dos casos de Universidades Colombianas (Facultades de Administración) donde se refleja el proceso que han seguido para la inclusión de las TIC en su quehacer educativo.

TIC mencionadas como utilizadas con mayor frecuencia en el contexto educativo:

$\rightarrow$ Medios audiovisuales: televisión, video y video interactivo.

$\rightarrow$ Medios informáticos: tutórales, práctica y ejercitación, simulación, hipertextos, multimedia e hipermedias, estas herramientas implican la utilización de computador.

$\rightarrow$ Medios telemáticos: correspondencia electrónica (e-mail), listas de discusión, grupos de noticias, grupos de conversación, videocomunicaciones, audiocomunicaciones, páginas Web, entornos de tele-educación, que implica tener una conexión de Internet

\section{$\rightarrow$ Educación a distancia, educación virtual}

Inconvenientes en la inclusión de las TIC

1. el costo

2. las políticas de administración

3. de carácter social: actitudes de la comunidad educativa en la utilización de las TIC en sus procesos académicos.

Ventajas en el aprendizaje

1. las TIC fomentan la creatividad,

2. permiten el fácil acceso a la información,

3. el desarrollo de habilidades de búsqueda de reinformación,

4. facilitan la motivación y el interés por parte del estudiante;

5. con respecto al docente, la principal ventaja de las TIC es el acceso a innumerables fuentes de recursos educativos de docencia,

6. la liberación de trabajos repetitivos de docencia y

7. la actualización en conocimientos; con respecto al estudiante, es que aprenden con menos tiempo,

8. permiten tener más contacto con el docente y

9. la personalización de los procesos de enseñanza y aprendizaje.

Aspectos desfavorables en el alumnado

1. altos grados de distracciones,

2. dispersión,

3. pérdida de tiempo, al buscar la información precisa por el amplio "abanico" que ofrece la red,

4. información no viable,

5. aprendizajes incompletos y superficiales (solo acumulación de datos),

6. ansiedad ante la continua interacción con una máquina (ordenador),

7. adición a determinados programas (chats, videojuegos);

Esto implica la correcta utilización de las TIC.

Estrategias para la continuidad del uso de TIC y mejora del aprendizaje con ellas 


\title{
PERCEPCIÓN SOBRE EL USO DE HERRAMIENTAS TECNOLÓGICAS DIGITALES COMO APOYO EN LA DOCENCIA E INVESTIGACIÓN CASO: DOCENTES-INVESTIGADORES UAM-A, MÉXICO, ADSCRITOS A QUÍMICA
}

\begin{abstract}
$\sqrt{ }$ mantener en el estudiante el deseo de aprender, su motivación, promover su interés, estimular el pensamiento crítico, creativo y metacognitivo del estudiante

$\checkmark$ Estar dispuesto al cambio, la utilización de medios de comunicación, medios audiovisuales deben tener como propósito diagnosticar necesidades de aprendizaje, crear nuevas experiencias de aprendizaje y ayudar a los estudiantes a aprender cómo aprender.

$\sqrt{ }$ Actitud positiva ante el uso de TIC

$\sqrt{ }$ Ingreso de las TIC a la currícula

$\checkmark$ Uso de las TIC como medio de información

$\checkmark$ Adaptar las TIC a la asignatura

$\checkmark$ Adquirir habilidades para su utilización

$\sqrt{ }$ Crear y transmitir el propio material didáctico

$\sqrt{ }$ La profesionalización docente en el uso de las TIC (alfabetización tecnológica)

Incorporación de TIC
\end{abstract}

Caso universidad privada: incorporó como asignatura las TIC en la Sociedad del Conocimiento, invierte en infraestructura adquiriendo equipo (medios audiovisuales, telemáticos e informáticos) en 11 salas de sistemas con conexión a internet, video beam, equipo de amplificación de sonido, DVD, equipos para la realización de video conferencias, televisor, proyector de acetatos y opacos; cuenta con una red inalámbrica para los portátiles personales tanto de docentes como de estudiantes. Cuenta con diversos software de apoyo para el desarrollo de los procesos de enseñanza - aprendizaje.

Capacitación docente: Se ha llevado a cabo a través de: Módulos de informática. Uso de las TIC en los proceso de enseñanza y aprendizaje.

Comunicación: Todos los Docentes y estudiantes posean una cuenta de correo, acceso a la plataforma virtual (Moodle), y a través de la web a servicios académicos.

Caso universidad pública: Ha levantado una Infraestructura de cinco salas de cómputo, dotadas con un promedio de 60 computadores tanto para profesores como alumnos y estudiantes de posgrado, utilizan el software instalado, se tiene una sala como laboratorio de idiomas y pronto se tendrá una para simulación empresarial. Hay una red inalámbrica para los portátiles del docente. Se cuenta con medios audiovisuales (tarjetas de video), circuito cerrado de TV a todos los salones, un equipo de videoconferencia. Cada salón está dotado de un computador, video beam, proyector de acetato, televisor y DVD.

El inventario de software de la facultad se puede considerar como muy diverso: Office (Word, Excel, Power Point, Access), base de datos de estados financieros e indicadores empresariales, de Comercio Exterior (base de datos y legislación), Software contable, para matemática y gestión financiera, SPSS, Graficadora de Flujos de datos, antivirus, software libre Open Office (se descarga de la página web institucional para docentes, alumnos y administrativos, se pueden descargar manuales) con solo contar con correo electrónico, graficadores y visores, compresores y descompresores de archivos, navegadores.

Se ofrece apoyo para el aprendizaje virtual, se realiza cursos a docentes orientados al manejo de las TIC, esporádicas capacitaciones a docentes sobre software específico para ser utilizado como herramienta didáctica.

Comunicación: para mejorar la comunicación entre docentes y estudiantes se cuenta con una página web donde se presentan noticias de la comunidad educativa; además cada docente cuenta con una página web donde puede publicar el material necesario para el desarrollo de las clases y al cual puede acceder el estudiante, igualmente, el docente puede utilizar el campus virtual (plataforma Moodle) para evaluar a los estudiantes o para 


\section{PERCEPCIÓN SOBRE EL USO DE HERRAMIENTAS TECNOLÓGICAS DIGITALES COMO APOYO EN LA DOCENCIA E INVESTIGACIÓN CASO: DOCENTES-INVESTIGADORES UAM-A, MÉXICO, ADSCRITOS A QUÍMICA}

desarrollar una clase.

Los roles de ambas universidades empiezan a encaminarse a un nuevo paradigma vinculando las TIC en sus currículos, donde las competencias del estudiante y del docente tendrá que actualizarlas y ajustarlas a los nuevos avances tecnológicos que se están vinculando en su entorno. Por tal motivo se ve la universidad de diseñar planes de mejoramiento en cursos de formación para docentes y estos a su vez tendrán el compromiso de compartir esta formación con sus estudiantes en las prácticas académicas.

16. Riascos-Erazo Sandra Cristina, Quintero-Calvache Diana María, Ávila-Fajardo Gloria Patricia (2009). Las TIC en el aula: percepciones de los profesores universitarios.

Educación y Educadores 21(2): Universidad de la Sabana. http://educacionyeducadores.unisabana.edu.co/index.php/eye/article/view/1536/1982

Este artículo es el resultado de una investigación que tiene como objetivo identificar la percepción del docente frente a la utilización de las TIC dentro del proceso enseñanzaaprendizaje, en los casos de dos universidades.

La metodología empleada partió del análisis de literatura relacionada con la percepción docente, el impacto de las TIC y su nivel de utilización. Además, se recolectó información en dos universidades, mediante la aplicación de una encuesta que permitiera identificar la opinión de los docentes. El análisis de los resultados se hizo por frecuencia y triangulación de variables.

Los principales resultados muestran que los docentes de la universidad privada tienen una percepción favorable ante la utilización de las TIC; en sentido contrario se manifiesta la percepción de los de la universidad oficial. Esto tiene diversas causas, que se presentan en el análisis de información. El estudio concluye proponiendo recomendaciones para mejorar la percepción docente frente a la utilización de las TIC en la educación superior.

El impacto de las TIC tanto en la universidad pública como en la privada muestra que estas herramientas fortalecen considerablemente la aprehensión de conocimiento y el enriquecimiento cognitivo; esto se constituye como el resultado de la percepción y el grado de utilización de las TIC en el proceso de enseñanza-aprendizaje.

La percepción docente frente a la utilización de las TIC en los entornos de enseñanzaaprendizaje de la educación superior muestra que estas son herramientas de gran utilidad en cuanto a la construcción de una sociedad del conocimiento se trata; por tanto, la apreciación de Navarro y Alberdi (2004) sobre la posibilidad que las TIC ofrecen de acceder en forma rápida a una gran cantidad de información hace necesario que el profesor complemente su tradicional actividad transmisora de conocimientos con un esfuerzo de aprendizaje del aprendizaje, se considera muy valedera en función del ambiente de la educación superior.

Como toda investigación, este estudio no busca únicamente presentar la radiografía de la percepción docente con respecto a las TIC a nivel del proceso de enseñanza-aprendizaje, sino también analizar posibles mecanismos que permitan potencializar el interés docente en apoyar el proceso de inclusión de las TIC en las instituciones de educación superior, considerando que la educación es un bien social y que debe estar acorde con los requerimientos y cambios que la sociedad experimenta.

17. Torres, S., Barona, C., García, O. (2010). Infraestructura tecnológica y apropiación de las TIC en la Universidad Autónoma del Estado de Morelos. Estudio de caso. Perfiles Educativos 32(127). IISUE-UNAM, México. 


\section{PERCEPCIÓN SOBRE EL USO DE HERRAMIENTAS TECNOLÓGICAS DIGITALES COMO APOYO EN LA DOCENCIA E INVESTIGACIÓN CASO: DOCENTES-INVESTIGADORES UAM-A, MÉXICO, ADSCRITOS A QUÍMICA}

http://webcache.googleusercontent.com/search?q=cache:MWQobm6CnewJ:www.scie lo.org.mx/scielo.php\%3Fscript\%3Dsci arttext\%26pid\%3DS0185$26982010000100006+\& c d=1 \& h l=e s-419 \& c t=c l n k \& g l=m x$

En este artículo se analizan los patrones de disponibilidad de infraestructura y equipamiento informático, así como los modos de apropiación y uso de las TIC por parte de los profesores de tiempo completo de la Universidad Autónoma del Estado de Morelos (UAEM). Se usó el método de estudio de casos. Como instrumentos de indagación se usó la encuesta, la entrevista y el análisis de documentos. Para la recolección de información se aplicó una encuesta electrónica, cuantitativa y cualitativa. Para la validación de la encuesta electrónica se realizó una prueba piloto de la encuesta con 10 profesores investigadores. La encuesta electrónica se estructuro en cinco categorías: 1) aspectos socio-demográficos de los informantes; 2) recursos tecnológicos disponibles en las unidades académicas; 3) uso y apropiación de las TIC en la docencia por parte de los profesores, tanto en su fase de integración como de re-orientación; 4) uso y apropiación de las TIC en la investigación; y 5) fase de opinión abierta que facilitó la expresión libre y cualitativa de los informantes. El cuestionario incluye 47 preguntas, con 219 posibles respuestas, unas de escala tipo Likert, y preguntas abiertas. El análisis de datos se realizó con apoyo del Paquete Estadístico para las Ciencias Sociales (Statistical Package for Social Sciences SSPS versión 15). En una primera instancia se aplicó el análisis de variables independientes —univariado-dejando para un reporte final global el análisis correlacional (multivariado). La selección de informantes se hizo mediante un procedimiento censal de una población de 303 profesores ubicados en las diferentes dependencias de educación superior. Los resultados del estudio se aglutinan en torno a cinco ámbitos mediados por las TIC (Perfil del profesor, Actividades de docencia, Actividades de investigación, Difusión de información, Percepción implantación de TICs e Infraestructura tecnológica)

\section{Conclusión:}

$\rightarrow$ Falta de sistematización (organización, catálogo) de la información referente a la infraestructura tecnológica y al equipamiento tele-informático.

$\rightarrow$ La infraestructura tecnológica, el equipamiento computacional y las redes teleinformáticas se encuentran actualmente en una fase media de desarrollo.

$\rightarrow$ La conexión a Internet y a las páginas web adolece de fuertes insuficiencias.

$\rightarrow$ El soporte técnico (recursos humanos, especializados o no) son insuficientes.

$\rightarrow$ Hay recursos digitales licencias de software y un $46.66 \%$ de páginas web, $42.85 \%$ no están actualizadas.

A pesar de que el docente reconoce los beneficios de las TIC en la docencia y en la investigación, se confirma, como hallazgo, que la posición de Infraestructura y equipos modernos no es sinónimo de apropiación y uso acertado de las TIC en los complejos ámbitos educativos universitarios

"La institución contará con la infraestructura y plataformas para el funcionamiento pleno de las TIC, que apuntalaran el establecimiento de programas educativos de calidad" (UAEM, IL, 2008: 21). Sin embargo, los avances y el cumplimiento de las propuestas enunciadas aún no han superado el modelo educativo tradicional.

18. Wright, N. (2013). Digital technologies and continuance theory in education. Annual International Conference On Infocomm Technologies In Competitive Strategies, 121124.

La teoría de la continuidad, que surge de la investigación en organizaciones comerciales que quieren incluir herramientas digitales como parte de los flujos de trabajo, sostiene que tanto los miembros de las organizaciones como sus clientes continuarán utilizando 


\section{PERCEPCIÓN SOBRE EL USO DE HERRAMIENTAS TECNOLÓGICAS DIGITALES COMO APOYO EN LA DOCENCIA E INVESTIGACIÓN CASO: DOCENTES-INVESTIGADORES UAM-A, MÉXICO, ADSCRITOS A QUÍMICA}

tecnologías que apoyen el trabajo.

En contextos educativos se puede aplicar la teoría de la continuidad para explicar porque los maestros persisten con las tecnologías digitales (que a menudo tienen su origen en el comercio) para mejorar el aprendizaje de los estudiantes. Educativamente, las HTD habilitan a los profesores y estudiantes con" posibilidades, "no con un recurso listo para usar"

En tanto que la teoría sociocultural a menudo incluye la comprensión de lo que ocurre en las aulas, la teoría de la continuidad puede ayudar a comprender el uso continuo (o no) de las tecnologías digitales por parte de los profesores de educación inicial (Initial Teacher Education ITE), examinando las decisiones de los estudiantes con respecto a las tecnologías digitales para el aprendizaje.

El estudio, se enmarcó en una investigación-acción de dos etapas, con aproximadamente 90 estudiantes ITE, se utilizó como datos los informes de estos estudiantes dentro de un Sistema para la Gestión del Aprendizaje( Learning Management System LMS) usando al menos una tecnología digital / herramienta / o asistencia en una lección.

Este trabajo extrapola los resultados que surgen de los datos, puestos a la luz de la teoría de la continuidad en una escuela de Nueva Zelanda

La teoría de la continuidad ayuda a comprender porque y en qué condiciones los nuevos maestros continúan con las herramientas y tecnologías digitales y los recursos en las aulas. Los hallazgos sugieren que condiciones hacen que los profesores experimentados utilicen repetidamente las tecnologías digitales para el aprendizaje.

19. La percepción. Lilia Fernández Sánchez

Percepción: La percepción es un proceso cognitivo que inicia con la observación de un objeto, proceso o fenómeno a través de los sentidos (estímulos externos distales), en el cerebro ocurre una transducción de los estímulo a impulsos eléctricos en el sistema nervioso que fluyen al cerebro (estímulos proximales), donde ocurre el proceso de organización, análisis, reflexión, creación significativa del percepto, almacenamiento y/o acción. Por tanto la percepción es el proceso que ocurre entre los estímulos (las partes) y la respuesta final de un organismo o imagen perceptual (el todo). Y sus implicaciones para el perceptor, en pocas palabras, se es conscientes de la situación (de mi pensamiento "el aquí y el ahora") y en consecuencia se actúa.

La percepción es un proceso que es realizado por todos los seres humanos. Por definición, es un proceso cerebral en donde por asociación de diferentes estímulos el cerebro se crea una realidad interna sobre lo que ocurre en su entorno (Larousse, s.f.). A través de este proceso el ser humano es capaz de sobrevivir ya que es capaz de satisfacer tanto sus necesidades inmediatas como sus necesidades básicas (Gorostiaga, 2012; Santiago, 2011).

Factores de la percepción. a) biológicos (el pensar), b) psicológicos (el sentir) y c) la experiencia (el actuar) (Pérez, 1986; Gorostiaga, 2012).

Medición de la percepción. A través de la percepción manifiesta de las personas se conoce su realidad (Silvestre, Gost, Astier y Ezpeleta, 2002; Mahtani-Chugani Vinita. 2009; FonsecaGarcía, González-Espinosa, 2008). La percepción es una representación mental que puede medirse a través de escalas (instrumentos: cuestionarios, encuestas) que se construyen, se determina su confiabilidad y consistencia, se validan y analizan por métodos estadísticos para obtener resultados cuantitativos (Espín, Quintero, Bayarre, 2001). Los ítems de la escala, pertenecientes a categorías o dimensiones pueden estructurarse (normas de calificación del instrumento) en escala Likert (Céspedes et al., 2011) o calificarlos de acuerdo 


\section{PERCEPCIÓN SOBRE EL USO DE HERRAMIENTAS TECNOLÓGICAS DIGITALES COMO APOYO EN LA DOCENCIA E INVESTIGACIÓN CASO: DOCENTES-INVESTIGADORES UAM-A, MÉXICO, ADSCRITOS A QUÍMICA}

a los principios de Moriyama, de acuerdo a la escala: mucho, poco, nada. (Moriyama, 1968). Conocer la forma de pensar, sentir y actuar de las personas, es común en la investigación cuantitativa y cualitativa en el área de salud, la psicología de la salud, psicología médica, estudios de mercado, del turismo, análisis del impacto de la tecnología digital educativa, en el campo de las humanidades e investigaciones sociales, entre otras áreas

Para Ries y Trout (2002), la esencia del posicionamiento consiste en aceptar las percepciones como realidad y en reestructurarlas con el fin de crear la posición deseada.

Mapas de posicionamiento para medir la percepción. Para poder conocer y medir las percepciones sobre un producto, servicio, empresa o el uso de HTD, se pueden utilizar los mapas de posicionamiento. Esta tarea se refiere a elaborar un mapeo perceptual, el cual sirve para representar las percepciones de los individuos en cuanto a un producto, un servicio o utilidad de en este caso de la TD, gráficamente. De acuerdo con Santesmases (1996), los mapas perceptuales son gráficos que representan las percepciones de individuos en función de una serie de atributos del objeto de estudio que lo caracterizan. Ries y Trout, (1986) consideran que la información obtenida en esos mapas es valiosa y fundamental para las empresas, para el sector salud, educativo, etc. de aquí que estos mapas dan información valiosa para la investigación cuantitativa y cualitativa. En la definición operacional de términos se define la categoría "sistema de apoyo" como la percepción que tiene el anciano de ser atendido y ayudado por su familia en la solución de sus problemas y necesidades (Espín, A., Quintero, G., Bayarre, H. 2001 p. 61). 


\section{PERCEPCIÓN SOBRE EL USO DE HERRAMIENTAS TECNOLÓGICAS DIGITALES \\ COMO APOYO EN LA DOCENCIA E INVESTIGACIÓN \\ CASO: DOCENTES-INVESTIGADORES UAM-A, MÉXICO, ADSCRITOS A QUÍMICA}

\section{CAPÍTULO 3: MARCO TEÓRICO Y CONCEPTUAL}

"Necesitamos diversidad de pensamiento (de mi reflexión diversidad de percepción) en el mundo para enfrentar los nuevos desafíos"

Tim Berners-Lee

"Cuando inventé la web, no tuve que pedirle permiso a nadie. Ahora, millones de personas la utilizan libremente. Me preocupa que todo eso se vaya a acabar"

Tim Berners-Lee

"The original idea of the web was that it should be a collaborative space where you can communicate through sharing information

Tim Berners-Lee

Introducción. La meta de este capítulo 3 del trabajo de investigación es proporcionar un marco teórico para el estudio de la percepción que los profesoresinvestigadores universitarios de la UAM-A tienen sobre el uso de las HTD y que se centra principalmente en la problemática de su uso o no en la docencia e investigación en química.

El desarrollo del capítulo se basó en la lectura de Monje (2011), y abarca también el marco conceptual. Del marco teórico se hará un resumen de las teorías sobre el aprendizaje asistido por la tecnología digital electrónica y la resistencia a su adopción. Cabe señalar que por sí misma la tecnología educativa es una materia de estudio en la educación (Castillo et al., 2010).

El marco teórico y conceptual de este estudio se basa en las variables de investigación, la percepción de los profesores-investigadores de la UAM-A adscritos a química como variable dependiente, descrita en cuatro dimensiones: la frecuencia, beneficios, infraestructura tecnológica, y políticas; de uso de HTD que vendrían a ser la variable independiente. Figura 3.1.

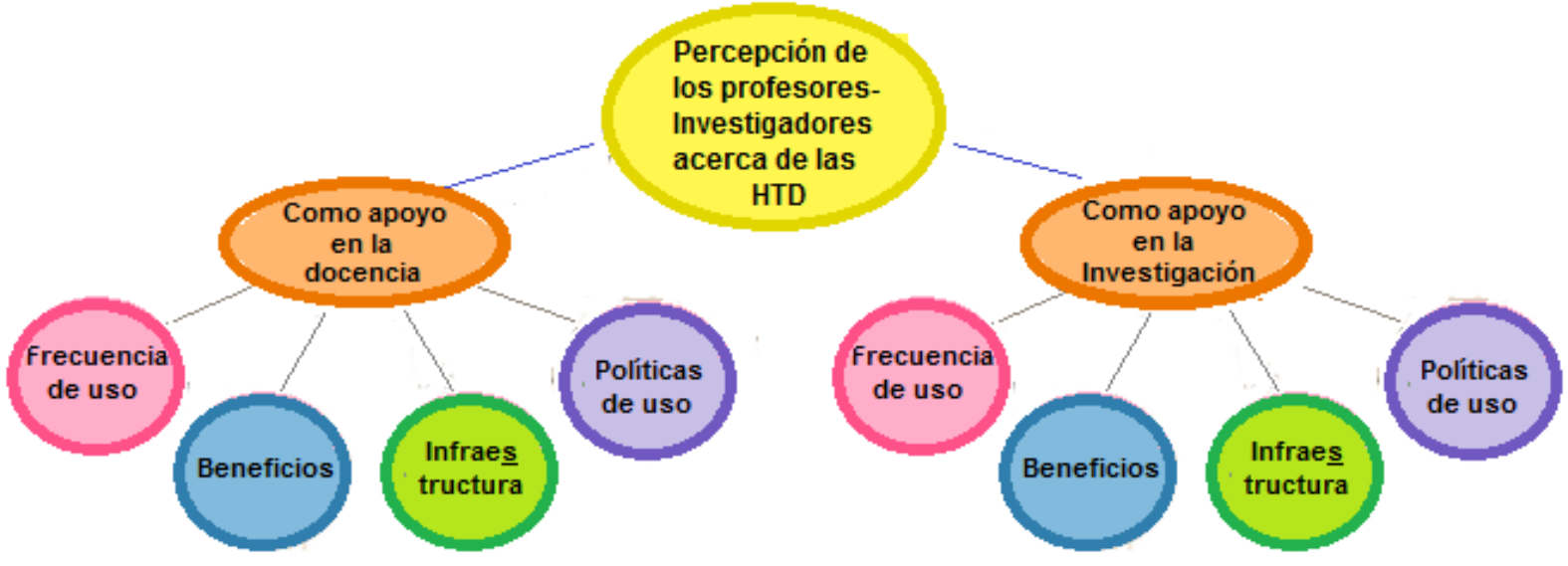

Figura 3.1. Estudio cuantitativo de caso. Uso de HTD como apoyo en la docencia y en la investigación en química en la UAM-A 


\section{PERCEPCIÓN SOBRE EL USO DE HERRAMIENTAS TECNOLÓGICAS DIGITALES COMO APOYO EN LA DOCENCIA E INVESTIGACIÓN CASO: DOCENTES-INVESTIGADORES UAM-A, MÉXICO, ADSCRITOS A QUÍMICA}

La teoría principal en que se basa el estudio es la teoría de la Percepción, la teoría de la tecnología digital educativa. También se mencionaran, a manera de apoyo para explicar los resultados de la investigación otras como, la teoría del aprendizaje de adultos, el constructivismo. A continuación se presenta una breve descripción de cada fundación con un enlace a la tecnología como herramienta de aprendizaje

La psicología cognitiva, uno de los dominio psicológicos, incluye el estudio de la percepción. La revolución cognitiva creó un ímpetu para que los sicólogos centraran su atención en una mejor comprensión de la mente y los procesos mentales que subyacen en el comportamiento. Por lo tanto, la psicología cognitiva es el área de la psicología cognitiva que se centra en el estudio de la cognición o pensamientos, y su relación con nuestras experiencias y acciones ${ }^{44}$. Es una ciencia interdisciplinaria que puede ser aplicada en la investigación educativa.

\subsection{Bases teóricas.}

Teorías de la percepción ${ }^{45}$. Al ser la percepción un proceso cognitivo, han surgido diversas teorías que explican la relación entre la magnitud del estímulo y la percepción:

Teoría empirista o asociacionista de la percepción. La percepción inicia con sensaciones caóticas que el sujeto perceptor ordenará (organizará) posteriormente, siempre desde conocimientos previos de la realidad. El sujeto es pasivo en un principio y se limita a recibir los estímulos externos para luego proceder activamente y organizar el "mosaico" de la percepción. El empirismo clásico fue una corriente denominada constructivismo, y considera que la percepción no puede aislarse de la actividad cognitiva del sujeto. En el acto de la percepción, el sujeto proyecta su atención hacia determinadas características ambientales y entonces hace un muestreo, es decir, selecciona cierta cantidad de información de los objetos y estímulos recibidos. A la vez, esta información activará o modificará los esquemas en que se encuadrará la percepción, y le dará un significado.

Teoría innatista o de la forma. También llamada teoría racionalista, supone que el sujeto percibe mediante capacidades innatas (de nacimiento, no adquiridas). Los datos de la experiencia vendrían organizados en el mismo acto de la percepción, no como datos dispersos, sino que se percibe el mosaico total. La escuela de la Gestalt ha considerado el concepto de organización como resultado directo de los procesos sensoriales. No existen sensaciones puras sino sensaciones organizadas. La organización perceptiva sería el resultado de los procesos físicos que tienen lugar en la corteza cerebral. Habría un cierto isomorfismo (una igualdad de forma) entre la estimulación externa y los efectos que esta produce en el cerebro. No cabría la posibilidad de plantearnos si lo que percibimos es una realidad subjetiva o una correspondencia con la realidad. Por tanto la visión que la percepción nos

\footnotetext{
${ }^{44}$ Domains in Psychology. Introduction to Psychology. Disponible en: https://courses.lumenlearning.com/wmopen-psychology/chapter/outcome-contemporary-fields-inpsychologyl

${ }^{45}$ ( Fdz. Lilia) (Tema 2. Resumen ejecutivo del marco teórico) 2. Investigación III. Dr. Rafael Demetrio Herrera.
} 


\section{PERCEPCIÓN SOBRE EL USO DE HERRAMIENTAS TECNOLÓGICAS DIGITALES COMO APOYO EN LA DOCENCIA E INVESTIGACIÓN CASO: DOCENTES-INVESTIGADORES UAM-A, MÉXICO, ADSCRITOS A QUÍMICA}

proporciona está ordenada en sí misma, estructurada con los caracteres propios de un todo.

Teoría racionalista de la percepción. También conocida como Teoría innatista de la percepción de Chomsky o de la forma. Supone que el sujeto percibe mediante capacidades innatas (de nacimiento, no adquiridas). Los datos de la experiencia vendrían organizados en el mismo acto de la percepción, no como datos dispersos, sino que se percibe el mosaico total. La escuela de la Gestalt ha considerado el concepto de organización como resultado directo de los procesos sensoriales. No existen sensaciones puras sino sensaciones organizadas. La organización perceptiva sería el resultado de los procesos físicos que tienen lugar en la corteza cerebral. Habría un cierto isomorfismo (una igualdad de forma) entre la estimulación externa y los efectos que esta produce en el cerebro. No cabría la posibilidad de plantearnos si lo que percibimos es una realidad subjetiva o una correspondencia con la realidad. Por tanto la visión que la percepción nos proporciona está ordenada en sí misma, estructurada con los caracteres propios de un todo.

Percepción y la Teoría de la Gestalt en la psicología. La percepción es una organización mental e interpretación de información sensorial. Los psicólogos de la Gestalt estudian ampliamente las formas en que las personas se organizan y seleccionan información (que transforman en energía) de la amplia gama de estímulos que se les presentan y que analizan, procesan, almacenan y sintetizan para dar una respuesta. Las experiencias pasadas influyen en la percepción. A través de la atención selectiva, el sujeto se enfoca en un número limitado de estímulos e ignora aquellos que se consideran menos importantes. Estudios recientes han demostrado que los estímulos se perciben realmente en el cerebro, mientras que los órganos sensoriales simplemente reúnen las señales (Perceptión in psycology, 2002; percepción en psicología, s.f.). La escuela de la Gestalt ha considerado el concepto de organización como resultado directo de los procesos sensoriales. No existen sensaciones puras sino sensaciones organizadas. La organización perceptiva sería el resultado de los procesos físicos que tienen lugar en la corteza cerebral. Habría un cierto isomorfismo (una igualdad de forma) entre la estimulación externa y los efectos que esta produce en el cerebro. Así pues, nuestra percepción sería el resultado de una adaptación biológica al medio. La visión que la percepción nos proporciona está ordenada en sí misma, estructurada con los caracteres propios de un todo. Las partes de la percepción dependen del todo de la percepción.

La psicología Gestalt (corriente que surgió a principios del siglo $\mathrm{XX}$ ) es un intento de comprender las leyes que respaldan la capacidad de adquirir y mantener percepciones significativas en un mundo aparentemente caótico. El principio central de la psicología gestalt es que la mente forma un todo global con tendencias autoorganizadas.

Gestalt: Proceso por el cual construimos marcos de percepción de la realidad ${ }^{46}$. Formamos formas o figuras en la mente sin darnos cuenta y de esta manera

\footnotetext{
${ }^{46}$ https://psicologiaymente.net/psicologia/teoria-gestalt
} 


\section{PERCEPCIÓN SOBRE EL USO DE HERRAMIENTAS TECNOLÓGICAS DIGITALES COMO APOYO EN LA DOCENCIA E INVESTIGACIÓN CASO: DOCENTES-INVESTIGADORES UAM-A, MÉXICO, ADSCRITOS A QUÍMICA}

interpretamos la realidad y tomamos decisiones sobre ella. La teoría de la Gestalt se enfoca en dar explicaciones de este proceso. Las formas o figuras se adquieren a través de los sentidos (suma de piezas: imagen, sonido, tacto, vista, y memoria), estos paquetes de información se suman en el cerebro (el todo perceptivo) y la experiencia es "más" (algo diferente o realidad algo diferente) que la simple suma de las piezas o partes, es la globalidad. No solo estimulo-respuesta. Las personas son activas, construyendo unidades de significación de la experiencia vivida, reestructurando formas mentales para tener puntos de vista, útiles (según la persona) para orientar sus decisiones y sus objetivos (de mi opinión: aunque se esté sentado oyendo una clase, se tiene una actividad cognitiva, está ocurriendo un proceso de percepción, no solo estimulo respuesta).

Teoría Gestalt de la percepción. Como toda teoría se construye con base en principios, leyes y procesos. La percepción es multisensorial y producto sinérgico de las mismas $^{47}$.

Principios de la organización perceptual según la Gestalt. Propuestos por la escuela alemana "psicología de la Gestalt o de la forma": Es la experiencia total resultante de organizar fragmentos de información en objetos y patrones significativos, base de la Gestalt es que la totalidad es "más" que la suma de las partes (de mi opinión es una sinergia), traducción incorrecta según Tuck Michael $(2010)^{48}$. Según la Ley de la Totalidad "El todo es diferente, distinto o algo distinto a la suma de las partes ${ }^{49}$. Es decir una realidad diferente a la realidad de sus partes. La comprensión de los objetos o conceptos resulta de la idea de la totalidad (Bonal, 1973). Wilhelm Dithley afirmaba que, en todos los procesos psíquicos, la percepción (aprensión, comprensión) de la totalidad precede a la comprensión del objeto o concepto.

Proceso perceptual según la Gestalt. El psicólogo de la Gestalt Leo Postman describe el proceso perceptual en una secuencia de 3 etapas:

Proceso de formulación de hipótesis por parte del sujeto que se encuentra frente al (a los) objeto(s)-estímulo. Una disposición general para percibir determinados aspectos del estímulo, que sean congruentes con la orientación de la personalidad (un estado de sintonía previo).

- $\quad$ El Input o entrada de la información perceptual que proviene del medio (información en el sentido de los "estímulos-signo" aquellos que son indicadores significativos de la realidad para el individuo que formula la hipótesis).

- Verificación de las hipótesis previas (ya sea confirmación o rechazo de las mismas). Existía una expectativa, una tendencia a percibir selectivamente, de un modo determinado, que se confronta con las características materiales del estímulo.

\footnotetext{
${ }^{47}$ Definición de sinergia. El concepto es utilizado para nombrar a la acción de dos o más causas que generan un efecto superior al que se conseguiría con la suma de los efectos individuales.

48 "El todo es distinto de la suma de las partes" a menudo se traduce incorrectamente (Tuck, 2010), como "El todo es mayor que la suma de sus partes"

${ }^{49}$ https://faecc.wordpress.com/2010/11/15/gestalt-el-todo-es-mas-que-la-suma-de-las-partes/
} 


\section{PERCEPCIÓN SOBRE EL USO DE HERRAMIENTAS TECNOLÓGICAS DIGITALES COMO APOYO EN LA DOCENCIA E INVESTIGACIÓN CASO: DOCENTES-INVESTIGADORES UAM-A, MÉXICO, ADSCRITOS A QUÍMICA}

De esa confrontación resultan la confirmación o el rechazo posibles de la hipótesis formulada.

Teoría fundamentada modificada y la percepción. La teoría fundmentada TF, traducción de grounded theory es un método de investigación que permite desarrollar una teoría la cual ofrece una explicación sobre un problema asunto o preocupación de una determinada población de personas de un área específica además permite emitir como puede resolverse o procesarse esta preocupación. El método de la "Modified Grounded Theory" permite el estudio de la percepción en la investigación cualitativa (Mahtani, 2009; Guerrero, 2005). Grounded theory. Traducido como Teoría Fundamentada TF, es una de las teorías que engloba la metodología (manera de pensar y estudiar la realidad) y el método de la investigación (conjunto de procedimientos y técnicas para recoger y analizar datos ${ }^{50}$ ), es decir, que se puede utilizar únicamente como método de análisis de datos, o de una forma más amplia como forma de enfocar todo el proceso de investigación. La teoría se "descubre" mediante la comparación constante entre las incidencias y las propiedades de una categoría; intentando hacer una observación profunda de tantas similitudes y diversidades como sea posible. Glaser y Strauss (1967), citado por Páramo (2015), definieron la TF como una "aproximación inductiva en la cual la inmersión en los datos sirve de punto de partida del desarrollo de una teoría sobre un fenómeno" (Guillemette, 2006), que tiende "a generalizar en la dirección de las ideas teóricas, subrayando el desarrollo de teorías más que la prueba de una teoría" (Hunt y Ropo, 1995). Desde mi punto de vista la TF es la aplicación del constructivismo en la investigación. La TF puede ser utilizada sobre todo en el campo de las ciencias sociales, en el sector salud, en el sector turístico, en la administración en general, en el desarrollo del conocimiento y en la mercadotecnia para conocer a través de la percepción de los consumidores acerca de las ventas de diferentes empresas. Pauleen, Corbitt y Yoong. (2007) utilizaron la TF y la acción de aprendizaje como estrategia de gestión de conocimientos cuando las personas trabajan con nuevas tecnologías.

Fundamentar construyendo redes esenciales más allá de lo aparente. Fundamentar construyendo lo que evidentemente no es observable a partir de: un orden sensible (percepción aparente y manifiesta) y otro explicativo (inteligible en el nivel de lo esencial y lo constitutivo).

El conductismo y la percepción: El conductismo, como teoría del aprendizaje, se centra en el estudio de conductas (respuestas a estímulos) que se pueden observar y medir cuantitativamente, ignorando lo que pueda ocurrir en la mente (Good y Brophy, 1990). La conducta del ser humano es el resultado de las interacciones con el ambiente tanto físico como cultural. Se percibe, se conoce, en la medida en que se responde a estos estímulos ambientales. La percepción es importante en la conducta,

\footnotetext{
${ }^{50}$ Fuentes de datos primarios: entrevistas (generalmente grabadas), observación participante y noparticipante, conversaciones grabadas en diarios y notas de campo. Fuentes de datos secundarios: experiencias personales, fotos, imágenes, etc.
} 


\section{PERCEPCIÓN SOBRE EL USO DE HERRAMIENTAS TECNOLÓGICAS DIGITALES COMO APOYO EN LA DOCENCIA E INVESTIGACIÓN CASO: DOCENTES-INVESTIGADORES UAM-A, MÉXICO, ADSCRITOS A QUÍMICA}

ya que ésta es la experiencia de organizar la información que se recibe, e interpreta de manera significativa. Dicha interpretación es única y personal en cada ser humano. La percepción en la conducta es básica porque todos los procesos psicológicos están relacionados con la percepción. La acción tiene que ver con: la percepción, la memoria, con brotes de emoción, con el pensamiento, con la motivación, con los sentimientos. Todos los procesos de la vida consciente e inconsciente están relacionados con la percepción. Estar conscientes de la percepción de los demás es estar abiertos a lo que las personas perciben como su realidad, de allí la importancia de la percepción en la conducta en la sociedad.

El cognitivismo, el enfoque ecológico y la percepción. Las teorías de la percepción intentan explicar la manera en que se obtiene la información del entorno. La teoría de la percepción indirecta afirma que la percepción esta mediada por: inferencias, conocimiento o mecanismos de procesamiento de información. Estos procesos intermedios son necesarios porque el estímulo de la percepción subdetermina $^{51}$ la respuesta (Contreras, 2012). La teoría de la percepción directa, en cambio, afirma que no hay necesidad de postular nada que medie entre el estímulo y la respuesta. Una teoría de este tipo es defendida por James J. Gibson (2014), quien propone analizar el problema desde el "enfoque ecológico". Según este último, el estímulo es informacionalmente rico. La percepción puede ser explicada como la detección de la información por parte de los sentidos. Al negar la pobreza del estímulo, la postulación de mecanismos intermedios se vuelve redundante. El enfoque ecológico de Gibson propone considerar a la percepción como un fenómeno en un sistema animal-ambiente. Siguiendo este principio, puede distinguirse entre la estimulación y la información en ella. La estimulación ambiental lleva información acerca del ambiente suficiente como para explicar la percepción. Esta última, además, se concibe como una actividad del organismo en la que éste busca y consigue la información ambiental para guiar su conducta. El enfoque ecológico, por lo tanto, afirma que en el ambiente hay información suficiente, disponible, y que los organismos que perciben son capaces de detectarla para guiar su conducta. De esta manera, la percepción sería directa. Ambas teorías (percepción directa y la percepción indirecta) tienen la verdad de sus principios teóricos condicionada por los resultados de la investigación empírica y que, por ende, ninguna de las dos tiene una ventaja a priori por sobre la otra en el marco cognitivista preponderante.

Teoría de las affordances y la percepción. La teoría de las posibilidades (affordances) es una traducción de The theory of affordances, también puede llamarse teoría de los ofrecimientos o facilidades ${ }^{52}$ ¿para qué sirven las cosas o que ofrecen? Considérese la teoría de la información ambiental de Gibson bajo el supuesto de que la percepción debe guiar a la acción. El medio ambiente, las sustancias, las superficies, los objetos, los lugares u otros animales deben ser percibidos por otro animal o por el hombre ya que proporcionan posibilidades

\footnotetext{
${ }^{51}$ En Filosofía de la ciencia, la subdeterminación se refiere a aquellas situaciones en las que la evidencia disponible no es suficiente para determinar la creencia que deberíamos tener acerca de tal evidencia.

${ }^{52}$ To afford: Traducción "permitir" "proporcionar"
} 


\section{PERCEPCIÓN SOBRE EL USO DE HERRAMIENTAS TECNOLÓGICAS DIGITALES COMO APOYO EN LA DOCENCIA E INVESTIGACIÓN CASO: DOCENTES-INVESTIGADORES UAM-A, MÉXICO, ADSCRITOS A QUÍMICA}

(affordances) que pueden ser de beneficio o de riesgo, de vida o muerte (Gibson, 1977). Dentro de ciertos límites, el hombre puede alterar las posibilidades (affordances) de su medio ambiente para bien o para mal.

El constructivismo y la percepción. El constructivismo considera que la percepción no puede aislarse de la actividad cognitiva del sujeto. Los seres humanos como receptores activos de experiencias y aprendizajes son constructores activos de su realidad "El que aprende construye su propia realidad o al menos la interpreta de acuerdo a la percepción derivada de su propia experiencia, de tal manera que el conocimiento de la persona es una función de sus experiencias previas, estructuras mentales y las creencias que utiliza para interpretar objetos y eventos" (Bartlett, 1920). En la psicología constructivista (Martorell y Prieto, s.f.) teorías y prácticas se enfocan en el modo en que los individuos crean sistemas de significado para así dar sentido a su mundo y experiencias, construyendo su personalidad. En la psicoterapia, por ejemplo, este enfoque puede expresarse en que el terapeuta proponga a su consultante preguntas que vuelvan su atención hacia los procesos de significado y desenvolvimiento en su mundo racional. Es así que el constructivismo a través de la percepción de los individuos, como el terapeuta, a través de preguntas pueda conocer y cuantificar lo que al individuo le signifique un objeto, un proceso o un fenómeno y pueda también conocer su desenvolvimiento en el mundo físico al respecto del objeto o estimulo distal. Recordemos una de las tesis principales de la Gestalt en su comprensión de la percepción: el pensamiento y la relación mentecerebro, su tesis del isomorfismo. La percepción (proceso psicológico), es uno de los Principios gestálticos fundamentales de "el todo es más, o mejor dicho es algo diferente o realidad diferente que la suma o la realidad de las partes". El todo perceptual no puede ser reducido a las partes constituyentes. Percibimos nuestro mundo en totalidades unificadas, significativas. Lo significativo es la organización, no los elementos. La Gestalt estudió la organización perceptual y ofreció una serie de principios, destacando como principal la ley de la pregnancia: la organización perceptual tiende a ser la mejor posible en unas condiciones dadas.

Neuroaprendizaje, neuroenseñanza y la percepción. El neuroaprendizaje es una disciplina, derivada de la neurociencia ${ }^{53}$, que explica los procesos neuronalescerebrales que se llevan a cabo durante el aprendizaje con base en la pedagogía, la psicología y la neurociencia. Es un proceso continuo que reconoce las capacidades y habilidades de las personas, visiona sus recursos y gestiona el máximo desarrollo de las potencialidades. Desde la perspectiva cerebral establece poderosas conexiones neuronales, para aprender más y mejor, propicia el desarrollo y potenciación de la percepción (función mental) así que el desarrollo exitoso adaptativo del que aprende, depende de su capacidad para generar nuevas conexiones neuronales y patrones cerebrales.

\footnotetext{
${ }^{53}$ La neurociencia es una disciplina científica que estudia la estructura, la función, la bioquímica, la farmacología y la patología del sistema nervioso y de cómo sus diferentes elementos interactúan, dando lugar a las bases biológicas de los procesos cognitivos y de la conducta.

Neurociencia Cognitiva: es una disciplina que estudia cómo el cerebro recibe, integra y procesa la información. Área académica que se ocupa del estudio científico de los mecanismos biológicos subyacentes a la cognición (busca las bases biológicas de la cognición)
} 


\section{PERCEPCIÓN SOBRE EL USO DE HERRAMIENTAS TECNOLÓGICAS DIGITALES \\ COMO APOYO EN LA DOCENCIA E INVESTIGACIÓN \\ CASO: DOCENTES-INVESTIGADORES UAM-A, MÉXICO, ADSCRITOS A QUÍMICA}

La neuroeducación y la percepción: La neurociencia cognitiva aplicada en el ambito educativo es señalada como neuroeducación ${ }^{54}$ o neurodidáctica. Esta nueva disciplina aporta estrategias y tecnologías educativas centradas en el funcionamiento del cerebro, El cual cambia y es único, su sistema nervioso/neuronal es plástico (neuroplasticidad) arma, fortalece, desarma y debilita redes neuronales (redes Hebbianas). Las percepciones de un individuo cambian con el tiempo, ya que es un proceso cognitivo de aprendizaje y supervivencia, este cambio debe ser atribuido a la neuroplasticidad en donde las neuronas crean conexiones entre ellas (sinapsis) durante un aprendizaje o se van perdiendo cuando el aprendizaje no se refuerza o resulta obsoleto. Es así que la neuroplasticidad puede definirse como el potencial para el cambio, facultad de modificar nuestra conducta y adaptarnos a las demandas de un contexto particular (Gollin, 1981) y en donde la percepción juega un papel importante. El cerebro se remodela una y otra vez a lo largo de la vida, es extremadamente plástico. Para tener buenas ideas y buenos aprendizajes (que sobrevivan o sean sostenibles) hay que tener buenas percepciones y sensaciones. Son los átomos del conocimiento, del pensamiento. Si ejercitamos adecuadamente la percepción, las conexiones cerebrales de las estructuras implicadas en esta capacidad se fortalecerán (plasticidad sináptica y procesos de neurogénesis).

Teorías en las cuales se basan el uso y aprendizaje de las HTD. Durante los años cincuenta la psicología del aprendizaje se va incorporando como campo de estudio de la currícula de tecnología educativa. La revolución electrónica apoyada inicialmente en la radio y en la televisión propicia a una profunda revisión de los modelos de comunicación, en los años setenta el desarrollo de la informática consolida la utilización de los ordenadores con fines educativos. Con los años ochenta llega bajo la denominación de «nuevas tecnologías de la información y la comunicación» apoyadas en el desarrollo de máquinas y dispositivos diseñados para almacenar, procesar y transmitir de modo flexible, grandes cantidades de información. La innovación constante en las tecnologías de la información y la comunicación TIC con la creación de nuevos materiales audiovisuales e informáticos cada vez más integrados (opciones multimedia) y la necesidad de diseñar sus correspondientes aplicaciones educativas ha ocupado el interés de los tecnólogos de la educación. A continuación se describirá brevemente el concepto de las teorías acerca de esta área de la educación.

La Teoría de e-learning examina estos enfoques. Estas perspectivas teóricas se agrupan en tres principales escuelas teóricas o marcos filosóficos: el conductismo, cognitivismo y el constructivismo aunados a aprendizajes, colaborativos y cooperativos (Johnson y Johnson, 1999).

Teoría de la capacidad cognitiva. Premisas teóricas subyacentes, describen la cantidad de esfuerzo mental que se relaciona con el desempeño de una tarea. (Sweller, 1988). Las ciencias de la computación y de la Tecnología de la información han tenido una gran influencia en la teoría de la Ciencia Cognitiva. Los conceptos

\footnotetext{
${ }^{54}$ https://escuelaconcerebro.wordpress.com/2012/12/27/neuroeducacion-estrategias-basadas-en-elfuncionamiento-del-cerebro/
} 


\section{PERCEPCIÓN SOBRE EL USO DE HERRAMIENTAS TECNOLÓGICAS DIGITALES \\ COMO APOYO EN LA DOCENCIA E INVESTIGACIÓN \\ CASO: DOCENTES-INVESTIGADORES UAM-A, MÉXICO, ADSCRITOS A QUÍMICA}

cognitivos de la memoria de trabajo (anteriormente conocidos como la memoria a corto plazo) y la memoria a largo plazo se han facilitado por la investigación y la tecnología en el campo de la informática. Hoy los investigadores se están concentrando en temas como la carga cognitiva, procesamiento de la información y la psicología de los medios. La carga cognitiva se la define generalmente como las demandas de recursos de la memoria de trabajo para aprender y resolver una tarea o problema de aprendizaje. La teoría de la carga cognitiva es una perspectiva psicocognitiva del aprendizaje y de la instrucción (Moreno, s. f.). Es una teoría de la instrucción de enfoque psicológico. Se basa en cómo funciona la arquitectura cognitiva humana que se compone de: la memoria de trabajo, la memoria de largo plazo, los esquemas y la automatización y la transferencia de esquemas. Estas perspectivas teóricas influyen en el diseño instruccional. (de Jong, 2010).

Teoría del aprendizaje de adultos o teoría de andragogía (The Adult Learning Theory - Andragogy) (Bruenjes, 2001). Malcohn Shepherd Knowles es considerado como el padre de la educación de adultos, introdujo la teoría de la andragogía, la cual proporciona información para la mejora o incremento de oportunidades en el desarrollo profesional. En su enfoque andragógico de aprendizaje (Knowles, 1984) definió la educación de adultos como un proceso de aprendizaje que no puede separarse de las necesidades percibidas por el alumno-profesor y sugirió que los estudiantes-profesores interesados en el autodesarrollo deben participar en la planificación y el diagnóstico de sus propias necesidades para que el aprendizaje significativo tenga lugar.

Teoría de la difusión de innovaciones (Theory of the difusión of innovations) (Rogers, 1995 en Jacobsen, 1998, Jacobson y Weller, 1987). La teoría de la difusión de innovaciones, define difusión como "el proceso por el cual una innovación es comunicada a través de ciertos canales a través del tiempo entre los miembros de un sistema social", Rogers define una innovación como una idea, práctica u objeto que es percibido como nuevo por el individuo, y la difusión como el proceso por el cual una innovación transita a través de un sistema social. En educción, la innovación es la tecnología educativa (instructional technology) para la enseñanza y el aprendizaje, y difusión es la medida en que los profesores han adoptado esta innovación. Porque individuos en un sistema social no adoptan una innovación al mismo tiempo, la innovatividad (innovativeness) es el grado en que un individuo es relativamente más adelantado (earlier) en la adopción de nuevas ideas que otros miembros de un sistema. Basado en investigaciones y estudios de mercado, Rogers, (1995) describe cinco categorías del adoptante en el continuo de innovatividad (Figura 3.2) que son tipos ideales (Innovador, Adoptante temprano, Vacilante, Adoptante y resistente) diseñados para hacer posible las comparaciones en base a características de la distribución normal y repartido por la media $(\bar{X})$ y desviación estándar $(s d)$. La variable innovatividad se reparte en cinco categorías de adoptantes, eliminando o sumando el valor de las desviaciones estandar ( $s d$ ) del tiempo medio de adopción $(X)$. 


\section{PERCEPCIÓN SOBRE EL USO DE HERRAMIENTAS TECNOLÓGICAS DIGITALES \\ COMO APOYO EN LA DOCENCIA E INVESTIGACIÓN \\ CASO: DOCENTES-INVESTIGADORES UAM-A, MÉXICO, ADSCRITOS A QUÍMICA}

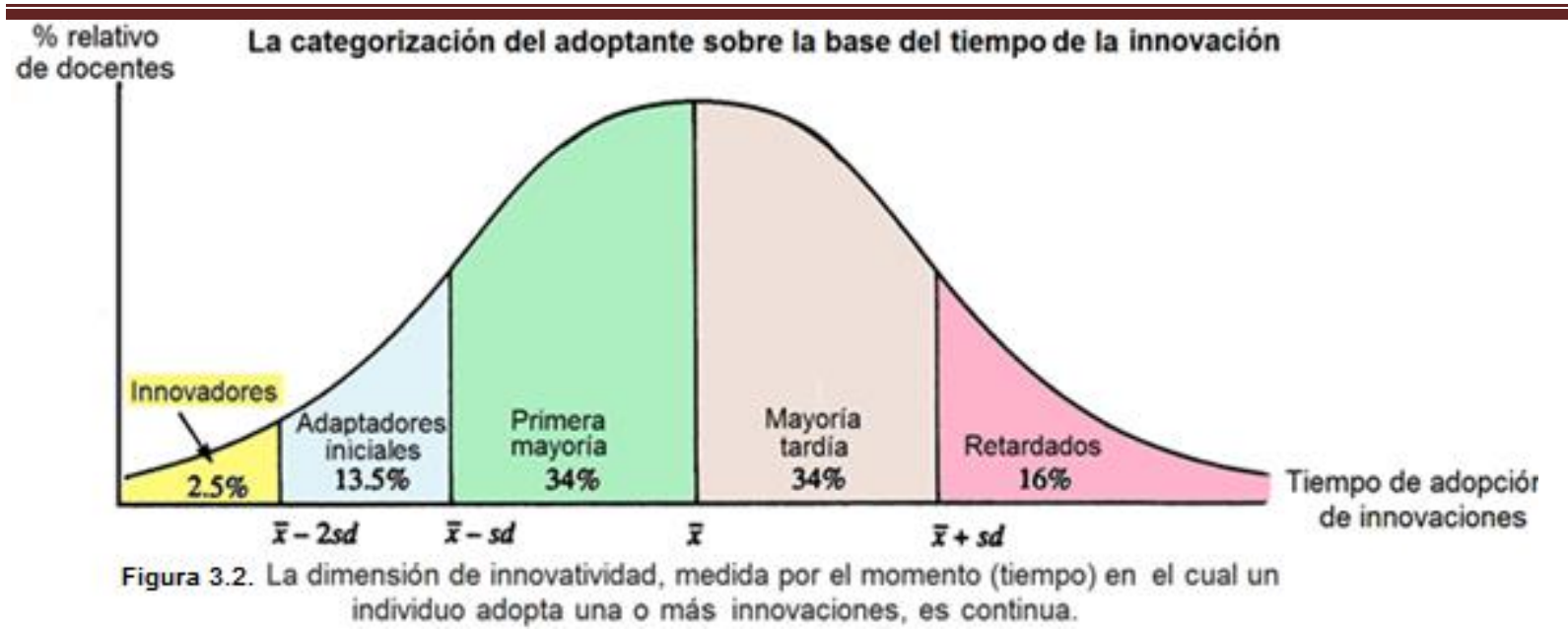

Teoría de la continuidad. Mencionada por Wright (2013) en el contexto de la educación esta teoría puede explicar porque los maestros persisten o no con las tecnologías digitales para mejorar el aprendizaje de los estudiantes

Teoría de la aceptación de la tecnología entre adjuntos TAAA (Technology Acceptance Amongst Adjuncts TAAA theory) (Mosley, 2014). Hay muchos factores que limitan el uso de HTD entre los profesores y pueden considerarse algunos como la falta de la habilidad en el manejo de HTD, el desconocimiento de sus beneficios, la resistencia al cambio. De estos hallazgos surge la teoría TAAA.

Teoría del desarrollo profesional. Bruenjes (2001) en su tesis de maestría se basa en la Teoría de desarrollo profesional entendiéndose este desarrollo como el conjunto de habilidades, actitudes y destrezas que fomentan, facilitan y enriquecen el desempeño eficaz del profesional docente. Un programa de entrenamiento efectivo para los docentes, no debe ser impuesto sino que debe diseñarse tomando en cuenta las necesidades particulares de los docentes. Para que la academia de docentes acepte la tecnología digital es necesario que vean en estas herramientas un método mas efectivo para satisfacer las necesidades cognitivas de los estudiantes (clase centrada en el alumno).

Modelos de enseñanza instructivistas: remiten más a la acción del profesor que a la del estudiante, como las teorías en las que se basan los diseños instruccionales del tipo Dick \& Carey (Myers, 1977) basados en la teoría Ecléctica; (Gagné \& Briggs, 1979). La enseñanza es vista como un proceso que se refiere principalmente a la acción mediadora del profesor entre el estudiante, el conocimiento y el poder de las herramientas tecnológicas le dan a los ambientes de enseñanza mediatizados.

Teoría del construccionismo Papertiano (Papert, 1999), como teoría del aprendizaje y conocimiento contemporánea, constituye la respuesta a la teoría constructivista de Jean Piaget por su discípulo Seymour Papert, poniendo el acento en el valor de las TICC como poderosas herramientas de construcción mental, útiles para desarrollar el pensamiento complejo en los estudiantes (rol totalmente activo). La premisa básica del aprendizaje desde el enfoque construccionista supone que existe una habilidad natural en los seres humanos para aprender a través de la 


\section{PERCEPCIÓN SOBRE EL USO DE HERRAMIENTAS TECNOLÓGICAS DIGITALES COMO APOYO EN LA DOCENCIA E INVESTIGACIÓN CASO: DOCENTES-INVESTIGADORES UAM-A, MÉXICO, ADSCRITOS A QUÍMICA}

experiencia, y para crear estructuras mentales que organicen y sinteticen la información y las vivencias de la vida cotidiana (Vicario, 2009: p. 5). La teoría es un referente de la innovación educativa para transformar la realidad y hacer frente a los retos que impone la civilización del conocimiento a los formadores. Caludia Mrina Vicario (Vicario, 2009) se apoya en la teoría de Papert para invitar a los educadores a reinventarse y mirar el aprendizaje mas alla del aula (delconocimiento en acción).

Teoría sobre la informática educativa. Elementos de una teoría para la civilización del conocimiento. En 2005 la Dra. Vicario formula la primera Teoría sobre la Informática Educativa que perfecciona en 2010 (Vicario, 2010; 2011). Propuesta de Matriz Filosófica Básica para la Informática Educativa. Misma que ha sido articulada desde el segundo sentido de paradigma de Kuhn, en el marco del contexto de la Civilización del Conocimiento, a partir de los referentes socio-tecno-científicos analizados.

Teoría o estudios relacionados con la resistencia al cambio (Guerrero, 2005). Fullan y Stiegelbauuer (1997) plantean una visión estratégica respecto de las resistencias en educación. Los autores señalan que los cambios en educación son paulatinos, lo que se explica en parte por las resistencias de los distintos actores. Para el caso de las resistencias de los profesores, la principal razón es que existe un alto nivel de exigencias y un deterioro en la calidad de vida: Las circunstancias de la enseñanza piden mucho a los maestros en términos de mantenimiento diario y responsabilidad por los estudiantes ( $y$ a veces el trabajo con el alumno es terriblemente agotador y lo que se quiere es relajarse y olvidarse) y corresponden con muy poco en cuanto al tiempo necesario para la planeación, análisis constructivo, reflexión e incluso simples recompensas y tiempo para recuperarse. (Fullan \& Stiegelbauuer, 1997 p. 109). Francesc Pedró (s. f.) da idea de cuales podían ser factores que inciden en la aceptación o no de tecnólogiás a través de modelos y teorías. Según el modelo de Davis (Davis et al., 1989) un factor sería la percepción de la facilidad de uso (tener la habilidad) y un segundo factor la percepción de la utilida (beneficios), si la percepción es negativa, nunca se adoptará la propuesta tecnológica. Cabe decir que aunque parezca sorprendente, el rechazo de los alumnos a usar la tecnología en la educación (Cérisier \& Popuri, 2011; Pedró, 2012), influye en el docente para no adoptarla y sus razones son las mismas del alumno: La tecnología no aporta mejora al aprendizaje o a la calidad de la enseñanza y, por consiguiente, el sobreesfuerzo que exige no compensa. El modelo de Davis se ha aplicado con éxito para analizar las expectativas de los docentes (Teo y Noyes, 2010), singularmente de los recién incorporados, con respecto a la adopción de la tecnología en el aula. Sin embargo, es preciso recordar que el éxito de esta adopción involucra igualmente a los alumnos. Basándose en la teoría de las zonas de desarrollo próximo, la forma en que los docentes adoptan progresivamente la tecnología sugiere que solo son capaces de integrarla en aquellas perspectivas y estrategias metodológicas que dominan (Mominó, et al., 2008), es decir que cuenten con competencias. Otras teorias (Schwarz y Chin, 2007; Venkatesh et al., 2007) suponen que para que un sujeto cambie lo tradicional (no del todo) es que con el cambio consiga una mayor eficiencia, una utilidad, una innovación. Desde el punto de vista de Guerrero (Guerrero 2005), todo cambio implica una resistencia. En el 


\section{PERCEPCIÓN SOBRE EL USO DE HERRAMIENTAS TECNOLÓGICAS DIGITALES COMO APOYO EN LA DOCENCIA E INVESTIGACIÓN CASO: DOCENTES-INVESTIGADORES UAM-A, MÉXICO, ADSCRITOS A QUÍMICA}

ámbito educativo la resistencia al cambio (como conflicto) se percibe a través de los profesores, estudiantes y directivos. Desde la Teoría del Funcionalismo (Parsons, 1985) en donde la escuela tiene una función socializadora para insertar al alumno al ejercicio profesional futuro y dotarlo de valores sociales para garantizar la integración social (integración y movilidad social). Todo cambio debe dirigirse a estas metas. El docente se guía por estas metas que son principalmente valores de la sociedad industrial. Surge la problemática de la resistenci a este modelo funcionalista. La teoría de la reproducción pone el acento en como el sistema educativo perpetua la estructura de las clases sociales (Bourdieu \& Passeron, 1997), perpetúa los intereses de las clases dominantes, la dominación es casi imperceptible y por tanto la resistencia se debe intencionar para develar y solucionar el conflicto. La teoría del capital humano sienta las bases de importantes cambios en la política educativa (Bonal, 1998) al señalar que la educación puede ser considerada como una forma de capital físico que puede dar una tasa de rentabilidad determinada, por tanto existe una relación positiva entre el desarrollo económico y las tasas de escolarización en todos los niveles educativos es así que la educación es un factor fundamental para el crecimiento económico y la competitividad internacional. El individuo es un capitalista que puede invertir en su educación (compara los ingresos con la escolaridad, la meritocracia) (Bonal, 1998; Guerrero, 1996; Ibarrola, 1994; Torres, 2001). Desde el punto de vista de que la educación es factor fundamental para el crecimiento económico y la competitividad internacional. En este contexto, la dirección del cambio es clara, precisa, orientada a las necesidades del mercado y la fuerza de trabajo (Bonal, 1998; Guerrero, 2000; Ibarrola, 1994; Rodríguez 2000; Torres, 2001). La claridad de las metas y su concordancia con el sistema político y económico dejan un limitado espacio a la aparición del conflicto. Las intervenciones en las escuelas, las resistencias de los grupos deben ser trabajadas porque los logros en educación tienden a mejorar el nivel social de los estudiantes. Bajo esta perspectiva se trata de solucionar los conflictos, la resistencia (que hacen ineficiente al sistema educativo) tratando de convencer a los profesores sobre los beneficios del cambio educativo, apelando a la vocación o rol social del docente (Bonal, 1998; Guerrero, 2000 o 2005).

La teoría de la resistencia. Está inscrita en la pedagogía radical o crítica (escuela como lugar de selección de grupos de estudiantes favorecidos que adquieren poder social e individual, se mantiene el dominio de la clase hegemónica), otorga importancia a la oposición o resistencia que genera cambios educativos (McLaren, 1998). La resistencia es a las intervenciones y acciones de la cultura dominante. Según Giroux (1992) y Apple (1996), para realizar cambios en contra de la cultura dominante se debe intervenir en el currículo, en las rutinas de los estudiantes y profesores y en la forma en que se estructura el pensamiento. El cambio incorpora al profesor crítico, quien debe promover desde su propia realidad nuevos valores democráticos en favor de la justicia y la igualdad. Desde esta perspectiva, la resistencia tiene también un contenido y una orientación.

3.2 Definición de Términos Básicos. La Informática Educativa es una disciplina científico-tecnológica en desarrollo, producto de la interdisciplinariedad isomórfica que se da entre la Pedagogía y la Informática 


\section{PERCEPCIÓN SOBRE EL USO DE HERRAMIENTAS TECNOLÓGICAS DIGITALES \\ COMO APOYO EN LA DOCENCIA E INVESTIGACIÓN \\ CASO: DOCENTES-INVESTIGADORES UAM-A, MÉXICO, ADSCRITOS A QUÍMICA}

EI profesor-Investigador (docente-investigador). La labor docente ha ido profesionalizándose y ésta no queda como una rutina en el aula sino que ha evolucionado hacia un quehacer de la investigación (Sánchez, 2001) de las propias experiencias educativas (Quintero, 2010) o de las innovaciones en el campo científico-tecnológico. La investigación educativa es una actividad estrechamente vinculada con la docencia. A través del conocimiento generado por los académicos se fortalece el proceso de enseñanza-aprendizaje y se pone al alumno en contacto con problemáticas sociales contemporáneas en la educación superior. La UAM-A, a través de sus Políticas generales, operacionales y operativas de docencia (Políticas Operativas de Docencia UAM-A, 2003) define un modelo deseable de profesorinvestigador como referente del quehacer cotidiano de los académicos. La UAM-A pone especial atención a la investigación aplicada. Procura fomentar en los alumnos su vocación por la búsqueda de nuevos conocimientos (jóvenes investigadores) o por la aplicación de los ya existentes, mediante su participación en los proyectos de investigación aprobados por los órganos colegiados de la Unidad (PDI UAM-A, 2014).

Herramientas tecnológicas digitales HTD. En los últimos años se han desarrollado una gran variedad de herramientas tecnológicas digitales para la labor docente y para la labor en la investigación tanto educativa como en la científica y tecnológica (Santana, 2012). Las HTD son variadas y pueden ser equipos de punta (herramientas físicas tecnológicas 0 dispositivos digitales), programas computacionales y las TIC (recursos de multimedia). Algunos ejemplos de HTD de apoyo a la docencia y a la investigación: calculadora científica, ordenador (computadora) para aplicar ajustes estadísticos, dispositivos electrónicos, simular procesos químicos con programas computacionales para proporcionar destrezas y habilidades a los estudiantes, software, wikis, e-learning, Web 2.0, correo electrónico, celulares, equipos científico para docencia e investigación con software (Microscopios de RX, Microscopio electrónico de barrido, Espectrómetro de masas, Equipo de análisis termogravimétrico y diferencial, Equipo de Resonancia magnética nuclear, Espectrómetro de infrarrojo y luz visible, medidores digitales de $\mathrm{pH}$, medidores digitales de punto de fusión, etc.). Redes académicas y sociales, YouTube, Facebook, Plataformas (Moodle, Prezi), Bibliotecas digitales, Pizarrones inteligentes, Bases de datos, Educación a distancia y Semi presencial, Internet, Motores de búsqueda de información, Simuladores de negocios, Laboratorio virtual LabVIEW, etc.

Definición de competencias básicas ${ }^{55}$. El mismo día que el Plan de Acción de Educación Digital se adoptó una recomendación para actualizar el marco de 2006 sobre las competencias clave. La definición de las competencias digitales se ha ampliado y actualizado para reflejar la evolución de la tecnología digital en la vida laboral y en la sociedad en general. La nueva definición también está en consonancia con el Marco de Competencias Digitales para los Ciudadanos: Definición 2018. La competencia digital implica el uso seguro, crítico y responsable de las tecnologías digitales para el aprendizaje, en el trabajo y para la participación en la sociedad, así como la interacción con estas. Incluye la

\footnotetext{
${ }^{55}$ Definición de competencia digital. Disponible en: https://ec.europa.eu/education/policy/strategicframework/education-technology es
} 


\section{PERCEPCIÓN SOBRE EL USO DE HERRAMIENTAS TECNOLÓGICAS DIGITALES COMO APOYO EN LA DOCENCIA E INVESTIGACIÓN CASO: DOCENTES-INVESTIGADORES UAM-A, MÉXICO, ADSCRITOS A QUÍMICA}

alfabetización en información y datos, la comunicación y la colaboración, la creación de contenidos digitales (incluida la programación), la seguridad (incluido el bienestar digital y las competencias relacionadas con la ciberseguridad) y la resolución de problemas.

En este apartado del Marco Teórico y conceptual se anexan los conceptos del Bienestar Financiero BF y la Satisfacción con la Vida SV (variable afectiva de la Calidad de Vida CV) la correlación positiva y significativa entre el BF y la satisfacción con la vida implica que se debería observar un mayor nivel de BF en aquellos trabajadores más satisfechos con su vida, lo cual sugiere que el BF estaría actuando como variable de trasmisión con la CV (Lobos, Ortiz y Guevara, 2018). Uno de los factores determinantes del BF es el ingreso que implica que a mayor sueldo mejor CV y BF. Estos conceptos son importantes en la docencia e investigación en las Universidades, ya que los programas de becas y estímulos favorecen a la investigación y el profesor investigador dedica más tiempo a su labor como investigador descuidando la docencia y por ende el uso de HTD estará dirigido a la investigación y es ignorada esta Tecnología Digital en la docencia y principalmente en la docencia experimental en química.

3.3 Sistema de variables. De acuerdo a la pregunta de investigación y al objetivo de la misma se identifican las siguientes variables $\mathrm{Ta}$

bla $3.1^{56}$

\begin{tabular}{|l|l|l|}
\hline \multicolumn{3}{|c|}{ Tabla 3.1. Variables: dependiente y variable independiente de la investigación } \\
\hline Componentes & De la pregunta de investigación & Desglose del objetivo general \\
\hline $\begin{array}{l}\text { Variable 1 } \\
\text { Variable dependiente }\end{array}$ & $\begin{array}{l}\text { La percepción de los profesores- } \\
\text { investigadores adscritos a } \\
\text { química, de la UAM-A }\end{array}$ & $\begin{array}{l}\text { La percepción de los } \\
\text { profesores-investigadores de } \\
\text { la UAM-A adscritos a química }\end{array}$ \\
\hline $\begin{array}{l}\text { Variable 2 } \\
\text { Variable independiente }\end{array}$ & $\begin{array}{l}\text { La frecuencia, beneficios, } \\
\text { infraestructura tecnológica, y } \\
\text { políticas; de uso de HTD como } \\
\text { apoyo en la docencia teórica y } \\
\text { experimental; y en la } \\
\text { investigación; en química }\end{array}$ & $\begin{array}{l}\text { La frecuencia, beneficios, } \\
\text { infraestructura tecnológica, y } \\
\text { políticas; de uso de las HTD } \\
\text { como apoyo en la docencia } \\
\text { teórica y experimental; y en } \\
\text { la investigación; en química. }\end{array}$ \\
\hline
\end{tabular}

En la Tabla $3.2^{57}$ se muestra la operacionalización de variables. En el Anexo 1 se muestra el instrumento-cuestionario para la recolección de información, llamado Escala USOHTD

Tabla 3.2. Operacionalización de variables, instrumento de toma de datos USOHTD \begin{tabular}{|l|l|l|l|l} 
Definición conceptual & $\begin{array}{l}\text { Definición } \\
\text { Dimensiones }\end{array}$ & Indicadores & Ítems
\end{tabular}

\footnotetext{
${ }^{56}$ Tabla 1 elaborada por el Dr. Miguel Ángel Parra Álvarez. (2007). Seminario "Metodología de la Investigación II" (Fdz. Lilia) (Hoja de trabajo 5. Construcción de instrumentos de recolección de datos). CESE, Jun.-Ag. 2017

${ }^{57}$ Tabla 2 elaborada por el Dr. Miguel Ángel Parra Álvarez. (2007). Seminario "Metodología de la Investigación II” (Fdz. Lilia) (Hoja de trabajo 5. Construcción de instrumentos de recolección de datos). CESE, Jun.-Ag. 2017
} 


\section{PERCEPCIÓN SOBRE EL USO DE HERRAMIENTAS TECNOLÓGICAS DIGITALES COMO APOYO EN LA DOCENCIA E INVESTIGACIÓN CASO: DOCENTES-INVESTIGADORES UAM-A, MÉXICO, ADSCRITOS A QUÍMICA}

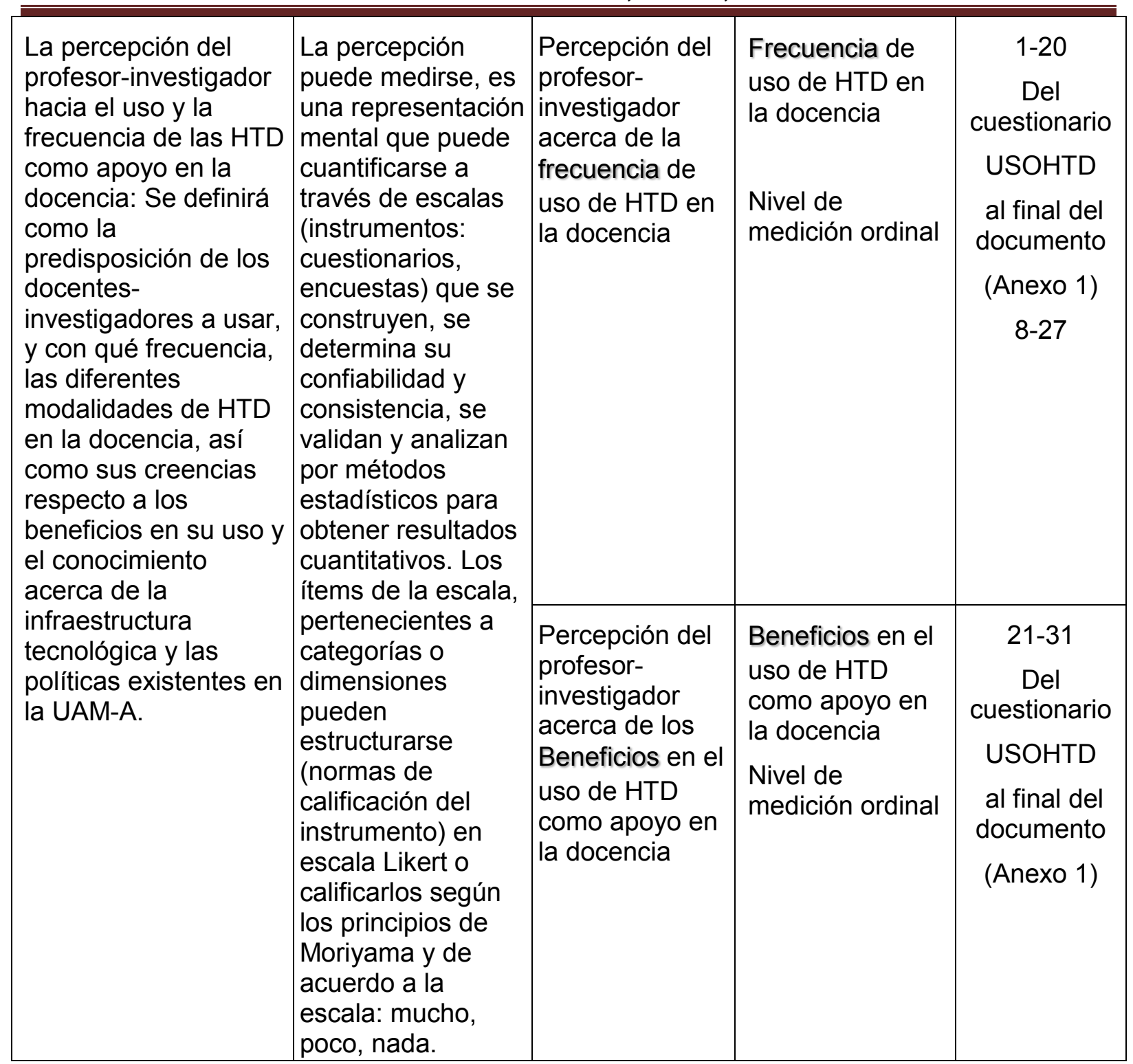




\section{PERCEPCIÓN SOBRE EL USO DE HERRAMIENTAS TECNOLÓGICAS DIGITALES COMO APOYO EN LA DOCENCIA E INVESTIGACIÓN CASO: DOCENTES-INVESTIGADORES UAM-A, MÉXICO, ADSCRITOS A QUÍMICA}

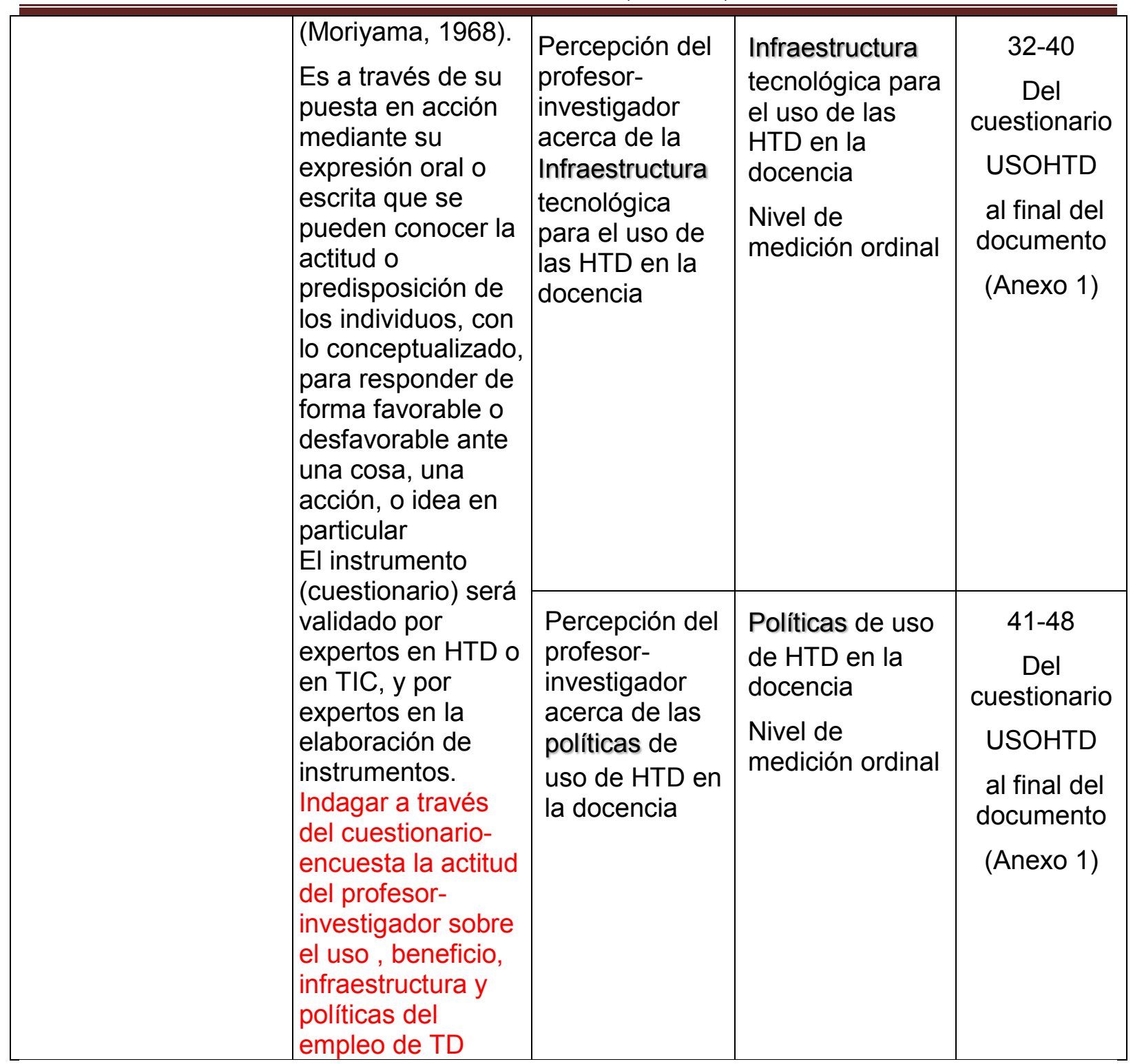

3.4 Síntesis del capítulo. Se definieron conceptos relacionados con la problemática del trabajo de tesis como son la percepción y su teoría (variable dependiente), las HTD (variable independiente), competencia digital, profesor-investigador, y la resistencia, que según los resultados de la investigación puede estar presente y que limita el uso de HTD como apoyo en la docencia y en la investigación en química. Se expusieron brevemente las teorías que conciernen con la tecnología o informática de la educación, los cambios y resistencias y los beneficios del uso de HTD en la educación:

- Teoría de e-learning

- Teoría de la capacidad cognitiva

- Teoría del aprendizaje de adultos o teoría de andragogía

- Teoría de la difusión de innovaciones 
- Teoría de la aceptación de la tecnología entre adjuntos TAAA

- Modelo de enseñanza instructivista

- Teoría del construccionismo Papertiano

- Teoría sobre la informática educativa

- Teoría o estudios con la resistencia al cambio

- Teoría de las zonas de desarrollo próximo

- Teoría del Funcionalismo

- Teoría de la reproducción

- Teoría del capital humano

- Teoría de la resistencia

La UAM-A como institución de educación superior goza de autonomía el uso de HTD no se imponen, hay libertad de cátedra y el profesor-investigador pone los límites a las innovaciones.

Por otro lado tal vez la resistencia al cambio de la clase tradicional a la mediatizada por HTD, por parte de los docentes, sea para protestar a seguir dominados por los países hegemónicos ya que las HTD se convierten en armas de dos filos para el conocimiento sostenible o como distractor de éste y que sirve a los interese hegemónicos. 


\section{PERCEPCIÓN SOBRE EL USO DE HERRAMIENTAS TECNOLÓGICAS DIGITALES \\ COMO APOYO EN LA DOCENCIA E INVESTIGACIÓN \\ CASO: DOCENTES-INVESTIGADORES UAM-A, MÉXICO, ADSCRITOS A QUÍMICA}

\section{CAPÍTULO 4: METODOLOGÍA}

Si no sabes a dónde vas entonces toma cualquier camino pues éste te llevará a alguna parte, no importa la que sea.

El gato de Alicia en el país de las maravillas

4.1 Enfoque de la investigación.

La metodología empleada fue de corte cuantitativo, con un enfoque (o nível de investigación) descriptivo sobre la utilización, concepción y creencias de los profesores-investigadores con relación a las HTD en su práctica docente (Castillo et al., 2010) y en la investigación científica. Los sujetos investigados, en un primer momento, serán los profesores de la UAM-A que imparten clases en el nivel de licenciatura, en la materia de química, y en un segundo momento los profesoresinvestigadores de las áreas de investigación en química. Para posteriormente verificar la hipótesis nula o no (diferencias significativas entre el uso de HTD en la docencia versus la investigación).

Los estudios descriptivos miden de forma independiente las variables, y aun cuando no se formulen hipótesis, las primeras aparecerán enunciadas en los objetivos de investigación (Percepción del docente hacia el uso de HTD). Por tanto hay que caracterizar y analizar el comportamiento de estas variables

$\sqrt{ }$ La percepción es una representación mental que puede medirse a través de escalas (instrumentos: cuestionarios, encuestas) que se construyen, se determina su confiabilidad y consistencia, se validan y analizan por métodos estadísticos para obtener resultados cuantitativos (Espín et al., 2001). Los ítems de la escala, pertenecientes a categorías o dimensiones pueden estructurarse (normas de calificación del instrumento) en escala Likert (Céspedes, Cortés y Madrihal, 2011) o calificarlos de acuerdo a los principios de Moriyama (1968). Escala: mucho, poco, nada; o similares respuestas. (Metodología cuantitativa).

$\checkmark$ Mi enfoque es un proceso (sistemático y empírico) cuyo propósito es generar conocimiento apegándose a las características y naturaleza de los datos a recabar, que son numéricos es decir cuantitativos (medición de la percepción).

$\checkmark$ Mi investigación es por tanto con un enfoque cuantitativo-descriptivo (práctico) aplicando una encuesta (Castillo et al., 2010; Jimenez et al., 2011; LagunesDomínguez et al., 2015).

4.2 Tipo (de estudio) de investigación.

- Cuantitativa (Lagunes-Domínguez et al., 2015)

- Descriptiva (holotipo de la investigación holística en Hurtado de Barrera, 2000 Cuadro comparativo) 


\section{PERCEPCIÓN SOBRE EL USO DE HERRAMIENTAS TECNOLÓGICAS DIGITALES \\ COMO APOYO EN LA DOCENCIA E INVESTIGACIÓN \\ CASO: DOCENTES-INVESTIGADORES UAM-A, MÉXICO, ADSCRITOS A QUÍMICA}

$\checkmark$ Mi investigación es cuantitativa-descriptiva, porque está en concordancia con mi objetivo general de la investigación "Describir y analizar a través de la medición de la percepción de los profesores-investigadores acerca del uso (frecuencia, bneficios, infraestructura y políticas) de HTD en la docencia e investigación"

$\checkmark$ Porque se centra en las variables

- Variable dependiente: percepción de los profesores-investigadores

- Variable independiente: uso de HTD

$\sqrt{ }$ Selecciona poblaciones, muestras.

- 30 Profesores-investigadores de la UAM-A adscritos a química, de tiempo completo y base, la mayoría con estudios de posgrado.

$\sqrt{ }$ Los objetivos derivan de las preguntas de investigación

$\checkmark$ El investigador no interviene axiológicamente ni éticamente en la investigación, se separa del objeto para generar conocimientos objetivos, por tanto la realidad es objetiva

$\checkmark$ Conceptos teóricos, concretos (Profesores-investigadores y uso de HTD).

$\checkmark$ Porque hace referencia al grado de profundidad (frecuencia y beneficio del uso de HTD, conocimiento de infraestructura y políticas de uso de HTD por parte del profesor-investigador de la UAM-A adscrito a química), y el tipo de resultado que se obtendrá al finalizar la investigación, que es conocer si está o no limitado el uso de HTD por los docentes y las posibles causas del uso limitado y tratando de encontrar relaciones de ésta(s) causa(s) con alguna(s) teoría(s) (pensamiento inductivo) de: la resistencia, cognitiva-constructivista-construccionista, teoría del aprendizaje de adultos o andragogía o con la carga cognitiva de los profesores sobre todo de los de edad adulta, teoría de las zonas de desarrollo próximo o potencial, teoría de la difusión de innovación de Rogers (Theory of the difusión of innovations) (Rogers, 1995 en Jacobsen, 1998), etc.; y con el análisis de datos proponer (en otra investigación) alguna estrategia para aumentar el uso de las HTD apoyándome en la teoría de la aceptación de la tecnología entre adjuntos TAAA y más. Todas estas teorías se enfocan a la educación y aprendizaje-enseñanza tanto del docente en su profesionalización como del aprendiz con la tecnología digital (Informática educativa).

4.3 Diseño de investigación. Es un procedimiento sistemático, adecuado y con lógica para responder a un problema, a una pregunta o una curiosidad (Arias, $1999^{58}$, Lankshear, 2000). Inicia con el problema, conceptos y teorías (marcos teórico y

\footnotetext{
${ }^{58}$ Arias, F. (1999). El proyecto de investigación. Guía para su elaboración. Caracas: Episteme. ORIAL EDICIONES. http://www.smo.edu.mx/colegiados/apoyos/proyecto-investigacion.pdf
} 


\section{PERCEPCIÓN SOBRE EL USO DE HERRAMIENTAS TECNOLÓGICAS DIGITALES COMO APOYO EN LA DOCENCIA E INVESTIGACIÓN CASO: DOCENTES-INVESTIGADORES UAM-A, MÉXICO, ADSCRITOS A QUÍMICA}

conceptual), tiene métodos, técnicas y herramientas de toma y análisis de datos. El resultado se dá en hallazgos y conclusiones.

Mi pregunta ¿cuál es la percepción? Es medible y objetiva por tanto corresponde a una investigación cuantitativa

Unidad de análisis, estudio de caso. Dentro del diseño metodológico se seleccionó como unidad de análisis (método) el estudio cuantitativo de caso, basado en cuestionarios-encuestas y entrevistas ya que el tipo de pregunta y objetivos lleva a esta opción de diseño (Quintero et al., s.f.).

El estudio de caso se centra específicamente en la Universidad Autónoma Metropolitana Unidad Azcapotzalco UAM-A en México. Universidad de carácter público, donde la infraestructura de las HTD depende del presupuesto de la universidad. Siguiendo la coherencia del proyecto de tesis, las preguntas de investigación y sus respectivos objetivos, se realizará el análisis de la percepción del profesor-investigador acerca del uso de HTD orientado de acuerdo a cuatro ejes de análisis tales como: frecuencia, beneficio, infraestructura tecnológica, y políticas; de uso de las HTD.

Propuesta educativa. No se diseñará o implementará una propuesta educativa como parte de la investigación.

4.4 Población y muestra. La selección de la población de informantes es una muestra no probabilística, seleccionada por conveniencia entre 42 profesoresinvestigadores de Tiempo Completo TC y plaza de base de la UAM-A del Departamento de Ciencias Básicas DCB, adscritos a química (Personal contratado UAM, 2013; Informe de actividades DCB, 2014; Siapi, 2017). La muestra es de 10 profesores-investigadores de docencia, 10 de la docencia experimental y 10 de investigación, la mayoría con estudios de posgrado que imparten clases de química y entre ellos que también realizan investigación científica en alguna de las 4 áreas de investigación. La encuesta se aplicó a 30 docentes que corresponde aproximadamente al $71 \%$ de profesores-investigadores de CB adscritos a química, de TC y base.

4.5 Técnicas e Instrumentos de Recolección de Datos. Técnica para la recolección de datos en la investigación del uso de HTD como apoyo a la docencia en química por parte de los profesores de la UAM-A Tabla $4.1^{59}$

Tabla 4.1. Técnicas e instrumentos a emplear, para adquirir información sobre el uso de HTD como apoyo en la docencia en química.

\begin{tabular}{|c|c|c|c|}
\hline \multicolumn{1}{|c|}{ Actividad } & $\begin{array}{c}\text { Fuentes de información. } \\
\text { Dónde lo encuentro }\end{array}$ & Técnica & Instrumento \\
\hline Aplicar un cuestionario- & Profesores-investigadores de & Cuestionario- & Respuestas a \\
\hline
\end{tabular}

\footnotetext{
59 Tabla 4.1 elaborada por el Dr. Miguel Ángel Parra Álvarez. (2007). Seminario "Metodología de la Investigación II" (Fdz. Lilia) (Hoja de trabajo 5. Construcción de instrumentos de recolección de datos). CESE, Jun.-Ag. 2017
} 


\section{PERCEPCIÓN SOBRE EL USO DE HERRAMIENTAS TECNOLÓGICAS DIGITALES COMO APOYO EN LA DOCENCIA E INVESTIGACIÓN CASO: DOCENTES-INVESTIGADORES UAM-A, MÉXICO, ADSCRITOS A QUÍMICA}

\begin{tabular}{|l|l|l|l|}
\hline encuesta a los profesores- & tiempo completo, la mayoría & encuesta & preguntas \\
investigadores acerca del uso & con estudios de posgrado, de & & cerradas \\
de HTD como apoyo en la & la UAM-A, adscritos a & & \\
docencia teórica en química & química y que imparten las \\
durante el trimestre 18-O & materias teóricas de química & & \\
\hline
\end{tabular}

Diseño del instrumento de toma de datos Escala USOHTD. Para el diseño ${ }^{60}$ del instrumento (cuestionario) se realizó un relevantamiento bibliográfico con relación a la enseñanza, aprendizaje, tecnologías y modelo académico (profesor-investigador), para obtener conceptos claves para la realización de las preguntas. Se establecieron cinco ejes de análisis: datos generales del profesor, frecuencia, beneficio, infraestructura tecnológica y políticas; del uso de HTD tanto en la docencia teórica y experimental como en la investigación científica.

1. Datos generales del profesor-investigador

2. Frecuencia de uso de las HTD

3. Beneficios de las HTD,

4. Infraestructura tecnológica

5. Políticas sobre el uso de las HTD

El método que se utilizó para el diseño del cuestionario es la escala de Likert, desarrollado por Rensis Likert, consiste en un conjunto de ítems presentados en forma de afirmaciones o juicios ante los cuales se pide la reacción de los participantes. Es decir, se presenta cada afirmación y se solicita al sujeto que externe su reacción eligiendo "si" o "no" o uno de los cinco puntos o categorías de la escala (Instrumento cuestionario USOHTD). A cada punto se le asigna un valor numérico (Hernández y otros, 2007:159) Tabla 4.2.

Tabla 4.2. Puntos del cuestionario USOHTD para los ítems

\begin{tabular}{|l|c|c|c|c|c|}
\hline Categoría & Nada & Poco & Regular & Aceptable & $\begin{array}{c}\text { Totalmente } \\
\text { aceptable }\end{array}$ \\
\hline $\begin{array}{l}\text { Valor numérico de la } \\
\text { categoríaa }\end{array}$ & 1 & 2 & 3 & 4 & 5 \\
\hline
\end{tabular}

En la Tabla 4.35 se resume el diseño de la metodología del presente proyecto de tesis.

Tabla 4.3. Método, técnicas y herramientas de producción de datos (Sautu, 2005; Lankshear, 2000)

\begin{tabular}{|c|c|c|c|}
\hline Metodología & Método & $\begin{array}{c}\text { Técnicas de producción } \\
\text { de datos } \\
\text { (estrategias) }\end{array}$ & $\begin{array}{c}\text { Herramienta o } \\
\text { instrumento }\end{array}$ \\
\hline
\end{tabular}

\footnotetext{
${ }^{60}$ El término de diseño se refiere al plan o la estrategia concebida para obtener la información que se desea. Hernández 2007:158.
} 


\section{PERCEPCIÓN SOBRE EL USO DE HERRAMIENTAS TECNOLÓGICAS DIGITALES COMO APOYO EN LA DOCENCIA E INVESTIGACIÓN CASO: DOCENTES-INVESTIGADORES UAM-A, MÉXICO, ADSCRITOS A QUÍMICA}

\begin{tabular}{|l|l|l|l|}
\hline \hline \multirow{5}{*}{ Cuantitativa } & $\begin{array}{l}\text { *Unidad de } \\
\text { análisis: Estudio de } \\
\text { caso basado en } \\
\text { Encuesta y análisis } \\
\text { estadístico } \\
\text { (cuantitativo) de } \\
\text { datos }\end{array}$ & *Cuestionarios-encuestas & $\begin{array}{l}\text { *Respuestas a preguntas } \\
\text { cerradas } \\
\text { *Información de } \\
\text { profesores- } \\
\text { investigadores, }\end{array}$ \\
\hline
\end{tabular}

Para el análisis de la información obtenida se utilizará el método estadístico descriptivo

De forma simple, el método genera una matriz de tamaño $\mathrm{MxN}$ que contiene como renglones $\mathrm{M}$ a los individuos representando la muestra de la población de estudio y como columnas $\mathrm{N}$ los atributos de los individuos que se quieren comparar, para identificar que tanto coinciden o se dispersan con relación a los atributos. Por la razón anterior, el cuestionario, haciendo preguntas cualitativas, debe registrar la apreciación de forma cuantitativa auxiliándonos con la escala de Likert.

Se tienen cinco atributos como tamaño de la matriz a comparar, no existiendo, por el contrario, restricción en la cantidad de individuos a comparar en la muestra. Entonces mediante manipulaciones estadísticas básicas se sacan, con base a la población, los valores característicos de la matriz MxN. Las gráficas que resulten don de fácil interpretación.

4.6 Modelo teórico. Técnicas de estadística descriptiva Mapeo perceptual. De acuerdo con Santesmases (1996), los mapas perceptuales son gráficos que representan las percepciones de un producto, una marca o una empresa en función de una serie de atributos que los caracterizan. Ries y Trout, (1986) consideran que la información obtenida en esos mapas es valiosa y fundamental para las empresas (Fonseca-García y González-Espinosa, 2008) y para la investigación cuantitativa y cualitativa 


\section{PERCEPCIÓN SOBRE EL USO DE HERRAMIENTAS TECNOLÓGICAS DIGITALES \\ COMO APOYO EN LA DOCENCIA E INVESTIGACIÓN \\ CASO: DOCENTES-INVESTIGADORES UAM-A, MÉXICO, ADSCRITOS A QUÍMICA}

\section{CAPITULO 5: RESULTADOS}

Los resultados de una investigación pueden ser los esperados o inesperados, pero de cualquier manera sorprendentes. Pero llegar a ellos puede tomarse un tiempo, muchas veces angustiante, otras lleno de optimismo lo importante es no desanimarse y seguir adelante.

Lilia Fernández Sánchez (profesora-investigadora).

\section{INTRODUCCIÓN}

En el capítulo cinco se hace un análisis de la información una vez recogido los cuestionarios cumplimentados, ya que se disponen de datos cuantitativos de preguntas cerradas a las cuales se aplican estadísticos sencillos como la media aritmética, la mediana y la moda. Para representarlos se usan gráficos y tablas llevadas a cabo a través de un tratamiento informático básico con una hoja de cálculo Excel (Guía, 2009).

Todas las respuestas reflejadas en los cuestionarios son presentadas en una matriz de categorías $(x)$ versus profesores investigadores $(y)$. El anexo 1 muestra la matriz para los profesores-investigadores en su labor de investigación en química y el cálculo de la media total por dimensión o eje de estudio, en el anexo 2 se presenta la matriz para los docentes de la teoría en química con igualmente los resultados de la media total de las dimensiones; y la matriz de los profesores de laboratorio de química en el anexo 3 con igualdad de cálculo de las anteriores, de manera que se visualiza en las gráficas 1, 2 y 3 una descripción real de la situación de frecuencia de uso, beneficios, infraestructura y políticas de las HTD, facilitando su estudio para clarificar en que ámbito (investigación 1, docencia 2 o laboratorio de docencia 3) la percepción es más positiva al uso, concepción y creencias de las HTD como apoyo (medio no fin) a la docencia e investigación.

El cuestionario contiene cinco dimensiones y preguntas o ítems por cada dimensión (para los tres ámbitos) como se muestra en el siguiente Cuadro 5.1:

Cuadro 5.1 Ejes de análisis y preguntas por cada eje

\begin{tabular}{|c|c|c|}
\hline DIMENSIÓN & ÍTEM & PREGUNTAS \\
\hline $\begin{array}{l}\text { Datos generales del } \\
\text { profesor }\end{array}$ & $1-6$ & $\begin{array}{l}\text { 1. Año que ingresó a la UAM-A: } \\
\text { 2. Licenciatura: } \\
\text { 3. Grado académico: } \\
\text { 4. UEA de química que imparte (solo una): } \\
\text { 5. Edad: } \\
\text { 6. Género: }\end{array}$ \\
\hline Frecuencia de uso HTD & $7-14$ & $\begin{array}{l}\text { 7. Usa HTD en su práctica docente } \\
\text { 8. Qué tanto utiliza las siguientes HTD.... } \\
\text { 9. Si su aula cuenta con medios tecnológicos } \\
\text { ¿Desarrolla sus clases utilizándolos? } \\
\text { 10. La UAM-A ofrece cursos para que los profesores } \\
\text { aprendan a usar las HTD }\end{array}$ \\
\hline
\end{tabular}




\section{PERCEPCIÓN SOBRE EL USO DE HERRAMIENTAS TECNOLÓGICAS DIGITALES COMO APOYO EN LA DOCENCIA E INVESTIGACIÓN CASO: DOCENTES-INVESTIGADORES UAM-A, MÉXICO, ADSCRITOS A QUÍMICA}

\begin{tabular}{|c|c|c|}
\hline & & $\begin{array}{l}\text { 11. Asiste a talleres y cursos de manera virtual para } \\
\text { actualizarse } \\
\text { 12. Usar HTD requiere invertir más tiempo en la } \\
\text { preparación de clases } \\
\text { 13. Usar HTD, como redes sociales y plataformas } \\
\text { implica más dedicación del docente para revisar } \\
\text { el trabajo del alumno } \\
\text { 14 Usar HTD implican un gasto extra } \\
\text { Para contestar las preguntas de este eje se } \\
\text { estableció cinco opciones de respuesta: a) nada, b) } \\
\text { poco, c) regular d) aceptable y, e) Mucho. }\end{array}$ \\
\hline Beneficios & $15-16$ & $\begin{array}{l}\text { 15. Usar HTD trae beneficios a la enseñanza } \\
\text { 16. Las HTD propias o de la UAM-A han contribuido } \\
\text { a mejorar la impartición de sus clases } \\
\text { Para contestar las preguntas de este eje se } \\
\text { estableció cinco opciones de respuesta: a) muy } \\
\text { desacuerdo, b) en desacuerdo, c) ni de acuerdo ni } \\
\text { en desacuerdo, d) de acuerdo y, e) muy de acuerdo. }\end{array}$ \\
\hline Infraestructura tecnológica & $17-25$ & $\begin{array}{l}\text { 17. ¿Cuenta con computadora en su casa? } \\
\text { 18. ¿Cuenta con internet en su casa? } \\
\text { 19. ¿Cuenta con computadora de uso personal en su } \\
\text { cubículo? } \\
\text { 20. ¿Cuenta con internet en su cubículo? } \\
\text { 21. Es conveniente invertir en infraestructura } \\
\text { tecnológica } \\
\text { 22. Es importante contar con una computadora en su } \\
\text { cubículo } \\
\text { 23. El aula tiene las condiciones tecnológicas } \\
\text { digitales para una clase } \\
\text { 24. La institución le brinda el apoyo para utilizar las } \\
\text { tecnologías HTD } \\
\text { 25. La infraestructura tecnológica es suficiente para } \\
\text { los profesores de tiempo completo } \\
\text { Para contestar las preguntas de este eje se } \\
\text { estableció cinco opciones de respuesta: a) nada, b) } \\
\text { poco, c) regular d) aceptable y, e) Mucho. }\end{array}$ \\
\hline Percepción de políticas & $26-31$ & $\begin{array}{l}\text { 26. Es importante el uso de las tecnologías o HTD en } \\
\text { la enseñanza y el aprendizaje } \\
\text { 27. La tecnología genera cambios en el modo de } \\
\text { enseñanza } \\
\text { 28. Poseo los conocimientos necesarios para utilizar } \\
\text { las HTD en mi práctica docente. } \\
\text { 29. Es importante invertir en capacitación de las HTD } \\
\text { orientada a los recursos humanos } \\
\text { 30. Existe difusión en el uso de HTD en la } \\
\text { enseñanza y aprendizaje }\end{array}$ \\
\hline
\end{tabular}




\section{PERCEPCIÓN SOBRE EL USO DE HERRAMIENTAS TECNOLÓGICAS DIGITALES COMO APOYO EN LA DOCENCIA E INVESTIGACIÓN CASO: DOCENTES-INVESTIGADORES UAM-A, MÉXICO, ADSCRITOS A QUÍMICA}

31. Se cuenta con personal capacitado en el uso de las HTD y que apoya al profesorado

Para contestar las preguntas de este eje se estableció cinco opciones de respuesta: a) nada, b) poco, c) regular d) aceptable y, e) Mucho.

Fuente: elaboración propia.

Para el análisis de cada eje se realizó un promedio de todas las respuestas, obteniendo un solo valor de cada eje. A continuación se presentan unas Tablas con los datos de los promedios

\subsection{Análisis de los datos cuantitativos.}

Puntuaciones directas. El resultado de frecuencias de respuestas iguales de los profesores-investigadores (puntuación media) por categoría numérica y dimensión de cada ámbito de estudio se presentan en las siguientes Tablas 5.1, 5.2 y 5.3. Donde se muestran: las equivalencias de categoría o escala numérica y la escala ordinal (aplicando la escala de Likert), las frecuencias de respuestas por profesor en los cuatro ejes de análisis, la media, mediana y moda; de los tres ámbitos de estudio (investigación, docencia y materia experimental de química).

Tabla 5.1. Ámbito de Investigación en química, 10 docentes que coinciden en sus respuestas sobre la utilización, creencias y concepción de las HTD.

\begin{tabular}{|c|c|c|c|c|c|}
\hline \multicolumn{2}{|c|}{ Categoría } & \multicolumn{4}{|c|}{ Dimensión o Eje de análisis } \\
\hline Numérica & Ordinal & Fr. de uso & Beneficios & Infraestructura & Políticas \\
\hline 1 & $\begin{array}{l}\text { Nada/Muy en } \\
\text { desacuerdo }\end{array}$ & 0 & 0 & 0 & 0 \\
\hline 2 & $\begin{array}{l}\text { Poco/En } \\
\text { desacuerdo }\end{array}$ & 0 & 0 & 0 & 0 \\
\hline 3 & $\begin{array}{l}\text { Regula/Ni de } \\
\text { acuerdo ni en } \\
\text { desacuerdo }\end{array}$ & 5 & 0 & 0 & 0 \\
\hline 4 & $\begin{array}{l}\text { Aceptable/De } \\
\text { acuerdo }\end{array}$ & 5 & 3 & 0 & 5 \\
\hline 5 & $\begin{array}{l}\text { Totalmente/Muy } \\
\text { de acuerdo }\end{array}$ & 0 & 7 & 10 & 5 \\
\hline \multicolumn{2}{|r|}{ Media } & 3.5 & 4.6 & 4.8 & 4.4 \\
\hline \multirow{2}{*}{\multicolumn{2}{|c|}{$\begin{array}{r}\text { Mediana } \\
\text { Moda }\end{array}$}} & 3.5 & 5 & 5 & 4.5 \\
\hline & & - & 5 & 5 & - \\
\hline
\end{tabular}

Fuente: elaboración propia 


\section{PERCEPCIÓN SOBRE EL USO DE HERRAMIENTAS TECNOLÓGICAS DIGITALES COMO APOYO EN LA DOCENCIA E INVESTIGACIÓN CASO: DOCENTES-INVESTIGADORES UAM-A, MÉXICO, ADSCRITOS A QUÍMICA}

Tabla 5.2. Ámbito de Docencia teórica en química, 10 docentes que coinciden en sus respuestas sobre la utilización, creencias y concepción de las HTD.

\begin{tabular}{|c|c|c|c|c|c|}
\hline \multicolumn{2}{|c|}{ Categoría } & \multicolumn{4}{|c|}{ Dimensión o Eje de análisis } \\
\hline Numérica & Ordinal & Fr. de uso & Beneficios & Infraestructura & Políticas \\
\hline 1 & $\begin{array}{l}\text { Nada/Muy en } \\
\text { desacuerdo }\end{array}$ & 0 & 0 & 0 & 0 \\
\hline 2 & $\begin{array}{l}\text { Poco/En } \\
\text { desacuerdo }\end{array}$ & 1 & 0 & 0 & 1 \\
\hline 3 & $\begin{array}{l}\text { Regula/Ni de } \\
\text { acuerdo ni en } \\
\text { desacuerdo }\end{array}$ & 7 & 3 & 0 & 1 \\
\hline 4 & $\begin{array}{l}\text { Aceptable/De } \\
\text { acuerdo }\end{array}$ & 2 & 3 & 7 & 6 \\
\hline 5 & $\begin{array}{l}\text { Totalmente/Muy } \\
\text { de acuerdo }\end{array}$ & 0 & 4 & 2 & 2 \\
\hline \multirow{3}{*}{\multicolumn{2}{|c|}{$\begin{array}{r}\text { Media } \\
\text { Mediana } \\
\text { Moda }\end{array}$}} & 3.1 & 3.8 & 4.1 & 3.7 \\
\hline & & 3 & 4 & 4 & 4 \\
\hline & & 3 & 5 & 4 & 4 \\
\hline
\end{tabular}

Fuente: elaboración propia.

Tabla 5.3. Ámbito de Docencia experimental en química, 10 docentes que coinciden en sus respuestas sobre la utilización, creencias y concepción de las HTD.

\begin{tabular}{|c|l|c|c|c|c|}
\hline \multicolumn{2}{|c|}{ Categoría } & \multicolumn{4}{c|}{ Dimensión o Eje de análisis } \\
\hline Numérica & Ordinal & Fr. de uso & Beneficios & Infraestructura & Políticas \\
\hline 1 & $\begin{array}{l}\text { Nada/Muy en } \\
\text { desacuerdo }\end{array}$ & 2 & 0 & 0 & 0 \\
\hline 2 & $\begin{array}{l}\text { Poco/En } \\
\text { desacuerdo }\end{array}$ & 3 & 0 & 1 & 1 \\
\hline 3 & $\begin{array}{l}\text { Regula/Ni de } \\
\text { acuerdo ni en } \\
\text { desacuerdo }\end{array}$ & 3 & 5 & 1 & 6 \\
\hline 4 & $\begin{array}{l}\text { Aceptable/De } \\
\text { acuerdo }\end{array}$ & 2 & 3 & 7 & 1 \\
\hline 5 & Totalmente/Muy & 0 & 2 & 1 & 2 \\
\hline
\end{tabular}




\section{PERCEPCIÓN SOBRE EL USO DE HERRAMIENTAS TECNOLÓGICAS DIGITALES \\ COMO APOYO EN LA DOCENCIA E INVESTIGACIÓN \\ CASO: DOCENTES-INVESTIGADORES UAM-A, MÉXICO, ADSCRITOS A QUÍMICA}

\begin{tabular}{|r|c|c|c|c|}
\hline \hline Media & & & & \\
\hline Mediana & 2.4 & 3.4 & 3.8 & 3.4 \\
\cline { 3 - 6 } Moda & 2.5 & 3.5 & 4 & 3 \\
\cline { 2 - 6 } & - & 3 & 4 & 3 \\
\hline
\end{tabular}

Fuente: elaboración propia

Porcentajes de respuestas. Las Gráficas resultantes 5.1, 5.2 y 5.3 son una matriz que tiene como filas el número de profesores y como columnas la dimensión mostrando la frecuencia de respuesta en porcentaje. El análisis de las gráficas permite obtener conclusiones gráficamente sobre los profesores en la investigación, en la docencia y en el laboratorio de química sobre su percepción sobre las HTD en su frecuencia de uso, beneficios, infraestructura tecnológica y políticas.

\section{PROFESORES \\ DE INVESTIGACIÓN}

10

9

8

7

6

5

4

3

2

1

0

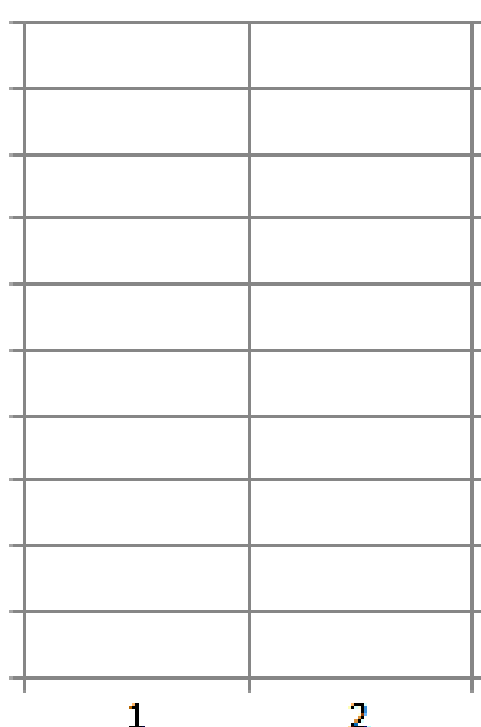

1

$\mathrm{Nada} /$ mus en

desacuerdo

Poco/en

desacuerdo

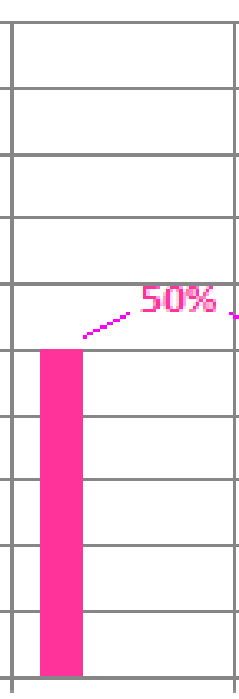

3

Regular/nide acuerdo ni en desacuerdo

$100 \%$

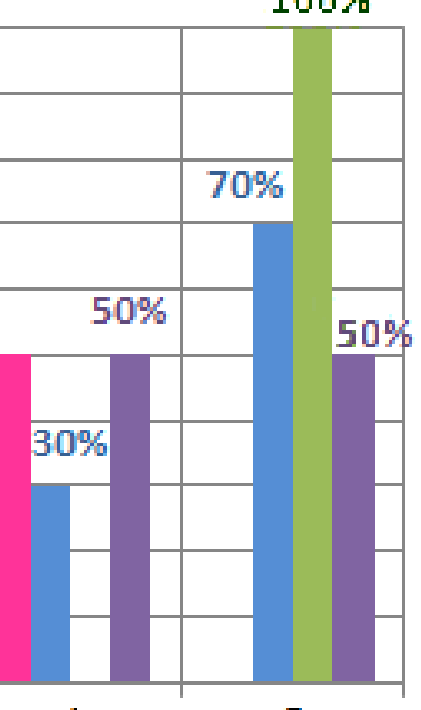

4

5
Dimensión

Fr. de uso

Beneficios

Infraestructura

Políticas

CATEGORIAS

Grafica 5.1. Resultad os porcentuales de los docentes en su percepción del uso de HTD en su labor de investigación

Fuente: Cuadro elaborado con datos obten idos de las respuestas del cuestionario USOHTD 


\section{PERCEPCIÓN SOBRE EL USO DE HERRAMIENTAS TECNOLÓGICAS DIGITALES COMO APOYO EN LA DOCENCIA E INVESTIGACIÓN CASO: DOCENTES-INVESTIGADORES UAM-A, MÉXICO, ADSCRITOS A QUÍMICA}

PROFESORES

DE QUÍl|rICA

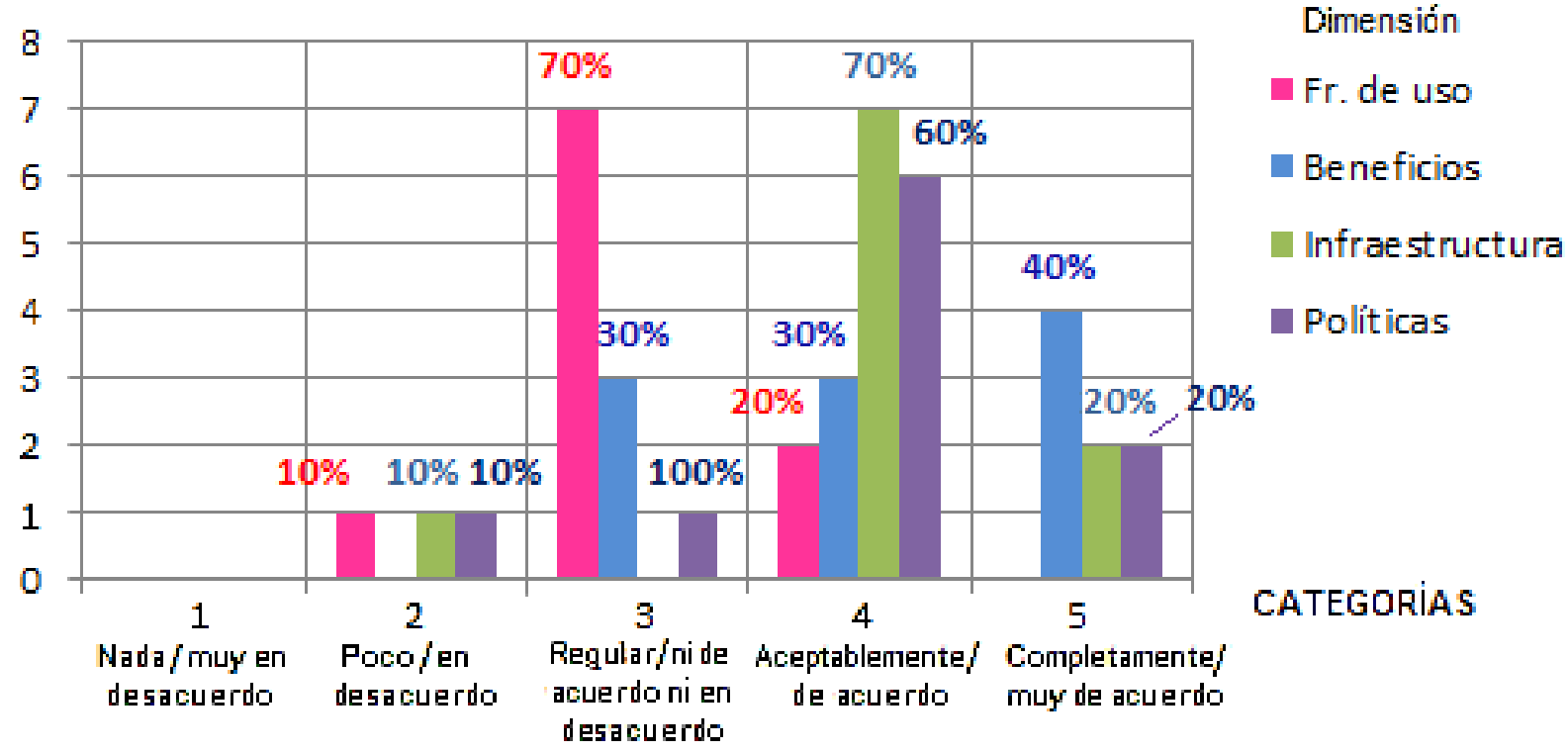

Grafica 5.2. Resultados porcentuales de los docentes en su percepción del uso de HTD en su labor de docencia teórica en química

Fuente: Cuadro elaborado con datos obten idos de las respuestas del cuestionario USO HTD

PROFESORES

DE QUIITIICA EXPERIHENTAL

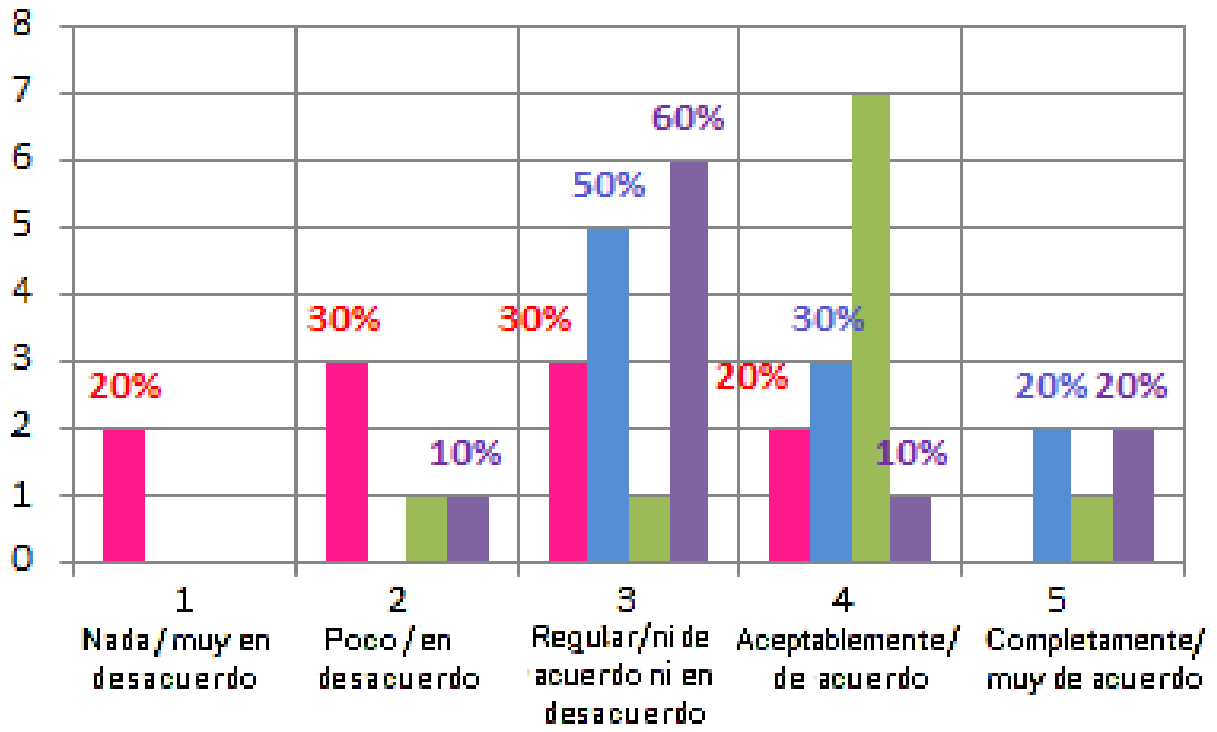

Dimensión

Fr. de uso

Beneficios

Infraestructura

Políticas

Grafica 5.3. Resultados porcentuales de los docentes en su percepción del uso de HTD en su labor de docencia experimental en química

Fuente: Cuadro elaborado con datos obten idos de las respuestas del cuestionario uso HTD

Análisis de los gráficos. A simple vista de los Gráficos se observa que: 


\section{PERCEPCIÓN SOBRE EL USO DE HERRAMIENTAS TECNOLÓGICAS DIGITALES COMO APOYO EN LA DOCENCIA E INVESTIGACIÓN CASO: DOCENTES-INVESTIGADORES UAM-A, MÉXICO, ADSCRITOS A QUÍMICA}

- El ámbito de la Investigación no presenta profesores-investigadores en las categorías 1 y 2 es decir, ellos no están en desacuerdo en usar HTD en su labor científica de investigación. Un $50 \%$ está de acuerdo en usarlas, no obstante que el $100 \%$ están completamente de acuerdo que hay infraestructura, el $70 \%$ está completamente de acuerdo que usar HTD trae beneficios y un $50 \%$ está completamente de acuerdo de que hay políticas.

- En el ámbito de la docencia teórica en química a simple vista se observa que no hay profesores en la categoría 1 de no usar HTD, aunque si hay un $10 \%$ de profesores que caen en la categoría 2 es decir que las usan poco, la mayor frecuencia de uso cae en la categoría 3 , es decir que un $70 \%$ las usan regular (ni mucho ni poco) no obstante que el $40 \%$ de profesores están completamente de acuerdo en que usar HTD trae beneficios, el $70 \%$ están de acuerdo que hay infraestructura y un $60 \%$ están de acuerdo en que hay políticas.

- En el ámbito de la docencia experimental en química se observa que existen profesores en la categoría 1 y 2 es decir $20 \%$ de los profesores no las usan en el laboratorio de química, $30 \%$ las usan poco, el $30 \%$ las usa regular (ni mucho ni poco) solo el $20 \%$ está de acuerdo en usarlas las siguientes observaciones pueden verse mejor en la Gráfica 5.4 .

Media aritmética. La siguiente Tabla 5.4 compara los resultados de las medias aritméticas obtenidas para cada ámbito en las cuatro dimensiones estudiadas acerca de la percepción sobre la utilización, concepción y creencias de los profesores con relación a las HTD en su práctica docente y de investigación

Tabla 5.4. Medias aritméticas obtenidas de los datos del cuestionario USOHTD en los ámbitos de Investigación y Docencia en Química

\begin{tabular}{|l|c|c|c|c|}
\hline Ámbitos de Química & Fr. de uso & Beneficios & Infraestructura & Políticas \\
\hline Investigación & 3.5 & 4.6 & 4.8 & 4.4 \\
\hline Docencia & 3.1 & 3.8 & 4.1 & 3.7 \\
\hline Docencia Experimental & 2.4 & 3.4 & 3.8 & 3.4 \\
\hline
\end{tabular}

Fuente: elaboración propia

El Grafico 5.4 resultante de la representación de los datos de la tabla 5.4 que tiene como marcadores o etiquetas las medias aritméticas por dimensión o eje de análisis: Frecuencia de uso de HTD, Beneficios al usar HTD, Infraestructura tecnológica y Políticas muestra que en todos los ámbitos (Investigación, docencia y laboratorio de química) la infraestructura, las políticas y los beneficios están por encima del uso de las HTD. Lo que confirma que por alguna razón en la docencia (medias de 3.1 y 2.4 ) los profesores no tienen las habilidades y conocimientos para hacer uso de las TIC en sus actividades de enseñanza. 


\section{PERCEPCIÓN SOBRE EL USO DE HERRAMIENTAS TECNOLÓGICAS DIGITALES COMO APOYO EN LA DOCENCIA E INVESTIGACIÓN CASO: DOCENTES-INVESTIGADORES UAM-A, MÉXICO, ADSCRITOS A QUÍMICA}

Gráfica 5.4. Medias aritméticas por Dimensión en los ámbitos de Investigación, Docencia y Docencia experimental

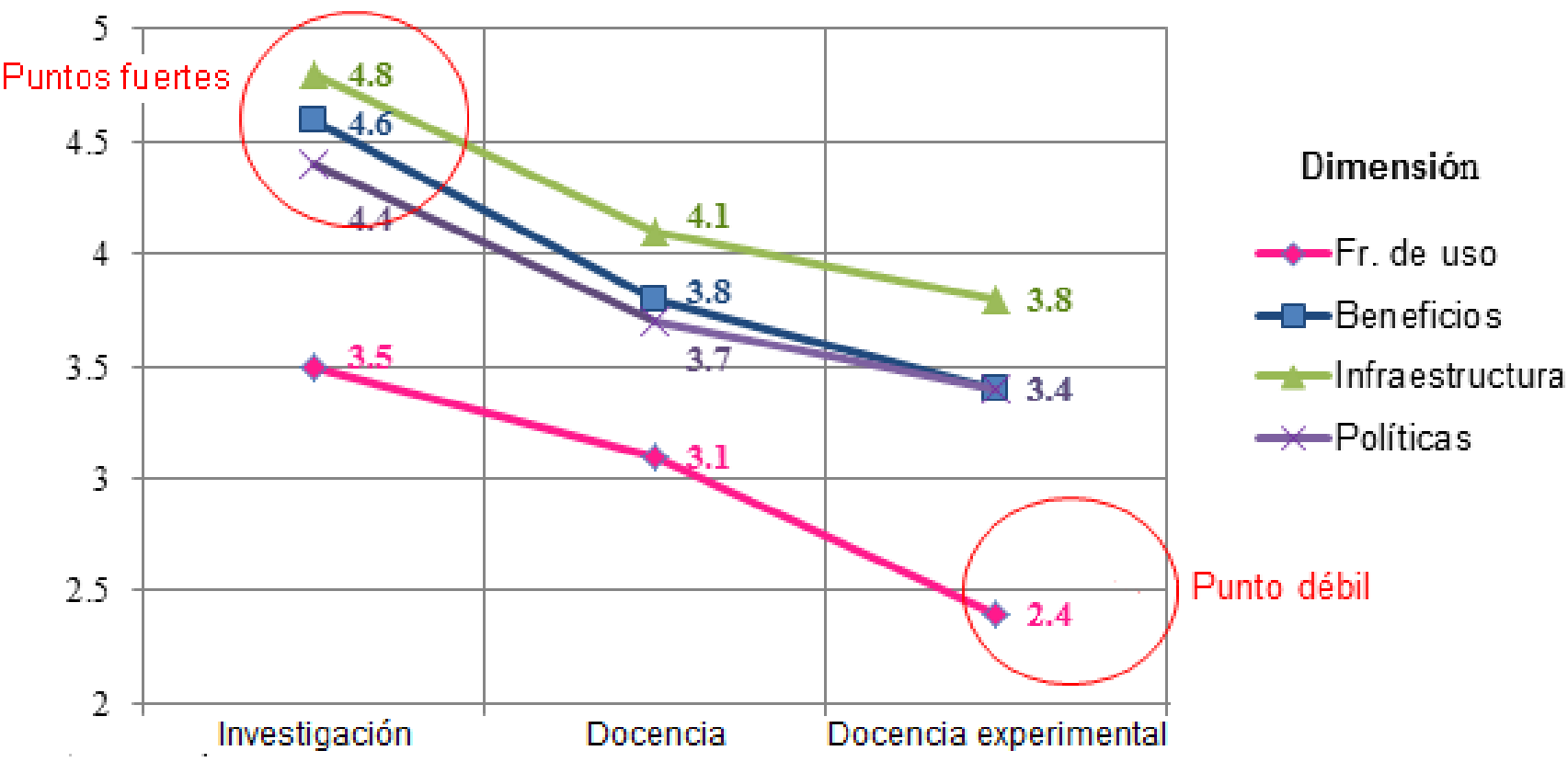

Fuente: elaboración propia

El Gráfico 5.5 tiene como etiquetas las medias aritméticas por Ámbito. Otra vez se observa que el docente en su labor de investigación tiene una actitud más positiva a usar HTD que el docente en el ámbito de la Docencia teórica y una actitud negativa en el Ámbito de la Docencia experimental de química. Todos presentan conocimiento de beneficios al usar HTD, cuentan con infraestructura y saben de políticas.

Gráfica 5.5. Medias aritméticas por Ảmbito en las dimensiones; Fr. de uso, Beneficios, Infraestructura tecnologica y Políticas sobre las HTD

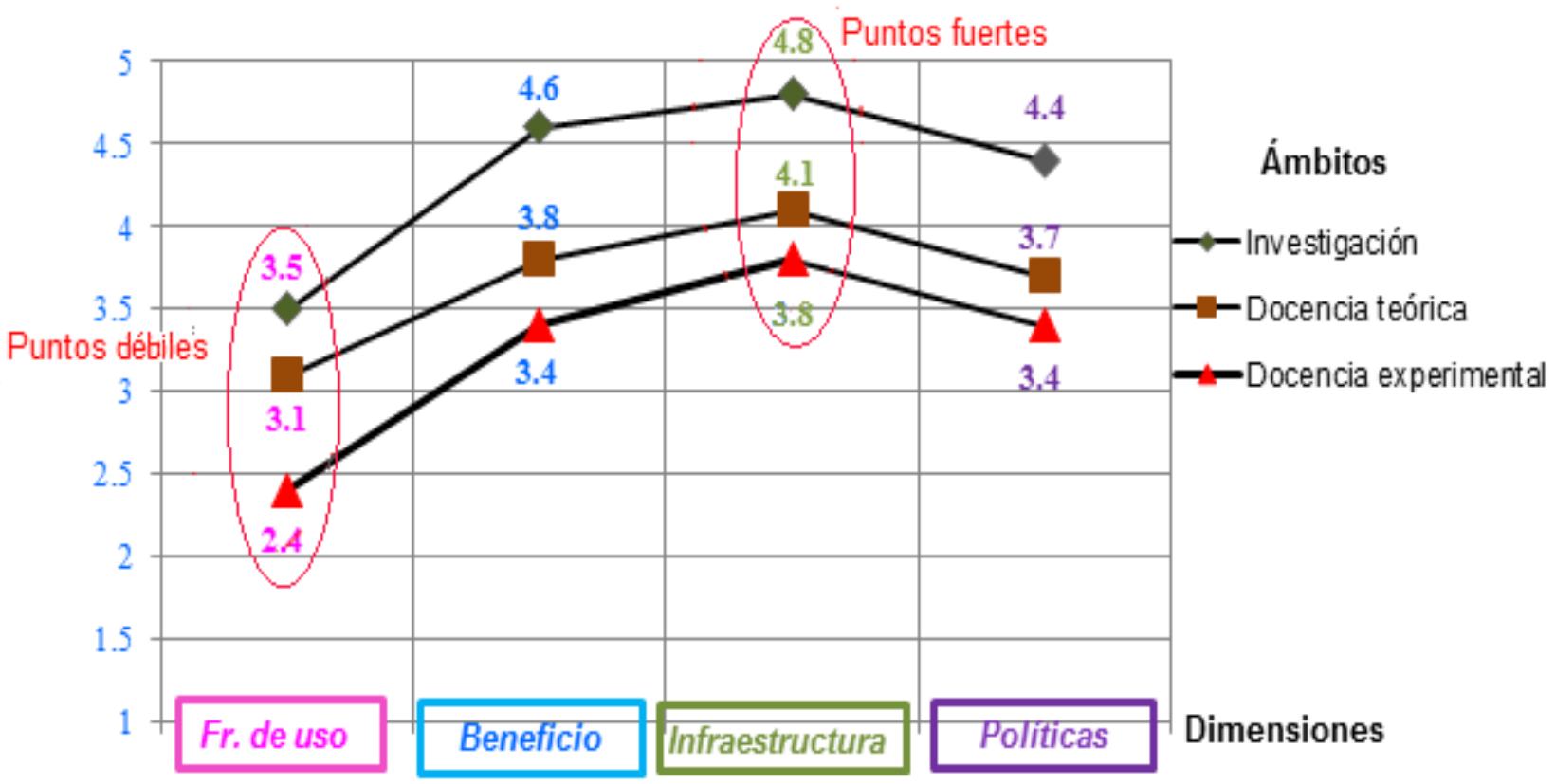

https://doi.org/10.24275/uama.355.6999 


\section{PERCEPCIÓN SOBRE EL USO DE HERRAMIENTAS TECNOLÓGICAS DIGITALES COMO APOYO EN LA DOCENCIA E INVESTIGACIÓN CASO: DOCENTES-INVESTIGADORES UAM-A, MÉXICO, ADSCRITOS A QUÍMICA}

Las Gráficas 5.4 y 5.5 nos muestran los puntos fuertes y débiles de la percepción del profesor-investigador de la UAM-A en el Uso, Beneficios, Infraestructura y Políticas en el área de química:

- Puntos Fuertes: Hay linfraestructura en la UAM-A, se sabe que hay Beneficios y Políticas en los tres ámbitos.

- Puntos débiles: Hay menos Infraestructura en los laboratorios de docencia en química (media = 3.8) y un Uso deficiente de HTD (media = 2.4)

Por tanto la Dimensión que debe ser atendida para lograr mejoras, es el uso de HTD es la Docencia experimental (los laboratorios de química).

El ámbito que mejores medias o actitudes positivas presenta en las cuatro dimensiones es el Ámbito de la Investigación.

Fundamentación de una teoría que explica los resultados. Con base en los hallazgos se propone una teoría para explicarlos (Grounded Theory) y es la del Bienestar financiero es decir los profesores-investigadores que se dedican a la Investigación ven en esta actividad docente un mejor ingreso económico ${ }^{61}$, una mejor calidad de vida y un poco (o mucho) de felicidad. Además de ser reconocidos como investigadores y no solo como un docente, es decir adquieren prestigio. La investigación es mejor valorada en las Dictaminadoras de Áreas que otorgan becas y estímulos económicos; y es calificada con menor puntaje las actividades solo de la docencia (cursos impartidos, profesionalización docente, servicio social, miembro de grupo temático, etc.) ver Tabla 5.5.

Tabla 5.5. Puntaje otorgado por las Comisiones Dictaminadoras a los productos de trabajo del profesor-investigador de la UAM-A

\begin{tabular}{|l|l|l|}
\hline \multicolumn{1}{|c|}{ FACTOR } & \multicolumn{1}{|c|}{ PRODUCTO DE TRABAJO } & PUNTAJE \\
\hline Investigación & Artículo de Investigación en revista internacional & 3300 \\
\hline Investigación & Artículo de investigación educativa en revista nacional & 330 a 850 \\
\hline Docencia & Curso & 330 \\
\hline Docencia & Miembro de Grupo Temático & 330 \\
\hline Docencia & Servicio social & $20-220$ \\
\hline Docencia & Proyecto terminal (tesis) & 220 \\
\hline Docencia & Manual & 220 \\
\hline Docencia & Notas de curso & 220 \\
\hline Docencia & Libro de texto & 2200 \\
\hline Docencia & Desarrollo de paquetes computacionales & 660 \\
\hline Profesionalización & Curso de actualización docente & 4 puntos/h \\
\hline
\end{tabular}

Fuente: Tabulador para Ingreso y Promoción del Personal Académico TIPPA. UAM

${ }^{61}$ Los salarios del investigador son superiores a los de los docentes que no realizan investigación. 


\section{PERCEPCIÓN SOBRE EL USO DE HERRAMIENTAS TECNOLÓGICAS DIGITALES \\ COMO APOYO EN LA DOCENCIA E INVESTIGACIÓN \\ CASO: DOCENTES-INVESTIGADORES UAM-A, MÉXICO, ADSCRITOS A QUÍMICA}

Por otro lado la UAMA apoya la investigación científica porque este indicador da prestigio a la institución a nivel nacional e internacional en la Sociedad del Conocimiento (Ruíz, R. y Martínez, R:M., 2007).

Recomendaciones. Mejorar la valoración de las Comisiones Dictaminadoras de Área a los productos de trabajo de la docencia. Considerar que la organización de la docencia sea acompañada, para su mejor cumplimiento, de una revisión de la estructura de gestión académica administrativa (Políticas Operativas de la Docencia, 2017).

La problemática de la docencia requiere que la Universidad procure revisar y actualizar la estructura de gestión académica administrativa, para poder apoyar la actuación de las Dictaminadoras de becas, estímulos y promoción. Es necesario y conveniente otorgar estímulos económicos mejores a los profesores por buen desempeño en su labor docente.

Futuras investigaciones. Se realizarán estudios que relacionen la edad del profesor, el género, el tipo de posgrado (en educación o en ciencias) con su percepción hacia el uso de HTD como herramienta de apoyo en el proceso de enseñanza. 


\section{PERCEPCIÓN SOBRE EL USO DE HERRAMIENTAS TECNOLÓGICAS DIGITALES \\ COMO APOYO EN LA DOCENCIA E INVESTIGACIÓN \\ CASO: DOCENTES-INVESTIGADORES UAM-A, MÉXICO, ADSCRITOS A QUÍMICA}

\section{CONCLUSIONES Y OBSERVACIONES}

1. Se Analizó en la percepción de los profesores-investigadores de la UAM-A adscrito a química, acerca del uso de las HTD como apoyo en la Docencia teórica en química, a través de un cuestionario-encuesta USOHTD(D) obteniéndose la siguiente información Cuadro 1:

Cuadro 1. Resultados del Cuestionario-Encuesta USOHTD(D) para el Ámbito de la Docencia teórica en química.

\begin{tabular}{|c|c|c|c|}
\hline DIMENSIÓN & $\begin{array}{c}\text { MEDIA } \\
\text { ARITMÉTICA } \\
\text { DE LAS } \\
\text { CATEGORÍAS 1-5 }\end{array}$ & CRITERIO & RECOMENDACIONES \\
\hline Fr. de uso & 3.1 & $\begin{array}{l}\text { Actitud ligeramente positiva } \\
\text { al uso de HTD en el proceso } \\
\text { de enseñanza }\end{array}$ & $\begin{array}{l}\sqrt{ } \text { Reconocimiento a la } \\
\text { labor Docente con } \\
\text { mejores estímulos } \\
\text { económicos. } \\
\sqrt{ } \text { Acompañamiento del } \\
\text { docente por pares y/o } \\
\text { estaff } \\
\text { el preparados en } \\
\text { mantenimiento de la } \\
\text { Tecnología Digital en } \\
\text { el proceso de } \\
\text { enseñanza } \\
\sqrt{ } \text { Reconocimiento ante } \\
\text { las Dictaminadoras de } \\
\text { Becas y Estímulos, el } \\
\text { proceso de } \\
\text { Profesionalización } \\
\text { Docente } \\
\sqrt{ } \text { Divulgación } \\
\text { adecuada de las } \\
\text { políticas de } \\
\text { alfabetización docente } \\
\text { en las HTD. }\end{array}$ \\
\hline Beneficios & 3.8 & $\begin{array}{l}\text { Actitud ligeramente positiva } \\
\text { al conocimiento de los } \\
\text { beneficios que tiene el usar } \\
\text { HTD en el proceso de la } \\
\text { enseñanza en química }\end{array}$ & $\begin{array}{l}\sqrt{ } \text { Divulgación } \\
\text { adecuada de las } \\
\text { políticas de } \\
\text { alfabetización docente } \\
\text { en la pedagogía con el }\end{array}$ \\
\hline
\end{tabular}

${ }^{62}$ Staff. Palabra muy usada en el castellano, no reconocida por la Real Academia Española. Grupo de trabajadores de una determinada área. 


\section{PERCEPCIÓN SOBRE EL USO DE HERRAMIENTAS TECNOLÓGICAS DIGITALES COMO APOYO EN LA DOCENCIA E INVESTIGACIÓN CASO: DOCENTES-INVESTIGADORES UAM-A, MÉXICO, ADSCRITOS A QUÍMICA}

\begin{tabular}{|c|c|c|c|}
\hline & & & uso de HTD. \\
\hline $\begin{array}{l}\text { Infraestructura } \\
\text { tecnológica }\end{array}$ & 4.1 & $\begin{array}{l}\text { Percepción positiva a la } \\
\text { existencia de Infraestructura } \\
\text { tecnológica propia o de la } \\
\text { UAM-A }\end{array}$ & $\begin{array}{l}\sqrt{ } \text { Desarrollar } \\
\text { estrategias } \\
\text { institucionales para } \\
\text { motivar al docente de } \\
\text { la teoría química a } \\
\text { emplear las HTD } \\
\text { propias o de la UAM-A } \\
\text { en el proceso de } \\
\text { enseñanza }\end{array}$ \\
\hline Políticas & 3.7 & $\begin{array}{l}\text { Actitud ligeramente positiva } \\
\text { del conocimiento de las } \\
\text { políticas institucionales, } \\
\text { nacionales y globales sobre } \\
\text { el uso de las HTD }\end{array}$ & $\begin{array}{l}\sqrt{ } \text { Desarrollar } \\
\text { estrategias } \\
\text { institucionales para } \\
\text { alfabetizar al docente } \\
\text { de la teoría en el } \\
\text { conocimiento de las } \\
\text { políticas propias, } \\
\text { nacionales e } \\
\text { internacionales sobre } \\
\text { el uso de las HTD en } \\
\text { favor de la calidad de } \\
\text { la Docencia }\end{array}$ \\
\hline
\end{tabular}

Cuadro 2. Resultados del Cuestionario-Encuesta USOHTD(E) para el Ámbito de la Docencia experimental en química.

\begin{tabular}{|c|c|c|c|}
\hline DIMENSIÓN & $\begin{array}{c}\text { MEDIA } \\
\text { ARITMÉTICA } \\
\text { DE LAS } \\
\text { CATEGORÍAS } \\
1-5\end{array}$ & CRITERIO & RECOMENDACIONES \\
\hline Fr. de uso & 2.4 & $\begin{array}{l}\text { Actitud negativa } \\
\text { al uso de HTD en } \\
\text { el proceso de la } \\
\text { Enseñanza } \\
\text { experimental en } \\
\text { química }\end{array}$ & $\begin{array}{l}\sqrt{ } \text { Reconocimiento a la } \\
\text { labor Docente con } \\
\text { mejores estímulos } \\
\text { económicos. } \\
\sqrt{ } \text { Acompañamiento del } \\
\text { docente por pares, } \\
\text { ayudantes de química } \\
\text { y/o estaff preparados } \\
\text { en el uso, aplicación y } \\
\text { mantenimiento de la } \\
\text { Tecnología Digital en } \\
\text { el proceso de } \\
\text { Enseñanza }\end{array}$ \\
\hline
\end{tabular}




\section{PERCEPCIÓN SOBRE EL USO DE HERRAMIENTAS TECNOLÓGICAS DIGITALES COMO APOYO EN LA DOCENCIA E INVESTIGACIÓN CASO: DOCENTES-INVESTIGADORES UAM-A, MÉXICO, ADSCRITOS A QUÍMICA}

\begin{tabular}{|c|c|c|c|}
\hline & & & $\begin{array}{l}\text { experimental (Teoría } \\
\text { del Acompañamiento } \\
\text { de Adjuntos) } \\
\sqrt{ } \text { Reconocimiento ante } \\
\text { las Dictaminadoras de } \\
\text { Becas y Estímulos, el } \\
\text { proceso de } \\
\text { Profesionalización } \\
\text { Docente } \\
\sqrt{ } \text { Divulgación } \\
\text { adecuada de las } \\
\text { políticas de } \\
\text { alfabetización docente } \\
\text { en las HTD en el } \\
\text { ámbito de la } \\
\text { Enseñanza } \\
\text { experimental. }\end{array}$ \\
\hline Beneficios & 3.4 & $\begin{array}{l}\text { Actitud } \\
\text { ligeramente } \\
\text { positiva al } \\
\text { conocimiento de } \\
\text { los beneficios que } \\
\text { tiene el emplear } \\
\text { HTD en el } \\
\text { proceso de la } \\
\text { Enseñanza } \\
\text { experimental en } \\
\text { química }\end{array}$ & $\begin{array}{l}\sqrt{ } \text { Divulgación } \\
\text { adecuada de las } \\
\text { políticas de } \\
\text { alfabetización docente } \\
\text { en la Pedagogía } \\
\text { Experimental en } \\
\text { química con el uso de } \\
\text { HTD. }\end{array}$ \\
\hline Infraestructura tecnológica & 3.8 & $\begin{array}{l}\text { Percepción } \\
\text { positiva a la } \\
\text { existencia de } \\
\text { Infraestructura } \\
\text { tecnológica } \\
\text { propia o de la } \\
\text { UAM-A }\end{array}$ & $\begin{array}{l}\sqrt{ } \text { Desarrollar } \\
\text { estrategias } \\
\text { institucionales para } \\
\text { motivar al docente de } \\
\text { la enseñanza } \\
\text { experimental en } \\
\text { química a emplear las } \\
\text { HTD propias o de la } \\
\text { UAM-A en el proceso } \\
\text { de enseñanza }\end{array}$ \\
\hline Políticas & 3.4 & $\begin{array}{l}\text { Actitud } \\
\text { ligeramente } \\
\text { positiva del } \\
\text { conocimiento de } \\
\text { las políticas } \\
\text { institucionales, } \\
\text { nacionales y } \\
\text { globales sobre el } \\
\text { uso de las HTD }\end{array}$ & $\begin{array}{l}\sqrt{ } \text { Desarrollar } \\
\text { estrategias } \\
\text { institucionales para } \\
\text { alfabetizar al docente } \\
\text { de la enseñanza } \\
\text { experimental de } \\
\text { química en el } \\
\text { conocimiento de las } \\
\text { políticas propias, }\end{array}$ \\
\hline
\end{tabular}




\section{PERCEPCIÓN SOBRE EL USO DE HERRAMIENTAS TECNOLÓGICAS DIGITALES COMO APOYO EN LA DOCENCIA E INVESTIGACIÓN CASO: DOCENTES-INVESTIGADORES UAM-A, MÉXICO, ADSCRITOS A QUÍMICA}

\begin{tabular}{|l|l|l|l|}
\hline \hline & & $\begin{array}{l}\text { en la enseñanza } \\
\text { experimental de } \\
\text { química }\end{array}$ & $\begin{array}{l}\text { nacionales e } \\
\text { internacionales sobre } \\
\text { el uso de las HTD en } \\
\text { favor de la calidad de } \\
\text { la docencia } \\
\text { experimental }\end{array}$ \\
\hline
\end{tabular}

3. Se Analizó en la percepción de los profesores-investigadores de la UAM-A adscrito a química, acerca del uso de las HTD como apoyo en la Investigación en química, a través de un cuestionario-encuesta USOHTD(E) obteniéndose la siguiente información Cuadro 3:

Cuadro 3. Resultados del Cuestionario-Encuesta USOHTD(I) para el Ámbito de la Investigación en química.

\begin{tabular}{|c|c|c|c|}
\hline DIMENSIÓN & $\begin{array}{c}\text { MEDIA } \\
\text { ARITMÉTICA } \\
\text { DE LAS } \\
\text { CATEGORÍAS } \\
1-5\end{array}$ & CRITERIO & RECOMENDACIONES \\
\hline Fr. de uso & 3.5 & $\begin{array}{l}\text { Actitud positiva al } \\
\text { uso de HTD en el } \\
\text { proceso de la } \\
\text { Investigación en } \\
\text { química }\end{array}$ & $\begin{array}{l}\sqrt{ } \text { Permitir el trabajo } \\
\text { cooperativo y } \\
\text { colaborativo de los } \\
\text { docentes que no } \\
\text { realizan investigación } \\
\text { porque no pertenecen } \\
\text { a una área de } \\
\text { Investigación } \\
\sqrt{ } \text { Permitir utilizar, con } \\
\text { la debida supervisión, } \\
\text { los equipos de punta } \\
\text { utilizados para elucidar } \\
\text { estructuras, determinar } \\
\text { procesos físicos y } \\
\text { químicos de las } \\
\text { sustancias, aunque } \\
\text { sea para una } \\
\text { investigación } \\
\text { educativa- } \\
\text { experimental de la } \\
\text { química } \\
\sqrt{ } \text { Evitar } \\
\text { balcanizaciones y } \\
\text { discriminaciones entre } \\
\text { los miembros o no del } \\
\text { área de Investigación } \\
\text { para un trabajo }\end{array}$ \\
\hline
\end{tabular}




\section{PERCEPCIÓN SOBRE EL USO DE HERRAMIENTAS TECNOLÓGICAS DIGITALES COMO APOYO EN LA DOCENCIA E INVESTIGACIÓN CASO: DOCENTES-INVESTIGADORES UAM-A, MÉXICO, ADSCRITOS A QUÍMICA}

\begin{tabular}{|c|c|c|c|}
\hline & & & $\begin{array}{l}\text { armonioso y de } \\
\text { aprendizaje en el uso } \\
\text { de las HTD }\end{array}$ \\
\hline Beneficios & 4.6 & $\begin{array}{l}\text { Actitud muy } \\
\text { positiva al } \\
\text { conocimiento de } \\
\text { los beneficios que } \\
\text { tiene el emplear } \\
\text { HTD en el } \\
\text { proceso de la } \\
\text { Investigación en } \\
\text { química }\end{array}$ & $\begin{array}{l}\sqrt{ } \text { La formación de } \\
\text { Investigadores jóvenes } \\
\text { en la producción } \\
\text { científica y la } \\
\text { innovación de los } \\
\text { conocimientos con el } \\
\text { uso de las HTD } \\
\sqrt{ } \text { Formación de } \\
\text { recursos humanos en } \\
\text { los Servicios Sociales, } \\
\text { Proyectos terminales y } \\
\text { de posgrado con el } \\
\text { uso de las HTD } \\
\sqrt{ } \text { Crear redes del } \\
\text { conocimiento con } \\
\text { pares inter e } \\
\text { intrainstitucionales } \\
\sqrt{ } \text { Levantamiento de } \\
\text { cursos virtuales para el } \\
\text { posgrado } \\
\sqrt{ } \text { Dar prestigio a la } \\
\text { UAM-A, tanto a nivel } \\
\text { nacional como } \\
\text { internacional de ser } \\
\text { una institución que } \\
\text { realiza investigación } \\
\text { de punta con el uso de } \\
\text { HTD }\end{array}$ \\
\hline Infraestructura tecnológica & 4.8 & $\begin{array}{l}\text { Percepción } \\
\text { positiva a la } \\
\text { existencia de } \\
\text { Infraestructura } \\
\text { tecnológica } \\
\text { propia o de la } \\
\text { UAM-A }\end{array}$ & $\begin{array}{l}\sqrt{ } \text { Planear la } \\
\text { Investigación científica } \\
\text { con base en la } \\
\text { presentación de } \\
\text { proyectos ante la } \\
\text { UAM-A y el CONACyT } \\
\text { para la obtención de } \\
\text { presupuesto y } \\
\text { equipamiento del } \\
\text { laboratorio de } \\
\text { investigación para el } \\
\text { uso de las HTD. } \\
\sqrt{ } \text { Informar anualmente }\end{array}$ \\
\hline
\end{tabular}




\section{PERCEPCIÓN SOBRE EL USO DE HERRAMIENTAS TECNOLÓGICAS DIGITALES COMO APOYO EN LA DOCENCIA E INVESTIGACIÓN}

CASO: DOCENTES-INVESTIGADORES UAM-A, MÉXICO, ADSCRITOS A QUÍMICA

\begin{tabular}{|c|c|c|c|}
\hline & & & $\begin{array}{l}\text { a CONACyT y a la } \\
\text { UAM-A los productos } \\
\text { de trabajo obtenidos } \\
\text { con el apoyo } \\
\text { financiero. } \\
\sqrt{ } \text { Tener como objetivo } \\
\text { mantener la } \\
\text { producción científica y } \\
\text { aún más, aumentarla. }\end{array}$ \\
\hline Políticas & 4.4 & $\begin{array}{l}\text { Actitud muy } \\
\text { positiva del } \\
\text { conocimiento de } \\
\text { las políticas } \\
\text { institucionales y } \\
\text { del gobierno que } \\
\text { atiende la } \\
\text { Investigación en } \\
\text { la Educación } \\
\text { Superior sobre } \\
\text { las estrategias } \\
\text { para aumentar el } \\
\text { uso de las HTD } \\
\text { en la } \\
\text { Investigación en } \\
\text { química }\end{array}$ & $\begin{array}{l}\sqrt{ } \text { Mantenerse } \\
\text { actualizado en la } \\
\text { evolución de las } \\
\text { políticas de la } \\
\text { investigación y la } \\
\text { producción científica }\end{array}$ \\
\hline
\end{tabular}

Se comparó la percepción de los profesores investigadores de la UAM-A adscrito a química, acerca de la utilización, concepción y creencias de las HTD como apoyo en la docencia teórica, en la docencia experimental y en la investigación en química obteniéndose que el porcentaje mayor se encuentra en los profesores que hacen investigación (Ámbito de Investigación) $86.5 \%$, seguido por los profesores que imparten la Teoría en química (Ámbito de la Docencia teórica) $73.5 \%$ y finalmente los que tienen menor percepción son los profesores de Laboratorio de química (Docencia experimental) 65\% como se muestra en la Figura 1 


\section{PERCEPCIÓN SOBRE EL USO DE HERRAMIENTAS TECNOLÓGICAS DIGITALES COMO APOYO EN LA DOCENCIA E INVESTIGACIÓN CASO: DOCENTES-INVESTIGADORES UAM-A, MÉXICO, ADSCRITOS A QUÍMICA}

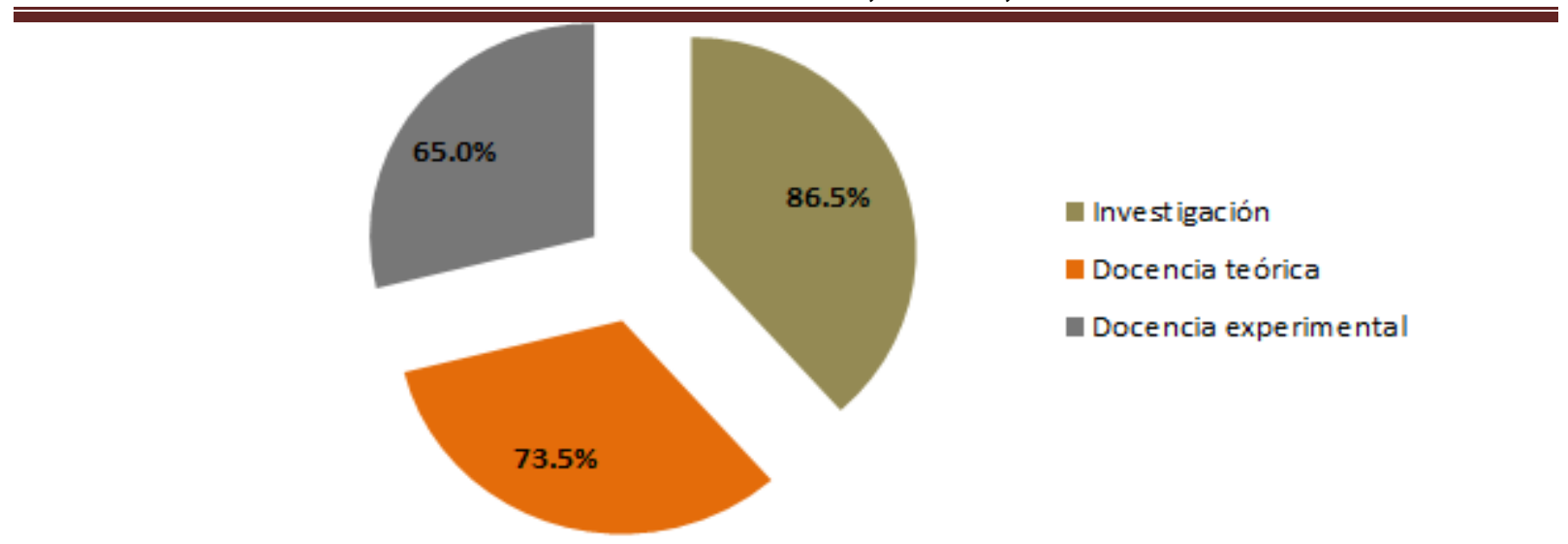

Figura 1. Porcentajes de la percepción del profesor-investigador acerca de la utilización, concepción y creencias en las HTD como apoyos en los ámbitos de Investigación, Docencia Teórica y Docencia experimental.

Fuente: elaboración propia

El Ámbito de la Investigación se encuentra favorecido en la utilización, concepción y creencias en relación a las HTD. El Ámbito más desfavorecido es el de la Docencia experimental

La Dimensión más favorecida es la de la Infraestructura Tecnológica. La menos favorecida es la de frecuencia de uso de las HTD.

Los profesores en la docencia seguirán con el confort de la clase tradicional a pesar de los esfuerzos de la UAM-A de mantener una buena Infraestructura tecnológica y Políticas pertinentes para el uso de las HTD (Teoría de la Resistencia al cambio)..

Los profesores de la docencia experimental (laboratorio de química) son los que por alguna razón casi no cuentan con HTD como equipos de punta para el reconocimiento de las propiedades y estructuras de los materiales y compuestos químicos y que por decisión propia o forzados por la situación seguirán trabajando la química tradicional sin las grandes Innovaciones que proporciona la tecnología digital y en cuanto a sus competencias digitales de comunicación, información y conocimiento con las Tecnologías de la Información y Comunicación TIC, pocos la utilizan.

Los profesores en la Investigación son motivados al uso de HTD porque les da prestigio como investigadores y calidad a sus investigaciones. Las HTD son herramientas poderosas para elucidar estructuras químicas y mecanismos de comportamiento físico y químico. La tecnología digital facilita el conocimiento científico agilizando su esclarecimiento e interpretación certera lo que conlleva a publicar artículos, presentar trabajos en congresos, en diversos foros académicos innovando el conocimiento, Además de preparar a estudiantes para llegar a ser futuros investigadores y un motivo más, tal vez el más poderoso, por supuesto, es el incremento del ingreso económico al sumar al salario becas y estímulos a la 


\section{PERCEPCIÓN SOBRE EL USO DE HERRAMIENTAS TECNOLÓGICAS DIGITALES COMO APOYO EN LA DOCENCIA E INVESTIGACIÓN CASO: DOCENTES-INVESTIGADORES UAM-A, MÉXICO, ADSCRITOS A QUÍMICA}

docencia $^{63}$ y a la investigación proporcionadas por la UAM-A, además de un ingreso extra por proyectos de investigación y productos de trabajo (ya mencionados como artículos, presentaciones en diversos foros académico, innovaciones al conocimiento, patentes, etc.) por el Consejo Nacional de Ciencia y Tecnología CONACyT ${ }^{64}$ al llegar a ser Investigador del Sistema Nacional de Investigadores SNI.

\section{Teorías aplicables a los hallazgos:}

$\checkmark$ Acompañamiento del docente por pares y/o estaff preparados en el uso, aplicación y mantenimiento de la Tecnología Digital en el proceso de enseñanza. Teoría de la ayuda de Adjuntos TAA

$\sqrt{ }$ Divulgación adecuada de las políticas de alfabetización docente en la pedagogía con el uso de HTD. Teoría de la profesionalización docente.

$\sqrt{ }$ Desarrollar estrategias institucionales para alfabetizar al docente de la teoría en el conocimiento de las políticas propias, nacionales e internacionales sobre el uso de las HTD en favor de la calidad de la Docencia. Teoría del Desarrollo profesional

La UAM-A, Institución inteligente. La Universidad Autónoma Metropolitana en su Unidad de Azcapotzalco revisa y establece currículas que contemplan la inclusión de las nuevas tecnologías y nuevos procesos de enseñanza aprendizaje basados en la moda de la globalización. Planea en el colectivo con los órganos colegiados los apoyos de la tecnología digital en la Docencia y en la Investigación.

Limitaciones: La UAM-A puede enfrentarse a recortes presupuestales para mantener y/o fortalecer la Infraestructura tecnológica, y a los estímulos y becas a la docencia e Investigación que en lo individual repercutiría en la falta de interés ya no se diga en la participación de la construcción de una nueva identidad de ciudadanos competentes en la tecnología digital como lo demanda las sociedades del conocimiento y la globalización, sino también en su diario quehacer de Investigación y Docencia, mayormente en esta última y simplemente optar por el confort de lo mínimo cotidiano en su quehacer docente y de investigación (Teoría de la resistencia).

Profesionalización docente. La UAM-A ofrece continuamente cursos de formación docente en métodos de enseñanza, uso de TIC, de convivencia en el aula en los 4 pilares de la educación y muchos más de pedagogía con eticidad, democracia participativa que va al ritmo del mundo globalizado y la calidad de la enseñanza.

Los académicos tienen la oportunidad de profesionalizarse realizando estudios de posgrado durante sus periodos sabáticos y optar por una posgrado en Educación que de acuerdo a lo analizado en las encuestas, son los docentes que más aplican las HTD en el proceso de enseñanza.

\footnotetext{
63 Siendo los beneficios económicos menores en la docencia con respecto a la investigación..

${ }^{64}$ CONACyT es una institución pública Federal, descentralizada que impulsa y gestiona la investigación y el desarrollo científico y tecnológico del país.
} 


\section{PERCEPCIÓN SOBRE EL USO DE HERRAMIENTAS TECNOLÓGICAS DIGITALES COMO APOYO EN LA DOCENCIA E INVESTIGACIÓN CASO: DOCENTES-INVESTIGADORES UAM-A, MÉXICO, ADSCRITOS A QUÍMICA}

Profesores-Investigadores agentes del cambio. Los profesores podemos ser agentes de cambio si decidimos no permanecer en el confort de lo tradicional y profesionalizarnos inicialmente y permanentemente, reflexionar en nuestro quehacer docente tanto de forma individual como en el colectivo de la academia (Marchesi y Martín,1998) y con las miras de contribuir a la calidad de la docencia con el uso de la Tecnología Digital.

La UAM-A establece lineamientos y políticas para la utilización de las tecnologías. Sin embargo, hace falta que los docentes conozcan tales políticas que les permitan un mayor uso de las HTD en sus actividades de gestión, docencia, difusión e investigación.

Una aportación que deja esta investigación consiste en ofrecer un método para que los directivos de la Universidad puedan proponer políticas para promover el uso de las Herramientas Tecnológicas Digitales adaptadas a la práctica docente y mediante los cuestionarios y el análisis estadístico poder medir, cuantitativamente, el efecto de esas políticas, de manera de realizar nuevas propuestas que lleven al objetivo final de alfabetización tecnológica. Esto tiene como beneficio que el docente gane eficiencia en sus actividades cotidianas de docencia e investigación, pues solo se concentra en preparar material adaptado a las herramientas más convenientes para facilitar el aprendizaje y como consecuencia, el alumno de la Universidad se beneficiaría indirectamente. La Tecnología Digital avanza vertiginosamente y es necesario para los directivos poder medir como se están empleando y tener indicadores para saber qué está fallando que, dentro de lo que arrojaron los cuestionarios y lo que en particular he vivido, puede ser por falta de infraestructura (Ámbito de los Laboratorios de química), conocimiento y capacitación ó dificultades de asimilación de las HTD, como puede ser en los casos de profesores de mayor edad (Teoría de la carga Cognitiva). Para lo que se requiere de contar con un método para medir la percepción de los profesores-Investigadores y, con base en ello, poder establecer políticas que refuercen la alfabetización tecnológica. Esto conlleva la formación del profesorado y la predisposición favorable de éste hacia las HTD, al no sentir que se están imponiendo políticas donde no se tome en cuenta su opinión, así como mantener un equilibrio entre capacitación, equipamiento y resultados tangibles. Finalmente, en este estudio, se encontró que la metodología proporcionada puede apoyar a los directivos en la definición de las mejores estrategias en este contexto de la percepción de la utilización, concepción y creencias acerca de las HTD, que lleve a una mayor eficiencia del sistema educativo y de Investigación en la UAM-A.. 


\section{PERCEPCIÓN SOBRE EL USO DE HERRAMIENTAS TECNOLÓGICAS DIGITALES COMO APOYO EN LA DOCENCIA E INVESTIGACIÓN CASO: DOCENTES-INVESTIGADORES UAM-A, MÉXICO, ADSCRITOS A QUÍMICA}

\section{REFERENCIAS}

Anderson, J. R.; Bower, G. H. (1973). Human Associative Memory. Trad. cast. Memoria Asociativa. (1977). México: Limusa. Winston \& Sons. Disponible en: https://es.wikipedia.org/wiki/percepci\%c3\%b3n

Andrade, R., Bozo, R., Cendrós, R. (2011). Percepción de los docentes universitarios en la implementación de las Tecnologías de Información y Comunicación (TIC). Télématique 10(2):107-120. Disponible en: https://www.redalyc.org/pdf/784/78421854007.pdf

Arancibia, M., Cosimo, D., Casanova, R. (2018). Percepción de los profesores sobre integración de TIC en las prácticas de enseñanza en relación a los marcos normativos para la profesión docente en Chile. Ensaio: aval. pol. públ. Educ., Rio de Janeiro 26(98): 163-184. Disponible en: http://www.scielo.br/pdf/ensaio/v26n98/1809-4465-ensaio-26-98-0163.pdf

ANUIES. (2017:44-45). Estado actual de las TIC en las IES en México: Estudio 2017: 1-266. México ANUIES. Disponible en: http://estudiotic.anuies.mx/ESTUDIO 2017 ANUIES-TIC v2 2.pdf

ANUIES. (2016). Estado actual de las TIC en las IES en México: estudio ejecutivo 2017: 1-116. México ANUIES. Disponible en: http://anuiestic.anuies.mx/web/encuentro2016/wpcontent/uploads/pdf//EstadoActualTIC en las IES.pdf

ANUIES. (2000: 7). La educación superior en el siglo XXI. Líneas estratégicas de desarrollo. México: ANUIES.

Ibid., p. 177.

Apple, M. (1996). Política cultural y educación. Madrid: Morata

Arias, E., Cristia, J. (2014). EI BID y la tecnología para mejorar el aprendizaje: ¿Cómo promover programas efectivos?: 1-75. Banco Interamericano de Desarrollo. Div. De Educación. Disponible en: https://publications.iadb.org/bitstream/handle/11319/6550/El\%20BID\%20y $\% 20 l a \%$ 20tecnolog\%C3\%ADa\%20para\%20mejorar\%20el\%20aprendizaje \%3A\%20\%C2\% BFC\%C3\%B3mo\%20promover\%20programas \%20efectivos\%3F.pdf?sequence=1

Banco Mundial. (2016). Tecnologías digitales: Su enorme potencial de desarrollo aun escapa a los 4000 millones de personas que no tienen acceso a Internet. Comunicado de prensa en la WEB. Disponible en: http://www.bancomundial.org/es/news/press-release/2016/01/13/digitaltechnologies-huge-development-potential-remains-out-of-sight-for-the-four-billionwho-lack-internet-access

Bartlett, F. C. (1920). 'Some experiments on the reproduction of folk stories', FolkLore 31(1): 30-47. Disponible en:

http://www.bartlett.psychol.cam.ac.uk/SomeExperimentsOn.htm 


\section{PERCEPCIÓN SOBRE EL USO DE HERRAMIENTAS TECNOLÓGICAS DIGITALES COMO APOYO EN LA DOCENCIA E INVESTIGACIÓN CASO: DOCENTES-INVESTIGADORES UAM-A, MÉXICO, ADSCRITOS A QUÍMICA}

BIDI-UAM. (2018). Biblioteca Digital. UAM-A. Disponible en:

http://cosei.azc.uam.mx/index.php?option=com content\&view=article\&id=77\&ltem id $=474$

Blosser, P. E. (1973). Principles of gestalt psychology and their application to teaching junior high school science. Science Education (Wiley Periodicals, Inc) 57 (1): 43-53. doi:10.1002/sce.3730570110

Bonal, X. (1998). Sociología de la educación. Barcelona: Paidós.

Bourdieu, P., Passeron, J. (1977). La reproducción. Elementos para una teoría del sistema de enseñanza. Barcelona: Laia.

Bruenjes, L. (2001). A multi-case study investigating the disposition of faculty use of technology as a theaching and learning tool in the higher education classroom. Tesis doctoral, Universidad de Massachusetts Lowell.

Brunner, J. (1990). "Educación Superior, Investigación Científica y Transformaciones Culturales en América Latina". En: BID-SECAB-CINDA. Vinculación Universidad Sector Productivo. Santiago de Chile, Colección Ciencia y Tecnología, No. 24, p. 83.

Brunner, J. (2003). "La Educación al Encuentro de las Nuevas Tecnologías". En: José Joaquín Brunner y Juan Carlos Tudesco. Las nuevas Tecnologías y el Futuro de la Educación. IIEP/UNESCO, Septiembre Grupo Editor, Buenos Aires, p. 22-23.

CAMVIA. (2018), Campus Virtual de la UAM-A. Disponible en: http://camvia.azc.uam.mx/index.php?option=com content\&view=featured\&ltemid= $\underline{272}$

Castillo, M. (2009). METODOLOGÍA PARA LA GESTIÓN DE POLÍTICAS EN EDUCACIÓN EN TORNO A LAS TECNOLOGÍAS DE LA INFORMACIÓN Y COMUNICACIÓN. Tesis de maestría. Universidad de Guadalajara, Zapopan Jalisco, México.

Castillo, M., Larios, V., Omar, P. (2010), "Percepción de los docentes de la utilización de las Tecnologías de la Información y la Comunicación", Revista Iberoamericana de Educación, 53(6) 1-10.

Cauas, D. (2006). Elementos para la elaboración y ejecución de un proyecto de investigación. Guía para presentación de proyectos de investigación. Calaméo. Disponible en: http://es.calameo.com/read/000109389399610bdd44f

Cérisier, J.F., Popuri, A. (2011). Computers and Schools: Indian and French students' discourse. European Journal of Education, 46(3), 373-387

Céspedes, Y., Cortés, R., Madrihal, M. (2011). Validación de un instrumento para medir la percepción de la calidad de los servicios farmacéuticos del Sistema Público de Salud de Costa Rica. Rev. Costarr Salud Pública 20(2):75-82. Disponible en: http://www.scielo.sa.cr/pdf/rcsp/v20n 


\section{PERCEPCIÓN SOBRE EL USO DE HERRAMIENTAS TECNOLÓGICAS DIGITALES COMO APOYO EN LA DOCENCIA E INVESTIGACIÓN CASO: DOCENTES-INVESTIGADORES UAM-A, MÉXICO, ADSCRITOS A QUÍMICA}

Cid, A., Andrés-Pérez, A. \& Zabalza, M. (2009). "Las prácticas de enseñanza declaradas de los mejores profesores' de la Universidad de Vigo", Relieve, 15(2) 1-29, Disponible en: http://www.uv.es/RELIEVE/vl5n2/RELIEVE vl5n2 7.htm

CMSI (2003-2005). Cumbre Mundial Consultada en: http://www.itu.int/net/wsis/outcome/vb-es/index.html

Coll, C. (2008). Ponencia: Los desafíos de la educación: El sentido de los aprendizajes escolares en el mundo actual. XII Congreso de UECo.E. Septiembre 2008. Disponible en: http://webcache.googleusercontent.com/search?q=cache:uAcEnAdWYJ:agora.xtec.cat/escolarel/moodle/pluginfile.php $/ 125 / \mathrm{mod}$ folder/content $/ 0 / \mathrm{Ce}$ sarCollSalvador Ponencia.doc\%3Fforce download\%3D1+\&cd=2\&hl=es419\&ct=clnk\&gl=mx

Coll, C. (2009). Los enfoques curriculares basados en competencias y el sentido de aprendizaje escolar. Congreso Mexicano de Investigación Educativa COMIE. X Congreso Nacional de Investigación Educativa. Veracruz, 21-25 de septiembre de 2009. Conferencia Magistral.

COM. (2010). EUROPA 2020 Una estrategia para un crecimiento inteligente, sostenible e integrador. Unión Europea. Disponible en: https://eurlex.europa.eu/legal-content/ES/TXT/?uri=celex:52010DC2020

Comisión Europea. $\left(2018^{\mathrm{a}}\right)$. Governance and Funding. European Commission. Disponible en: https://ec.europa.eu/education/policy/higher-education/governancefunding en

Comisión Europea. $\left(2018^{\mathrm{b}}\right)$. Quality and relevance in higher education. European Commission. Disponible en: https://ec.europa.eu/education/policy/highereducation/quality-relevance en

Comisión Europea. $\left(2018^{\mathrm{C}}\right)$. Knowledge Triangle and Innovation. European Commission. Disponible en: https://ec.europa.eu/education/policy/highereducation/knowledge-innovation-triangle en

Comisión Europea. $\left(2018^{\mathrm{d}}\right)$. Competencias digitales y tecnología en la educación. Unión Europea. Disponible en: https://ec.europa.eu/education/policy/strategicframework/education-technology es

Comisión Europea. $\left(2018^{\mathrm{e}, \mathrm{f}}\right)$. 2nd Survey of Schools: ICT in education. Unión Europea. Disponible en: https://ec.europa.eu/digital-single-market/en/news/2ndsurvey-schools-ict-education

Comisión Europea. $\left(2018^{\mathrm{g}}\right)$. European Framework for Digitally Competent Educational Organisations. Promoting effective digital-age learning. Disponible en: http://ec.europa.eu/jrc/en/digcomporg

Comisión Europea. $\left(2018^{\mathrm{h}}\right)$. Self-reflection tool for digitally capable schools (SELFIE). Disponible en: http://ec.europa.eu/jrc/en/digcomporg/selfie-tool

Comisión Europea. (2018i). Schools participating in SELFIE pilots. Disponible en: https://ec.europa.eu/jrc/en/digcomporg/selfie-tool/selfie-map 


\section{PERCEPCIÓN SOBRE EL USO DE HERRAMIENTAS TECNOLÓGICAS DIGITALES COMO APOYO EN LA DOCENCIA E INVESTIGACIÓN CASO: DOCENTES-INVESTIGADORES UAM-A, MÉXICO, ADSCRITOS A QUÍMICA}

Comisión Europea. (2018j). Centro Común de Investigación de la Comisión.

Disponible en: https://ec.europa.eu/jrc/en/research-topic/learning-and-skills

Comisión Europea. $\left(2018^{k}\right)$. Funding. Oportunidades de financiación Erasmus + . Unión Europea. Disponible en: https://eacea.ec.europa.eu/erasmusplus/funding en

Comisión Europea. (2018). Contribución de los fondos estructurales a las capacidades digitales. Unión Europea. Disponible en:

Comisión Europea. (2015). Promoting Effective Digital-Age Learning: A European Framework for Digitally-Competent Educational Organisations. Disponible en: https://ec.europa.eu/jrc/en/publication/eur-scientific-and-technical-researchreports/promoting-effective-digital-age-learning-european-framework-digitallycompetent-educational

Comisión Europea. (2013). Survey of schools: ICT in Education - data in SPSS format. Databases in SPSS. Unión Europea. Dispnible en:

https://ec.europa.eu/digital-single-market/en/news/survey-schools-ict-educationdata-spss-format https://ec.europa.eu/newsroom/dae/document.cfm?doc id=1826

Comisión Europea. (2010). Survey of schools: ICT in Education. Technical report (pdf). Unión Europea: Disponible en: https://ec.europa.eu/digital-singlemarket/en/news/survey-schools-ict-education-technical-report-pdf

Conrads, J., Rasmussen, M., Winters, N., Geniet, A., Langer, L., Redecker, C., Kampylis, P., Bacigalupo, M., Punie, Y. (2017). Políticas de educación digital en Europa y el resto del mundo: principios clave para la creación de políticas más eficaces. EUR - Scientific and Technical Research Reports. Disponible en: https://ec.europa.eu/irc/en/publication/eur-scientific-and-technical-researchreports/digital-education-policies-europe-and-beyond-key-design-principles-moreeffective-policies

Contreras, P. A. (2012). Percepción Directa El enfoque ecológico como alternativa al cognitivismo en la percepción. (Tesis de licenciatura inédita). Universidad de Chile. Santiago, Chile, Disponible en:

http://repositorio.uchile.cl/bitstream/handle/2250/113758/Contreras\%20Pablo.pdf? sequence $=1$

Coordinación de Docencia. (2018). UAM-A. Disponible en: (http://www.azc.uam.mx/coord general/docencia/PerfilDocente.pdf)

COSEI (2018). Coordinación de Servicios de Información. UAM-A. Disponible en: http://cosei.azc.uam $\cdot \mathrm{mx} /$ index $\cdot$ php?option=com content\&view=article\&id=72\&ltemid=290 \#? Itemid=294

Davis, F., Bagozzi, R., Washaw, P. (1989). User acceptance of computer technologuy: a comparison of two theoretical models. Management Science, 35(8), 982-1003. 


\section{PERCEPCIÓN SOBRE EL USO DE HERRAMIENTAS TECNOLÓGICAS DIGITALES COMO APOYO EN LA DOCENCIA E INVESTIGACIÓN CASO: DOCENTES-INVESTIGADORES UAM-A, MÉXICO, ADSCRITOS A QUÍMICA}

de Jong, T. (2010). Cognitive Load Theory, Educational Research, and Instructional Design: Some Food for Thought. Instructional Science: An International Journal of the Learning Sciences: 38(2), pp 105-134. Disponible en: https://link.springer.com/article/10.1007/s11251-009-9110-0

Del-Fresno, M.; Marqués, P.; \& Sánchez, D. (2014). Conectados por redes sociales introducción al análisis de redes sociales y casos prácticos, Universitat Oberta de Catalunya. (UOC), Barcelona. España

DESI. (2018). Índice de la Economía y la Sociedad Digitales (Digital Economy and Society Index). Unión Europea. Disponible en: https://ec.europa.eu/digitalsingle-maket/en/desi

Didriksson, A. (2007). Universidad y las sociedades del conocimiento. UNESCOMéxico, p. 32.

Ellison, N. B., Steinfield, C., Lampe, C. (2007). The benefits of Facebook "friends:" Social capital and college students' use of online social network sites. Journal of Computer-Mediated Communication 12 (4), article 1

Fernández, A. (2007). Crítica de la tecnología de reencantamiento: la comunicación en la era digital. Tesis doctoral. Universidad de Murcia. Disponible en: http://www.tdx.cat/handle/10803/10909

Fonseca-García, A.; González-Espinosa, P. (2008). Bases Para la Creación de una Campaña Promocional para Posicionar la Imagen del Estado de Chiapas. (Tesis profesional inédita). Colección de tesis digitales UDLAP. Universidad de las Américas Puebla, Santa CATARINA Mártir, San Andrés Cholula, Puebla. Disponible en: http://catarina.udlap.mx/u dl a/tales/documentos/lmk/fonseca g a/portada.html

Fullan, M., Stieegelbauer, S. (1997). El cambio educativo. Cuidad de México: Trillas.

Gagné, R., Briggs I. (1979). Principles of instructional design (2nd edition). Holt, Rinehart and Winston, Inc.: New York, NY (USA).

Gibson, J. J. (2014). The Ecological Approach to Visual Perception. New York: Psychology Press.

Gibson, J. J. (1977). The Theory of Affordances. De: The Ecological Approach to Visual Perception (Capítulo 8), 1-15. Disponible en: http://cs.brown.edu/courses/cs137/readings/Gibson-AFF.pdf

Giroux, H. (1992). Teoría y resistencia en educación. Ciudad de México: Siglo XXI

Glaser, B., Strauss, A. (1967). The discovery of grounded theory. Chicago: Aldine Press.

Gollin, E. (1981) Developmental Plasticity: Behavioral and Biological Aspects of Variations in Development. Publisher: Academic Pr. ISBN: 978-0122896200

Good, T. L., Brophy, J. E. (1990). Looking in Classrooms. Boston, Massachusetts: Addison-Wesley. 


\section{PERCEPCIÓN SOBRE EL USO DE HERRAMIENTAS TECNOLÓGICAS DIGITALES COMO APOYO EN LA DOCENCIA E INVESTIGACIÓN CASO: DOCENTES-INVESTIGADORES UAM-A, MÉXICO, ADSCRITOS A QUÍMICA}

Gorostiaga, J. (2012). La percepción como medio de desarrollo del individuo.

(Factores fundamentales.). Proyectos de Graduación. Universidad de Palermo UP. Palermo, Argentina. Disponible en:

http://fido.palermo.edu/servicios_dyc/proyectograduacion/detalle_proyecto.php?id _proyecto $=1126$

Guerrero, A. (1996). Manual de sociología de la educación. Madrid: Síntesis.

Guerrero, P. (2005). Estudio de las Resistencias de los Profesores a una Estrategia Para el Desarrollo de la Creatividad en Tres Unidades Educativas. Psykhe (Santiago), 14(1): 31-45. Disponible en: http://www.scielo.cl/scielo.php?script=sci arttext\&pid=S0718$\underline{22282005000100003}$

Guía. (2009). Guía para medir la satisfacción respecto a los servicios prestados. Evaluación y Calidad. Gobierno de Navarra. Disponible en: . http://www.navarra.es/NR/rdonlyres/5A006CFC-7EBC-4A3F-9FA54574ADA817D8/0/GuiaPARAMEDIRLASATISFACCION2012.pdf

Guillemette, F. (2006). L'approche de la Grounded Theory; pour innover? Recherches qualitatives, 26(1), 32-50.

Guzmán, J.C. (2011). La calidad de la enseñanza en educación superior ¿Qué es Rodríguez una buena enseñanza en este nivel educativo? Perfiles educativos vol.33. Disponible en: http://www.scielo.org.mx/scielo.php?script=sci arttext\&pid=S018526982011000500012

Guzmán, T.; Larios, V.; Chap Liaw arro, R. (2010). De la sociedad de la información a la sociedad del conocimiento: la restructuración de la universidad rumbo a la virtualización. Revista de Educación y Desarrollo, 15. Disponible en http://www.cucs.udg.mx/revistas/edu desarrollo/anteriores/15/015 Guzman.pdf

Hativa, N. (2000). Teaching for Effective Learning in Higher Education, Dordrecht/Boston/ London, Kluwer Academic Publishers

Hativa, N., Goodyear, P. (2002). Teacher Thinking, Beliefs and Knowledge in Higher Education, Dordrecht/Boston/Londres, Kluwer Academic Publishers

Hernández, L., Mera, L., Chávez, M., Soto, M.L., Fernández, L., Naranjo, F. (2018). La comunicación socio digital como apoyo docente a una Unidad de Enseñanza Aprendizaje (UEA) en la Universidad Autónoma Metropolitana Azcapotzalco (UAM-A). IV CONGRESO MULTIDISCIPLINARIO DE CIENCIAS APLICADAS EN LATINOAMÉRICA COMCAPLA 2018. Noviembre 20-23, Mérida, Yucatán, México.

Hernández, R., Fernández, C., Baptista, P. (2006). Metodología de la investigación (4ta ed.). México: Mc Graw Hill

Hunt, J. G. y Ropo, A. (1995). Multi-level leadership: Grounded theory and mainstream theory applied to the case of general motors. Leadership Quarterly, 6(3), 379-412.Fresnogher Education InstitutionsEUR - Scientific and Technical 


\section{PERCEPCIÓN SOBRE EL USO DE HERRAMIENTAS TECNOLÓGICAS DIGITALES COMO APOYO EN LA DOCENCIA E INVESTIGACIÓN CASO: DOCENTES-INVESTIGADORES UAM-A, MÉXICO, ADSCRITOS A QUÍMICA}

Research Reports. Disponible en: https://ec.europa.eu/jrc/en/publication/eurscientific-and-technical-research-reports/opening-education-support-frameworkhigher-education-institutions

INEGI (2007). Ciencia y Tecnología. Disponible en: http://www.inegi.gob.mx/inegi/default.aspx?s=est\&c=126

Jacobsen, D.M. (1998). Adoption Patterns of Faculty who Integrate Computer Technology for Teaching and Learning in Higher Education. Social Sciences and Humanities Research Counci of Canada, Ottawa (Ontario).

https://www.researchgate.net/publication/234774180_Adoption_Patterns_of_Faculty_Who _Integrate_Computer_Technology_for_Teaching_and_Learning_in_Higher_Education [accedido el 23 de junio de 2017]

Jacobson, M.J., Weller, M. H. (1987). A profile of computer use among the University of Illinois humanities faculty. Journal of Educational Technology Systems 16(2), 83-98.

Jimenez, J., Eliecer, J., Vivas M. (2011). Percepciones de los Docentes Universitarios sobre las Tecnologías de la Información y la Comunicación. Acción pedagógica, No 20 / Enero - Diciembre, 2011 - pp. $74-90$

Johnson, D., Johnson, R., Holubec, E. (1999). Aprendizaje cooperativo en el aula. Rubén Darío 118, México D.F.: Ediciones en españo Paidós Mexicana SA.

K-12 Education Team. (2015). What Educators Want from Digital Instructional Tools 2.0 - Report, Bill y Melinda Gates foundation. Disponible en: k12education.gatesfoundation.org download Num=2333\&filename=TeachersKnow-Best-2.0-1

Knowles, M. S. (1984). Andragogy in action: Applying modern principles of adult learning. San Francisco: Jossey Bass Publishers.

Lagunes-Domínguez, A., Torres-Gastelú C., Flores-García, M., Rodríguez-Figueroa, A. (2015). Comparativo del uso de tecnologías de la información y comunicación (TIC) por Profesores de dos universidades públicas de México. Scielo 8(2) 11-18.

Larousse. (s.f.). «Percepción». Diccionarios.com. Disponible en: https://www.diccionarios.com/detalle.php?palabra=percepci\%C3\%B3n\&dicc 100= on\&Buscar. $x=0 \&$ Buscar. $y=0$ \&palabra2

Lezaca, J. A. (Marzo de 2004). Concepciones sobre el problema en investigación. @puntes cont@bles, No. 5, 89-91.16 de marzo de 2018, de Facultad de Contaduría Pública Universidad Externado de Colombia Base de datos. Disponible en: revistas.uexternado.edu.co/index.php/contad/article/viewFile/1313/1250 http://revistas.uexternado.edu.co/index.php/contad/issue/view/144

López de la Madrid María Cristina; Katiuzka Flores Guerrero. (2010). Las TIC en la Educación Superior de México. Políticas y acciones. Módulo: La universidad en la sociedad del conocimiento. DIsponible en: 


\section{PERCEPCIÓN SOBRE EL USO DE HERRAMIENTAS TECNOLÓGICAS DIGITALES COMO APOYO EN LA DOCENCIA E INVESTIGACIÓN CASO: DOCENTES-INVESTIGADORES UAM-A, MÉXICO, ADSCRITOS A QUÍMICA}

http://reposital.cuaed.unam.mx:8080/jspui/bitstream/123456789/1507/1/Las\%20TI

C\%20en\%20la\%20educaci\%C3\%B3n\%20superior\%20de\%20M\%C3\%A9xico.doc.

Liaw, S.S. (2002). An Internet survey for perceptions of computers and the World Wide Web: relationship, prediction, and difference. Computers in Human Behavior 18, 17-35. Disponible en: https://ai2-s2pdfs.s3.amazonaws.com/b0d8/799c0dbd944ea7809d0323e2a9a2dedae6ba.pdfhtt ps://pdfs.semanticscholar.org/b0d8/799c0dbd944ea7809d0323e2a9a2dedae6ba.p df

Lobos, G., Ortiz, E., Guevara, D. (2018). Factores Determinantes del Bienestar Financiero y su Relación con la Calidad de Vida. Revista ICT (en prensa).

Llorens, F.; Capdeferro, N. (2011). Posibilidades de la plataforma Facebook para el aprendizaje colaborativo en línea. Revista de Universidad y Sociedad del Conocimiento RUSC, 8(2):31-45. Disponible en: http://rusc.uoc.edu/ojs/index.php/rusc/article/view/v8n2-llorens-capdeferro/v8n2$\underline{\text { llorens-capdeferro }}$

Logan, R.K. (1995) "El Quinto Lenguaje" Aprendiendo en la era de la computadora, en: Las interacciones sociales y escolares Ed. Stoddart, Canadá

López de la Madrid, M.C.; Flores, K. (2011). Las TIC en la Educación Superior de México. Políticas y acciones. Módulo: La universidad en la sociedad del conocimiento. Disponible en: http://recursos.portaleducoas.org/sites/default/files/11961.pdf

Mahtani-Chugani V. (2009). Estudio cualitativo sobre la percepción del beneficio y el riesgo de ansiolíticos y antidepresivos en los usuarios. (Tesis de doctorado inédita). Universidad de la Laguna. Provincia de Santa Cruz de Tenerife, Canarias España. Disponible en: ftp://tesis.bbtk.ull.es/ccppytec/cp321.pdf

Manso, M., Pérez, P., Libedinsky. L., Garzón, M. (2011). Las TIC en las aulas. Experiencias latinoamericanas. Argentina: Paidós

Marchesi, A., Martín, E. (1998). Calidad en la enseñanza en los tiempos de cambio. España: Alianza Editorial SA.

Martínez, F. (2007). "La sociedad de la Información. La tecnología desdede estudios CTS". En CABERO, J. (coordinador): Tecnología Educativa. Madrid: Mc-GrawHill.

Martorell J. L., Prieto, J. L. (s.f.). El constructivismo. En Fundamentos de la psicología: UNED. Centro de Estudios de Daniela Dendal Santohueso. Colección de Psicología. Disponible en: http://www.e-torredebabel.com/UnedParla/Asignaturas/IntroduccionPsicologia/ResumenManual-Capitulo10.htm

McLaren, P. (1998). La vida en las escuelas. Ciudad de México: Siglo XXI.

Mellado, F. (2010). Percepción. Investigación cuantitativa. Disponible en: https://mellado1.com/2010/03/26/la-percepcion/ 


\section{PERCEPCIÓN SOBRE EL USO DE HERRAMIENTAS TECNOLÓGICAS DIGITALES COMO APOYO EN LA DOCENCIA E INVESTIGACIÓN CASO: DOCENTES-INVESTIGADORES UAM-A, MÉXICO, ADSCRITOS A QUÍMICA}

Mishra, D., Deichmann, U. (2016). Informe sobre el Desarrollo Mundial 2016.

Dividendos Digitales Panorama General. 11 de septiembre 2018, de Grupo Banco Mundial Disponible en: http://documents.worldbank.org/curated/en/658821468186546535/pdf/102724WDR-WDR2016Overview-SPANISH-WebResBox-394840B-OUO-9.pdf

Mominó, J., Sigalés, C., Meneses, J. (2008). La escuela en la sociedad red. Internet en la educación primaria y secundaria. Barcelona: Ariel.

Monje, C. (2011). Metodología de la investigación cuantitativa y cualitativa. Guía didáctica. Universidad Surcolombiana. Facultad de Ciencias Sociales y Humanas. Programa de comunicación social y periodismo. NEIVA. Disponible en: http://cese21.edu.mx/doctorado/pluginfile.php/11281/mod resource/content/2/ante cedentes.pdf

Moreno, R.; Park, B. (s. f.) «Cognitive load theory: Historical development and relation to other theories». En Plass, Jan L. Cognitive load theory (Cambridge; New York: Cambridge University Press).

Moriyama, (1968). Indicators of Social Changes: problems in the meassurements of health status. New York: Ed. Rusel Sage Foundation.

file:///D:/Investigación\%20III/Construcción\%20de\%20un\%20instruemento\%20para \%20medir\%20la\%20percepción\%204669-14938-1-PB.pdfl.M.

Mosley, S. (2014). The Overlooked Faculty: A qualitative case study of adjunct instructors' perspective on using educational technology tools in traditional classrooms. PhD in Philosophy, Capella University.

Mwalongo, A. (2011). Teachers' perceptions about ICT for teaching, professional development, administration and personal use. International Journal of Education and Development using Information and Communication Technology (IJEDICT), 2011, Vol. 7, Issue 3, pp. 36-49.

Myers, D., Dick, W., Carey, L. (1978). The Systematic Design of Instruction.

Obaya, A., Vargas, M., Delgadillo G. (2012). Aspectos relevantes de la Educación basada en competencias. Educación Química 22(1) 63-68.

OCDE. (2015). Reporte Estudiantes, Computadoras y Aprendizaje: Haciendo la Conexión. Disponible en: https://www.oecd.org/centrodemexico/medios/estudiantes-computadoras-yaprendizaje-haciendo-la-conexion.htm

OECD (2017), La educación a distancia en la educación superior en América Latina, Estudios del Centro de Desarrollo, OECD Publishing, Paris. Disponible en: https://doi.org/10.1787/9789264277977-es.

OECD (2015), Students, Computers and Learning: Making the Connection, PISA, OECD Publishing, Paris. Disponible en: https://doi.org/10.1787/9789264239555en.

OEV. (2018). Oficina de Educación Virtual. UAM-A. Disponible en: http://www.evirtual.azc.uam.mx/ 


\section{PERCEPCIÓN SOBRE EL USO DE HERRAMIENTAS TECNOLÓGICAS DIGITALES COMO APOYO EN LA DOCENCIA E INVESTIGACIÓN CASO: DOCENTES-INVESTIGADORES UAM-A, MÉXICO, ADSCRITOS A QUÍMICA}

Oppenheimer, A. (2011). ¡Basta de historias! La obsesión latinoamericana con el pasado y las 12 claves del futuro. España. DEBATE

Papert, S. (1999): Logo Philosophy and Implementation, Logo Computer Systems Inc., LCSI, USA. Disponible en:

http://www.microworlds.com/company/philosophy.pdf [Consulta diciembre del 2016].

Páramo, D. (2015). La teoría fundamentada (Grounded Theory). Pensamiento \& gestión, 39. Universidad del Norte, 119-146. Disponible en: http://www.scielo.org.co/pdf/pege/n39/n39a01.pdf

Parsons, T. (1985). La clase como sistema social: Algunas de sus funciones en la sociedad americana. En A. Grass (Ed.), Sociología de la educación. Textos fundamentales. (pp. 53-78). Madrid: Narcea.

Pauleen, D. J., Corbitt, B., Yoong, P. (2007). Discovering and articulating what is not yet known Using action learning and grounded theory as a knowledge management strategy. The Learning Organization, 14(3), 222- 240.

PDI UAM-A. (2014). Plan de Desarrollo Institucional de la Unidad Azcapotzalco de la Universidad Autónoma Metropolitana 2014-2024. Disponible en: http://www.azc.uam.mx/app/ca/docs/ca PlanDesarrollo2014-2024.pdf

Pedró, F. (s. f.) La resistencia a la innovación tecnológica en educación. 25 de marzo del 2017, de Red Latinoamericana de Portales Educativos Relpe. Disponible en: http://www.relpe.org/la -resistencia-a-la-innovación-tecnológica-en educación/

Pedró, F. (2012). Connected Minds. Technology and Today's Learners. Paris: OECD Publishing:

Pérez, M. T. (1986). Mecanismo de la Conducta. Percepción, pensamiento, acción. Madrid: Iberoamericanas, colección Quorum, Biblioteca Básica de Psicología General y Aplicada, $\mathrm{n}^{\circ} 10$

Plan de Acción de Educación Digital de la UE (2018). Competencias Digitales y Tecnología en la educación. Comisión Europea. Disponible en: https://ec.europa.eu/education/policy/strategic-framework/educationtechnology es

PND. (2013). Plan nacional de Desarrollo 2013-2018 de México. Gobierno de la República.. Disponible en: http://pnd.gob.mx/wp-content/uploads/2013/05/PND.pdf

Políticas Operativas de Docencia UAM-A. (2003). Políticas Operativas de Docencia de la Universidad Autónoma Metropolitana Unidad Azcapotzalco (generales y operacionales). Aprobadas por el Consejo Académico en la sesión 243, celebrada los días 30 de enero y 12 de febrero de 2003. Disponible en: http://www.azc.uam.mx/coord general/docencia/08politicas operativas.pdf

Políticas Operativas de la Docencia. (2017). Universidad Autónoma Metropolitana Unidad Azcapotzalco. Disponible en: (https://www.azc.uam.mx/coord general/docencia/08politicas operativas.pdf 


\section{PERCEPCIÓN SOBRE EL USO DE HERRAMIENTAS TECNOLÓGICAS DIGITALES COMO APOYO EN LA DOCENCIA E INVESTIGACIÓN CASO: DOCENTES-INVESTIGADORES UAM-A, MÉXICO, ADSCRITOS A QUÍMICA}

Pomerantz, J. R. (2006). Perception/overview. Disponible en: https://www.researchgate.net/publication/229709847 Perception Overview

Pomerantz, J. R. (2003). Perception: overview. En L. Nadel (Ed.). Encyclopedia of Cognitive Science. Londres: Nature Publishing Group.

Portal UAM-A. (2018). Disponible en: https://www.azc.uam.mx/

Prats. (2012). La formulación de hipótesis. De Histodidáctica, Universidad de Barcelona Disponible en: http://www.ub.edu/histodidactica/index.php?option=com content\&view=article\&id= 25:la-formulacion-de-hipotesis\&catid=11: metodologia-y-epistemologia\&ltemid=103

Quintero, D.M., Avila, G.P. \& Riascos, S.C. (2010). Inclusión de las TIC en la Educación Superior.-Estudio de casos. Universidad del Valle, Colombia. En Zoloamati (UAM-A) o disponible en: http://www.academia.edu/11527759/INCLUSI\%C3\%93N DE LAS TIC EN LA E DUCACI\%C3\%93N SUPERIOR ESTUDIO DE CASOS

Riascos-Erazo S.C., Quintero-Calvache, D.M., Ávila-Fajardo G.P. (2009). Las TIC en el aula: percepciones de los profesores universitarios. Educación y Educadores 21(2): Universidad de la Sabana. Disponible en: http://educacionyeducadores.unisabana.edu.co/index.php/eye/article/view/1536/19 $\underline{82}$

Ries, A., Trout, J. (1986). Posicionamiento: el concepto que ha revolucionado la comunicación publicitaria y la mercadotecnia. México: McGraw-Hill.

Ries, A., Trout, J. (2002). Posicionamiento: una batalla por la mente. México: McGraw-Hill

Rocha E., Pérez, M. (s.f.). Acceso y uso de las TIC en la UNAM. Educción y Cultura $A Z$. Disponible en: http://www.educacionyculturaaz.com/ciencia-ytecnologia/acceso-y-uso-de-las-tic-en-la-unam

PND, H. (2013). Importancia de la formación de docentes en las instituciones educativas. Ciencia Huasteca. Boletín Científico de la Escuela Superior de Huelutla. Universidad Autónoma del Estado de Hidalgo. México. Disponible en: https://www.uaeh.edu.mx/scige/boletin/huejutla/n9/e2.html

Rogers, E.M. (1995). Diffusion of innovations.4th ed. New York: Free Press

Ruiz, R.; Martínez, R.M. (2007). La renovación de las políticas de educación superior, ciencia y tecnología: una tarea estratégica para la construcción de las sociedades del conocimiento. Transatlántica de educación 3(3):18-31. Disponible en: https://dialnet.unirioja.es/servlet/autor?codigo $=234777$

Ruiz, R., Martínez, R., Noguera, R., Valladares, L. (2009). "La educación superior en las sociedades del conocimiento" en Suárez R. (Coordinador) SOCIEDAD DEL CONOCIMIENTO: PROPUESTAS PARA UNA AGENDA CONCEPTUAL, México, Coordinación de Humanidades, UNAM. pp. 209-236 


\section{PERCEPCIÓN SOBRE EL USO DE HERRAMIENTAS TECNOLÓGICAS DIGITALES COMO APOYO EN LA DOCENCIA E INVESTIGACIÓN CASO: DOCENTES-INVESTIGADORES UAM-A, MÉXICO, ADSCRITOS A QUÍMICA}

Sánchez, R. (2001). Transmitir el oficio mismo de generar conocimientos científicos. En Enseñar a investigar. Una didáctica nueva de la investigación científica en ciencias sociales y humanas. Capítulo IV: (125-171). México, ANUIS-UNAM.

Sangra, A., González, M. (2004). La transformación de las universidades a través de las TIC: discursos y prácticas. Barcelona: UOC

Santana, I. (2012). Herramientas para la docencia en autómatica orientadas hacia la metodología ECTS. (Tesis doctoral). Universidad Polítécnica de Madrid, Madrid, España.

Santesmases, M. (1996). Marketing: conceptos y Estrategias. Madrid: Pirámide

Santiago M-A. (2011). Un análisis en Ciencias de la Actividad Física y el Deporte de la Universidad de Alicante. La percepción desde la psicología social. Disponible en: https://dialnet.unirioja.es/servlet/tesis?codigo $=59631$

Sautu, R., Boniolo, P., Dalle, P. \& Elbert, R. (2005). «La construcción del marco teórico en la investigación social» En: Manual de Metodología. Construcción del marco teórico, formulación de los objetivos y elección de la metodología. CLACSO, Colección. Campus virtual, Buenos Aires, Argentina. Capítulos II y III. pp. 129-145. Disponible en: http://bibliotecavirtual.clacso.org.ar/ar/libros/campus/metodo/RSCapitulo\%201.pdf $\mathrm{H}$

Schwarz, A., Chin, W. (2007). Looking Forward: Toward an Understanding of the Nature and Definition of IT Acceptance. Journal of the association for information systems, 8(4).

SEP. (2007: 11). Programa Sectorial de Educación 2007 - 2012 de los Estados Unidos Mexicanos. Disponible en: https://www.oei.es/historico/quipu/mexico/programa_sectorial_educacion_mexico. pdf

Ibid., pp. 40-41.

Silvestre, C., Gost, J., Astier, P., Ezpeleta, P. (2002). Análisis cualitativo de la percepción que tienen las personas que participan en un ensayo clínico, Navarra. Rev. Esp. Salud Publica 76(5). Disponible en: http://scielo.isciii.es/scielo.php?script=sci arttext\&pid=S1135$\underline{57272002000500020}$

Solórzano, M., (2013). ESCALA ACTDIV PARA MEDIR LA ACTITUD HACIA LA DIVERSIDAD. Revista Electrónica "Actualidades Investigativas en Educación" 13(1) 1-26. Universidad de Costa Rica. ISSN 1409-4703. Disponible en: https://revistas.ucr.ac.cr/index.php/aie/article/view/11715/18193

Souto-Otero, M., Inamorato Dos Santos, A., Shields, R., Lazetic, P., Castaño, J., Devaux, Axelle., Oberheidt, S., Punie, Y. (2016). OpenCases: Case Studies on Openness in Education. EUR - Scientific and Technical Research Reports. Disponible en: https://ec.europa.eu/jrc/en/publication/eur-scientific-and-technicalresearch-reports/opencases-case-studies-openness-education 


\section{PERCEPCIÓN SOBRE EL USO DE HERRAMIENTAS TECNOLÓGICAS DIGITALES COMO APOYO EN LA DOCENCIA E INVESTIGACIÓN CASO: DOCENTES-INVESTIGADORES UAM-A, MÉXICO, ADSCRITOS A QUÍMICA}

Sweller, J. (1988). "Cognitive load during problem solving: Effects on learning". Cognitive Science 12(2): 257-285. Disponible en: https://en.wikipedia.org/wiki/Elearning (theory)\#cite note-16

https://en.wikipedia.org/wiki/Cognitive load http://onlinelibrary.wiley.com/doi/10.1207/s15516709cog1202 4/abstract;jsessioni $\mathrm{d}=68089 \mathrm{~B} 5 \mathrm{FBB} 551 \mathrm{BC} 99 \mathrm{~B} 6 \mathrm{DA06C2E344108.f01t01}$

Teo, T., Noyes, J. (2010). Exploring attitudes towards computer use among preservice teachers from Singapore and the UK: A multi-group invariance test of the technology acceptance model (TAM). Multicultural Education \& Technology Journal, 4(2), 126-135.

Torres, C. (2001). Sociología de la educación [En red]. Disponible en: http://www.clacso.org/

Torres, S., Barona, C., García, O. (2010). Infraestructura tecnológica y apropiación de las TIC en la Universidad Autónoma del Estado de Morelos. Estudio de caso. Perfiles Educativos 32(127). IISUE-UNAM, México. Disponible en: http://webcache.googleusercontent.com/search?q=cache:MWQobm6CnewJ:www. scielo.org.mx/scielo.php\%3Fscript\%3Dsci arttext\%26pid\%3DS0185$\underline{26982010000100006+\& \mathrm{~cd}=1 \& \mathrm{hl}=\mathrm{es}-419 \& \mathrm{ct}=\mathrm{clnk} \& \mathrm{gl}=\mathrm{mx}}$

Tuck, M. (2010). Gestalt Principles Applied in Design. Disponible en: https://judiths 710.wordpress.com/2014/03/09/summary-michael-tucks-gestaltprinciples-applied-in-design/

UAM-A. (2003). Políticas operativas de Docencia Unidad Azcapotzalco 2017. Disponible en: https://www.azc.uam.mx/coord general/docencia/08politicas operativas.pdf

UIT. (2005). Cumbre Mundial sobre la Sociedad de la Información CMSI. Documentos Finales. Ginebra 2003-Túnez 2005. Disponible en: http://www.itu.int/net/wsis/outcome/vb-es/index.html

UNESCO. (2005). Hacia las sociedades del conocimiento, United Nations Educational, Scientific and Cultural Organization. París. Disponible en: http://unesdoc.unesco.or UNESCO g/images/0014/001419/141908s.pdf

UNESCO y la Educación. (2011). Disponible en: http://unesdoc.unesco.org/images/0021/002127/212715s.pdf

. $\left(2017^{\mathrm{a}}\right)$. Las TIC en la Educación. Disponible en: http://www.unesco.org/new/es/unesco/themes/icts/

UNESCO. $\left(2017^{\mathrm{b}}\right)$. ICT policies and Educational Transformation. Disponible en: http://www.unesco.org/new/fileadmin/MULTIMEDIA/HQ/ED/ICT/pdf/ICTpoliedtran. pdf

Venkatesh, V., Davis, F.D., Morris, M.G. (2007). Dead Or Alive? The Development, Trajectory And Future Of Technology Adoption Research. Journal of the association for information systems, 8(4). 


\section{PERCEPCIÓN SOBRE EL USO DE HERRAMIENTAS TECNOLÓGICAS DIGITALES COMO APOYO EN LA DOCENCIA E INVESTIGACIÓN CASO: DOCENTES-INVESTIGADORES UAM-A, MÉXICO, ADSCRITOS A QUÍMICA}

Vicario, C. (2009). Construccionismo: referente sociotecnopedagógico para la era digital. Artículo publicado en el número especial "Conocimiento en Acción" de la Revista Innovación Educativa, IPN, México.

Vicario, C. (2010). Informática Educativa: Elementos de una teoría para la civilización del conocimiento. ESPECIALIDAD: INGENIERÍA EN COMUNICACIONES Y ELECTRÓNICA. Tesis doctoral en psicología. UNAM, Facultad de Filosofía y Letras, Cd. de México.

Vicario, C. (2011). FRAGMENTOS DE UNA TEORÍA DE LA INFORMÁTICA EDUCATIVA PARA LA CIVILIZACIÓN DEL CONOCIMIENTO. Pp. 32-38 http://www.ai.org.mx/ai/archivos/coloquios/11/fragmentos de una teoria.pdf

Williams, R. (2011). Estudio de comunicación. En Televisión: Tecnología y forma cultural. (36, 76, 159). Buenos Aires: Paidós

Winocur, R., Sánchez, J.A. (2015). Redes socio digitales en México. pp 171, 180, 181. México: Fondo de cultura económica

Wright, N. (2013). Digital technologies and continuance theory in education. Annual International Conference On Infocomm Technologies In Competitive Strategies, 121-124.

Zaloamati. (2018). Repositorio Institucional. UAM-A. Disponible en: http://zaloamati.azc.uam.mx/ 
PERCEPCIÓN SOBRE EL USO DE HERRAMIENTAS TECNOLÓGICAS DIGITALES

COMO APOYO EN LA DOCENCIA E INVESTIGACIÓN

CASO: DOCENTES-INVESTIGADORES UAM-A, MÉXICO, ADSCRITOS A QUÍMICA

ANEXOS 


\section{ANEXO 1}
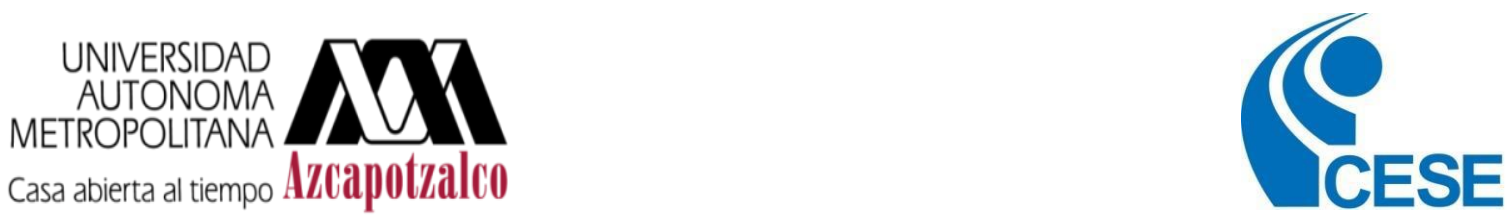

\section{CUESTIONARIO USOHTD PARA MEDIR LA PERCEPCIÓN EN EL USO DE HERRAMIENTAS TECNOLÓGICAS DIGITALES EN LA INVESTIGACIÓN EN QUÍMICA}

Fecha:

Trimestre:

Esta investigación realizada a través de un cuestionario en la Universidad Autónoma Metropolitana Unidad Azcapotzalco UAM-A en las áreas de química, tiene como objetivo conocer la opinión que usted profesor-investigador tiene acerca de las Herramientas Tecnológicas Digitales HTD como apoyo en la investigación en química.

Instrucciones: Elija la opción que le parezca conveniente. El cuestionario es anónimo

$\rightarrow$ Datos del profesor-investigador de tiempo completo:

1. Año que ingresó a la UAM-A:

2. Licenciatura:

3. Grado académico:

Licenciatura ( ) Maestría ( ) Doctorado ( )

4. Laboratorio de Inv. (nombre):

5. Edad:

6. Género:

Femenino ( ) Masculino ( )

$\rightarrow$ Frecuencia del uso de HTD (Herramientas Tecnológicas Digitales, ver pregunta 8) en la Investigación en Química

Indique el número de su preferencia 


\section{PERCEPCIÓN SOBRE EL USO DE HERRAMIENTAS TECNOLÓGICAS DIGITALES COMO APOYO EN LA DOCENCIA E INVESTIGACIÓN CASO: DOCENTES-INVESTIGADORES UAM-A, MÉXICO, ADSCRITOS A QUÍMICA}

\begin{tabular}{|c|c|c|c|c|c|}
\hline & Nada & Poco & Regular & Aceptable & $\begin{array}{l}\text { Totalmente } \\
\text { Aceptable } \\
\text { (mucho) }\end{array}$ \\
\hline $\begin{array}{l}\text { 7. Usa HTD en su práctica } \\
\text { como investigador }\end{array}$ & 1 & 2 & 3 & 4 & 5 \\
\hline \multicolumn{6}{|c|}{ 8. Qué tanto utiliza las siguientes HTD o Tecnología digital en la investigación } \\
\hline & Nada & Poco & Regular & Aceptable & $\begin{array}{l}\text { Totalmente } \\
\text { Aceptable } \\
\text { (mucho) }\end{array}$ \\
\hline Video proyector & 1 & 2 & 3 & 4 & 5 \\
\hline Computadora & 1 & 2 & 3 & 4 & 5 \\
\hline Internet $^{+}$ & 1 & 2 & 3 & 4 & 5 \\
\hline $\begin{array}{l}\text { Facebook (comunicación } \\
\text { por internet, red social) }\end{array}$ & 1 & 2 & 3 & 4 & 5 \\
\hline $\begin{array}{l}\text { Otras HTD de } \\
\text { comunicación entre } \\
\text { investigadores } \\
\text { Mencione alguna }\end{array}$ & 1 & 2 & 3 & 4 & 5 \\
\hline $\begin{array}{l}\text { Plataforma de recursos de } \\
\text { investigación en línea }\end{array}$ & 1 & 2 & 3 & 4 & 5 \\
\hline Simuladores & 1 & 2 & 3 & 4 & 5 \\
\hline Videos & 1 & 2 & 3 & 4 & 5 \\
\hline Audios & 1 & 2 & 3 & 4 & 5 \\
\hline Chat & 1 & 2 & 3 & 4 & 5 \\
\hline Foros & 1 & 2 & 3 & 4 & 5 \\
\hline Correo electrónico & 1 & 2 & 3 & 4 & 5 \\
\hline Blog & 1 & 2 & 3 & 4 & 5 \\
\hline Sitio web personal & 1 & 2 & 3 & 4 & 5 \\
\hline Videoconferencia & 1 & 2 & 3 & 4 & 5 \\
\hline Biblioteca digital & 1 & 2 & 3 & 4 & 5 \\
\hline $\begin{array}{l}\text { Otras HTD como equipos } \\
\text { de punta o hardware y } \\
\text { software científico } \\
\text { Mencione alguna }\end{array}$ & 1 & 2 & 3 & 4 & 5 \\
\hline 9. Si su laboratorio cuenta & 1 & 2 & 3 & 4 & 5 \\
\hline
\end{tabular}




\section{PERCEPCIÓN SOBRE EL USO DE HERRAMIENTAS TECNOLÓGICAS DIGITALES \\ COMO APOYO EN LA DOCENCIA E INVESTIGACIÓN \\ CASO: DOCENTES-INVESTIGADORES UAM-A, MÉXICO, ADSCRITOS A QUÍMICA}

\begin{tabular}{|c|c|c|c|c|c|}
\hline $\begin{array}{l}\text { con medios } \\
\text { tecnológicos } \\
\text { ¿Desarrolla sus } \\
\text { investigaciones } \\
\text { utilizándolos? }\end{array}$ & & & & & \\
\hline $\begin{array}{l}\text { 10. La UAM-A ofrece } \\
\text { cursos para que los } \\
\text { investigadores aprendan } \\
\text { a usar las HTD }\end{array}$ & 1 & 2 & 3 & 4 & 5 \\
\hline $\begin{array}{l}\text { 11. Asiste a talleres y } \\
\text { cursos de manera } \\
\text { virtual para actualizarse }\end{array}$ & 1 & 2 & 3 & 4 & 5 \\
\hline $\begin{array}{l}\text { 12. Usar HTD tecnología } \\
\text { digital, (equipos de } \\
\text { punta o software), } \\
\text { requiere invertir más } \\
\text { tiempo en el desarrollo } \\
\text { de la investigación }\end{array}$ & 1 & 2 & 3 & 4 & 5 \\
\hline $\begin{array}{l}\text { 13. Usar HTD (tecnología } \\
\text { digital), como redes } \\
\text { sociales, plataformas, } \\
\text { equipos de punta } \\
\text { implica más dedicación } \\
\text { del investigador para } \\
\text { apoyar el trabajo de } \\
\text { investigación }\end{array}$ & 1 & 2 & 3 & 4 & 5 \\
\hline $\begin{array}{l}\text { 14. Usar HTD (tecnología } \\
\text { digital) implica un } \\
\text { gasto extra }\end{array}$ & 1 & 2 & 3 & 4 & 5 \\
\hline
\end{tabular}

$\rightarrow$ Beneficios al usar Herramientas HTD en el proceso de la investigación en química.

Elija el número de su preferencia

\begin{tabular}{|c|c|c|c|c|c|}
\hline & $\begin{array}{c}\text { Muy en } \\
\text { desacuer } \\
\text { do }\end{array}$ & $\begin{array}{c}\text { En } \\
\text { desacuerd } \\
\mathbf{0}\end{array}$ & $\begin{array}{c}\text { Ni de } \\
\text { acuerdo } \\
\text { o } \\
\text { desacuerdo }\end{array}$ & $\begin{array}{c}\text { De } \\
\text { acuerd } \\
\text { o }\end{array}$ & $\begin{array}{c}\text { Muy en } \\
\text { acuerdo }\end{array}$ \\
\hline $\begin{array}{c}\text { 15.Usar HTD trae beneficios a } \\
\text { la investigación }\end{array}$ & 1 & 2 & 3 & 4 & 5 \\
\hline
\end{tabular}

16. Las HTD propias o de la UAM-A han contribuido a mejorar su investigación

\begin{tabular}{|l|l|l|l|l|l|}
\hline Agilizan su trabajo como & 1 & 2 & 3 & 4 & 5 \\
\hline
\end{tabular}




\section{PERCEPCIÓN SOBRE EL USO DE HERRAMIENTAS TECNOLÓGICAS DIGITALES COMO APOYO EN LA DOCENCIA E INVESTIGACIÓN CASO: DOCENTES-INVESTIGADORES UAM-A, MÉXICO, ADSCRITOS A QUÍMICA}

\begin{tabular}{|l|c|c|c|c|c|}
\hline \hline investigador & & & & \\
\hline $\begin{array}{l}\text { Aprovecha más el tiempo para } \\
\text { su investigación }\end{array}$ & 1 & 2 & 3 & 4 & 5 \\
\hline $\begin{array}{l}\text { Facilita sus actividades } \\
\text { administrativas de la } \\
\text { investigación }\end{array}$ & 1 & 2 & 3 & 4 & 5 \\
\hline $\begin{array}{l}\text { Posibilita que el investigador } \\
\text { acceda más rápido a los } \\
\text { conceptos tétricos y } \\
\text { experimentales }\end{array}$ & 1 & 2 & 3 & 4 & 5 \\
\hline $\begin{array}{l}\text { Los investigadores desarrollan } \\
\text { capacidades analíticas }\end{array}$ & 1 & 2 & 3 & 4 & 5 \\
\hline $\begin{array}{l}\text { Favorecen el trabajo en equipo } \\
\text { de investigadores }\end{array}$ & 1 & 2 & 3 & 4 & 5 \\
\hline $\begin{array}{l}\text { Los investigadores aumentan } \\
\text { su producción }\end{array}$ & 1 & 2 & 3 & 4 & 5 \\
\hline $\begin{array}{l}\text { El investigador (o la } \\
\text { investigación) tienen mejor } \\
\text { reconocimiento }\end{array}$ & 1 & 2 & 3 & 5 \\
\hline $\begin{array}{l}\text { La virtualidad (investigación a } \\
\text { distancia por internet) puede } \\
\text { lograr un proceso de } \\
\text { investigación anclado en la } \\
\text { interacción, colaboración y } \\
\text { cooperación entre investigadores } \\
\text { para lograr la construcción del } \\
\text { conocimiento }\end{array}$ & 1 & & 3 & 3 & \\
\hline
\end{tabular}

\section{$\rightarrow$ Infraestructura tecnológica como apoyo en la investigación.}

Elija su respuesta
17. ¿Cuenta con computadora en su casa?
( ) $\mathrm{Si}$
( ) No

18. ¿Cuenta con internet en su casa? ( ) $\mathrm{Si} \quad$ ( ) No

19. ¿Cuenta con computadora de uso personal en su cubículo? ( ) $\mathrm{Si} \quad$ ( ) No

20. ¿Cuenta con internet en su cubículo? ( ) Si ～( ) No

\begin{tabular}{|c|c|c|c|c|c|}
\hline & Nada & Poco & Regular & Aceptable & $\begin{array}{c}\text { Totalmente } \\
\text { aceptable }\end{array}$ \\
\hline $\begin{array}{c}\text { 21. Es conveniente invertir en } \\
\text { infraestructura tecnológica para el } \\
\text { uso de HTD en la Inv. Quím. }\end{array}$ & 1 & 2 & 3 & 4 & 5 \\
\hline 22. Es importante contar con una & 1 & 2 & 3 & 4 & 5 \\
\hline
\end{tabular}




\section{PERCEPCIÓN SOBRE EL USO DE HERRAMIENTAS TECNOLÓGICAS DIGITALES COMO APOYO EN LA DOCENCIA E INVESTIGACIÓN CASO: DOCENTES-INVESTIGADORES UAM-A, MÉXICO, ADSCRITOS A QUÍMICA}

\begin{tabular}{|c|c|c|c|c|c|}
\hline $\begin{array}{l}\text { computadora en su cubículo para } \\
\text { la investigación }\end{array}$ & & & & & \\
\hline $\begin{array}{l}\text { 23. Mi laboratorio tiene las } \\
\text { condiciones tecnológicas digitales } \\
\text { para una investigación }\end{array}$ & 1 & 2 & 3 & 4 & 5 \\
\hline $\begin{array}{l}\text { 24. La institución me brinda el apoyo } \\
\text { (o financiamiento) para utilizar las } \\
\text { tecnologías HTD (tecnología } \\
\text { digital) en la investigación }\end{array}$ & 1 & 2 & 3 & 4 & 5 \\
\hline $\begin{array}{l}\text { 25. La infraestructura tecnológica es } \\
\text { suficiente para los investigadores } \\
\text { de tiempo completo }\end{array}$ & 1 & 2 & 3 & 4 & 5 \\
\hline
\end{tabular}

\section{Percepción de políticas de uso de HTD como apoyo en la investigación}

Elija su respuesta

\begin{tabular}{|c|c|c|c|c|c|}
\hline & Nada & Poco & Regular & Aceptable & $\begin{array}{c}\text { Totalmente } \\
\text { aceptable }\end{array}$ \\
\hline $\begin{array}{c}\text { 26.Es importante el uso de las } \\
\text { tecnologías o HTD en la } \\
\text { investigación }\end{array}$ & 1 & 2 & 3 & 4 & 5 \\
\hline $\begin{array}{c}\text { 27. La tecnología genera cambios en el } \\
\text { modo de investigar }\end{array}$ & 1 & 2 & 3 & 4 & 5 \\
\hline $\begin{array}{c}\text { 28. Poseo los conocimientos } \\
\text { necesarios para utilizar las HTD } \\
\text { en mi práctica como investigador. }\end{array}$ & 1 & 2 & 3 & 4 & 5 \\
\hline $\begin{array}{c}\text { 29.Es importante invertir en } \\
\text { capacitación de las HTD orientada } \\
\text { a los recursos humanos en la } \\
\text { investigación }\end{array}$ & 1 & 2 & 3 & 4 & 5 \\
\hline $\begin{array}{c}\text { 30.Existe difusión en el uso de HTD } \\
\text { en la investigación (apoyar a otros } \\
\text { investigadores que requieran el } \\
\text { servicio) }\end{array}$ & 1 & 2 & 3 & 4 & 5 \\
\hline $\begin{array}{c}\text { 31.Se cuenta con personal capacitado } \\
\text { en el uso de las HTD y que apoya } \\
\text { al investigador (en el software y } \\
\text { hardware) }\end{array}$ & 1 & 2 & 3 & 4 & 5 \\
\hline
\end{tabular}


PERCEPCIÓN SOBRE EL USO DE HERRAMIENTAS TECNOLÓGICAS DIGITALES

COMO APOYO EN LA DOCENCIA E INVESTIGACIÓN

CASO: DOCENTES-INVESTIGADORES UAM-A, MÉXICO, ADSCRITOS A QUÍMICA 


\section{PERCEPCIÓN SOBRE EL USO DE HERRAMIENTAS TECNOLÓGICAS DIGITALES COMO APOYO EN LA DOCENCIA E INVESTIGACIÓN CASO: DOCENTES-INVESTIGADORES UAM-A, MÉXICO, ADSCRITOS A QUÍMICA}

$\rightarrow$ Frecuencia del uso de HTD (Herramientas Tecnológicas Digitales, ver pregunta 8) en la docencia en química

Indique el número de su preferencia

\begin{tabular}{|c|c|c|c|c|c|}
\hline & Nada & Poco & Regular & Aceptable & $\begin{array}{c}\text { Totalmente } \\
\text { Aceptable } \\
\text { (mucho) }\end{array}$ \\
\hline $\begin{array}{l}\text { 7. Usa HTD en su } \\
\text { práctica docente }\end{array}$ & 1 & 2 & 3 & 4 & 5 \\
\hline \multicolumn{6}{|c|}{ 8. Qué tanto utiliza las siguientes HTD } \\
\hline & Nada & Poco & Regular & Aceptable & $\begin{array}{l}\text { Totalmente } \\
\text { Aceptable } \\
\text { (mucho) }\end{array}$ \\
\hline Video proyector & 1 & 2 & 3 & 4 & 5 \\
\hline Computadora & 1 & 2 & 3 & 4 & 5 \\
\hline Internet $^{+}$ & 1 & 2 & 3 & 4 & 5 \\
\hline $\begin{array}{l}\text { Facebook } \\
\text { (comunicación por } \\
\text { internet, red social) }\end{array}$ & 1 & 2 & 3 & 4 & 5 \\
\hline $\begin{array}{l}\text { Plataforma educativa } \\
\text { (Moodle, Prezi, } \\
\text { Eminus, Blackboard, } \\
\text { WebCT, Claroline, } \\
\text { otra) ¿Cuál? }\end{array}$ & 1 & 2 & 3 & 4 & 5 \\
\hline $\begin{array}{l}\text { Plataforma de cursos } \\
\text { en línea }\end{array}$ & 1 & 2 & 3 & 4 & 5 \\
\hline Simuladores & 1 & 2 & 3 & 4 & 5 \\
\hline Videos & 1 & 2 & 3 & 4 & 5 \\
\hline Audios & 1 & 2 & 3 & 4 & 5 \\
\hline Chat & 1 & 2 & 3 & 4 & 5 \\
\hline Foros & 1 & 2 & 3 & 4 & 5 \\
\hline Correo electrónico & 1 & 2 & $3 x$ & 4 & 5 \\
\hline
\end{tabular}




\section{PERCEPCIÓN SOBRE EL USO DE HERRAMIENTAS TECNOLÓGICAS DIGITALES \\ COMO APOYO EN LA DOCENCIA E INVESTIGACIÓN \\ CASO: DOCENTES-INVESTIGADORES UAM-A, MÉXICO, ADSCRITOS A QUÍMICA}

\begin{tabular}{|l|l|l|l|l|l|}
\hline \hline Blog & 1 & 2 & 3 & 4 & 5 \\
\hline Sitio web personal & 1 & 2 & 3 & 4 & 5 \\
\hline Videoconferencia & 1 & 2 & 3 & 4 & 5 \\
\hline Biblioteca digital & 1 & 2 & 3 & 4 & 5 \\
\hline Usa otra HTD icuál? & 1 & 2 & 3 & 4 & 5 \\
\hline $\begin{array}{l}\text { 9. } \\
\begin{array}{l}\text { Si su aula cuenta } \\
\text { con medios } \\
\text { tecnológicos } \\
\text { iDesarrolla sus } \\
\text { clases } \\
\text { utilizándolos? }\end{array}\end{array}$ & 1 & 2 & 3 & 4 & 5 \\
\hline $\begin{array}{l}\text { 10. La UAM-A ofrece } \\
\text { cursos para que los } \\
\text { profesores } \\
\text { aprendan a usar las } \\
\text { HTD }\end{array}$ & 1 & 2 & 3 & 4 & 5 \\
\hline $\begin{array}{l}\text { 11. Asiste a talleres y } \\
\text { cursos de manera } \\
\text { virtual para } \\
\text { actualizarse }\end{array}$ & 1 & 2 & 3 & 4 & 5 \\
\hline $\begin{array}{l}\text { 12. Usar HTD requiere } \\
\text { invertir más tiempo } \\
\text { en la preparación } \\
\text { de clases }\end{array}$ & 1 & 2 & 3 & 4 & 5 \\
\hline $\begin{array}{l}\text { 13. Usar HTD, como } \\
\text { redes sociales y } \\
\text { plataformas } \\
\text { implica más } \\
\text { dedicación del } \\
\text { docente para } \\
\text { revisar el trabajo } \\
\text { del alumno }\end{array}$ & 1 & 2 & 3 & 4 & 5 \\
\hline $\begin{array}{l}\text { 14. Usar HTD } \\
\text { implican un gasto } \\
\text { extra }\end{array}$ & 1 & 2 & 2 & 4 & 5 \\
\hline
\end{tabular}

Beneficios al usar Herramientas HTD en el proceso de enseñanza-aprendizaje.

Elija el número de su preferencia

\begin{tabular}{|c|c|c|c|c|c|}
\hline & $\begin{array}{c}\text { Muy en } \\
\text { desacuer } \\
\text { do }\end{array}$ & $\begin{array}{c}\text { En } \\
\text { desacuer } \\
\text { do }\end{array}$ & $\begin{array}{c}\text { Ni de } \\
\text { acuerdo } \\
\text { Ni en }\end{array}$ & $\begin{array}{c}\text { De } \\
\text { acuerd } \\
\text { o }\end{array}$ & $\begin{array}{c}\text { Muy de } \\
\text { acuerd } \\
\text { o }\end{array}$ \\
\hline
\end{tabular}




\section{PERCEPCIÓN SOBRE EL USO DE HERRAMIENTAS TECNOLÓGICAS DIGITALES COMO APOYO EN LA DOCENCIA E INVESTIGACIÓN CASO: DOCENTES-INVESTIGADORES UAM-A, MÉXICO, ADSCRITOS A QUÍMICA}

\begin{tabular}{|c|c|c|c|c|c|}
\hline & & & $\begin{array}{c}\text { desacuerd } \\
0\end{array}$ & & \\
\hline $\begin{array}{l}\text { 15. Usar HTD trae beneficios a } \\
\text { la enseñanza }\end{array}$ & 1 & 2 & 3 & 4 & 5 \\
\hline \multicolumn{6}{|c|}{ 16. Las HTD propias o de la UAM-A han contribuido a mejorar la impartición de sus clases } \\
\hline $\begin{array}{l}\text { Agilizan su trabajo como } \\
\text { docente }\end{array}$ & 1 & 2 & 3 & 4 & 5 \\
\hline $\begin{array}{l}\text { Aprovecha más el tiempo } \\
\text { para su clase }\end{array}$ & 1 & 2 & 3 & 4 & 5 \\
\hline $\begin{array}{l}\text { Facilita sus actividades } \\
\text { administrativas }\end{array}$ & 1 & 2 & 3 & 4 & 5 \\
\hline $\begin{array}{l}\text { Posibilita que el alummo } \\
\text { acceda más rápido a los } \\
\text { conceptos }\end{array}$ & 1 & 2 & 3 & 4 & 5 \\
\hline $\begin{array}{l}\text { Los alumnos desarrollan } \\
\text { capacidades analíticas }\end{array}$ & 1 & 2 & 3 & 4 & 5 \\
\hline $\begin{array}{l}\text { Favorecen el trabajo en } \\
\text { equipo }\end{array}$ & 1 & 2 & 3 & 4 & 5 \\
\hline $\begin{array}{l}\text { Los alumnos aumentan su } \\
\text { rendimiento }\end{array}$ & 1 & 2 & 3 & 4 & 5 \\
\hline $\begin{array}{l}\text { Los alumnos salen mejor } \\
\text { preparados }\end{array}$ & 1 & 2 & 3 & 4 & 5 \\
\hline $\begin{array}{l}\text { La virtualidad (educación a } \\
\text { distancia por internet) } \\
\text { puede lograr un proceso } \\
\text { de enseñanza-aprendizaje } \\
\text { anclado en la interacción, } \\
\text { colaboración y } \\
\text { cooperación entre } \\
\text { estudiantes: y con los } \\
\text { estudiantes y el profesor } \\
\text { para lograr la construcción } \\
\text { del conocimiento }\end{array}$ & 1 & 2 & 3 & 4 & 5 \\
\hline
\end{tabular}

\section{Infraestructura tecnológica como apoyo en la docencia.}

Elija su respuesta
17. ¿Cuenta con computadora en su casa?
( ) $\mathrm{Si}$
( ) No

18. ¿Cuenta con internet en su casa? ( ) Si ( ) No

19. ¿Cuenta con computadora de uso personal en su cubículo? ( ) $\mathrm{Si} \quad$ ( ) No

20. ¿Cuenta con internet en su cubículo? ( ) $\mathrm{Si} \quad($ ) No 


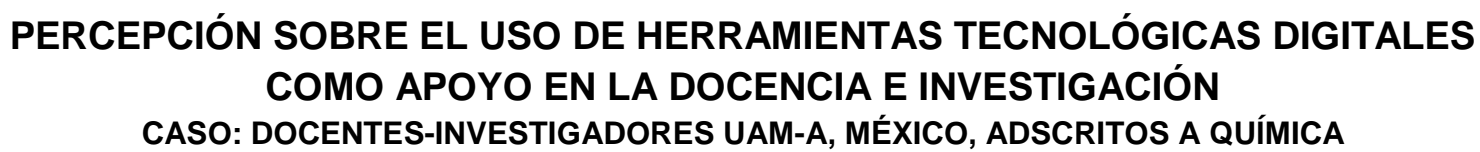

\begin{tabular}{|l|c|c|c|c|c|}
\hline & Nada & Poco & Regular & Aceptable & $\begin{array}{c}\text { Totalmente } \\
\text { aceptable }\end{array}$ \\
\hline $\begin{array}{l}\text { 21. Es conveniente invertir en } \\
\text { infraestructura tecnológica }\end{array}$ & 1 & 2 & 3 & 4 & 5 \\
\hline $\begin{array}{l}\text { 22. Es importante contar con una } \\
\text { computadora en su cubículo }\end{array}$ & 1 & 2 & 3 & 4 & 5 \\
\hline $\begin{array}{l}\text { 23. El aula tiene las condiciones } \\
\text { tecnológicas digitales para una } \\
\text { clase }\end{array}$ & 1 & 2 & 3 & 4 & 5 \\
\hline $\begin{array}{l}\text { 24. La institución le brinda el apoyo } \\
\text { para utilizar las tecnologías HTD }\end{array}$ & 1 & 2 & 3 & 4 & 5 \\
\hline $\begin{array}{l}\text { 25. La infraestructura tecnológica es } \\
\text { suficiente para los profesores de } \\
\text { tiempo completo }\end{array}$ & 1 & 2 & 3 & 4 & 5 \\
\hline
\end{tabular}

$\rightarrow$ Percepción de políticas de uso de HTD como apoyo en la docencia

Elija su respuesta

\begin{tabular}{|c|c|c|c|c|c|}
\hline & Nada & Poco & Regular & Aceptable & $\begin{array}{c}\text { Totalmente } \\
\text { aceptable }\end{array}$ \\
\hline $\begin{array}{c}\text { 26.Es importante el uso de las } \\
\text { tecnologías o HTD en la } \\
\text { enseñanza y el aprendizaje }\end{array}$ & 1 & 2 & 3 & 4 & 5 \\
\hline $\begin{array}{c}\text { 27.La tecnología genera cambios en el } \\
\text { modo de enseñanza }\end{array}$ & 1 & 2 & 3 & 4 & 5 \\
\hline $\begin{array}{c}\text { 28. Poseo los conocimientos } \\
\text { necesarios para utilizar las HTD } \\
\text { en mi práctica docente. }\end{array}$ & 1 & 2 & 3 & 4 & 5 \\
\hline $\begin{array}{c}\text { 29.Es importante invertir en } \\
\text { capacitación de las HTD orientada } \\
\text { a los recursos humanos }\end{array}$ & 1 & 2 & 3 & 4 & 5 \\
\hline $\begin{array}{c}\text { 30.Existe difusión en el uso de HTD } \\
\text { en la enseñanza y aprendizaje }\end{array}$ & 1 & 2 & 3 & 4 & 5 \\
\hline $\begin{array}{c}\text { 31.Se cuenta con personal capacitado } \\
\text { en el uso de las HTD y que apoya } \\
\text { al profesorado }\end{array}$ & 1 & 2 & 3 & 4 & 5 \\
\hline
\end{tabular}

¡MUCHAS GRACIAS POR SU PARTICIPACIÓN!

Lilia Fernández Sánchez 


\section{PERCEPCIÓN SOBRE EL USO DE HERRAMIENTAS TECNOLÓGICAS DIGITALES \\ COMO APOYO EN LA DOCENCIA E INVESTIGACIÓN \\ CASO: DOCENTES-INVESTIGADORES UAM-A, MÉXICO, ADSCRITOS A QUÍMICA}

\section{ANEXO 3}
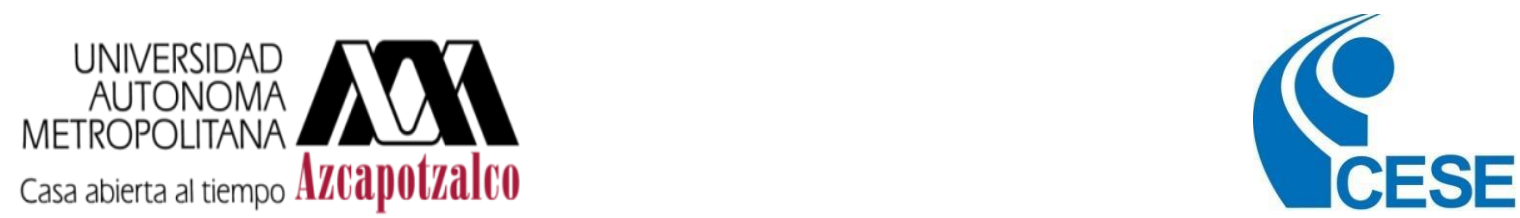

\section{CUESTIONARIO USOHTD PARA MEDIR LA PERCEPCIÓN EN EL USO DE HERRAMIENTAS TECNOLÓGICAS DIGITALES EN LA ENSEÑANZA EXPERIMENTAL EN QUÍMICA}

Fecha:

Trimestre:

Esta investigación realizada a través de un cuestionario en la Universidad Autónoma Metropolitana Unidad Azcapotzalco UAM-A en las áreas de química, tiene como objetivo conocer la opinión que usted profesor-investigador tiene acerca de las Herramientas Tecnológicas Digitales HTD como apoyo en la docencia experimental en química.

Instrucciones: Escriba en los espacios en blanco o marque con una $\mathrm{X}$ la opción que le parezca conveniente. El cuestionario es anónimo

$\rightarrow$ Datos del profesor-investigador de tiempo completo:

\begin{tabular}{|l|l|}
\hline 1. Año que ingresó a la UAM-A: & \\
\hline 2. Licenciatura: & Licenciatura ( ) Maestría ( ) Doctorado ( ) \\
\hline 3. Grado académico: & \\
\hline 4. UEA de Quím. Exp. que imparte (solo 1): & \\
\hline 5. Edad: & Femenino ( ) Masculino ( ) \\
\hline 6. Género: &
\end{tabular}

$\rightarrow$ Frecuencia del uso de HTD (Herramientas Tecnológicas Digitales, ver pregunta 8) en la docencia experimental en química 


\section{PERCEPCIÓN SOBRE EL USO DE HERRAMIENTAS TECNOLÓGICAS DIGITALES COMO APOYO EN LA DOCENCIA E INVESTIGACIÓN CASO: DOCENTES-INVESTIGADORES UAM-A, MÉXICO, ADSCRITOS A QUÍMICA}

Indique el número de su preferencia

\begin{tabular}{|l|c|c|c|c|c|}
\hline & Nada & Poco & Regular & Aceptable & $\begin{array}{c}\text { Totalmente } \\
\text { Aceptable } \\
\text { (mucho) }\end{array}$ \\
\hline \begin{tabular}{c} 
7. $\begin{array}{c}\text { Usa HTD en su } \\
\text { práctica docente } \\
\text { experimental }\end{array}$ \\
\hline
\end{tabular} & 1 & 2 & 3 & 4 & 5 \\
\hline 8. & & & & \\
\hline
\end{tabular}

8. Qué tanto utiliza las siguientes HTD en la docencia experimental en química

\begin{tabular}{|c|c|c|c|c|c|}
\hline & Nada & Poco & Regular & Aceptable & $\begin{array}{c}\text { Totalmente } \\
\text { Aceptable } \\
\text { (mucho) }\end{array}$ \\
\hline Video proyector & 1 & 2 & 3 & 4 & 5 \\
\hline Computadora & 1 & 2 & 3 & 4 & 5 \\
\hline Internet $^{+}$ & 1 & 2 & 3 & 4 & 5 \\
\hline $\begin{array}{l}\text { Facebook } \\
\text { (comunicación por } \\
\text { internet, red social) }\end{array}$ & 1 & 2 & 3 & 4 & 5 \\
\hline $\begin{array}{l}\text { Plataforma educativa } \\
\text { (Moodle, Prezi, } \\
\text { Eminus, Blackboard, } \\
\text { WebCT, Claroline, } \\
\text { otra) ¿Cuál? }\end{array}$ & 1 & 2 & 3 & 4 & 5 \\
\hline $\begin{array}{l}\text { Plataforma de cursos } \\
\text { en línea }\end{array}$ & 1 & 2 & 3 & 4 & 5 \\
\hline Simuladores & 1 & 2 & 3 & 4 & 5 \\
\hline Videos & 1 & 2 & 3 & 4 & 5 \\
\hline Audios & 1 & 2 & 3 & 4 & 5 \\
\hline Chat & 1 & 2 & 3 & 4 & 5 \\
\hline Foros & 1 & 2 & 3 & 4 & 5 \\
\hline Correo electrónico & 1 & 2 & 3 & 4 & 5 \\
\hline $\mathrm{Blog}$ & 1 & 2 & 3 & 4 & 5 \\
\hline Sitio web personal & 1 & 2 & 3 & 4 & 5 \\
\hline
\end{tabular}




\section{PERCEPCIÓN SOBRE EL USO DE HERRAMIENTAS TECNOLÓGICAS DIGITALES \\ COMO APOYO EN LA DOCENCIA E INVESTIGACIÓN \\ CASO: DOCENTES-INVESTIGADORES UAM-A, MÉXICO, ADSCRITOS A QUÍMICA}

\begin{tabular}{|c|c|c|c|c|c|}
\hline Videoconferencia & 1 & 2 & 3 & 4 & 5 \\
\hline Biblioteca digital & 1 & 2 & 3 & 4 & 5 \\
\hline $\begin{array}{l}\text { Usa otra HTD en el } \\
\text { laboratorio de química, } \\
\text { balanza analítica, } \\
\text { medidor digital de pH, } \\
\text { espectrofotómetro } \\
\text { digital u otra. } \\
\text { Especifique ¿cuál? }\end{array}$ & 1 & 2 & 3 & 4 & 5 \\
\hline $\begin{array}{l}\text { 9. Si su laboratorio } \\
\text { cuenta con medios } \\
\text { tecnológicos } \\
\text { ¿Desarrolla sus } \\
\text { clases } \\
\text { utilizándolos? }\end{array}$ & 1 & 2 & 3 & 4 & 5 \\
\hline $\begin{array}{l}\text { 10. La UAM-A ofrece } \\
\text { cursos para que los } \\
\text { profesores } \\
\text { aprendan a usar las } \\
\text { HTD }\end{array}$ & 1 & 2 & 3 & 4 & 5 \\
\hline $\begin{array}{l}\text { 11. Asiste a talleres y } \\
\text { cursos de manera } \\
\text { virtual para } \\
\text { actualizarse }\end{array}$ & 1 & 2 & 3 & 4 & 5 \\
\hline $\begin{array}{l}\text { 12. Usar HTD requiere } \\
\text { invertir más tiempo } \\
\text { en la preparación } \\
\text { de clases }\end{array}$ & 1 & 2 & 3 & 4 & 5 \\
\hline $\begin{array}{l}\text { 13. Usar HTD, como } \\
\text { redes sociales y } \\
\text { plataformas } \\
\text { implica más } \\
\text { dedicación del } \\
\text { docente para } \\
\text { revisar el trabajo } \\
\text { del alumno }\end{array}$ & 1 & 2 & 3 & 4 & 5 \\
\hline $\begin{array}{l}\text { 14. Usar HTD } \\
\text { implican un gasto } \\
\text { extra }\end{array}$ & 1 & 2 & 3 & 4 & 5 \\
\hline
\end{tabular}

\section{Beneficios al usar Herramientas HTD en el proceso de enseñanza-aprendizaje}

experimental.

Elija el número de su preferencia 


\section{PERCEPCIÓN SOBRE EL USO DE HERRAMIENTAS TECNOLÓGICAS DIGITALES \\ COMO APOYO EN LA DOCENCIA E INVESTIGACIÓN \\ CASO: DOCENTES-INVESTIGADORES UAM-A, MÉXICO, ADSCRITOS A QUÍMICA}

\begin{tabular}{|c|c|c|c|c|c|}
\hline & $\begin{array}{c}\text { Muy en } \\
\text { desacuerdo }\end{array}$ & $\begin{array}{c}\text { En } \\
\text { desacuerdo }\end{array}$ & $\begin{array}{c}\text { Ni de } \\
\text { acuerdo } \\
\text { Ni en } \\
\text { desacuerdo }\end{array}$ & $\begin{array}{c}\text { De } \\
\text { acuerdo }\end{array}$ & $\begin{array}{l}\text { Muy de } \\
\text { acuerdo }\end{array}$ \\
\hline $\begin{array}{l}\text { 15. Usar HTD trae beneficios a } \\
\text { la enseñanza }\end{array}$ & 16.1 & 17. 2 & 18. 3 & 19. 4 & 20.5 \\
\hline \multicolumn{6}{|c|}{ 16. Las HTD propias o de la UAM-A han contribuido a mejorar la impartición de su laboratorio } \\
\hline $\begin{array}{l}\text { Agilizan su trabajo como } \\
\text { docente }\end{array}$ & 1 & 2 & 3 & 4 & 5 \\
\hline $\begin{array}{l}\text { Aprovecha más el tiempo } \\
\text { para su clase }\end{array}$ & 1 & 2 & 3 & 4 & 5 \\
\hline $\begin{array}{l}\text { Facilita sus actividades } \\
\text { administrativas }\end{array}$ & 1 & 2 & 3 & 4 & 5 \\
\hline $\begin{array}{l}\text { Posibilita que el alumno } \\
\text { acceda más rápido a los } \\
\text { conceptos }\end{array}$ & 1 & 2 & 3 & 4 & 5 \\
\hline $\begin{array}{l}\text { Los alumnos desarrollan } \\
\text { capacidades analíticas }\end{array}$ & 1 & 2 & 3 & 4 & 5 \\
\hline $\begin{array}{l}\text { Favorecen el trabajo en } \\
\text { equipo }\end{array}$ & 1 & 2 & 3 & 4 & 5 \\
\hline $\begin{array}{l}\text { Los alumnos aumentan su } \\
\text { rendimiento }\end{array}$ & 1 & 2 & 3 & 4 & 5 \\
\hline $\begin{array}{l}\text { Los alumnos salen mejor } \\
\text { preparados }\end{array}$ & 1 & 2 & 3 & 4 & 5 \\
\hline $\begin{array}{l}\text { La virtualidad (educación a } \\
\text { distancia por internet) puede } \\
\text { lograr un proceso de enseñanza- } \\
\text { aprendizaje anclado en la } \\
\text { interacción, colaboración y } \\
\text { cooperación entre estudiantes: y } \\
\text { con los estudiantes y el profesor } \\
\text { para lograr la construcción del } \\
\text { conocimiento }\end{array}$ & 1 & 2 & 3 & 4 & 5 \\
\hline
\end{tabular}

$\rightarrow$ Infraestructura tecnológica como apoyo en la docencia experimental en química.

Elija su respuesta

17. ¿Cuenta con computadora en su casa? ( ) $\mathrm{Si} \quad$ ( ) No

18. ¿Cuenta con internet en su casa? ( ) Si ( ) No

19. ¿Cuenta con computadora de uso personal en su cubículo? ( ) $\mathrm{Si} \quad$ ( ) No

20. ¿Cuenta con internet en su cubículo? ( ) Si ） ( ) No 


\section{PERCEPCIÓN SOBRE EL USO DE HERRAMIENTAS TECNOLÓGICAS DIGITALES \\ COMO APOYO EN LA DOCENCIA E INVESTIGACIÓN \\ CASO: DOCENTES-INVESTIGADORES UAM-A, MÉXICO, ADSCRITOS A QUÍMICA}

\begin{tabular}{|l|c|c|c|c|c|}
\hline & Nada & Poco & Regular & Aceptable & $\begin{array}{c}\text { Totalmente } \\
\text { aceptable }\end{array}$ \\
\hline $\begin{array}{c}\text { 21. Es conveniente invertir en } \\
\text { infraestructura tecnológica }\end{array}$ & 1 & 2 & 3 & 4 & 5 \\
\hline $\begin{array}{c}\text { 22. Es importante contar con una } \\
\text { computadora en su cubículo }\end{array}$ & 1 & 2 & 3 & 4 & 5 \\
\hline $\begin{array}{l}\text { 23. El laboratorio tiene las } \\
\text { condiciones tecnológicas } \\
\text { digitales para una clase de lab. }\end{array}$ & 1 & 2 & 3 & 4 & 5 \\
\hline $\begin{array}{c}\text { 24. La institución le brinda el } \\
\text { apoyo para utilizar las } \\
\text { tecnologías HTD }\end{array}$ & 1 & 2 & 3 & 4 & 5 \\
\hline $\begin{array}{c}\text { 25. La infraestructura tecnológica } \\
\text { es suficiente para los profesores } \\
\text { de tiempo completo }\end{array}$ & 1 & 2 & 3 & 4 & 5 \\
\hline
\end{tabular}

Percepción de políticas de uso de HTD como apoyo en la docencia experimental

\begin{tabular}{|l|c|c|c|c|c|}
\hline & Nada & Poco & Regular & Aceptable & $\begin{array}{c}\text { Totalmente } \\
\text { aceptable }\end{array}$ \\
\hline $\begin{array}{c}\text { 26. Es importante el uso de las } \\
\text { tecnologías o HTD en la } \\
\text { enseñanza y el aprendizaje en el } \\
\text { laboratorio }\end{array}$ & 1 & 2 & 3 & 4 & 5 \\
\hline $\begin{array}{c}\text { 27.La tecnología genera cambios en el } \\
\text { modo de enseñanza exp. }\end{array}$ & 1 & 2 & 3 & 4 & 5 \\
\hline $\begin{array}{c}\text { 28. Poseo los conocimientos } \\
\text { necesarios para utilizar las HTD } \\
\text { en mi práctica docente exp. }\end{array}$ & 1 & 2 & 3 & 4 & 5 \\
\hline $\begin{array}{c}\text { 29.Es importante invertir en } \\
\text { capacitación de las HTD orientada } \\
\text { a los recursos humanos }\end{array}$ & 1 & 2 & 3 & 4 & 5 \\
\hline $\begin{array}{c}\text { 30.Existe difusión en el uso de HTD } \\
\text { en la enseñanza Exp. en Quím. }\end{array}$ & 1 & 2 & 3 & 4 & 5 \\
\hline $\begin{array}{c}\text { 31.Se cuenta con personal capacitado } \\
\text { en el uso de las HTD y que apoya } \\
\text { al profesorado }\end{array}$ & 1 & 2 & 3 & 4 & 5 \\
\hline
\end{tabular}

¡MUCHAS GRACIAS POR SU PARTICIPACIÓN!

Lilia Fernández Sánchez 


\section{PERCEPCIÓN SOBRE EL USO DE HERRAMIENTAS TECNOLÓGICAS DIGITALES COMO APOYO EN LA DOCENCIA E INVESTIGACIÓN CASO: DOCENTES-INVESTIGADORES UAM-A, MÉXICO, ADSCRITOS A QUÍMICA}

\section{ANEXO 4}

Profesores-Investigadores de los ámbitos de Investigación, Docencia teórica y

\begin{tabular}{|c|c|c|c|c|c|}
\hline \multicolumn{2}{|c|}{$\begin{array}{l}\text { PROFESORES-INVESTIGADORES DE INVESTIGACIÓN EN } \\
\text { QUÍMICA }\end{array}$} & \multicolumn{4}{|c|}{$\begin{array}{l}\text { Dimensiones/ejes de análisis. Cuantos docentes } \\
\text { de Investigación han coincidido en sus respuestas }\end{array}$} \\
\hline $\begin{array}{l}\text { Categoría } \\
\text { Numérica }\end{array}$ & Categoría Ordinal & Fr. de uso & Beneficios & Infraestructura & Políticas \\
\hline 1 & Nada/Muy en desacuerdo & 0 & 0 & 0 & 0 \\
\hline 2 & Poco/En desacuerdo & 0 & 0 & 0 & 0 \\
\hline 3 & Regula/Ni de acuerdo ni en desacuerdo & 5 & 0 & 0 & 0 \\
\hline 4 & Aceptable/De acuerdo & 5 & 3 & 0 & 5 \\
\hline 5 & Totalmente/Muy de acuerdo & 0 & 7 & 10 & 5 \\
\hline & Media & 3.5 & 4.6 & 4.8 & 4.4 \\
\hline & Mediana & 3.5 & 5 & 5 & 4.5 \\
\hline & Moda & - & 5 & 5 & - \\
\hline
\end{tabular}

Docencia experimental en Química. Frecuencia de respuestas iguales.

\begin{tabular}{|c|c|c|c|c|c|}
\hline \multicolumn{2}{|c|}{$\begin{array}{l}\text { PROFESORES-INVESTIGADORES DE DOCENCIA EN } \\
\text { QUÍMICA }\end{array}$} & \multicolumn{4}{|c|}{$\begin{array}{l}\text { Dimensiones/ejes de análisis. Cuantos docentes } \\
\text { de la Teoría han coincidido en sus respuestas }\end{array}$} \\
\hline $\begin{array}{l}\text { Categoría } \\
\text { Numérica }\end{array}$ & Categoría Ordinal & Fr. de uso & Beneficios & Infraestructura & Políticas \\
\hline 1 & Nada/Muy en desacuerdo & 0 & 0 & 0 & 0 \\
\hline 2 & Poco/En desacuerdo & 1 & 0 & 1 & 1 \\
\hline 3 & Regula/Ni de acuerdo ni en desacuerdo & 7 & 3 & 0 & 1 \\
\hline 4 & Aceptable/De acuerdo & 2 & 3 & 7 & 6 \\
\hline \multirow[t]{4}{*}{5} & Totalmente/Muy de acuerdo & 0 & 4 & 2 & 2 \\
\hline & Media & 3.1 & 3.8 & 4.1 & 3.7 \\
\hline & Mediana & 3 & 4 & 4 & 4 \\
\hline & Moda & 3 & 5 & 4 & 4 \\
\hline
\end{tabular}

\begin{tabular}{|c|l|}
\hline \multicolumn{2}{|c|}{ PROFESORES-INVESTIGADORES DE LA DOCENCIA } \\
EXPERIMENTAL EN QUíMICA
\end{tabular}

Dimensiones/ejes de análisis. Cuantos docentes del Laboratorio han coincidido en sus respuestas

\begin{tabular}{|r|r|r|r|}
\hline Fr. de uso & Beneficios & Infraestructura & Políticas \\
\hline 2 & 0 & 0 & 0 \\
3 & 0 & 1 & 1 \\
\hline 3 & 5 & 1 & 6 \\
\hline 2 & 3 & 7 & 1 \\
\hline 0 & 2 & 1 & 2 \\
\hline 2.4 & 3.4 & 3.8 & 3.4 \\
\hline 2.5 & 3.5 & 4 & 3 \\
\hline- & 3 & 4 & 3 \\
\hline
\end{tabular}




\section{PERCEPCIÓN SOBRE EL USO DE HERRAMIENTAS TECNOLÓGICAS DIGITALES \\ COMO APOYO EN LA DOCENCIA E INVESTIGACIÓN \\ CASO: DOCENTES-INVESTIGADORES UAM-A, MÉXICO, ADSCRITOS A QUÍMICA}

\section{ANEXO 5}

Medias aritméticas de los cuatro Ejes de Análisis por Ámbito de química

\begin{tabular}{rccccc}
\multicolumn{5}{c}{ Medias aritméticas por Ámbito } \\
Ámbitos de química & Fr. de uso & Beneficios & Infraestruc & Políticas \\
Investigación & $\mathbf{3 . 5}$ & 4.6 & 4.8 & 4.4 \\
Docencia teórica & $\mathbf{3 . 1}$ & 3.8 & 4.1 & 3.7 \\
Docencia experimental & 2.4 & 3.4 & 3.8 & 3.4
\end{tabular}

Media aritmética Global del Uso de HTD por Ámbito de Química

Media Global de las dimensiones por Ámbitos de

Química

\begin{tabular}{cc|c|} 
Media Global & $\begin{array}{c}\text { Porcentaje } \\
\text { de la Media }\end{array}$ \\
\hline 4.3 & 86.5 & $86.5 \%$ \\
3.7 & 73.5 & $73.5 \%$ \\
3.3 & 65 & $65.0 \%$ \\
\hline
\end{tabular}

